\title{
An Experimental Comparison of the Performance of Two Impulse Micro-Hydro Turbine Impellers
}

Joshua A. Matheny

Follow this and additional works at: https://researchrepository.wvu.edu/etd

\section{Recommended Citation}

Matheny, Joshua A., "An Experimental Comparison of the Performance of Two Impulse Micro-Hydro Turbine Impellers" (2016). Graduate Theses, Dissertations, and Problem Reports. 6174.

https://researchrepository.wvu.edu/etd/6174

This Thesis is protected by copyright and/or related rights. It has been brought to you by the The Research Repository @ WVU with permission from the rights-holder(s). You are free to use this Thesis in any way that is permitted by the copyright and related rights legislation that applies to your use. For other uses you must obtain permission from the rights-holder(s) directly, unless additional rights are indicated by a Creative Commons license in the record and/ or on the work itself. This Thesis has been accepted for inclusion in WVU Graduate Theses, Dissertations, and Problem Reports collection by an authorized administrator of The Research Repository @ WVU. For more information, please contact researchrepository@mail.wvu.edu. 


\title{
An Experimental Comparison of the Performance of Two Impulse Micro-Hydro Turbine Impellers
}

\author{
Joshua A. Matheny \\ Thesis Submitted to the \\ Benjamin M. Statler College of Engineering and Mineral Resources \\ at West Virginia University \\ in Partial Fulfillment of the Requirements \\ for the Degree of \\ Master of Science \\ In \\ Mechanical Engineering \\ Andrew C. Nix, Ph.D., Chair \\ Greg Thompson, Ph.D. \\ Kenneth Means, Ph.D.
}

Department of Mechanical and Aerospace Engineering Morgantown, West Virginia

2016

Keywords:

Turgo Hydro Turbine, Performance, Efficiency, Micro-Hydro

Copyright $($ C 2016, Joshua A. Matheny 


\title{
Abstract
}

\section{An Experimental Comparison of the Performance of Two Impulse Micro-Hydro Turbine Impellers}

\author{
Joshua A. Matheny
}

The goal of this project was to measure the performance of two micro-hydro Turgo Impulse Turbine Impellers. In 2014, Hydropower accounted for 6\% of total electric power produced and $48 \%$ of electricity produced by renewable sources in the United States. Micro-hydro power is an established, robust, and versatile technology that can help society produce electric power without the emission of greenhouse gases and with minimal environmental impact. Competition from other renewable energy sources is causing the operational efficiency and power production of microhydro turbines to become increasingly important. This competition puts pressure on manufacturers to improve the quality of their turbine designs and manufacturing methods. Computational fluid dynamics (CFD), combined with numerical methods and increased computing power, have become more widely used tools in the past several decades for design improvement. However, empirically derived performance data is still needed to validate modeling improvements and support further development of hydropower technology. Two impellers were chosen for study because they were used in an operational turbine system that the experiments were modeled after. The first impeller was designed and partially manufactured by Hartvigsen Hydro and assembled by Preston Machine, Inc. The second impeller had been in operation in the turbine system for several years and showed signs of wear. The blades on the two impellers were shaped very differently due to having completely different manufacturers. A test setup was designed and constructed to measure the overall efficiency and power output of both impellers. Two types of performance experiments were conducted. The first experiment determined the most efficient setting for the inlet nozzles which are used to increase the kinetic energy of the water prior to impinging on the turbine impeller. The second experiment measured the efficiency and power output of each impeller while varying the flow rate and shaft speed for each of two impellers. The results were analyzed and displayed as three dimensional maps for graphical interpretation of turbine performance as conditions were varied. The experiments indicate that the new impeller (impeller A) operated most efficiently with a peak efficiency $84.6 \%$ (with mechanical losses excluded). The older impeller (impeller B) reached a peak efficiency of $74.8 \%$. Both impellers produced approximately the same amount of shaft power (28.6 hp with mechanical losses included) at their peak operating points. The experiments indicated that both turbines were sensitive to varying conditions and properly managing those conditions is necessary to obtain reliable and efficient energy output over a long operational lifetime. 


\section{Table of Contents}

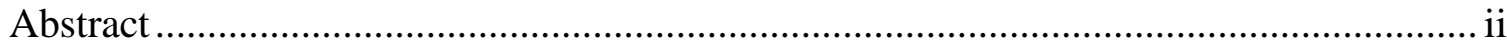

Table of Contents ................................................................................................ ii

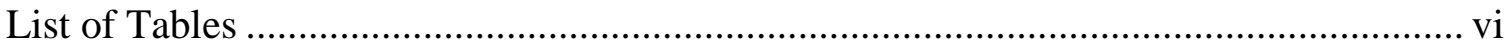

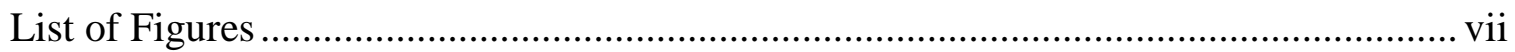

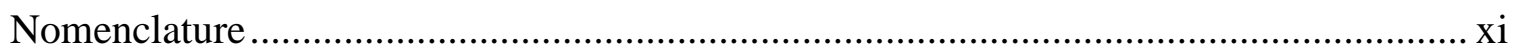

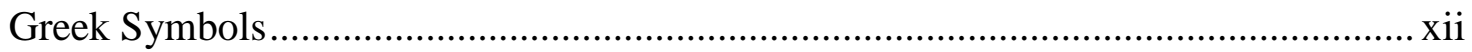

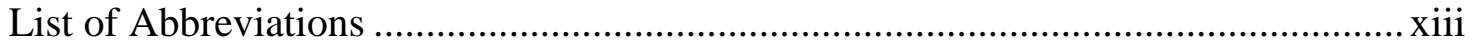

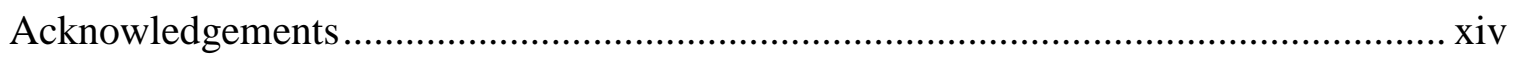

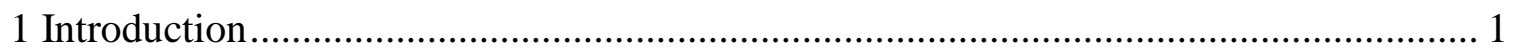

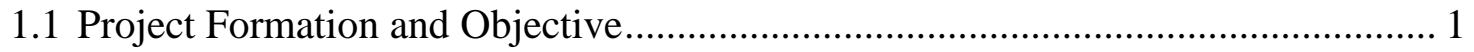

1.2 Basic Principles of Hydro Power .................................................................... 3

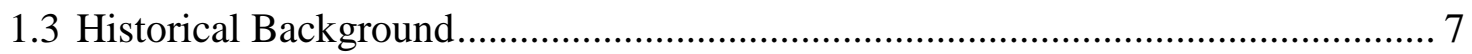

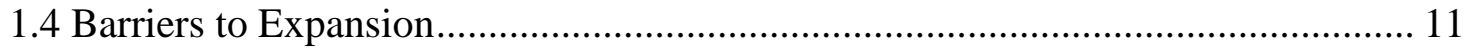

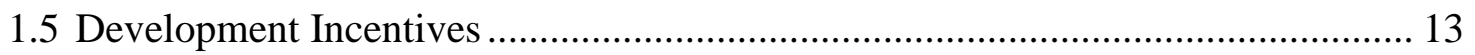

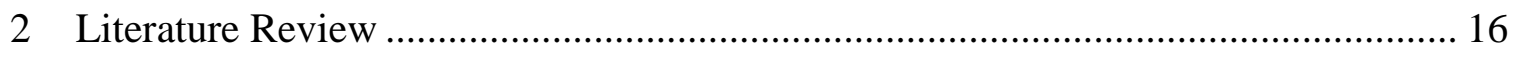

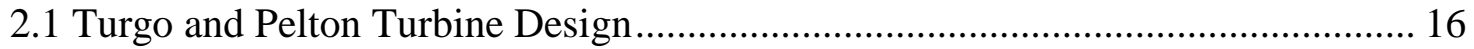

2.2 Experimental Evaluations of Performance ...................................................... 22

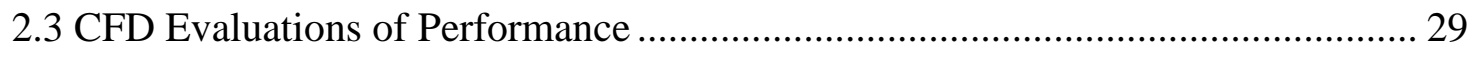

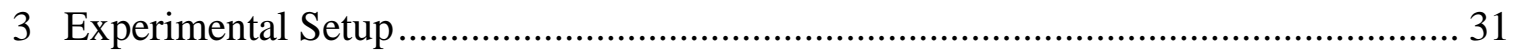

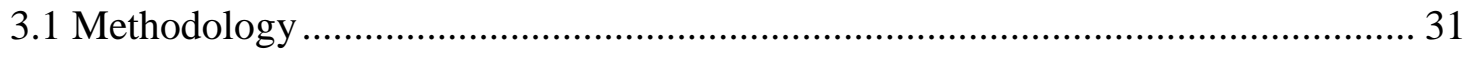

3.1.1 Evaluating Turbine Efficiency …......................................................... 31

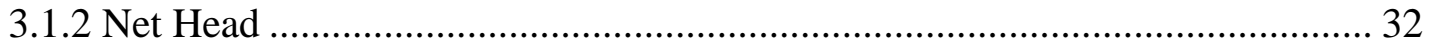

3.1.3 Design and Sizing of Water Nozzles ......................................................... 33

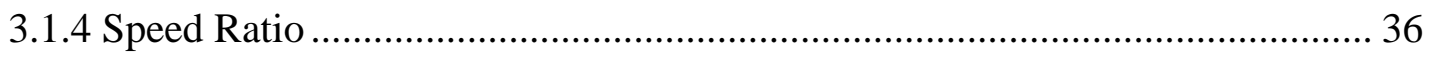

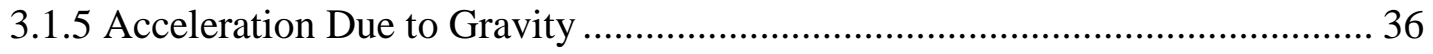

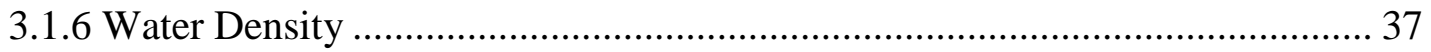

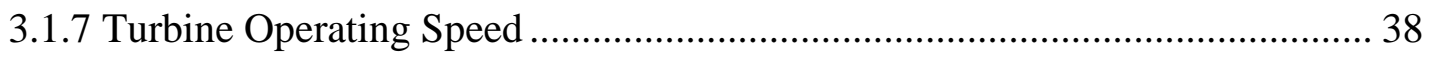

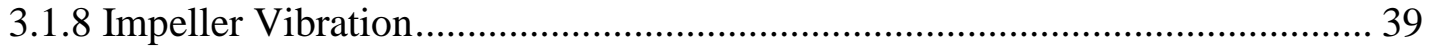


3.1.9 Coast-down Testing ..................................................................................... 40

3.1.10 Testing Conditions and Test Matrix ………………………………............. 45

3.1.11 Uncertainty Analysis................................................................................... 50

3.2 Design, Fabrication, and Layout of Experimental Apparatus................................. 51

3.2.1 Centrifugal Pump ........................................................................................... 53

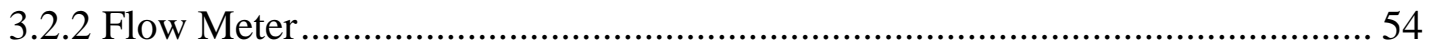

3.2.3 Flow Splitter and Nozzle Inlet Hoses .............................................................. 56

3.2.4 Test Stand Frame …………………………………....................................... 57

3.2.5 Water Nozzles and Mounting Brackets ........................................................... 59

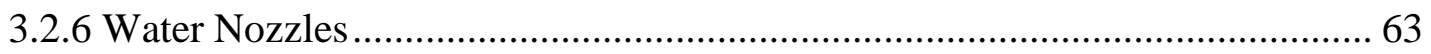

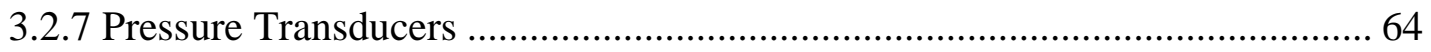

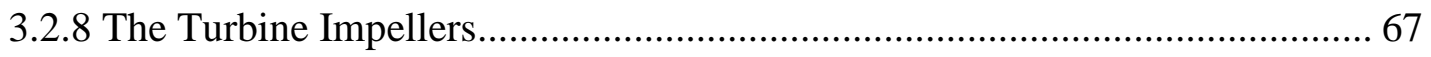

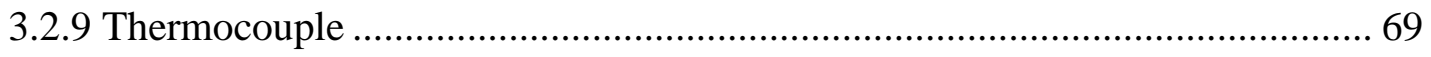

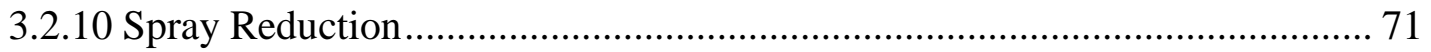

3.2.11 Induction Motor .................................................................................... 72

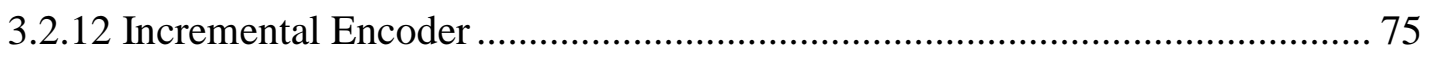

3.2.13 Torque Meter and Drive Shaft Components .................................................. 76

3.2.14 Variable Frequency Drive (VFD) .............................................................. 80

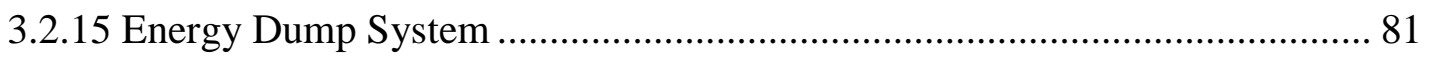

3.2.16 Data Acquisition (DAQ) Hardware and Software ........................................ 84

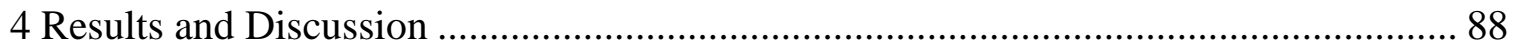

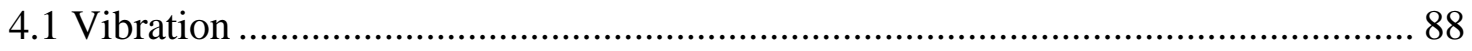

4.2 Coast-Down Experiments ................................................................................ 90

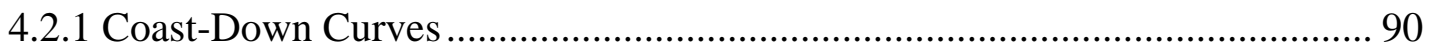

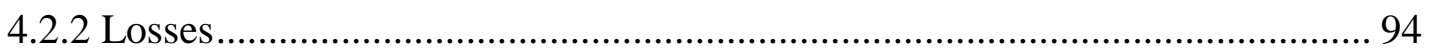

4.3 Performance at Different Nozzle Angles ................................................................ 99

4.4 Performance at Varying Flow Rates and Motor Speeds ........................................ 103

4.4.1 Impeller A Performance Results ...................................................................... 104

4.4.2 Impeller B Performance Results .................................................................. 109

4.4.3 Comparison of the Performance Results............................................................. 113 
4.5 Turbine Operating Speed .............................................................................. 114

4.6 Water Jet Quality ............................................................................................ 115

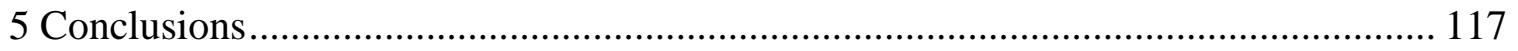

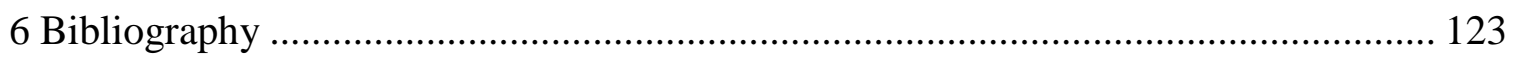

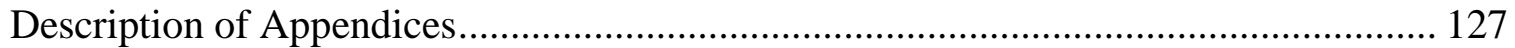

Appendix A - IRD General Machinery Vibration Severity Chart .................................. A-1

Appendix B - Coast-down Test Component Configurations............................................ B-1

Appendix C - Transducer Calibration Certificates ………….......................................... C-1

Siemens Sitrans MAG 5100W Flow Meter and MAG 5000 Transmitter .................... C-1

Keller Valueline Pressure Transducer for Nozzle 1 ................................................ C-4

Keller Valueline Pressure Transducer for Nozzle 2 ………........................................ C-5

Interface Force Calibration Certificate for T23 Rotary Torque Meter ......................... C-6

Appendix D - Reliance Induction Motor Speed-Torque Curve......................................... D-1

Appendix E - Scimitar Parameter Tree..........................................................................

Appendix F - Example Uncertainty Calculation.............................................................F-1 


\section{List of Tables}

Table 1: Classifications of hydropower system size by generating capacity and country [9-12]... 5

Table 2: List of nozzle diameters for the nozzles used in testing ................................................. 36

Table 3: List of operating conditions for the entire water flow at the Antrim turbine site........... 45

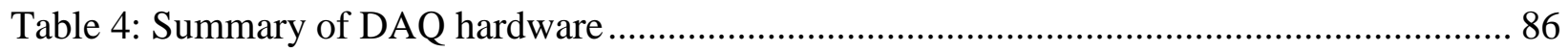

Table 5: Data describing the vibration condition for the test stand with impeller A installed ..... 89

Table 6: Data describing the vibration condition for the test stand with impeller B installed ..... 89

Table 7: Data describing the vibration condition for the test stand with no impeller installed .... 89 


\section{List of Figures}

Figure 1: Illustrates the setup of the turbines housed at the Antrim Facility [1] ........................ 2

Figure 2: Illustration of the layout of a run-of-river hydropower scheme [14] .......................... 6

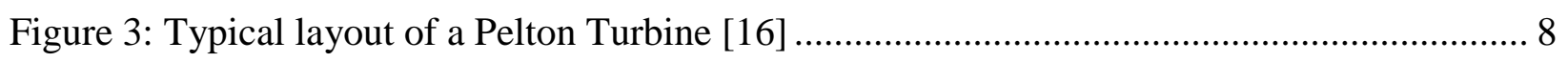

Figure 4: Illustrations of a water jet striking a Pelton bucket from a 3D view (Left) and a cross

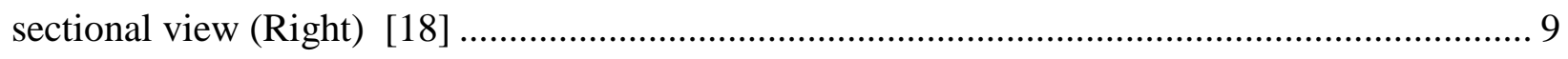

Figure 5: Typical layout of a Turgo Turbine [21]............................................................ 10

Figure 6: Illustrations of a water jet striking a Turgo Bucket from a 3D view (Left) and a cross

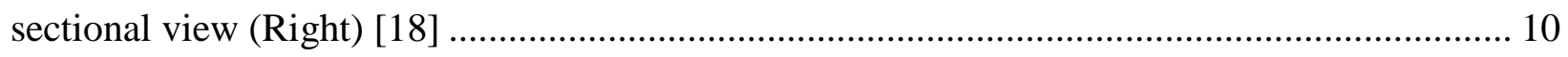

Figure 7: Map showing renewable portfolio standards of U.S. states and territories [28] .......... 14

Figure 8: Illustration of the velocity triangles associated with Turgo Turbine buckets [20]....... 18

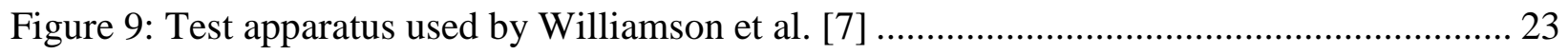

Figure 10: Impulse Turbine test setup created Cobb and Sharp [41] ..................................... 25

Figure 11: Test set-up created by Sakurai, Funato, Ogasawara [44] ........................................ 28

Figure 12: Schematic of experimental set-up for Climescu et al. [45] .................................... 28

Figure 13: Illustration of the geometry of the water nozzles used in the test stand [6] ............... 35

Figure 14: Topographical map of test site at Morgantown Municipal Airport in Morgantown, WV

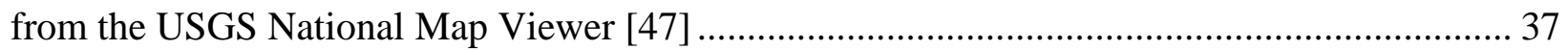

Figure 15: Pictures of torque meter mounted between motor and impeller on test stand (Left), Picture of impeller B directly mounted to motor shaft in Antrim turbines (Right) .................... 41

Figure 16: Illustrations of models used for calculating moment of inertia with (A) impeller A included, (B) impeller B included, and (C) no impeller attached to the driveshaft..................... 44

Figure 17: Illustration of nozzle aim points on a top view of impeller A.................................. 46

Figure 18: Illustration of nozzle aim points on a side view of impeller A ............................... 47

Figure 19: Illustrates an overview of the CAD model of the test set-up ................................... 52

Figure 20: Picture of the final assembly of the test set-up.................................................. 52

Figure 21: Schematic of the impulse turbine test set-up..................................................... 53

Figure 22: Rain for Rent HH150SA Pump used to circulate water in the test stand.................. 54

Figure 23: Magnetic flow meter used to measure flow rate in the test stand ............................ 55

Figure 24: Flow splitter that routes the main line flow to each water nozzle ............................ 57 
Figure 25: Test stand frame (Left-Front View, Right-Back View) ....................................... 58

Figure 26: Nozzle 2 in an angled position on the inside of the test stand................................. 59

Figure 27: CAD model developed to guide the fabrication of the nozzle brackets that hold each water nozzle..... 60

Figure 28: Illustration of an underside view of the nozzle bracket without the piece of channel it is mounted on shown 61

Figure 29: Picture of water nozzle alignment being checked with a combination square............ 62

Figure 30: CAD model of one of the water nozzles used in the experiment ............................. 63

Figure 31: Picture of the pressure transducer mounting for nozzle 1 ...................................... 65

Figure 32: Picture of the Heise calibrator and hand pump connected to the pressure transducer 67

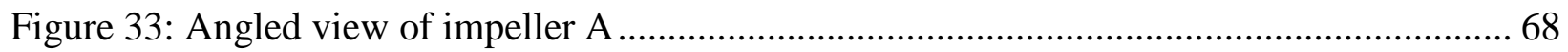

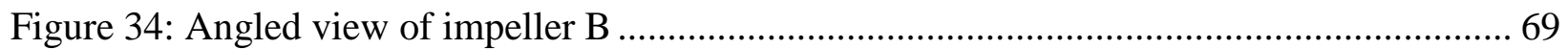

Figure 35: Thermocouple mounted on the inside of test stand frame.................................... 70

Figure 36: Spray shields and mesh installed on the inside the test stand ................................ 72

Figure 37: Picture of the Reliance motor mounted on top of the test stand frame ..................... 73

Figure 38: Picture of the Dynapar H20 Encoder mounted on the reliance motor ...................... 75

Figure 39: Machined coupler used for torque meter calibration............................................ 77

Figure 40: Set-up of the torque wrench accuracy check .................................................... 78

Figure 41: Picture showing drive shaft the impellers were mounted on while it was separated from

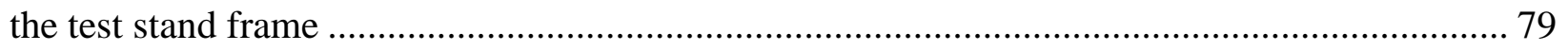

Figure 42: Depiction of the straight edge (Left) and dial indicator (Right) used to align the motor

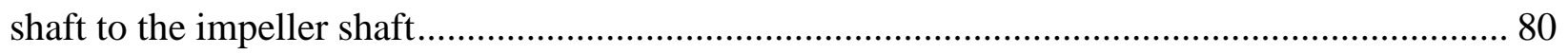

Figure 43: Picture of the Delta VFD in final position (Left) and with cover open (Right) ......... 81

Figure 44: Illustration of a cutaway view of the Chromolox Immersion Heater ........................ 82

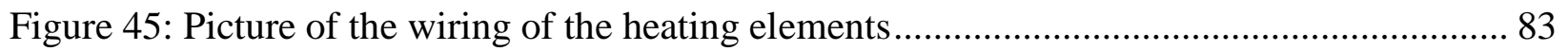

Figure 46: A picture of the energy dump system configuration ........................................... 83

Figure 47: Picture of the Labjack UE9 and ICP CON PET-7019Z DAQ devices in the electrical

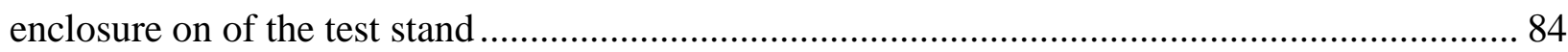

Figure 48: Data being recorded in Scimitar during an experiment......................................... 87

Figure 49: Plot of coast-down curves for tests done with impeller A ..................................... 91 
Figure 50: Plot of coast-down curves for tests done with impeller B..................................... 92

Figure 51: Plot of coast-down curves for tests done without an impeller ................................ 93

Figure 52: Plot of coast-down curves for tests done with the motor only ............................... 94

Figure 53: Plot of the losses measured in various configurations of the test stand .................... 95

Figure 54: Plot of the estimated losses due to windage and mechanical components................. 96

Figure 55: Plot of percentage of the power losses with respect to the shaft power produced by

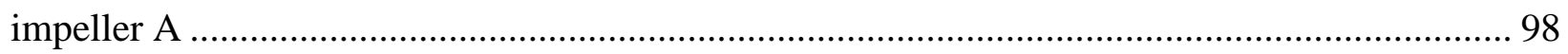

Figure 56: Plot of percentage of the power losses with respect to the shaft power produced by

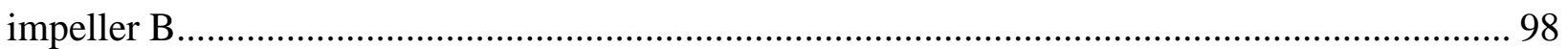

Figure 57: Plot of the efficiency of impeller A at different nozzle angles ............................. 100

Figure 58: Plot of the shaft power produced by impeller A at different nozzle angles ............. 100

Figure 59: Plot of the efficiency of impeller B at different nozzle angles............................. 101

Figure 60: Plot of the shaft power produced by impeller B at different nozzle angles ............. 101

Figure 61: Plot of the uncertainty of the efficiency during nozzle angle tests on impeller A .... 102

Figure 62: Plot of the uncertainty of the efficiency during nozzle angle tests on impeller B .... 103

Figure 63: Plot of the efficiency map for impeller A........................................................... 104

Figure 64: Plot of the efficiency of impeller A adjusted for power losses .............................. 105

Figure 65: Plot of the speed ratio for the nozzle 1 jet during impeller A tests ........................ 106

Figure 66: Plot of the speed ratio for the nozzle 2 jet during impeller A tests ........................ 106

Figure 67: Plot of the shaft power output during performance tests on impeller A .................. 107

Figure 68: Plot of a map of uncertainty in the turbine efficiency of impeller A ..................... 108

Figure 69: Plot of the efficiency map for impeller B........................................................ 109

Figure 70: Plot of the efficiency of impeller B adjusted for power losses ............................. 110

Figure 71: Plot of the speed ratio for the nozzle 1 jet during impeller B tests ........................ 111

Figure 72: Plot of the speed ratio for the nozzle 2 jet during impeller B tests ........................ 111

Figure 73: Plot of the shaft power output during performance tests on impeller B.................. 112

Figure 74: Plot of a map of the overall uncertainty in the turbine efficiency measurement for impeller B

Figure 75: Plot of torque versus rotational speed for the motor and impeller A ..................... 114

Figure 76: Plot of torque versus rotational speed for the motor and impeller B ...................... 114 
Figure 77: Picture of water jet impinging on impeller A after it exits the water nozzle ........... 116

Figure 78: Plot of the calibration check for the pressure transducer for nozzle 1 .................... C-4

Figure 79: Plot of the calibration check for the pressure transducer for nozzle 2 ................... C-5

Figure 80: Plot of the calibration check for the T23 torque meter....................................... C-7 


\section{Nomenclature}

A

$a_{\text {vibration }}$

B

C

$C_{1}$

$C_{1 T}$

$C_{2}$

$C_{2 T}$

$C_{C}$

$C_{V}$

$d_{\text {vibration }}$

$D_{\text {nozzle }}$

$D_{P C D}$

$f_{\text {vibration }}$

$g$

$h$

$h_{1}$

$h_{2}$

I

$\dot{m}$

$\dot{n}$

$n_{\text {jet }}$

$P_{\text {hydraulic }}, P_{\text {total hydraulic }}$

$P_{\text {hydraulic } 1}$

$P_{\text {hydraulic } 2}$

$P_{\text {shaft }}$

$P_{\text {loss }}$
Constant for the Calculation of Water Density (-)

Acceleration Due to Vibration $\left(\mathrm{m} / \mathrm{s}^{2}\right)$

Constant for the Calculation of Water Density (-)

Constant for the Calculation of Water Density (-)

Absolute Velocity of Water Jet at Impeller Bucket Inlet (m/s)

Tangential Component of Absolute Velocity at Inlet $(\mathrm{m} / \mathrm{s})$

Absolute Velocity of Water Jet at Impeller Bucket Outlet (m/s)

Tangential Component of Absolute Velocity at Outlet (m/s)

Water Nozzle Contraction Coefficient (-)

Water Nozzle Velocity Coefficient (-)

Displacement Due to Vibration (mils)

Water Nozzle Diameter (in., m)

Impeller Pitch Circle Diameter (in., m)

Vibration Frequency (Hz or CPM)

Local Acceleration Due to Gravity $\left(\mathrm{m} / \mathrm{s}^{2}\right)$

Elevation Head (ft. of water)

Net Head Measured at Nozzle 1 (ft. of water)

Net Head Measured at Nozzle 2 (ft. of water)

Mass Moment of Inertia $\left(\mathrm{kg} \mathrm{m}^{2}\right)$

Mass Flow Rate $\left(\mathrm{kg} / \mathrm{m}^{3}\right)$

Shaft Speed (RPM)

Number of Nozzles or Water Jets in the Test Stand (-)

Total System Hydraulic Power (kW or hp)

Hydraulic Power at Nozzle 1 (kW or hp)

Hydraulic Power at Nozzle 2 (kW or hp)

Shaft Power (kW or hp)

Power Losses Calculated from Coast Down (kW or hp) 


\begin{tabular}{|c|c|}
\hline$p$ & Pressure (PSI or kPa) \\
\hline$p_{\text {nozzle } 1}$ & Pressure at Nozzle 1 (PSI or kPa) \\
\hline$p_{\text {nozzle } 2}$ & Pressure at Nozzle 2 (PSI or kPa) \\
\hline$\dot{Q}$ & Volumetric Flow Rate $\left(m^{3} / s, G P M\right)$ \\
\hline$\dot{Q}_{\text {half }}$ & Volumetric Flow Rate of the Test Stand Halved $\left(\mathrm{m}^{3} / \mathrm{s}\right)$ \\
\hline$x$ & Speed Ratio (-) \\
\hline$T_{\text {water }}$ & Water Temperature in Test Stand $\left({ }^{\circ} \mathrm{C}\right)$ \\
\hline $\mathrm{T}$ & Torque or Moment (Nm, ft. lbs.) \\
\hline$U, U_{1}, U_{2}$ & Tangential Velocity of the Impeller Buckets at the PCD (m/s) \\
\hline$V_{1}$ & Relative Velocity of Water Jet at Impeller Bucket Inlet (m/s) \\
\hline$V_{2}$ & Relative Velocity of Water Jet at Impeller Bucket Outlet (m/s) \\
\hline$V_{j e t}$ & Jet Velocity (m/s) \\
\hline$V_{\text {vibration }}$ & Vibration Velocity (mm/s) \\
\hline$z$ & Altitude Above Sea Level of Test Site (m) \\
\hline \multicolumn{2}{|c|}{ Greek Symbols } \\
\hline$\alpha_{1}$ & Angle of Absolute Velocity at Impeller Bucket Inlet $\left(^{\circ}\right)$ \\
\hline$\alpha_{2}$ & Angle of Absolute Velocity at Impeller Bucket Outlet $\left(^{\circ}\right)$ \\
\hline$\beta_{1}$ & Angle of Relative Velocity at Impeller Bucket Inlet $\left(^{\circ}\right)$ \\
\hline$\beta_{2}$ & Angle of Relative Velocity at Impeller Bucket Outlet $\left(^{\circ}\right)$ \\
\hline$\eta, \eta_{\text {overall }}$ & Overall Efficiency of Nozzles, Impeller, and Test Stand (-) \\
\hline$\omega$ & Angular Velocity (rad/s) \\
\hline$\psi$ & Latitude at Test Site Location $\left({ }^{\circ}\right)$ \\
\hline$\rho$ & Water Density $\left(\mathrm{kg} / \mathrm{m}^{3}\right)$ \\
\hline$v_{0}$ & Specific Volume of Water $\left(\mathrm{m}^{3} / \mathrm{kg}\right)$ \\
\hline$d \omega / d t$ & Angular Acceleration $\left(\mathrm{rad} / \mathrm{s}^{2}\right)$ \\
\hline
\end{tabular}




\section{List of Abbreviations}

\begin{tabular}{|c|c|}
\hline AMD & acid mine drainage \\
\hline AWG & American Wire Gauge \\
\hline BCWA & Babb Creek Watershed Association \\
\hline CAD & computer aided drafting \\
\hline CAFEE & Center for Alternative Fuels, Engines, and Emissions \\
\hline CFD & computational fluid dynamics \\
\hline CNC & computer numeric control \\
\hline CPM & cycles per minute \\
\hline DAQ & data acquisition \\
\hline DOA & U.S. Department of the Army \\
\hline DOE & U.S. Department of Energy \\
\hline DOI & U.S. Department of the Interior \\
\hline FERC & U.S. Federal Energy Regulatory Commission \\
\hline FLS & Fast La'Grangian Simulation \\
\hline GPM & gallons per minute \\
\hline IEC & International Electrotechnical Commission \\
\hline PCD & pitch circle diameter \\
\hline PMI & Preston Machine, Inc. \\
\hline PPR & pulses per revolution \\
\hline PSI & pounds per square inch \\
\hline PVC & polyvinyl chloride \\
\hline RMS & root mean square \\
\hline RPM & revolutions per minute \\
\hline RPS & renewable portfolio standards \\
\hline $\mathrm{SPH}$ & Smooth Particle Hydrodynamics \\
\hline USGS & U.S. Geological Survey \\
\hline WVU & West Virginia University \\
\hline
\end{tabular}




\section{Acknowledgements}

I would first like to state that none of this would be possible without the love and support of my parents and family. I appreciate their patience and encouragement during my graduate studies. I would like to extend a special thanks to my friends for their support throughout my project. Their support during the many frustrating and challenging times during the program means the world to me. I would like to thank Dan Carder, Stephen Hayes, John Smallwood, and Molly Wilson for reviewing drafts of my thesis to help me improve it.

I also want to dedicate a special thank you to John Bassler. I hope someday that I will be able to assist you with hard work and support the way you did during my experiment. You volunteered to help me until two o'clock in the morning for a week with no more than "Thank You" in return. You did that in good spirits and without hesitation. You gave me the motivation to keep working even when I wanted to quit. Thank you.

This project would not have been possible without the effort and funding provided by Dan Carder and the Center for Alternative, Fuels, Engines and Emissions. I deeply appreciate the support from CAFEE. Their knowledge, experience, and equipment were essential to my success. Specifically, I would like to thank Richard Atkinson, Ross Ryskamp, Aaron Barnett, Chris Rowe, Jason England, Josh Israel and Zac Luzader for their help especially when they had other pressing responsibilities. I would also like to thank Elbert Rohrbough, Evan Judy, John Revercomb, Justin Grimley and Kyle Hilling for their hard work during the set-up of my experiment.

I would also like to thank Mark Tonkovich and Mike Jenkins for providing the funding and the setting for making this project possible. In the future, I hope that the information and data collected in this project benefits them and Preston Machine, Inc. as much as it has benefited me to work on their project. Thank you for the opportunities you have given me and your friendship. I xiv 
also want to thank everyone at Preston Machine, Inc. for their friendship and support while working there and working on this project. Jeff Clawges, Chris Baker, Randy Bohon, Tommy Johnson, Harry Hawkins and Sharon Mankins all put forth a large effort to help me reach my goals. Next, I would like to thank Tim Danehy, Margarett Dunn and the rest of Biomost, Inc. for being the impetus for starting this project. They began this project long before I ever contributed anything to it and overcame numerous challenges to get it started. I would also like to thank Bryan Page for showing me around the Antrim Acid Mine Drainage Treatment Facility and helping me to get my bearings on how their system was designed, installed, and is operated on a daily basis. I think Biomost, Inc.'s efforts to improve the environment are sorely needed and I hope my work can help them continue to do so in the future.

Finally, I would like to thank my committee members Gregory Thompson, Kenneth Means, and my advisor and committee chair Andrew C. Nix for their guidance. Dr. Thompson provided a valuable source of advice on mechanical design and guidance on the logistics of conducting a research project. Dr. Nix provided additional funding and advice for the project that was greatly appreciated. Dr. Means provided positive reinforcement that is always appreciated during a challenging project like this one. 


\section{Introduction}

\subsection{Project Formation and Objective}

This project was initiated by Preston Machine, Inc. (PMI) of Kingwood, West Virginia. The objective was to document the overall performance of two different Turgo Impulse Turbine impeller designs under different operating conditions. Through instrumentation, impeller efficiency and power output were determined and used to make a comparison of each turbines performance. The performance data collected will be used to build a knowledge base for PMI and partner Biomost, Inc. to make future design and manufacturing process improvements. The data will also be used to estimate the return on investment period for future projects and analyze their feasibility. This experiment initiated the collection of information and data for a database that can be referenced during the design of new micro-hydro systems. It also addresses design challenges, common practices of operation, strengths, and weaknesses of micro-hydro power systems that will be useful for future interested parties [1].

It was also the intent of the author to increase the awareness of the potential for microhydro power technology to produce energy with minimal environmental impact. The turbine system that this project is modeled after illustrates an example of this potential benefit. The site consists of two $30 \mathrm{~kW}$ capacity Turgo Impulse Turbines operated by Biomost, Inc. for the Babb Creek Watershed Association (BCWA) in Antrim, Pennsylvania. The turbines provide electricity to a water treatment facility that is used to treat acid mine drainage (AMD) from an abandoned coal mine. Electricity produced from the turbines power electric motors in the treatment facility [1]. Any excess energy is sold back to the local utility company through net metering via a connection to the electrical grid. 
The benefits realized at the Antrim Acid Mine Drainage Treatment Plant are an example of how micro-hydro power can produce clean energy without the emissions of greenhouse gases. In December 2015, 195 nations across the world signed the Paris Climate Agreement. This agreement legally bound those countries to limit global temperature increase to below $2^{\circ} \mathrm{C}$ when compared to pre-industrial levels and create a "net zero" balance of greenhouse gas emissions during the second half of the $21^{\text {st }}$ century [2]. The U.S. Energy Information Agency recently stated in a monthly review that approximately $67 \%$ of electricity production in the U.S. comes from fossil fuel sources [3]. The U.S., as a part of the Paris Climate Agreement, agreed to reduce greenhouse gas emissions by $26-28 \%$ by 2025 compared to 2005 levels [2]. Micro-hydro power is an established, robust, and versatile technology that can produce clean energy and help to reach this goal. The turbines operated by Biomost, Inc. for the BCWA are shown below in Figure 1.

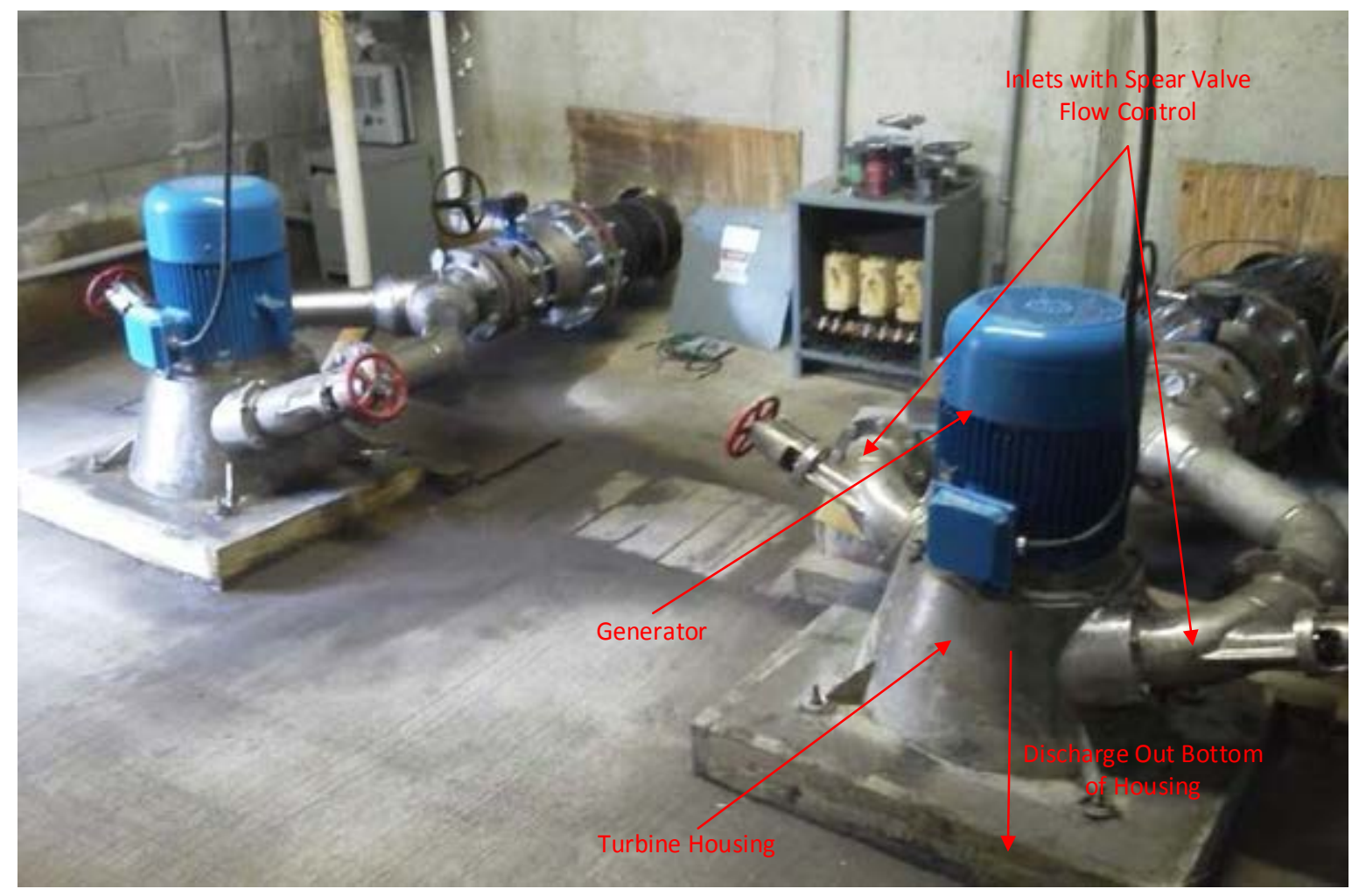

Figure 1: Illustrates the setup of the turbines housed at the Antrim Facility [1] 


\subsection{Basic Principles of Hydro Power}

A turbine is defined as a device that extracts energy from a flowing fluid. A hydraulic turbine is a turbine in which the working fluid is water. The geometry of the turbine blading is such that the fluid exerts a torque on a rotor to which the blades are mounted [4]. The work done on the turbine rotor causes it to rotate [5]. Work produced from the rotating turbine can be utilized by coupling another device via an output drive shaft make use of the available energy. A common arrangement for modern turbines is to attach a generator to the rotating shaft to convert mechanical energy to electric power. The mechanical power produced by the turbine may also be used to drive rotating machinery such as: crop-processing equipment, saw mills, irrigation pumps, workshop machinery, looms, and forges [6].

There are two main types of hydro turbines, impulse and reaction, each classified by their means of transferring the energy from the working fluid to the rotor. Impulse turbines typically operate at high head and low flow and reaction turbines which operate at high flows and low head [4]. This project focused entirely on impulse turbines. The opportunity to utilize energy from flowing water is created by converting it into different forms throughout the turbine system. Potential energy is at its highest at the inlet to the turbine system, called the penstock, where the working fluid is elevated above the outlet of the turbine system. The penstock piping carries water from the sources to the turbine impeller itself. The hydrostatic pressure head of the water increases as elevation decreases and the column of water builds inside the penstock. This available potential energy from hydrostatic pressure is converted to kinetic energy as the water transitions through nozzles and before impinging on the turbine blades as a free jet inside the housing of the turbine. An effective nozzle converts most of the pressure head to velocity head during this process. An impulse turbine utilizes this kinetic energy as water impacts the turbine blade, transferring its 
momentum to the impeller. Impulse turbine blades are curved to redirect the water jet around their surface. They are often called buckets or cups. As the water jet impinges on the bucket surface, the torque that causes the shaft to rotate is produced by the change in momentum of the water jet as it is redirected around the surface of the bucket before exiting in the reversed direction [7]. The turbine housing is not pressurized and is open to atmospheric pressure [8]. The water exits the turbine housing through piping or a channel called the tail-race.

For perspective, reaction turbines have a pressurized casing. They extract energy by creating a pressure differential on opposing sides of the turbine impeller blades, similar to an aircraft wing. The pressure differential induces a torque on the rotor which creates rotational work. They are more comparable to modern gas or steam turbines used in aircraft engines and power generation plants.

Micro-hydropower output tends to be classified below $100 \mathrm{~kW}$ as can be seen in Table 1 . This classification can vary from country to country. Most run-of-river systems that are not connected to a power grid fall within this power classification [9]. Larger systems are usually connected to a utility grid. For reference, Table 1 also shows different classifications of hydropower systems from different countries. 
Table 1: Classifications of hydropower system size by generating capacity and country [9-12]

\begin{tabular}{|c|c|c|c|c|c|c|}
\hline Country & $\begin{array}{c}\text { Pico } \\
(\mathrm{kW})\end{array}$ & $\begin{array}{c}\text { Micro } \\
(\mathrm{kW})\end{array}$ & $\begin{array}{c}\text { Mini } \\
(\mathrm{kW})\end{array}$ & $\begin{array}{c}\text { Small } \\
(\mathrm{MW})\end{array}$ & $\begin{array}{c}\text { Medium } \\
(\mathrm{MW})\end{array}$ & $\begin{array}{c}\text { Large } \\
(\mathrm{MW})\end{array}$ \\
\hline \multirow{2}{*}{$\begin{array}{c}\text { UK } \\
\text { (multiple } \\
\text { classifications })\end{array}$} & $<5$ & $5-100$ & $100-1000$ & $<5$ & $10-100$ & $>100$ \\
\cline { 2 - 7 } & & & & $1-10$ & $15-100$ & \\
\hline US & & $<100$ & $100-1000$ & $1-30$ & & \\
\hline China & & - & $<500$ & $0.5-25$ & & \\
\hline France & & $5-5000$ & - & - & & \\
\hline India & & $<100$ & $101-1000$ & $1-15$ & & \\
\hline Brazil & & $<100$ & $100-1000$ & $1-30$ & & \\
\hline Norway & & $<100$ & $100-1000$ & $1-10$ & & \\
\hline
\end{tabular}

The source of water used to power hydro turbines is commonly provided by natural landscapes such as a small streams, rivers, or tidal flows. Man-made water sources are also used as well. These can include: domestic water lines, drainage systems from highways or city streets, and pumped storage facilities. The amount of energy that a turbine can produce depends on the characteristics of the water source. With this being said, the feasibility of a micro-hydro project is highly dependent on the site it is selected for.

A commonly used sub classification of micro-hydro power systems is a "run-of-river" layout. A diagram of this configuration is can be seen in Figure 2 with the major components defined. Run-of-river systems often use high head and low flow conditions in mountainous regions to produce power [11]. This layout avoids the environmental impact of a dam which is needed to create a reservoir and elevation head for large turbine systems. Run-of-river systems also have a minimal effect on the flow and wildlife in the water source that feeds them because they normally do not divert the entire flow to the turbine. These two advantages are generating more interest in micro-hydro systems as environmental concerns and regulations increase [13]. The turbine 
impellers examined in this project would normally be operated in a run-of-river micro-hydro turbine system.

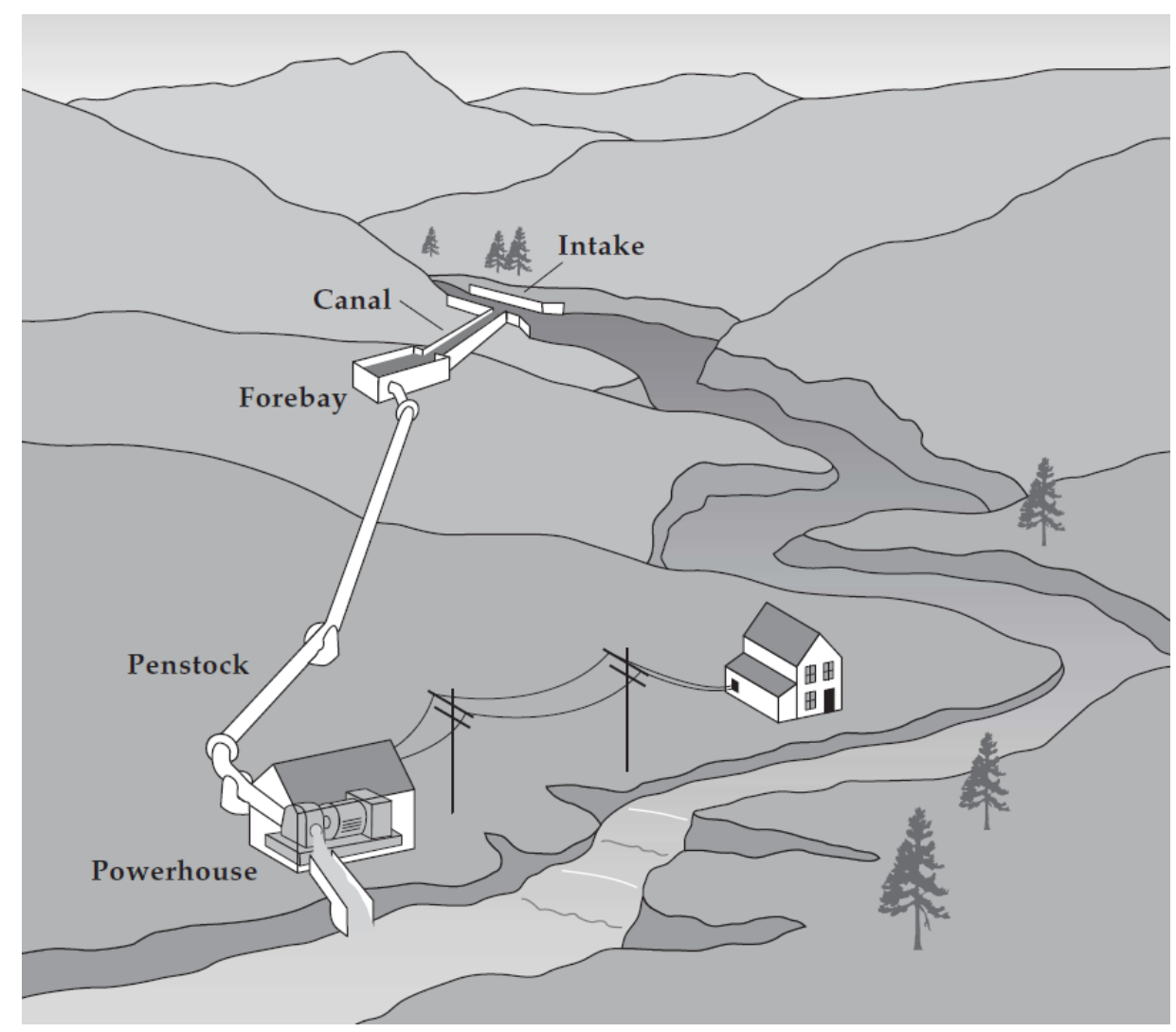

Figure 2: Illustration of the layout of a run-of-river hydropower scheme [14]

For perspective, other hydropower schemes include pumped storage and impoundment layouts. An impoundment layout requires blocking the flow of the water source to create a reservoir resulting in an increase of the hydraulic head and flow to the turbine at the site. Large dam based turbine set-ups are impoundment layouts. A pumped storage layout stores water at a high elevation by pumping from a water source or reservoir. The systems operates by directing water to the turbine system when demand for power is high. Water is then pumped back to the storage area when demand for electric power is lower so the process can be repeated [15]. 


\subsection{Historical Background}

Hydropower has been in use for many centuries and began with wooden waterwheels. Various types were used in many parts of Europe and Asia, mostly for milling of grains. Waterwheel technology was well developed by the time of the industrial revolution and produced efficiencies up to 70\% [16]. There are still thousands of waterwheels in use today in Nepal [6].

The first hydro turbine is thought to have been developed by Benoit Fourneyron in France in the 1820's [16]. Since then, many people experimented with different forms of turbines, including famous names such as Euler and Navier [6]. Improved engineering skill during the $19^{\text {th }}$ century, combined with the need for higher rotational speeds for the production of electricity, fostered the development of smaller devices.

Large scale hydropower development during the first half of the $20^{\text {th }}$ century was driven by increased demand for electricity production. Dams and hydropower stations were built at a rapid rate in North America and Europe. Since the 1960's, large hydropower manufacturers and equipment suppliers have flourished by exporting to developing countries, while small hydropower (<10 MW by this definition) demand has declined [16]. However, in 2004 a study was conducted by the U.S. Department of Energy (DOE) that analyzed every stream segment in the United States with a minimum length of two miles for the potential to support a small scale hydropower system. Approximately 500,000 viable sites were identified with a potential electrical generation capacity of 100,000 MW [17]. Of those sites, 93,831 were identified as feasible microhydropower sites representing a power generation capacity of 3,052 MW [10]. This would seem to suggest that there is still potential for micro-hydropower to expand and grow to take advantage of this potential. 
The most well-known impulse hydro turbine design is the Pelton Wheel. It is named for Lester Pelton who is credited with developing the split bucket design. Although others patented similar configurations, Pelton tested a range of bucket shapes in 1878 and eventually patented the design that became known as the Pelton Wheel [16]. Several features distinguish Pelton Wheels from other turbines which can be seen in the layout of the turbine and how the water jet strikes the buckets shown in Figures three and four. The nozzle that directs the water jet at the wheel is in the same plane as the buckets of the wheel. A notch is cut in the outer edge of each bucket on the wheel. Each bucket is also spilt in half by a ridge that forms two elliptically shaped cups on the inside of each bucket. The ridge directs the water jet when it hits the bucket around the inner surface of the elliptical cups and then out each side of the bucket. The notch in each bucket allows the water jet to hit the center of the tangential bucket for a longer duration without interference from the edge of the next bucket on the wheel. Efficiencies of large Pelton turbines are typically over $90 \%$. Micro-hydro Pelton impellers commonly have simpler designs that typically have efficiencies ranging from $75 \%$ to $85 \%$ [6].

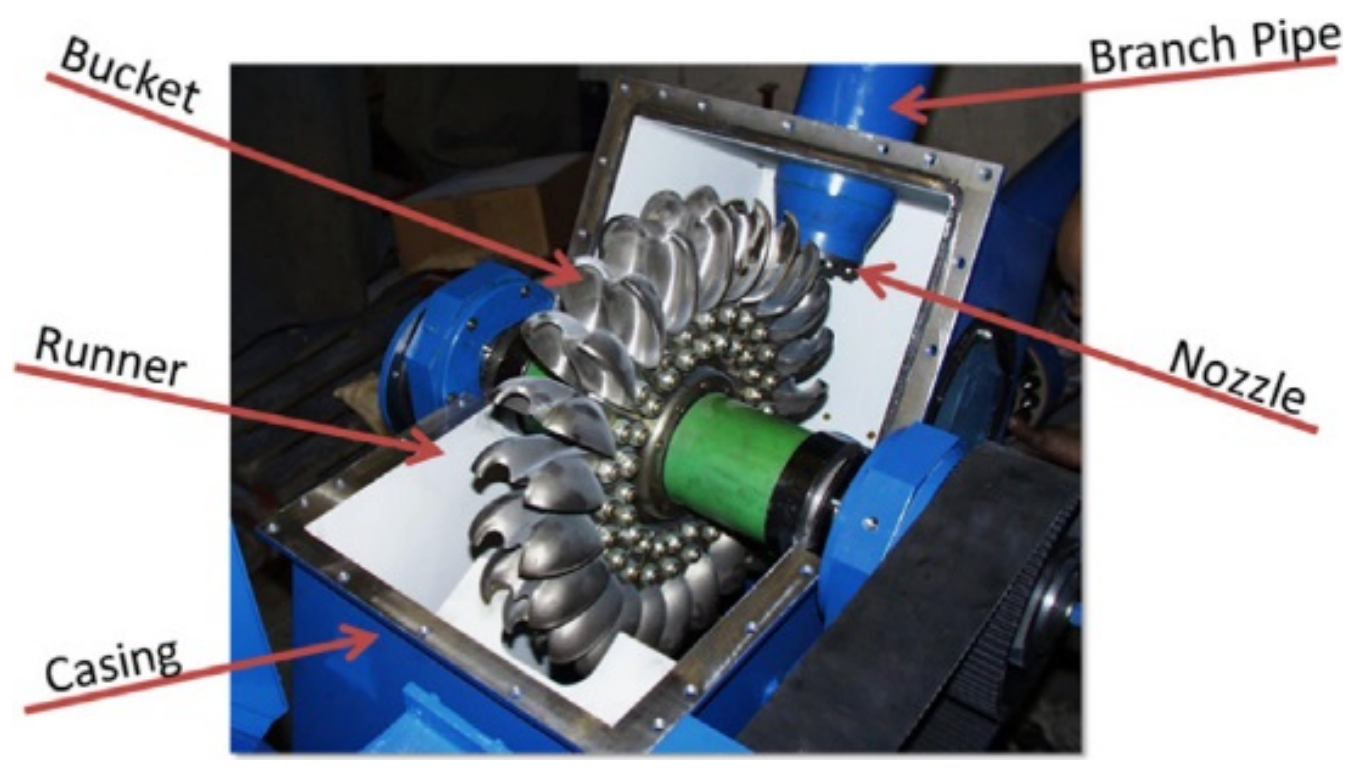

Figure 3: Typical layout of a Pelton Turbine [16] 

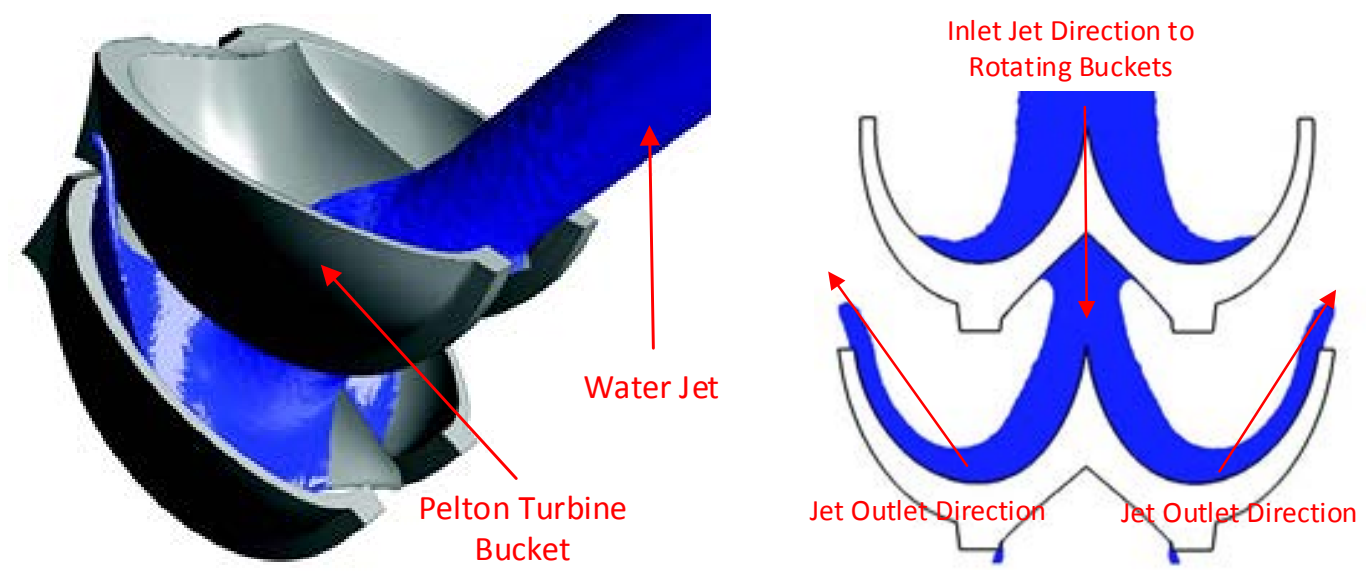

Figure 4: Illustrations of a water jet striking a Pelton bucket from a 3D view (Left) and a cross sectional view (Right) [18]

Turgo Turbines are similar to Pelton Wheels but with several key differences. Pictures of the Turgo Turbine layout and diagram of how the water jet strikes the buckets are shown in Figure 5. Figure 6 shows the shape of a Turgo buckets and the typical orientation of the jet as it strikes the impeller. In a Turgo Turbine, the water jet is positioned at an angle from a plane through the rotating impeller causing the jet to impinge on the bucket at an angle. The jet enters on one side of the impeller and then exists the other side [19]. There are no notches in Turgo buckets. This configuration keeps water exiting the impeller separate from the water jet entering the bucket on the other side of the wheel. Eliminating this interference allows a Turgo impeller to be more compact and operate at faster speeds when compared to a Pelton Wheels operating in the same conditions [19].

Eric Crewdson is credited with patenting the Turgo Turbine design in 1919 for Gilbert Gilkes and Gordon, Ltd. Gilkes was the sole manufacturer of Turgo Turbines until the 1970's. The company improved on the design with additional patents in 1936 and 1962 [18]. Experimental performance tests on Turgo Turbine impellers have shown peak efficiencies as high as 91\% [7] $[20]$. 


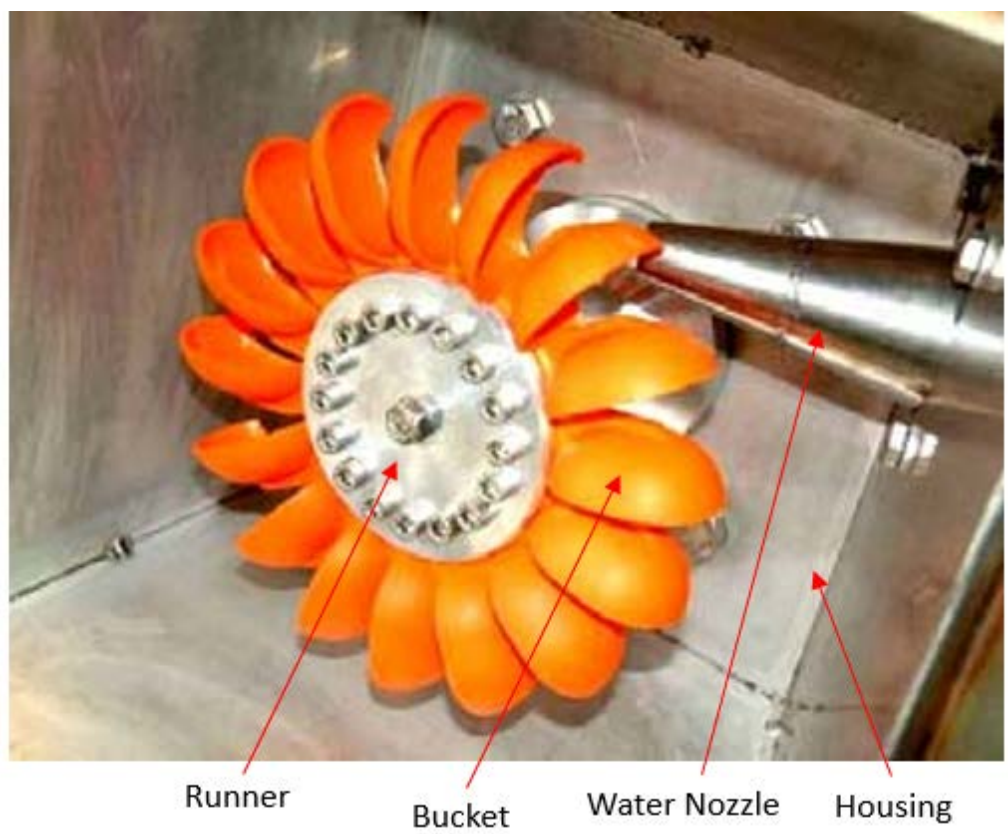

Figure 5: Typical layout of a Turgo Turbine [21]
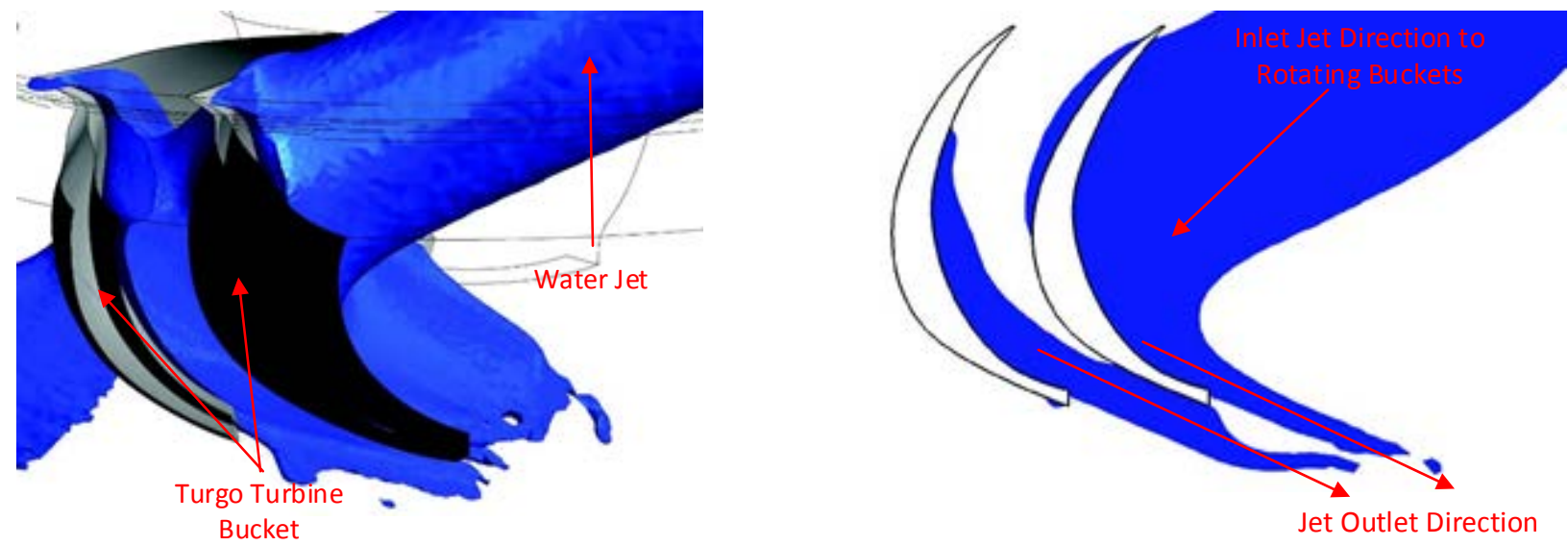

Figure 6: Illustrations of a water jet striking a Turgo Bucket from a 3D view (Left) and a cross sectional view (Right) [18]

Turgo turbines are installed in locations throughout the world. They have developed a reputation for robust reliability when compared to other micro-hydro turbine designs, especially when operated with water containing erosive particles. This has made them popular for use in areas where large amounts of erosive particles in the water supply is present [22]. Turgo Turbines are the main focus of this project. 


\subsection{Barriers to Expansion}

There are barriers in place that will impede growth of micro-hydropower systems in the current energy market. Such impediments are significant because they can be far more costly to future micro-hydropower projects than design challenges faced by each proposed individual turbine system. If these barriers are not addressed, they will limit the growth of hydropower industry and severely limit the expansion of micro-hydropower by destroying the incentives for developing the technology further. Improvement of micro-hydropower technology through research will not overcome these challenges. The U.S. Government can help reduce the effects of these challenges so that the opportunity to utilize a reliable energy producing technology is not wasted.

The biggest challenge is the investment of time and money necessary to obtain a license for a small hydropower facility [23]. A new hydropower installation must obtain a license from the Federal Energy Regulatory Commission (FERC) for construction, operation, and maintenance of the facility [23]. A hydropower facility must have this license or a license exemption before it can sell electricity produced to a utility. This road block can have a project-killing effect on some micro hydro projects because of their smaller budget and limited resources.

Most run-of-river micro hydro projects would be eligible for a license exemption because they commonly use natural water features and have relatively small generating capacities. However, large and small hydropower facilities go through the same application process, resulting in lengthy application periods. Also, the complex regulatory processes makes obtaining permits, licenses, or exemptions from the FERC costly and time consuming. Regulatory costs can exceed equipment costs in some cases and environmental studies needed to build new projects can take years to complete [23]. Poor integration and communication among government regulatory 
agencies leads to redundancy in the licensing process. Upon analysis of regulatory costs, FERC found that the water quality certification (Section 401 of the Clean Water Act) in particular drove up costs for many projects [23]. A report published by the National Hydropower Association Small Hydro suggested that removal of redundancies resulting from the clean water act should be pursued to improve the licensing process [24].

A journal article published in March 2013 stated that there were 1,600 non-federal hydropower facilities licensed by the federal government at that time [25]. In 2011, there were 130 non-federal hydropower facilities with pending license applications and relicense applications filed with the FERC [25]. A consistent complaint from the hydropower industry is that the process is unwieldy, lengthy, and uncertain. One reason the FERC's application process is known to be complex is because equal consideration must be given to energy conservation, fish, other wildlife, recreational opportunities, and other federally mandated needs. These considerations involve other agencies of the government causing significant delay in the licensing process. In 2001, the FERC filed a report with congress on hydroelectric licensing policies, procedures, and regulations to give direction on how to reduce the cost and time of obtaining a license. Recent legislation has been aimed at trying to improve the licensing process [25].

The “Hydropower Regulatory Efficiency Act of 2013” signed into law on August 9" 2013 raised the generating capacity classification for hydropower facilities eligible for a license exemption from 5 to $10 \mathrm{MW}$ [26]. Though this change increased the number of hydropower facilities eligible for exemption, it did little to address the inefficiencies in the licensing process. More recently, the "Hydropower Improvement Act of 2015" (S.1236) was proposed by the U.S. Senate with the intent to streamline the permit and licensing process for hydropower installations. If signed into law, this would be beneficial for the hydropower industry by reducing the permit 
and license processing time which currently takes an average of eight to ten years to complete. The key provisions of S.1236 includes, but is not limited to, the following: the FERC is designated as the lead agency to set a binding schedule; the FERC coordinates federal authorizations for licensing; requires federal agencies responsible for portions of the application to adhere to a timeline established by FERC to facilitate processing of the application; the FERC compiles and makes a comprehensive collection of studies and data available to the public to ensure that studies are not duplicated for federal authorizations; and limits the licensing and permitting process to three years after the application date. The Hydropower Improvement Act of 2015 is aimed at fixing poorly designed legislation passed as the Energy Policy Act of 2005 that had the same goal of streamlining licensing and project development [27].

Barriers to growth of hydropower also include a variety of other issues. Getting connected to the utility grid for net metering is difficult because it can be costly and may not be in the best interest of the utility company. There is a lack of standards and incentives for the development of new hydropower [23]. The National Hydropower Association Small Hydro Council has proposed modifications and improvements to address many of these issues and has initiated communications with FERC to begin the work [24]. Work completed to reduce these barriers includes the signing of a memorandum of understanding for hydropower by the Department of the Interior (DOI), the Department of Energy (DOE), and the Department of Army (DOA). This memorandum was one of the first steps to increase communication between the agencies and to prioritize the development of new sustainable hydropower [23].

\subsection{Development Incentives}

Based on new incentives and increased interest in renewable energy, the U.S. hydropower industry is primed for considerable growth [24]. Many states in the U.S. are active in adopting or 
increasing renewable portfolio standards (RPS) in an effort to utilize renewable energy sources. These policies have helped to drive the U.S.’s $\$ 36$ billion market for renewable energy. Policies such as these can be integral in helping the states diversify their energy portfolios, reduce emissions, and promote economic development [28]. Figure 7 shows states with established RPS goals in dark green, states with voluntary RPS goals and targets in light green, and states with no goals or standards in grey [28]. The Database for State Incentives for Renewables and Efficiency reports that 16 states, Washington D.C., and Puerto Rico offer rebate programs for renewables. Sales tax incentives are available in twenty eight states as well as Puerto Rico while tax credits for renewables are offered in twenty four states [23].

\begin{tabular}{l|l|l}
$\begin{array}{l}\text { States and territories with } \\
\text { Renewable Portfolio Standards }\end{array}$ & $\begin{array}{l}\text { States and territories with a voluntary } \\
\text { renewable energy standard or target }\end{array}$ & $\begin{array}{l}\text { States and territories with no } \\
\text { standard or target }\end{array}$ \\
\hline
\end{tabular}

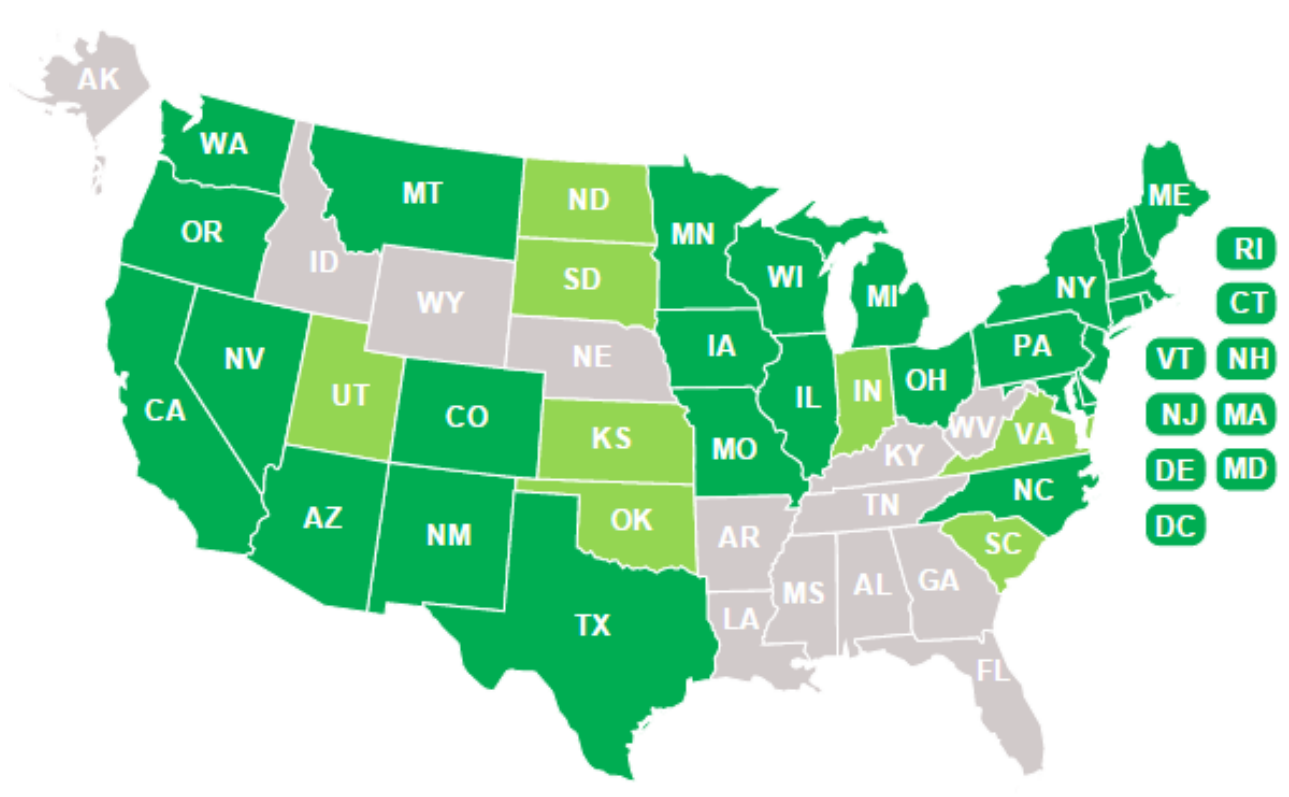

HI

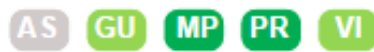

Figure 7: Map showing renewable portfolio standards of U.S. states and territories [28]

Hydropower is a well-established technology, and has been producing electricity at competitive prices for more than a century. It produces electricity with a very flexible and quick 
response time. This makes it well suited to cover peak-power demands and production gaps left by other forms of electricity production by varying the output from generating turbines [13]. These qualities make hydropower a stable source of energy for the electric grid [25]. A large majority of hydropower generation in the United States comes from large scale projects with generating capacities of more than $30 \mathrm{MW}$ [14]. In the U.S. in 2015, hydropower supplied 25\% of the total domestic renewable power consumed and $2.5 \%$ of overall electric power consumed [29]. The World Small Hydropower Development Report stated that in 2013, small hydropower (less than 10 MW capacity installations) had an estimated maximum power generation capacity of approximately 9,246 MW [23]. If the 3,052 MW of potential generation capacity from feasible micro-hydropower sites described in DOE Report 11263 were able to be put into operation, it would represent an approximate increase of 33\% in the total electrical power generation capacity from small hydropower in the United States.

Despite the barriers in place that impede the expansion of small scale hydropower, each turbine system's viability depends on their ability to obtain satisfactory performance in a given set of operational conditions. That is why the objective of this project was set on measuring the efficiency and power producing capability of each of the selected turbine impellers. Their efficiency and power output will determine if the cost of installing a new turbine system at a given site will be justified. 


\section{Literature Review}

The production efficiency of hydro turbines has become increasingly important to the hydropower industry in recent years. Economic viability and net production of electric power are closely tied to the efficiency of the turbines, especially for large systems. Market penetration and competitiveness is increasingly important as growth of other sources of renewable energy continues on both large and small scales. It will be important for hydro turbine manufacturers to continually improve turbine design and performance to keep hydropower as a viable business option in today's increasingly competitive renewable energy market [30].

Literature on impulse hydro turbines is relatively scarce. Published information most commonly comes in the form of academic articles, descriptions of individual installations, and textbooks on hydropower [6]. Of the information that is published on impulse turbines, a large portion of it is focused on Pelton style impulse turbines. The following presents work previously completed in the areas of design, performance evaluation, and CFD evaluation methods of Turgo and Pelton Turbines. These works provided insight into different approaches that could be taken for the performance analysis conducted in this project. Descriptions of experimental methodology, procedure, and set-up from these works were considered during the formation of the experiments in this project.

\subsection{Turgo and Pelton Turbine Design}

Accumulated knowledge on impulse turbine design is generally limited to proprietary commercial companies to preserve their competitive advantage [6]. In comparison to the Pelton Turbine, there is little published research on Turgo Turbines [7]. The traditional turbine designs, including the Turgo, were based on the accumulated experience of the manufacturers and the 
engineers who originally commercialized each design. Over time, improvements were made to each design through trial and error. The development of these technologies was based more on the intuition of a small group of engineers rather than hydrodynamic theory [30].

This trend in design practice has changed over the past two decades. Fluid mechanics theory is increasingly being applied to hydro turbine design challenges due to the large increase in available computing power and the availability of commercial open-source evaluation tools. Most turbine manufacturers now make use of computational fluid dynamics (CFD) to analyze the flow development inside turbine components. The engineers using these tools are more competent in the methods of numerical analysis and CFD as well [30].

Impulse turbine modeling is much more difficult than that of reaction turbines because of the complex, unsteady, two-phase, free-surface flow developed by the interaction between the buckets of an impeller, the water jet transferring the impulse, and the air inside the turbine housing. Complex flow phenomena include flow separation and cavitation in the impact area of the jet on the bucket and where the turbine bucket cuts through the impinging water jet. Degradation of the surface of the water jet as it passes through air after leaving the water nozzles is another type of phenomena that is difficult to analyze but does have an effect on the performance of the turbine. Water droplets in the turbine housing can also impact the water jet and change the amount of kinetic energy transferred to the impeller. The uniformity of the water flow is changed by bends in the piping just upstream of the nozzle entrance causing the water jet to deform. These phenomena combine to make impulse turbine modeling difficult even with the help of numerical methods assisted by increased computing power and CFD. Increased modeling complexity for impulse turbines causes computer processing times to increase by two orders of magnitude when compared to similar simulations for reaction turbines. Smaller turbine manufacturers are typically 
at a disadvantage because they are unable to afford a numerical modeling, design, and testing department to do research on their products [30].

The surfaces of Turgo Turbine buckets were originally designed using velocity triangles based on inlet and outlet angles combined with assumptions regarding the flow within the impeller. This approach typically assumes the blades are short enough to prevent frictional losses to the relative velocity, but long enough to prevent "eddy" losses due to the bending of the water as it travels along the blades. It was noted that the exit angle was the most important consideration in the design of the impeller. An example of the velocity triangles associated with Turgo Turbine buckets is shown below in Figure 8. A smaller exit angle would result in a higher efficiency due to less momentum loss at the exit. Reducing the exit angle too greatly would reduce the capacity and efficiency of the turbine by restricting the flow through the impeller because the exiting jet would impact the next bucket on the impeller. A common value for the exit angle $\left(\beta_{2}\right)$ is between $10-15^{\circ}$. The exit angle could be made slightly smaller than this common range because the discharge angle of the water jet exiting the impeller may be greater than the physical exit angle on outlet side of the bucket. This is due to the Coanda Effect which causes the water film exiting to be slightly deflected towards the trailing edge of the bucket [22].

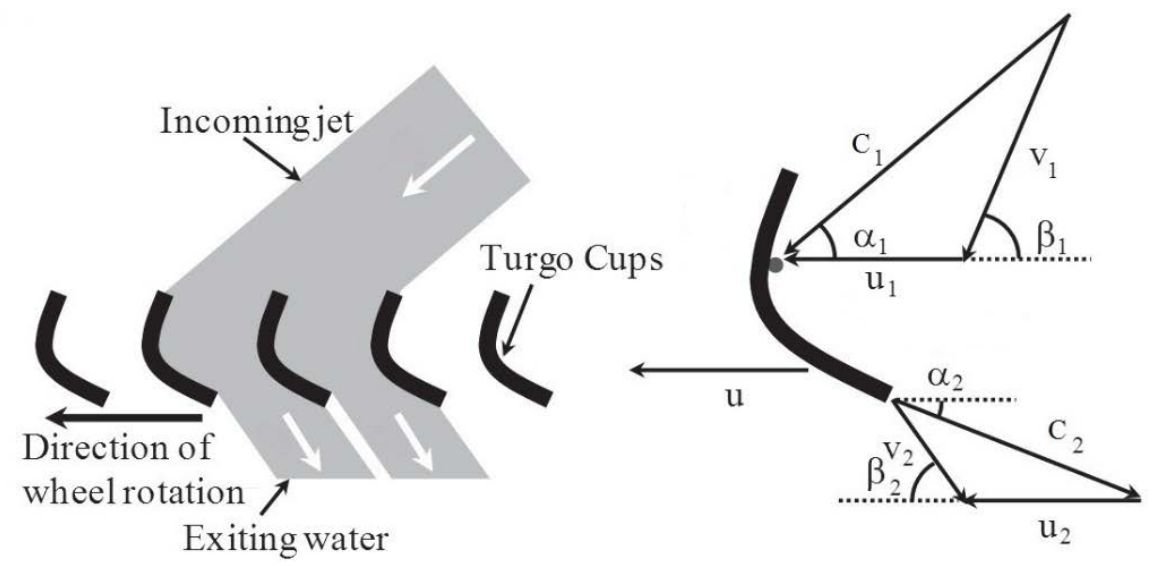

Figure 8: Illustration of the velocity triangles associated with Turgo Turbine buckets [20] 
In Figure $8, C_{1}$ represents the absolute velocity of the water jet at the inlet to the bucket and $C_{2}$ represents the absolute velocity at the outlet to the bucket. The relative velocity at the inlet is represented by $V_{1}$ and the relative velocity at the out is represented by $V_{2}$. The angle of the absolute velocities at the inlet and outlet are $\alpha_{1}$ and $\alpha_{2}$, respectively. The angle of the relative velocities at the inlet and outlet to the bucket are $\beta_{1}$ and $\beta_{2}$, respectively. The tangential velocity of the moving bucket is represented by $U_{1}$ and $U_{2}$ (these are equal and can be called $U$ ).

The Euler Turbomachine Equation can be combined with knowledge of the shape of the buckets to provide an idealized estimate of the power output of the turbine based on the geometry of the blades and properties of the incoming water jet. The velocity triangles in Figure 8 show the inputs to the Euler Equation listed below in Equation 1. Equation 1 is an adapted form of Euler Equation as described by Young, et al. [4].

$$
P_{\text {shaft }}=\dot{m} U\left(c_{2 T}-c_{1 T}\right)=\dot{m} U\left(C_{2} \cos \left(\alpha_{2}\right)-C_{1} \cos \left(\alpha_{1}\right)\right)
$$

In Equation 1, $\dot{m}$ represents the mass flow rate of water entering and exiting the turbine buckets. The tangential speed of the bucket as it rotates is represented by $U$. The tangential components of the absolute velocity at the inlet and the exit are represented by $c_{1 T}$ and $c_{2 T}$, respectively. They are related to the absolute velocities marked in Figure 8 using the cosine of the angles of absolute velocities which are also shown in Equation 1. This model assumes the jet hits each bucket in the same location which is not the case for a rotating impeller [20]. It also fails to account for the effect of the water jet being cut by multiple buckets at once during rotation, spray interfering with the incoming jet, and the aforementioned flow phenomena.

An original paper describing the design of the Turgo Turbine by Crewdson states that the inlet angle of the bucket should be set at $20^{\circ}$ [31]. The paper also states that it is better to have the physical inlet angle of the bucket larger than the angle of the incoming jet to reduce losses of 
efficiency. These losses occur as water being deflects away from the impeller as it impacts the transition surface at the top of the bucket between the front and rear faces. Crewdson also provides a guideline for the speed ratio of the turbine. This is the ratio of water jet velocity to the tangential rotational velocity of the bucket at the point where the jet impinges and it is dimensionless. The range of this ratio should be $0.45-0.47$ [31].

Turgo Turbine impellers have a more complex three dimensional shape when compared to Pelton Turbine Impellers. The efficiency of a Turgo impeller is more sensitive to the impeller shape than that of a Pelton design. Studies have shown that small shape variations in Turgo designs can lead to $5-10 \%$ reductions in efficiency [32]. As a result, a small number of manufacturers design and construct Turgo Turbines [30].

Work by Thake [6] titled “The Micro-Hydro Pelton Turbine Manual: Design, Manufacture and Installation for Small-Scale Hydro-Power” served as valuable reference for impulse turbine design methodology. Thake's work focuses on the Pelton Turbine but it still provides valuable insights into the design and maintenance of the penstock and nozzle systems used on both Pelton and Turgo Turbines. The nozzle design for the nozzles in this experiment was based on guidelines for an effective short nozzle from this reference [6].

A work by Harvey [19]reviews the design of a micro-hydro system. It covers a broad range of topics including reaction turbines, impulse turbines, pump run as turbines, and many of the components that are unique to those designs. This reference also focuses on methods used for selecting a turbine for a particular site, estimating costs for building on that site, and estimating the amount of power that can be produced by the proposed design [19].

A work done by Davis [33] presents a collection of case studies from small hydropower projects around the world. This provides lessons learned through design concepts, maintenance 
practices, and cost estimation information from previous projects. Diagrams showing multiple system designs were helpful during the creation of the experiment conducted in this project by identifying different components that might be used in the experimental set-up [33].

Work by Daugherty [34] provided a detailed reference of the basic theory behind blade shape of impulse and reaction turbines. A description of how velocity triangles can be used to create basic estimations of torque produced on the turbine impeller, force exerted by the jet, and the relation of time rate change of momentum to force on the impeller are also included. Other sources also touch on these subjects and provide a general perspective of turbomachinery, but Daugherty explains each concept in detail from the perspective of how it pertains to hydro turbines. This reference also states that a Pelton Turbine can be expected to operate with a 75-85\% efficiency if it is reasonably well designed and fabricated [34]. It also contains a chapter about turbine performance testing, specifically identifying test setup challenges. This reference also identifies guidelines on how to determine mechanical losses in the test set-up [34]. This information was utilized when designing a "coast down" test to determine the mechanical losses in the test rig before the performance test.

Correa et al. [35] performed a study utilizing a new methodology for designing Turgo Turbine impellers with the concept of three dimensional potential flows. The profile obtained from certain potential flow streamlines were modified using several algorithms to select one that would accurately represent an efficient profile of the inner surface of a Turgo impeller bucket. The profile was combined with other geometric parameters to form a design for a Turgo Impeller [35].

Dorji and Ghomashchi [36] present four critical failure modes that can occur in most hydro turbine systems. The failure modes identified were cavitation, erosion, fatigue, and material defects. This reference outlined the causes of these failure modes, parts of turbine systems that are 
susceptible to them, and preventative maintenance practices that can help avoid them [36]. The causes of these failure modes are often present in a turbine system for months or years before a failure may be realized. They did not directly affect the equipment in this project. However, understanding their causes provides value perspective that is needed if new turbine designs are made in the future.

\subsection{Experimental Evaluations of Performance}

As mentioned above, complex flow phenomena reduce the accuracy of numerical models of impulse turbine performance. Numerical simulation and design tools need experimental support to validate their accuracy [37]. The following set of works describe previous experimental evaluations of impulse turbine performance, test apparatus designs, and the methodology used to conduct the experiments. Studies on the Pelton Turbine proved valuable when examining Turgo Turbines because they use the same nozzle and spear injector systems and operate on the same principles [22].

The International Electrotechnical Commission (IEC) Standard 60193 [38] was used as a general guideline for conducting the performance tests in this project. This reference provided standard practices for model acceptance tests for hydraulic turbines and storage pumps [38]. Due to budgetary constraints, the entire standard was not followed due to equipment needed. However, many aspects of the standard were utilized including: the definition of the turbine efficiency; the methods for the measurement and calculation of the water density; and an approximation for acceleration due to gravity at the test site. Guidelines for mounting pressure transducers were used during the fabrication of the water nozzles used in the test stand. General information regarding the layout of data acquisition systems and component selection was utilized from this reference. 
Although similarity laws were not applied in this test, IEC 60193 gives guidelines for applying similarity laws in performance tests on different types of hydro turbines.

Numerous experiments have been conducted to characterize the performance of different types of impulse turbines. Booker et al. [20] experimentally optimized the operational parameters of a pico-hydro Turgo turbine in an effort to maximize the efficiency and power output of the turbine. In this study, parameters including nozzle diameter, head, inclination angle of water jets, impeller pitch diameter, number of impeller cups, and the vertical aim position were varied in order to optimize the power output of the Turgo impeller being tested. For each design point tested, the rotational speed was plotted versus efficiency to find the optimal conditions [20]. A picture of the experimental setup is shown in Figure 9.

The same apparatus shown in Figure 9 was also used by Booker et al. [7] to perform a study that showed that pico-hydro Turgo Turbines can also perform favorably in low-head conditions. A turbine efficiency of $91 \%$ was shown at $3.5 \mathrm{~m}$. of water head pressure and $87 \%$ efficiency at $1 \mathrm{~m}$.

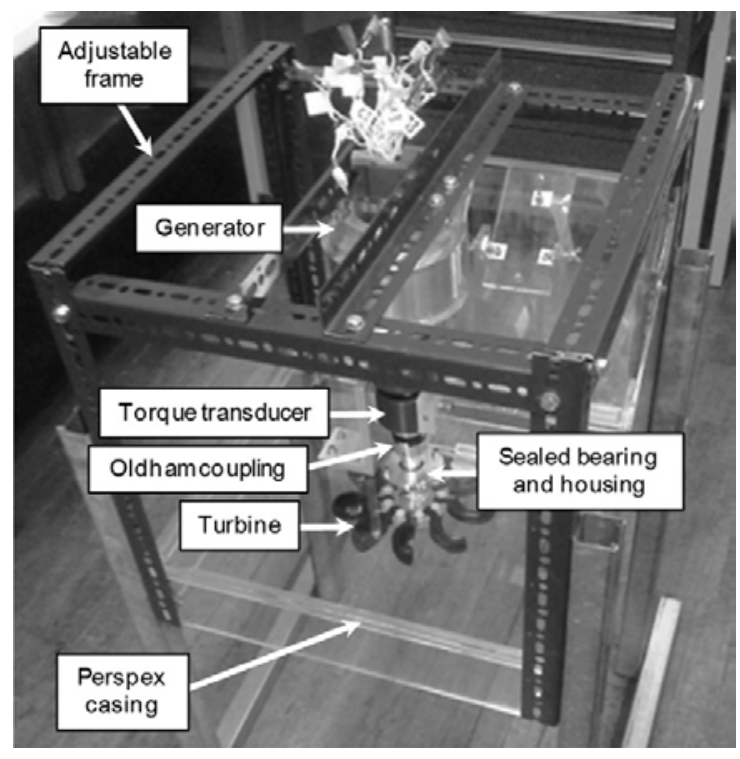

Figure 9: Test apparatus used by Williamson et al. [7] 
In this set-up, a Turgo Turbine impeller was fabricated from commercially available cups for testing. The impeller was coupled to a low speed permanent magnet generator which was rated for $1 \mathrm{~kW}$ of generating capacity. A torque meter was coupled between the generator and the impeller. The speed of the turbine was controlled by changing the electrical load on the generator. Speed of the rotating shaft was calculated by measuring the frequency of the output current on the generator. Water flow came from a header tank and the head was controlled by controlling the water level in the tank. Water was fed in a continuous closed loop during the test resulting in a constant tank water level. A single nozzle supplied water to the turbine with constant pressure head because of the level of water maintained in the head tank. Piping leading to the nozzle was extended by 50 pipe diameters to ensure that the flow was fully developed before entering the nozzle [7].

Aggidis and Zidonis [39] conducted a study to show a process for automating performance testing of various turbine models. The goal of the project was to quickly turn data collected into three dimensional efficiency maps. Their test apparatus was built to test models of impulse and reaction turbines that had been scaled down by applying similarity laws. Francis (a type of reaction turbine) and Pelton Turbines were evaluated in the study. The testing apparatus was originally built by the Gilbert Gilkes \& Gordon Ltd. who originally patented the Turgo Turbine [39].

Water flow and head for this set-up were supplied by a centrifugal pump coupled to an electric motor. The turbine was coupled to a mechanical brake that applied load to the output shaft so the speed of the turbine could be controlled. The water flow in the apparatus was indirectly measured using a triangularly shaped weir. The readings of shaft speed and torque were taken directly from the output shaft of the set-up using a load cell and optical speed sensor. Stepper 
motors were used to actuate valves and the mechanical brake so that test conditions could be changed via computer program [39].

Cobb and Sharp [40] [41] conducted a study to test the performance characteristics of impulse turbines. Data collected was used to describe the effect of speed ratio, jet misalignment, and jet quality on the efficiency of the turbine [40]. Two plastic Turgo Impellers and one brass Pelton Turbine were tested. One of the Turgo impellers tested was a $169 \mathrm{~mm}$ pitch diameter impeller produced by Hartvigsen Hydro. Measured test results indicated a peak efficiency of 85\%. It was stated in this study that the optimum speed ratio should be set near 0.5. However, during actual operation the optimal speed ratio ranged between 0.46 and 0.48 . Reducing the inlet angle of the water jet (angle $\alpha_{1}$ from Figure 8) before it impinged on the turbine from 20 to 18 degrees resulted in a 5\% drop in efficiency [41].

The test stand used in the Cobb and Sharp experiment consisted of vertically mounted turbines directly coupled to a permanent magnet alternator. A 2 hp centrifugal pump was used to circulate water through the system. A variable cross section valve was installed in the flow loop to control the flow rate [41]. A picture of the test stand is shown below in Figure 10.

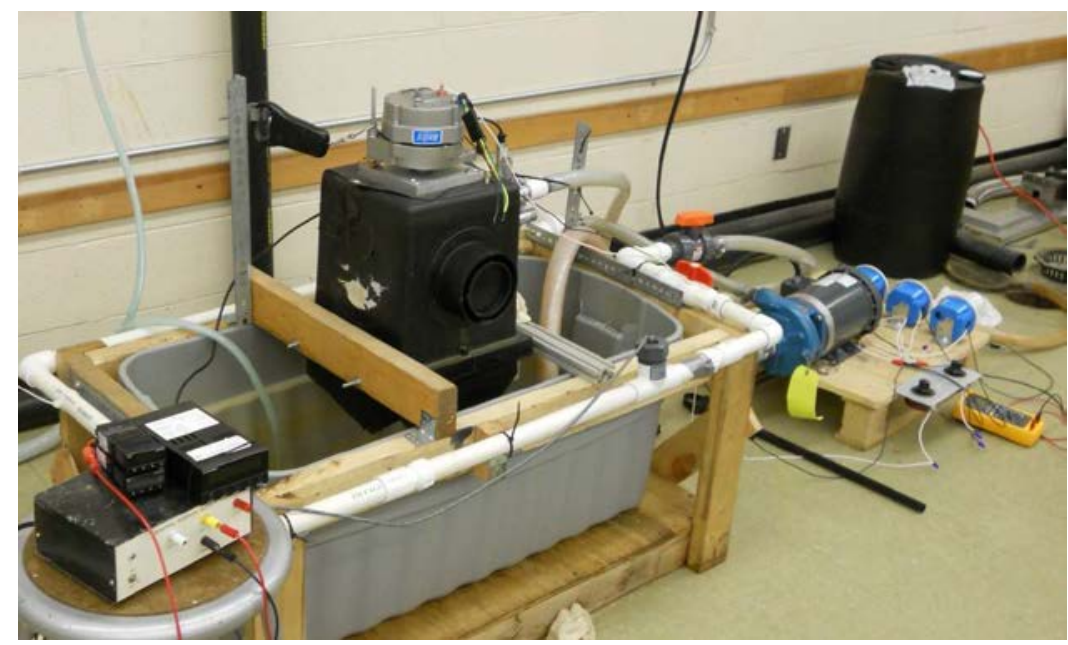

Figure 10: Impulse Turbine test setup created Cobb and Sharp [41] 
This set-up was capable of testing Pelton or Turgo Turbines limited to $170 \mathrm{~mm}$ in diameter. The shaft speed could be varied between 400 and 1900 RPM by altering the electrical load on the alternator. A maximum of $29 \mathrm{~m}$ of water of head could be achieved with the set-up. A maximum of $350 \mathrm{~W}$ of hydraulic power could be delivered to the turbine from the centrifugal pump supply. Four different water nozzles were used ranging from 7.94 to $12.7 \mathrm{~mm}$ in diameter to achieve different jet diameters and flow conditions [41].

Stamatelos et al. [37] completed this project to determine detailed performance measurements on a Pelton Turbine and the nozzles. Geometrical dimensions of the impeller, buckets, and spear valves were documented because this type of information is usually proprietary for manufacturers. This experimental set-up was constructed to mirror the design of an operational turbine used by the Greek Public Power Corporation and was built to a scale that represents 1/6 of the actual size of the turbine [37].

This study modeled the spear valve flow losses using the CFD software Fluent and a method called smooth particle hydrodynamics (SPH). By numerically estimating the losses in the spear valve, a more accurate assertion of the efficiency due to the water jet and bucket interaction could be obtained. Turbine efficiency charts were constructed to show the overall results [37].

The maximum attainable efficiency for the Pelton turbines tested in this study was $86 \%$ for a power range of up to $80 \mathrm{~kW}$. Mechanical losses with the spear valves in their smallest cross sectional position were approximately $14.5 \%$ of the average hydraulic power input to that valve. The efficiency of the water jet and bucket interaction was approximated to be near 96\% [37]. To be clear, the jet bucket interaction represents only one form of loss that reduces the efficiency of the turbine. Others include mechanical losses from the bearings the turbine shaft is mounted on and windage loss of the impeller as the buckets push through air. 
Agar and Rosi [42] performed an experiment to model a Pelton Turbine. The model was used to educate students and describe the procedure for measuring the mechanical efficiency of a turbine. The Pelton buckets used in the experiments were found to have an efficiency of $47 \%$ [42]. Thapa and Dahlhaug [43] proposed the design of a turbine testing facility that would serve the hydropower industry in Nepal. The Water Power Laboratory would be dedicated to the performance analysis of Crossflow and Pelton turbines. In addition, research on the erosion of turbine components from particulate in the water flow would also be studied. Construction of a laboratory at Kathmandu University has been proposed to further the development of small hydropower that is common in rural Nepal. The proposed facility would use an overhead water reservoir to feed test stands for both impulse and reaction turbines. The reservoir would be able to provide $30 \mathrm{~m}$ of static head to each setup. The water would be circulated between the upper reservoir and a lower one by two pumps with a capacity of approximately 4,000 GPM. Electromagnetic flow meters and pressure transducers would be used to measure some of the performance parameters. The largest capacity turbine that can be tested would be $300 \mathrm{~kW}$ [43].

Sakurai et al. [44] used an experimental test stand for performance measurement of a centrifugal pump operated in reverse as a turbine. The pump-turbine had a rated efficiency of 55\% and a maximum flow of approximately 132 GPM. It was connected to a six pole generator with a generating capacity of $1.5 \mathrm{~kW}$. The maximum output of the pump turbine set-up was $402 \mathrm{~W}$ and the maximum efficiency achieved was 51\% [44]. A schematic of the test set up is shown below in Figure 11. 


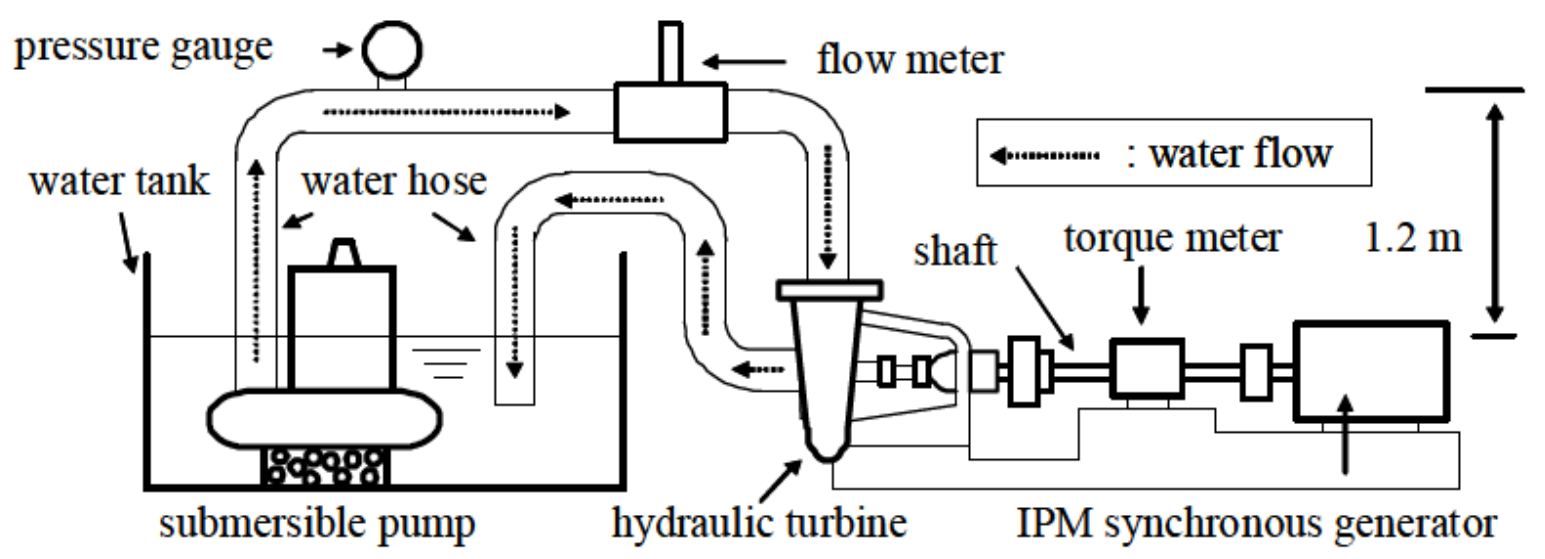

Figure 11: Test set-up created by Sakurai, Funato, Ogasawara [44]

Climescu et al. [45] documented the design of an impulse turbine testing rig with an integrated planetary speed increaser to change the rotational speed of the output shaft. The system was meant to function unattended [45]. A diagram of the system is shown in Figure 12. Although no numerical data was reported, the efficiency of the Turgo Turbine in experimental was measured with and without the speed increase coupled between the generator and the turbine impeller. The schematic of the test setup served as another reference for the design of the test stand in this project.

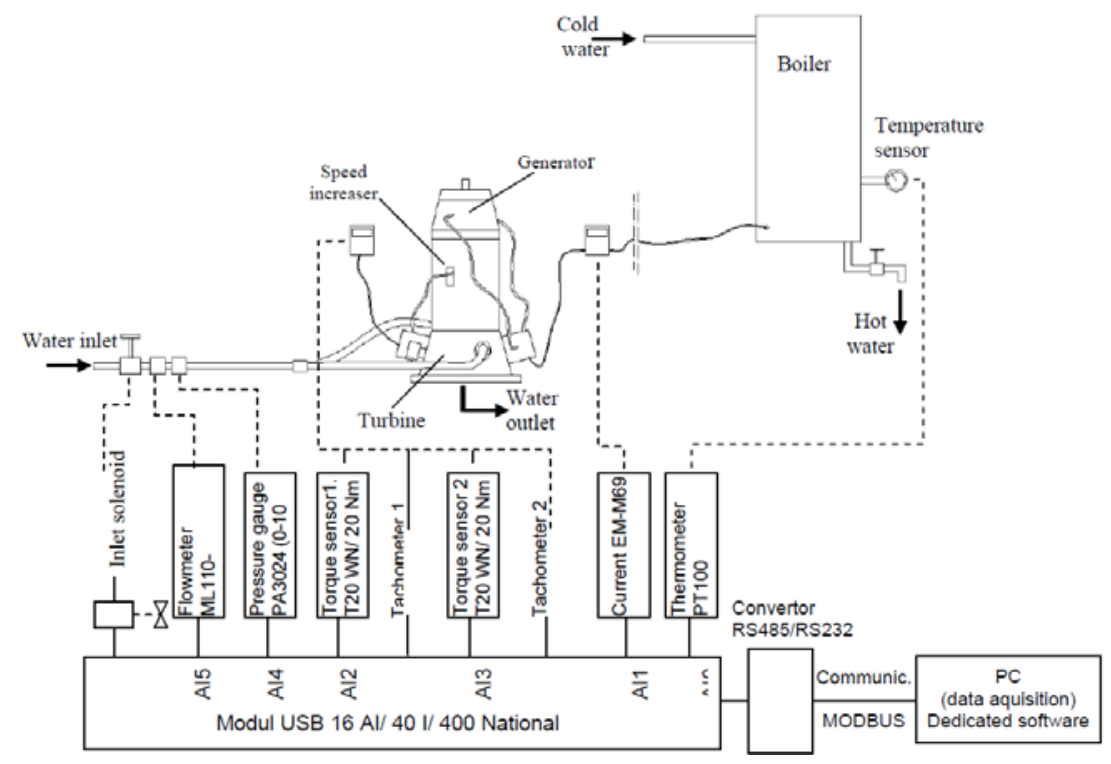

Figure 12: Schematic of experimental set-up for Climescu et al. [45] 


\subsection{CFD Evaluations of Performance}

This section discusses recent studies of impulse turbines that involved CFD and numerical methods. Main regions of interest on a turbine for study are piping leading to the nozzles (distributor), the nozzles themselves, the impeller buckets, and turbine casings. The distributor and nozzles are critical to the overall efficiency of the system and the operational life of the impeller. The turbine efficiency is highly dependent on the shape of the buckets of the impeller. Casing design is important because it can cause losses via disturbances of the incoming water jets from spray. Sheets of spent water can deflect off of the walls of the casing and disrupt the jet [22].

Anagnostopoulos et al. [32] presented a new CFD based design methodology for Turgo Turbines using a La'Grangian perspective that tracks a number of particles as they move through a Turgo impeller bucket. The Fast La'Grangian Simulation (FLS) was beneficial because it could be completed with negligible computation time when compared to other modern CFD methods. The bucket shape of a $70 \mathrm{~kW}$ Turgo model was parameterized and then optimized using stochastic optimization software. The model was fabricated, tested, and the results were compared to the numerical simulation. The simulation showed satisfactory agreement with the experimental results [32].

Anagnostopoulos et al. also presented a Smooth Particle Hydrodynamics (SPH) methodology for simulating unsteady free-surface flows in a rotating Turgo bucket. The meshless nature of the method allows it to capture flow features appearing in the turbine without diffusion at the interface between air and the water jet. Two different geometries for the buckets were compared and the results were compared to a simulation obtained by the commercial CFD package Fluent. The SPH method proved capable of obtaining similar results with much less computation time [21]. 
Keck and Sick provided a comprehensive overview of CFD development in regards to hydro turbines over the last 30 years. It lists mile stones and breakthroughs in analytical methods up to 2008. The timeline is phased into several time periods with different methods, levels of complexity, and simulation accuracy common to each period [46].

These works provided a valuable reference during the process of forming the procedures, methods, and equipment that were used to conduct this experiment. The insight provided by each individual work mentioned served to create a perspective of how performance analysis of microhydro impulse turbine should be conducted. 


\section{Experimental Setup}

\subsection{Methodology}

\subsubsection{Evaluating Turbine Efficiency}

The main goal of this project was to measure the efficiency and shaft power produced by two Turgo impellers to judge their performance. The first impeller which will be called impeller A was a brand new impeller made from stainless steel. A picture of impeller A can be seen in Figure 33 in Section 3.2.8. The second impeller had been in operation before the project and had been worn and corroded on a lot of its surfaces. It will be called impeller B. A picture of impeller $\mathrm{B}$ is shown in Figure 34 of Section 3.2.8. Knowing the performance parameters allows for a more accurate prediction of the energy produced by the turbine system. This information is needed if the system is going to be competitively marketed.

Efficiency $(\eta)$ for a hydro turbine is defined as the shaft power output $\left(P_{\text {shaft }}\right)$ from the turbine divided by the hydraulic power $\left(P_{\text {hydraulic }}\right)$ put into the system [4]. This is shown below in Equation 2 seen below.

$$
\eta=\frac{P_{\text {shaft }}}{P_{\text {hydraulic }}}
$$

Shaft power is defined as the power produced from the shaft connected between the generator and impeller [38]. It is defined below by Equation 3.

$$
P_{\text {shaft }}=2 \pi \dot{n} \mathrm{~T}
$$

In Equation 3, $\dot{n}$ represents the shaft rotational speed and T represents the torque imposed on the impeller. Hydraulic power is defined as the power produced from the water flow exiting the nozzles under pressure. It is defined by Equation 4 .

$$
P_{\text {hydraulic }}=\rho g h \dot{Q}
$$


In Equation 4, $\rho$ represents the density of the water and $g$ is the local acceleration due to gravity. Net head $(h)$ is the elevation head produced by the pump that is circulating water through the test stand. The pump is simulating the natural head pressure that would be built up by water flowing down an elevation decline such as a hill or from a dam reservoir. Volumetric flow rate of the water flowing through the test stand is represented by $\dot{Q}$.

\subsubsection{Net Head}

Before conducting the experiment, an approximation of the major and minor losses in the piping of the Antrim site was conducted using knowledge of the penstock construction. This calculation determined that the losses present in the Antrim penstock did not warrant changing the value of pressure head for the experiment. The centrifugal pump used to create head pressure in the experiment could approximately control the pressure head within $\pm 5 \mathrm{ft}$. of water. The losses calculated for the Antrim penstock were within this range. Therefore, the head pressure to be used in the experiment was kept at $160 \mathrm{ft}$. of water which was the elevation difference between the entrance to the penstock and the water nozzles that serve as the inlets to the turbine. The net head at each nozzle was measured during the experiment in an effort to achieve the target head in each water nozzle. Net head was calculated by rearranging the equation for hydrostatic pressure below in Equation 5 and measuring the pressure $(p)$ and water density $(\rho)$ at each water nozzle in the test stand.

$$
h=\frac{p}{\rho g}
$$

Two water nozzles were used as the inlets to the turbine in this experiment. They will be called nozzle 1 and nozzle 2. They can be seen in the schematic in Figure 21 and will be described in detail in Section 3.2.5 of the experimental set-up. It should be noted that there was a pressure 
difference between the two nozzles because of different lengths of piping and fittings leading to each. Nozzle 2 had a lower pressure when compared to that of nozzle 1 because of this. Nozzle 1 was kept near the target of $160 \mathrm{ft}$. of water or 69.3 PSI for each test while nozzle 2 fell to approximately a 1-5\% lower value than that of nozzle 1 .

\subsubsection{Design and Sizing of Water Nozzles}

When operating an actual turbine for power production it is important to monitor the flow rate of water to the turbine. Obtaining the maximum power output and efficiency that can be produced for a given set of operating conditions requires controlling a flow rate set-point entering the turbine. The speed of the water jet exiting the water nozzles $\left(V_{j e t}\right)$ is dependent on the net head supplied to the nozzles. This is shown below by Equation 6, derived from Bernoulli’s Principle.

$$
V_{j e t}=C_{V} \sqrt{2 g h}
$$

In Equation 6, $C_{V}$ is a velocity coefficient associated with the speed of the water jet exiting the nozzle. Typical turbine nozzles have values between 0.95 and 0.99 for the velocity coefficient. A properly designed and manufactured nozzle should have a coefficient of at least 0.97 [6].

Since the jet velocity is fixed by the head at the water nozzle, the flow rate provided to the turbine is adjusted by varying the diameter of the water nozzles. Flow rate could also be increased by adding multiple nozzles to the turbine system because it has the same effect as increasing the exit diameter of a single nozzle. Actual turbine systems use two methods to control the nozzle diameter. A spear valve controls the cross sectional area of the nozzle by controlling the position of a spear head which translates axially into and out of the middle of the nozzle opening. The spear head is advanced in and out of the opening by rotating a threaded shaft attached to the head.

The second method to control flowrate into the turbine consists of using different sizes of nozzles in a set. Each nozzle in the set is sized to fit a certain range of flow rates. When the flow 
rate provided to the turbine varies out of a specified range, the nozzle must be changed to one that delivers the correct amount of flow to the impeller. Spear valves are more complicated and expensive than the fixed sized water nozzles; however, they can be precisely adjusted to the available water flow for a wide range of flow rates. Five different sizes of water nozzles were used in the test stand for this experiment.

The water nozzles used in this experiment were classified as short nozzles based on a design presented by Thake. Values of the contraction coefficient $\left(C_{C}\right)$ were given to be $0.83-0.85$ and the velocity coefficient $\left(C_{V}\right)$ was 0.97 [6]. A drawing of the nozzles used in the test stand is shown below in Figure 13. Instead of having a flanged connection to the piping as depicted in Thake, the nozzle was threaded on to a $90^{\circ}$ pipe elbow in the test stand. It should be noted that the inner diameter of the inlet pipe matched the entrance diameter of the nozzle. However, a small gap was left between the nozzle and the end of the inlet pipe. This was due to the fact that the machined threads on the nozzle end before the nozzle entrance meets the end of the pipe elbow it is connected to. This does not allow the inlet pipe to thread completely into the nozzle. This small gap could cause a disturbance in the water flow through the nozzle but this effect was deemed negligible because each nozzle produced a uniformly shaped water jet during the experiment. As a side note, an ideal water jet is conical in shape and has very little dispersion away from that shape as it travels through air and spray before it impinges on the impeller. A uniform jet will transfer the maximum possible amount of kinetic energy to the impeller. Any excessive dispersion away from the jet will result in lost kinetic energy that will not be transferred to the impeller [6]. The quality of the water jets in this experiment will be discussed in Section 4.6. 


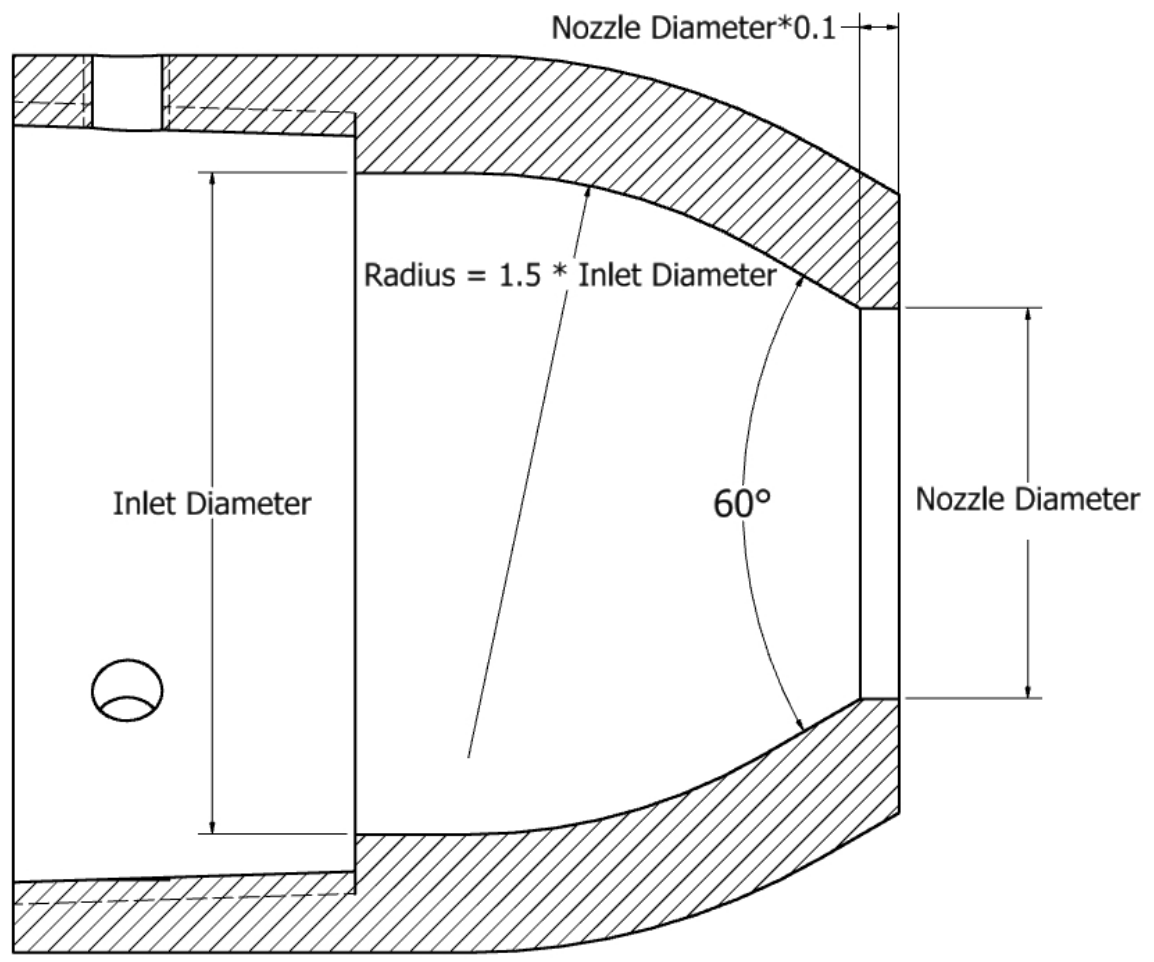

Figure 13: Illustration of the geometry of the water nozzles used in the test stand [6]

An expression for the required diameter at the nozzle exit can be obtained by combining the expressions for the jet velocity (Equation 6) and the area of the nozzle into the expression for volumetric flow rate. The expression for nozzle diameter is shown below by Equation 7.

$$
D_{\text {Nozzle }}=\sqrt{\frac{4 \dot{Q}}{\pi n_{j e t} C_{c} C_{V} \sqrt{2 g h}}}
$$

In Equation 7, $n_{j e t}$ represents the number of water nozzles used in the system. The contraction coefficient $\left(C_{c}\right)$ represents the amount of contraction the water jet experiences after it exits the nozzle and reaches the vena contracta [6]. For this experiment, five different sets of nozzles were machined to be tested at various flow rates. The different sizes and flow conditions for each nozzle are shown in Table 2. 
Table 2: List of nozzle diameters for the nozzles used in testing

\begin{tabular}{|c|c|c|c|c|}
\hline $\begin{array}{c}\text { Rated } \\
\text { Flow Rate }\end{array}$ & $\begin{array}{c}\text { Rated } \\
\text { Flow Rate }\end{array}$ & Flow Description & $\begin{array}{c}\text { Nozzle } \\
\text { Diameter }\end{array}$ & Nozzle Diameter \\
\hline$(\mathrm{GPM})$ & $\left(\mathrm{m}^{3} / \mathrm{s}\right)$ & & $(\mathrm{m})$ & (in) \\
\hline 250 & 0.016 & Min & 0.020 & 0.781 \\
\hline 500 & 0.032 & & 0.028 & 1.105 \\
\hline 750 & 0.047 & Average & 0.034 & 1.353 \\
\hline 1000 & 0.063 & & 0.040 & 1.563 \\
\hline 1200 & 0.076 & Experimental Max & 0.043 & 1.712 \\
\hline
\end{tabular}

\subsubsection{Speed Ratio}

As previously mentioned, the speed ratio is used to determine the optimum operating conditions for the turbine. The speed ratio is defined as the tangential velocity of the rotating buckets at the pitch diameter to the jet velocity. It is shown below in Equation 8.

$$
x=\frac{U}{V_{j e t}}=\frac{\dot{n} \pi D_{P C D}}{60 C_{V} \sqrt{2 g h}}
$$

In Equation 8, $D_{P C D}$ represents the pitch circle diameter of the impeller. The pitch circle diameter is defined as the diameter formed by the distance between the water jet impingement location on the impeller bucket and the axis the impeller rotates on.

\subsubsection{Acceleration Due to Gravity}

It was recommended by IEC 60193 that the performance experiments be conducted using an approximation of the local acceleration due to gravity at the test site [38]. Equation 9, shown below gives an approximation of acceleration due to gravity based on local latitude and altitude.

$$
g=9.7803\left(1+0.0053 \sin ^{2} \psi\right)-\left(3 * 10^{6}\right) z
$$

In Equation 9, $\psi$ represents the latitude in degrees and $\mathrm{z}$ represents the altitude in meters above sea level at the test site. The latitude and altitude of the test site (Morgantown Municipal Airport) were found using the U.S. Geological Survey National Map Viewer [47]. A map of the location is 
shown with the test site labeled in Figure 14. A value of $9.80026 \mathrm{~m} / \mathrm{s}^{2}$ was used for the acceleration due to gravity based on a latitude of $39.64^{\circ}$ and an altitude of $376.7 \mathrm{~m}$ (1236 ft.).

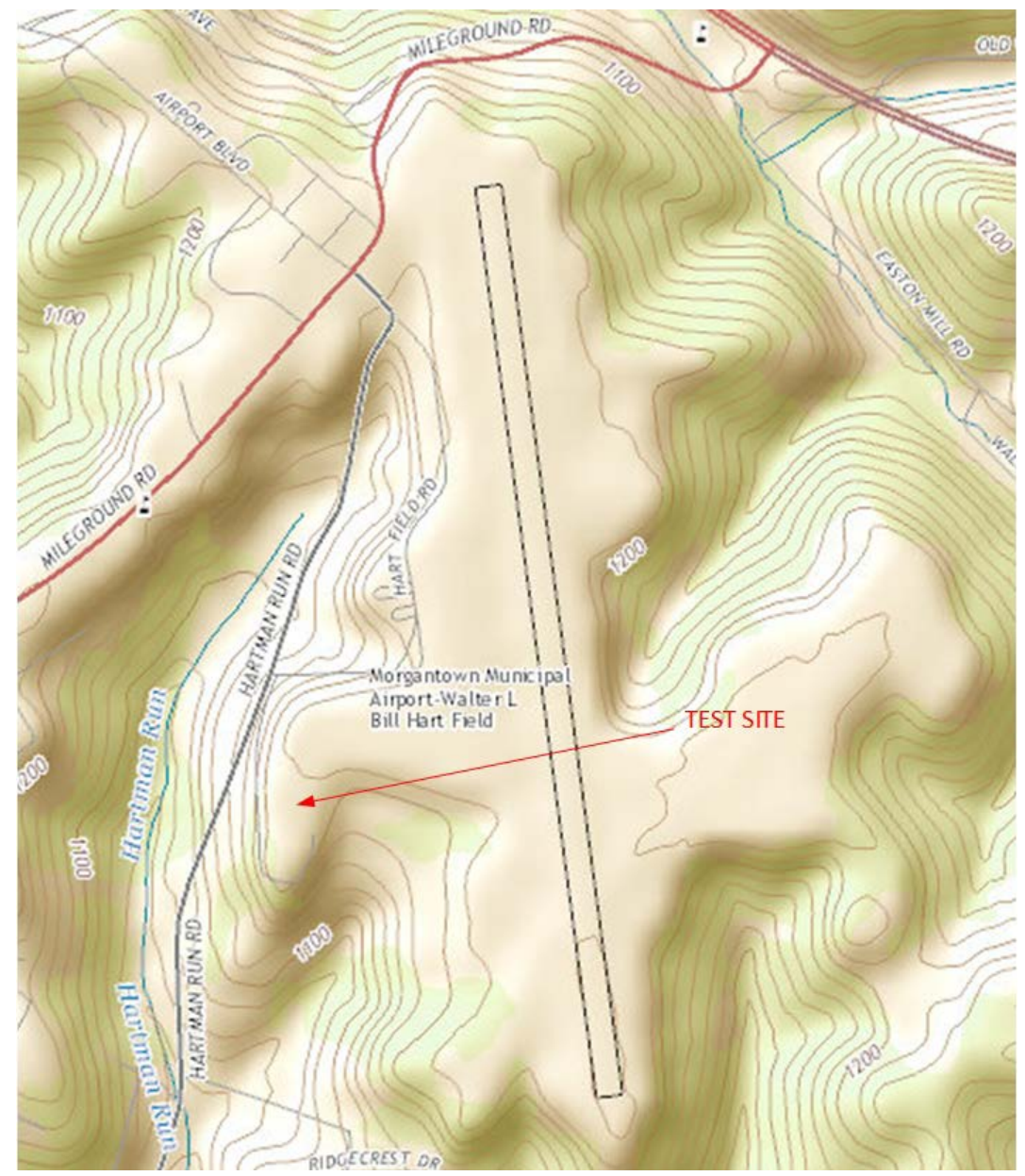

Figure 14: Topographical map of test site at Morgantown Municipal Airport in Morgantown, WV from the USGS National Map Viewer [47]

\subsubsection{Water Density}

IEC 60193 also recommended that the density of the water used in the test apparatus during experimentation be monitored to account for variation due to a temperature increase from being circulated through the turbine and centrifugal pump repeatedly [38]. The maximum temperature reached by the water being circulated was $36^{\circ} \mathrm{C}\left(96.8^{\circ} \mathrm{F}\right)$. During each day of testing, an increase in water temperature between $15^{\circ} \mathrm{F}$ and $25^{\circ} \mathrm{F}$ was measured depending on the atmospheric 
temperature during testing. Although this magnitude of temperature change caused a relatively small change in water density, it was accounted for using the expression shown below in Equation 10.

$$
\rho=\frac{1}{v_{0}\left[(1-A * p)+8 * 10^{-6}\left(T_{\text {water }}-B+C * p\right)^{2}-6 * 10^{-8}\left(T_{\text {water }}-B+C * p\right)^{3}\right]}
$$

In Equation 10, $\mathrm{A}, \mathrm{B}$, and $\mathrm{C}$ are constants. The specific volume of water, represented by $v_{0}$, was $0.001 \mathrm{~m}^{3} / \mathrm{kg}$ [38]. The temperature of the water in the test apparatus is represented by $T_{\text {water }}$. The pressure at the nozzle where the density is being calculated is represented by $p$. This expression was formed from empirical data and is accurate to $\pm 0.01 \%$ of the calculated value [38]. The accuracy of the density Equation was included in the uncertainty analysis.

\subsubsection{Turbine Operating Speed}

In practice, a directly coupled turbine should operate at a speed driven by the load being applied. The turbine impeller must be correctly designed and fabricated to achieve the desired rotational speed given the operating conditions [6]. Graphing turbine output torque and the required input torque to drive the load versus rotational speed can provide an estimate of what the turbine speed will be during operation. Micro-hydro turbines often have electronic load controllers that maintain the rotational speed of the turbine at the desired value [6]. A graph of this type will be shown in the results section for each impeller.

Equation 11 below be used to estimate the rotational speed of the turbine if the speed ratio is known over a wide range of operating conditions.

$$
\dot{n}=\frac{60 x C_{V} \sqrt{2 g h}}{\pi D_{P C D}}
$$


In Equation 11, x represents the speed ratio previously mentioned in Section 2.1. It should be noted that the actual rotational speed of the impeller is related to the efficiency of the impeller and the amount of electrical load placed on the generator that the turbine is attached to.

\subsubsection{Impeller Vibration}

All impellers should be balanced before use. Vibration caused by imbalance will not be obvious at low speeds. It is more likely to become a problem for directly coupled turbines that run above 1500 RPM [6]. A well balanced turbine impeller that runs without rough vibration while rotating can increase the efficiency and the durability of the impeller, shaft components, and generator. Vibration measurements were taken during this experiment to determine how well each impeller was balanced. This measurement was also used to monitor the operation of the test stand to ensure safe operation.

Vibration acceleration and velocity were measured using an Omega HHVB82 hand held vibration meter. Equations 12 and 13 below were used to calculate the frequency and displacement of the vibration.

$$
\begin{aligned}
f_{\text {vibration }} & =\frac{3690 a_{\text {vibration }}}{v_{\text {vibration }}} \\
d_{\text {vibration }} & =\frac{19,100 v_{\text {vibration }}}{f_{\text {vibration }}}
\end{aligned}
$$

In Equation 12, $a_{\text {vibration }}$ represents the acceleration of the vibration, $v_{\text {vibration }}$ represents the velocity of the vibration, and $f_{\text {vibration }}$ represents the frequency of the vibration. In Equation 13, $d_{\text {vibration }}$ represents the displacement of the measured vibration. Values for the frequency and displacement of the vibration were then used to assess the severity of the vibration using a general machinery vibration severity chart. This chart is displayed in Appendix A. 


\subsubsection{Coast-down Testing}

An ideal test apparatus to measure the performance of the turbine impellers in this project would be built to replicate the design, construction, and operation of the actual turbines at the Antrim site. This was not possible for this experiment because of the project resources but several key similarities were able to be reproduced. These similarities include: both impellers in the experiment were the actual impellers used in the Antrim Turbines; the test apparatus had two water nozzles, and both the actual turbine and test apparatus rotational speed were controlled by varying the load on the generator the turbines were coupled to. Integration of the various sensors into the test stand also prevented mimicking the actual turbine assembly completely. The most important difference between the test apparatus and the operational turbines is that the impellers were not directly coupled to the motor shaft in the test stand. This is illustrated by the pictures shown in Figure 15.

The rotary torque meter in the test apparatus had to be mounted vertically between two bearings to allow for rotation of the motor shaft without putting axial load on the torque meter shaft. This configuration introduces mechanical losses associated with the ball bearings that would not be present in a directly coupled turbine set-up. If the value of mechanical losses associated with the test stand were known, they could be used to calculate the efficiency of the impeller separately without the effect of the test stand design included. This would allow for a direct comparison between the measurements on the test stand and the actual performance of the turbines at the Antrim, PA site. 


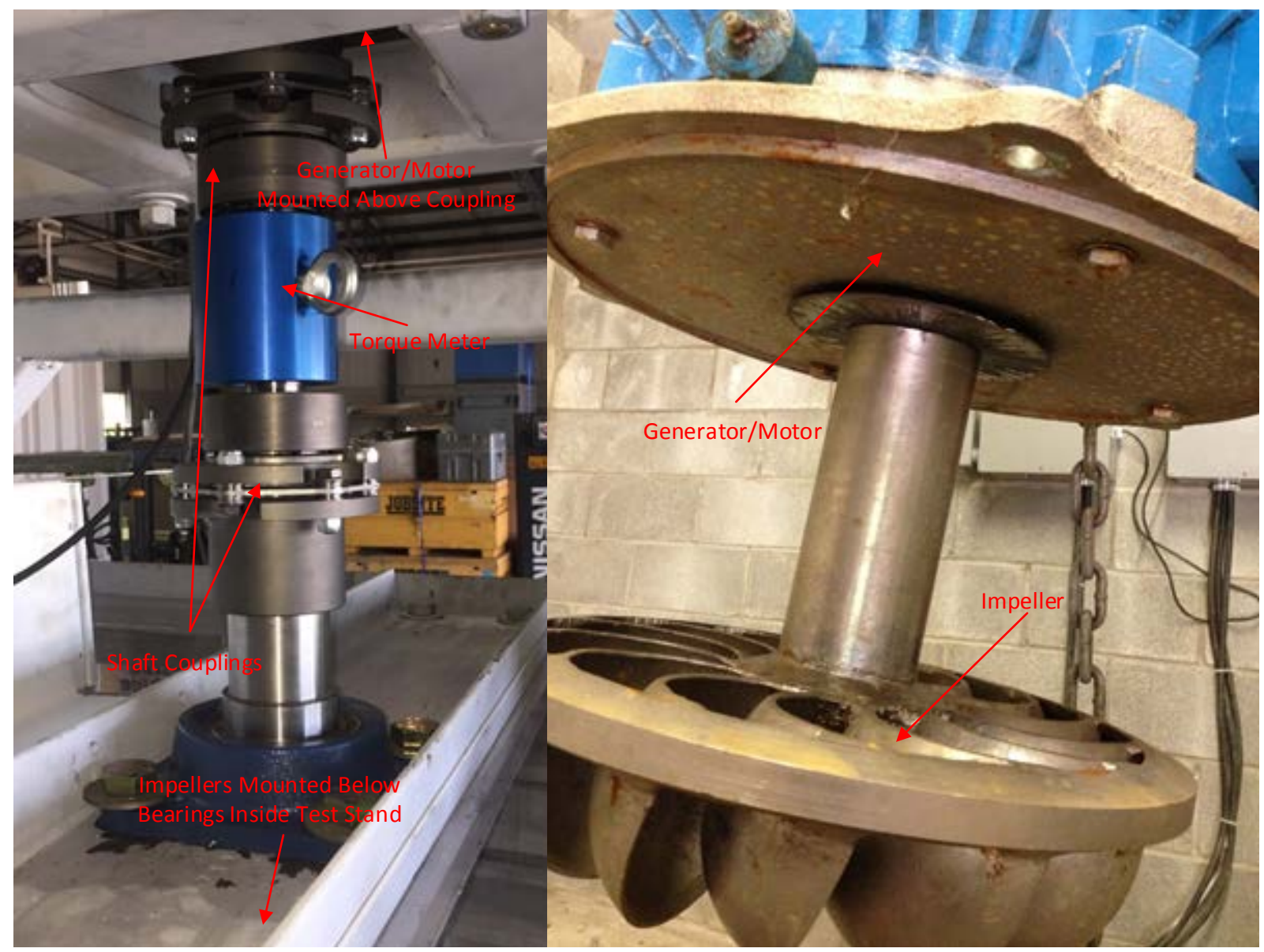

Figure 15: Pictures of torque meter mounted between motor and impeller on test stand (Left), Picture of impeller B directly mounted to motor shaft in Antrim turbines (Right)

Estimating the mechanical losses associated with the rotating components of the test stand and aerodynamic drag on the impeller were the main reasons for conducting the coast-down tests in this project. The expression used to estimate the mechanical losses from the coast-down test data was adapted from the Equation of Motion for Rotation [48] and an expression presented by Daugherty [34], as shown in Equation 14.

$$
P_{\text {loss }}=\omega I \frac{d \omega}{d t}
$$


In Equation 14, $I$ is the mass moment of inertia of the drive train components of the test stand. The angular acceleration, $\frac{d \omega}{d t}$, represents the time rate of change of the angular velocity of the motor drive shaft (angular acceleration), $\omega$ represents the rotational speed of the shaft, and $P_{\text {loss }}$ represents the power lost in different sets of components in the test stand.

Equation 14 was applied the same way in four different situations. They included calculating the power losses in the test stand with impeller A mounted, impeller B mounted, no impeller mounted but the other rotating components still connected to motor, and with only the motor shaft rotating. This was done in an effort to try to characterize the losses associated with each set of components in the test stand. The power losses calculated with both impellers attached represent all losses present in the test stand and aerodynamic drag on each impeller. When the impellers are removed it is expected that the aerodynamic drag associated with them is no longer present. It should be noted that aerodynamic drag was not eliminated because it would still be present when the driveshaft alone is rotating through air. However, it was being assumed that the majority of the drag was associated with the rotating impeller and removing the impeller would remove the majority of the aerodynamic drag from the rotating components. By subtracting the losses calculated with the drive shaft from the overall power loss, the aerodynamic drag associated with each impeller can be separated from the overall losses. This process was then repeated by subtracting the losses associated with the motor only from the power loss calculated with rotating stand components connected. This yielded an estimation of the mechanical losses associated with the two bearings in the test stand. CAD model pictures of the components involved in each coastdown scenario are shown in Appendix B to give a visual perspective. 
During a coast-down test, the rotating components of the test stand were spun up to a certain rotational speed using the electric motor. Once this speed was reached and the system was stable, the motor was shut down and the torque it applied to the shaft and the impeller was removed. With no motor torque acting on the system, it was assumed that the only torque remaining was due to the frictional losses and aerodynamic drag of the ball bearings supporting the drive shaft and the aerodynamic drag created by the impeller buckets moving through air as they rotate. As mentioned earlier, these losses were isolated by running coast-down tests with different components attached and calculating the power loss with each combination.

In order to calculate an estimate of the losses, the moment of inertia needed to be calculated beforehand. The moments of inertia could have been estimated by approximating the different rotating components as solid cylinders. However, complex shapes of the shaft couplings, impeller blades, and motor shaft would have produced inaccuracies in this approximation. To provide a better estimate, the drive shaft components were modeled in Autodesk Inventor ${ }^{\circledR}$ and a built-in calculator was used to determine the moment of the inertia for all of the components in their assembled configuration. The inertia for the electric motor was then added to this since it could not be completely modeled in Inventor ${ }^{\circledR}$. A picture of the models used to calculate each moment of inertia value is shown below in Figure 16. 

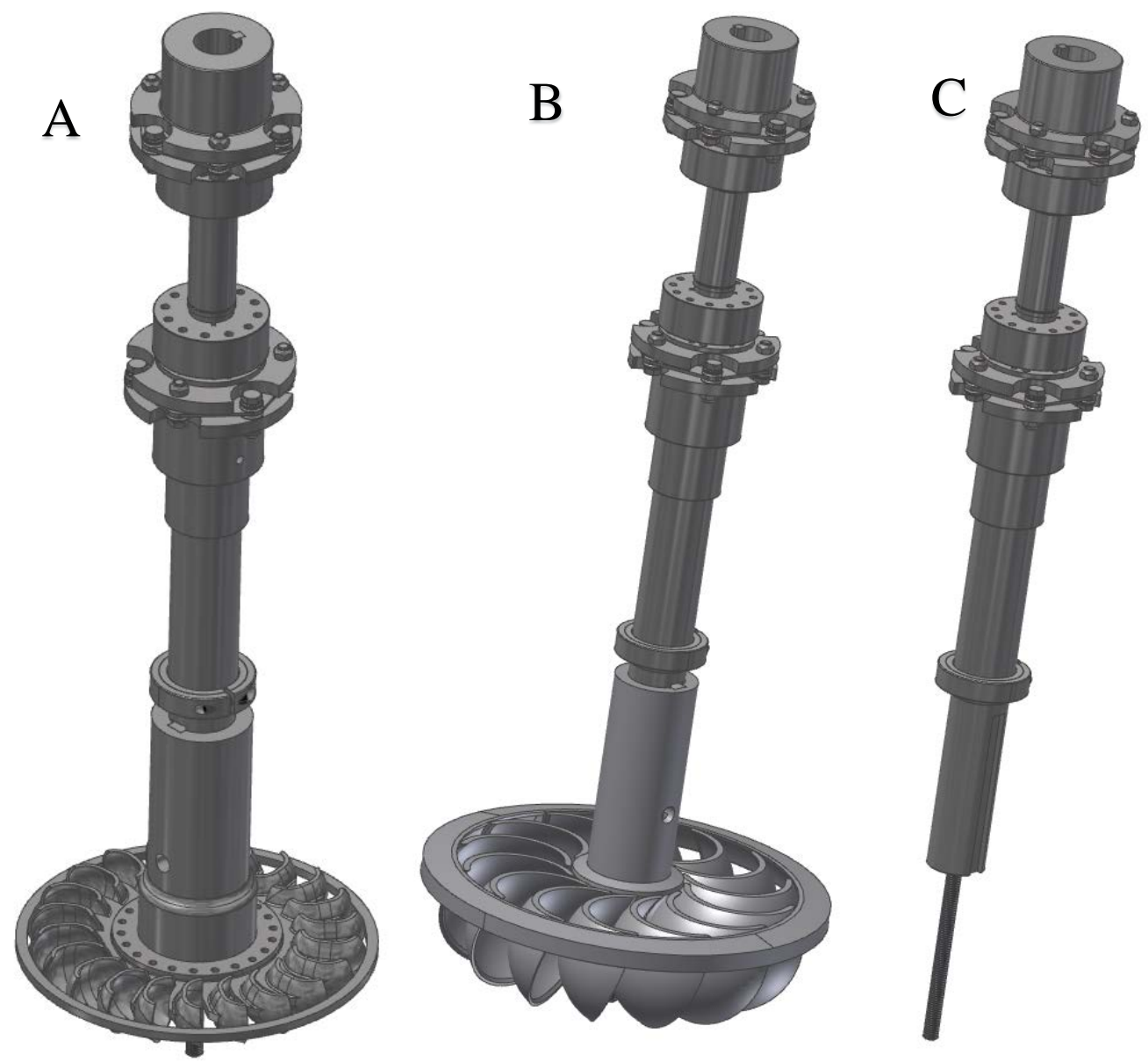

Figure 16: Illustrations of models used for calculating moment of inertia with (A) impeller $A$ included, (B) impeller $B$ included, and (C) no impeller attached to the driveshaft

The angular acceleration term in Equation 14 can be approximated in different ways. The method used in this experiment involved creating a polynomial that represented the angular acceleration of the test stand versus time. This was done by taking the derivative of a second order polynomial created from a curve fit of the coast-down curve which was a plot of the angular velocity versus time. 


\subsubsection{Testing Conditions and Test Matrix}

Experimental conditions used in this project were designed to mirror the operating conditions of the Antrim, PA site. The average conditions at the site are listed below in Table 3.

Table 3: List of operating conditions for the entire water flow at the Antrim turbine site

\begin{tabular}{|c|c|c|}
\hline Variable & \multicolumn{2}{|c|}{ Value } \\
\hline Maximum Flow Rate & $4000 \mathrm{GPM}$ & $0.252 \mathrm{~m}^{3} / \mathrm{s}$ \\
\hline Minimum Flow Rate & $500 \mathrm{GPM}$ & $0.031 \mathrm{~m}^{3} / \mathrm{s}$ \\
\hline Average Flow Rate & $1500 \mathrm{GPM}$ & $0.095 \mathrm{~m}^{3} / \mathrm{s}$ \\
\hline Gross Pressure Head & $160 \mathrm{ft}$. & $48.8 \mathrm{~m}$ \\
\hline Nameplate Generating Capacity & 27 hp on each turbine & $20 \mathrm{~kW}$ on each turbine \\
\hline Generator Operating Speed & \multicolumn{2}{|c|}{$1800 \mathrm{RPM}$} \\
\hline Estimated Inlet Angle & \multicolumn{2}{|c|}{$\sim 6^{\circ}$} \\
\hline
\end{tabular}

The values in this table are based on the estimated full flow of water being directed to the Antrim powerhouse. The actual testing conditions used were chosen based on the capabilities of equipment available and the conditions that one of the two installed turbines could see on a regular basis. The conditions the test stand is capable of testing in are shown in Table 4.

Table 4: List of general operating conditions used for performance testing of the impellers

\begin{tabular}{|c|c|c|}
\hline Variable & \multicolumn{2}{|c|}{ Value } \\
\hline Maximum Flow Rate & $1200 \mathrm{GPM}$ & $0.076 \mathrm{~m}^{3} / \mathrm{s}$ \\
\hline Minimum Flow Rate & $250 \mathrm{GPM}$ & $0.016 \mathrm{~m}^{3} / \mathrm{s}$ \\
\hline Gross Pressure Head & $160 \mathrm{ft}$. & $48.8 \mathrm{~m}$ \\
\hline Nameplate Generating Capacity & $40 \mathrm{hp}$ & $30 \mathrm{~kW}$ \\
\hline Max Operating Speed & $3600 \mathrm{RPM}$ & - \\
\hline Range Inlet Angle & $16^{\circ}-24^{\circ}$ & - \\
\hline
\end{tabular}

Several different variables were selected to be varied to show the effect of different operating conditions on the turbine efficiency and power output. These variables included flow rate $(\dot{Q})$, motor shaft rotational speed $(\dot{n})$, diameter of the nozzle being used $\left(D_{\text {nozzle }}\right)$, angle to which the nozzles are set $\left(\alpha_{1}\right)$, and impeller pitch diameter $\left(D_{P C D}\right)$. The gross head at the nozzle outlet $(h)$ and the aim points of the nozzles were held constant. The nozzle aim points determine where the water jets will impinge on the turbine buckets. They are shown in Figures 17 and 18. 
They are located on the pitch circle diameter of each impeller in a horizontal plane that is formed by the top edge of the impeller buckets. Each aim point is in line with the centerline rotational axis of the impeller if view from the side (as in Figure 18). Values used in experiments for the variables mentioned above are shown in Tables 5 and 6.

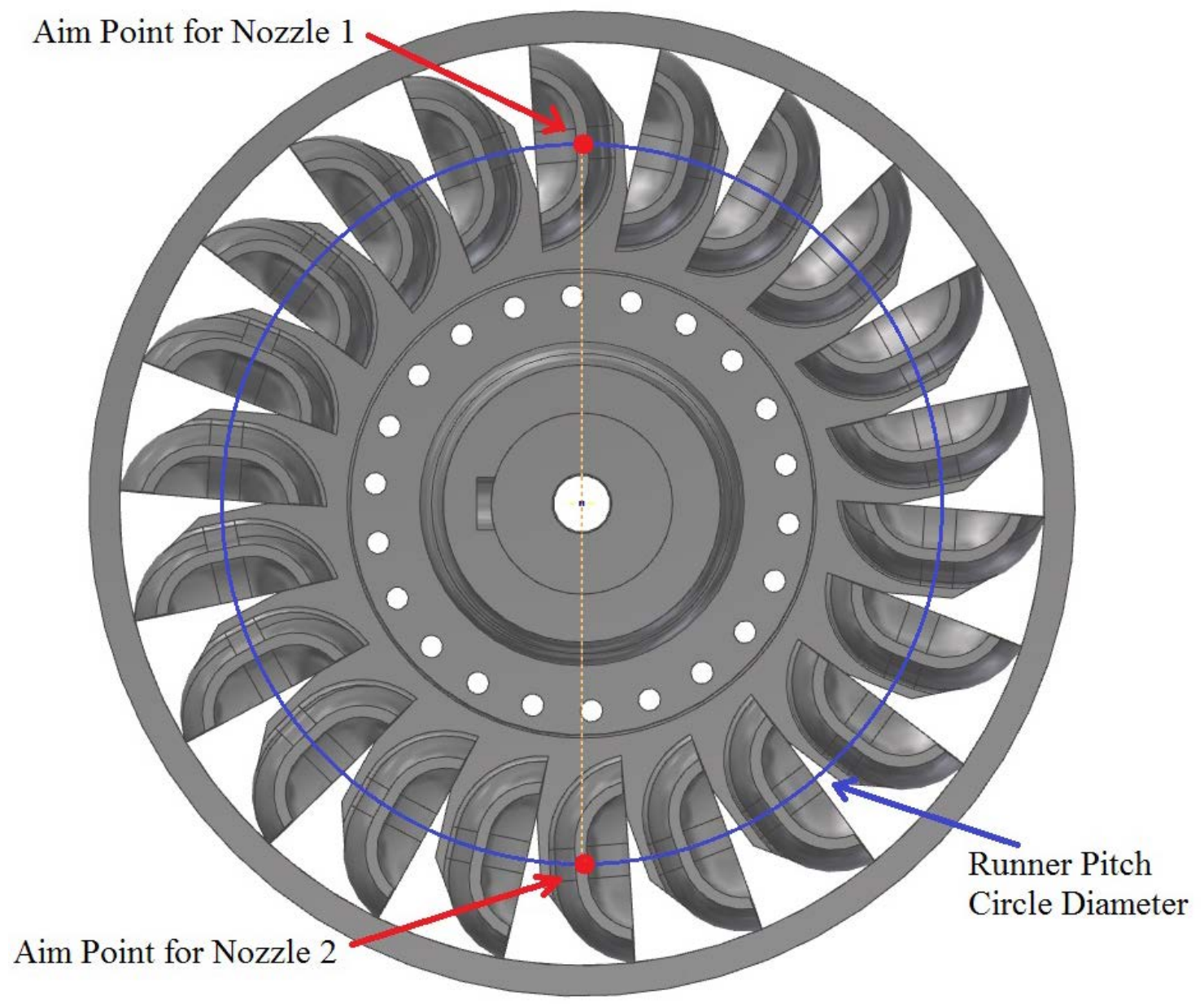

Figure 17: Illustration of nozzle aim points on a top view of impeller A 


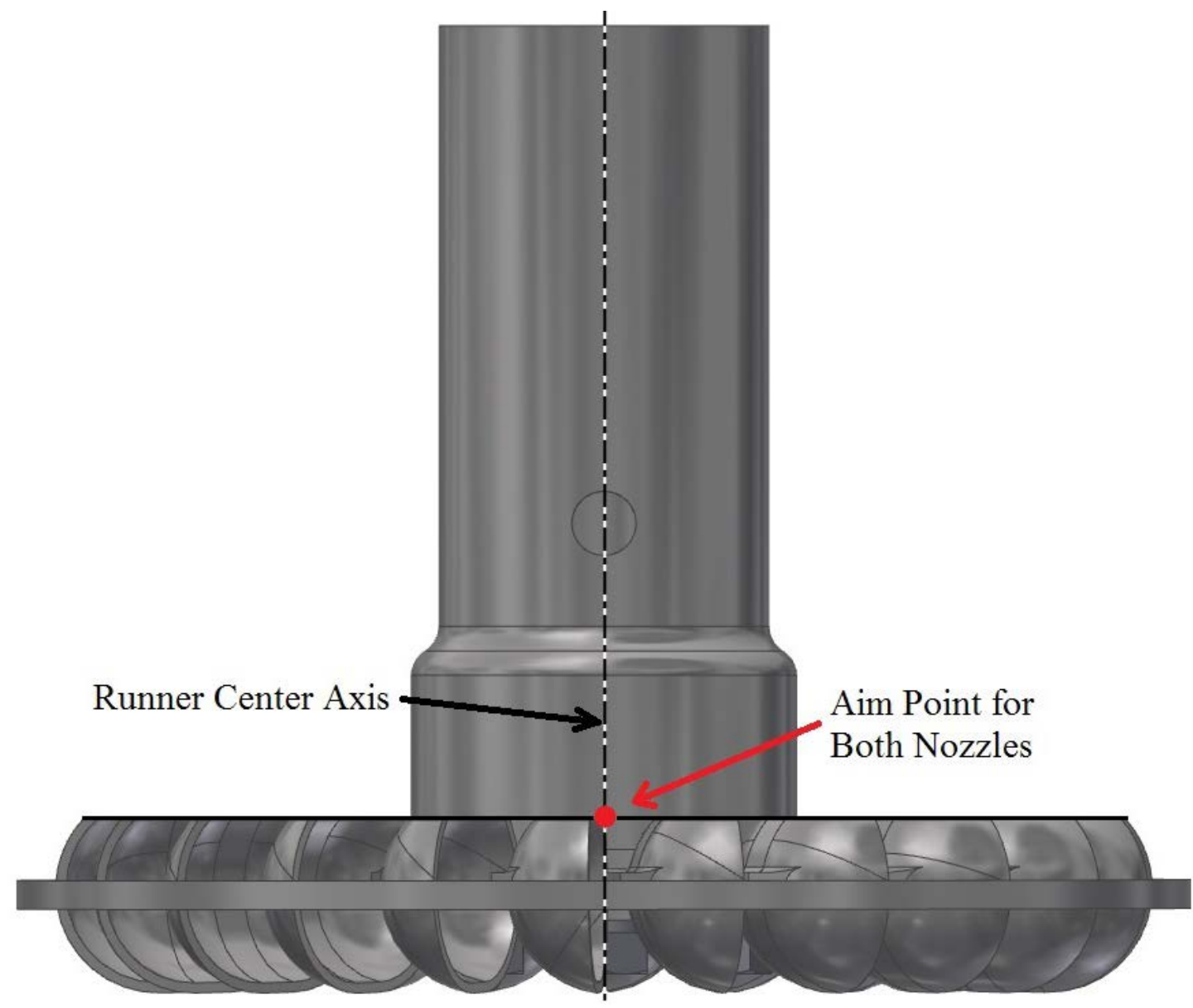

Figure 18: Illustration of nozzle aim points on a side view of impeller $A$

Getting the water nozzle pointed at the aim points shown meant controlling three different factors. These factors were the elevation of the water nozzle above the top edge of the impeller buckets, separation of the water nozzle from the center axis of the impeller, and the nozzle angle. Of these three factors, the nozzle angle was deemed most important for investigation. As a result, the separation of the water nozzle from the impeller was held constant for each impeller. When the nozzle angle was varied, the elevation of the nozzle outlet above the impeller blades was adjusted accordingly to get the nozzle aligned with the aim point. The process for aligning the water nozzles will be detailed further in Section 3.2.5 when the design of the water nozzle mounting brackets are described in detail. 
A parametric approach to conducting this experiment would have exhausted the project resources before completion by creating thousands of test points in the experiment [49]. This would have meant varying one experimental parameter at a time to see how each affects the others in the experiment. It was decided that the experiment would be constructed using the process of design of experiments so that meaningful results could be obtained in a reasonable time frame and within project resources. As a result, the performance measurements in the experiment were split into two types. The first experiment was aimed at finding the nozzle angle that resulted in the most efficient output while producing the most shaft power from each impeller. Below, Table 5 shows the factors included in this experiment and the respective values used for testing.

Table 5: List of experimental factors used in nozzle angle performance test

\begin{tabular}{|c|c|}
\hline Factor Name & Values Tested \\
\hline Shaft Speed $(\dot{n})$ & $150-1800$ by increments of 150 (RPM) \\
\hline Flow Rate $(\dot{Q})$ & $750(\mathrm{GPM})-$ held constant \\
\hline Head $(h)$ & $160(\mathrm{ft}$. of water) - held constant \\
\hline Nozzle Angle $\left(\alpha_{1}\right)$ & $24,22,20,18,16\left(^{\circ}\right)$ \\
\hline Impeller Pitch Diameter $\left(D_{P C D}\right)$ & Impeller A-7.497 (in.), Impeller B-7.861 (in.) \\
\hline Nozzle Diameter $\left(D_{\text {nozzle }}\right)$ & 1.353 (in.) - held constant \\
\hline
\end{tabular}

Including three repeated trials for each test point, 360 individual set-points were involved in running the experiment test matrix. The experiment to characterize the performance of the turbine at different inlet angles was run first and would determine the conditions for the performance mapping experiment. This reduced the number of runs in the test matrix because performance mapping would not be conducted at all five nozzle angles. For each impeller, the nozzle angle that resulted in the best efficiency and power production would be used to conduct the second performance experiment. 
The performance mapping experiment was used to further characterize the performance of each impeller. The data produced by this type of experiment was used to create the three dimensional performance maps that will be shown in the results section. Table 6 shown below lists the factors included in this experiment and their respective values used in the test.

Table 6: List of experimental factors used in a performance mapping test

\begin{tabular}{|c|c|}
\hline Factor Name & Values Tested \\
\hline Shaft Speed $(\dot{n})$ & $150-1800$ by increments of $150(\mathrm{RPM})$ \\
\hline Flow Rate $(\dot{Q})$ & $250,500,750,1000,1200(\mathrm{GPM})$ \\
\hline Head $(h)$ & 160 (ft. of water) - held constant \\
\hline Nozzle Angle $\left(\alpha_{1}\right)$ & $24\left(^{\circ}\right)-$ held constant \\
\hline Impeller Pitch Diameter $\left(D_{P C D}\right)$ & Impeller A-7.497 (in.), Impeller B-7.861 (in.) \\
\hline Nozzle Diameter $\left(D_{\text {nozzle }}\right)$ & $0.781,1.105,1.353,1.563,1.712$ (in.) \\
\hline
\end{tabular}

Including repeated trials, the performance mapping experiment also included 360 individual set-points. It should be noted that using the centrifugal pump to circulate water for these experiments made it difficult to obtain the exact head and flow rate values described in the test matrix. The flow rate and head the pump supplied were adjusted from a digital control panel that controlled the speed of the diesel engine attached to the pump. This made fine adjustment of the pump very difficult. Although the value of the head could be held constant, it was difficult to get the flow rate and pressure to settle at exactly the desired value.

The head was controlled by increasing and decreasing the speed of the pump. An increase in the head also resulted in an increase and decrease of the flow rate sent to the turbine. However, a second factor that made it difficult to achieve the desired conditions was that the flow rate was less than the planned value for each head pressure. For example, for the 1200 GPM flow rate the maximum flow rate achieved during testing was 1182 GPM. One factor that could have attributed to this difference was the use of the top end value (0.85) of the prescribed range for the nozzle 
contraction coefficient when sizing the outlet to each water nozzle. Using a smaller value such as (0.83) would have increased the prescribed size of the water nozzle and therefore increased the flow rate. Losses between the nozzle exit and pressure sensor could contribute to this as well.

\subsubsection{Uncertainty Analysis}

The process used for the experimental uncertainty analysis used in this project was based on a method described by Moffat [50] that was well suited for computerized analysis. It involves creating a bias uncertainty for each measured quantity and a precision uncertainty based on the number of trials for each experiment. The bias uncertainty was calculated by sequentially perturbing the inputs to see the effect on the result for each measured value. The perturbation of the inputs was based on the manufacturing specifications of each transducer used in the experiment [51]. Precision uncertainty is associated with the randomness or variation of run-to-run measurements taken in the experiment [52]. Both types of uncertainty were calculated in a MATLAB ${ }^{\circledR}$ script that simultaneously collected and averaged data from the data files created by the DAQ software. An overall uncertainty value was formed for each measured and calculated variable at each set-point tested in the experiment. 


\subsection{Design, Fabrication, and Layout of Experimental Apparatus}

The experimental test apparatus built for this project was a dynamometer built specifically to evaluate the performance of impulse turbine impellers. It was designed to simulate a range of operational conditions common to micro-hydro turbines. Most of the structural components of the stand were first modeled using Autodesk Inventor ${ }^{\circledR}$ before fabrication and assembly. The final assembly was $40 \mathrm{ft}$. long, $10 \mathrm{ft}$. tall, and $4 \mathrm{ft}$. wide without the pump attached.

The test apparatus measured the efficiency $(\eta)$ of the turbine impeller and water nozzles together by dividing the power produced at the turbine by the amount of hydraulic power input to the turbine (Equation 2). Two different quantities were measured to accomplish this. The power produced at the turbine $\left(P_{\text {shaft }}\right)$ was calculated using Equation 3 with measurements of torque produced by the turbine $(T)$ and rotational speed of the generator shaft $(\dot{n})$. The hydraulic power $\left(P_{\text {hydraulic }}\right)$ produced for the test was calculated using Equation 4 and measuring quantities of water density $(\rho)$, pressure head $(h)$, and volumetric flow rate $(\dot{Q})$. The calculated efficiency and all measured values were continuously recorded during each experiment by DAQ software [53] at $10 \mathrm{~Hz}$.

The test was designed to be able to vary the operating conditions of the test stand in an effort to collect as much useful data as possible. The stand was designed to accommodate maximum testing parameters of 1800 RPM generator rotational speed, 1200 GPM flow rate, 160 ft. of water pressure head, and a maximum inlet water jet angle of $24^{\circ}$. A CAD model of the test stand is shown in Figure 19. The final assembly of the test stand is shown in Figure 20 for comparison. A schematic is shown in Figure 21 to illustrate different components of the test stand. Figure 21 will be referred often to facilitate discussion of the different components of the test stand. 


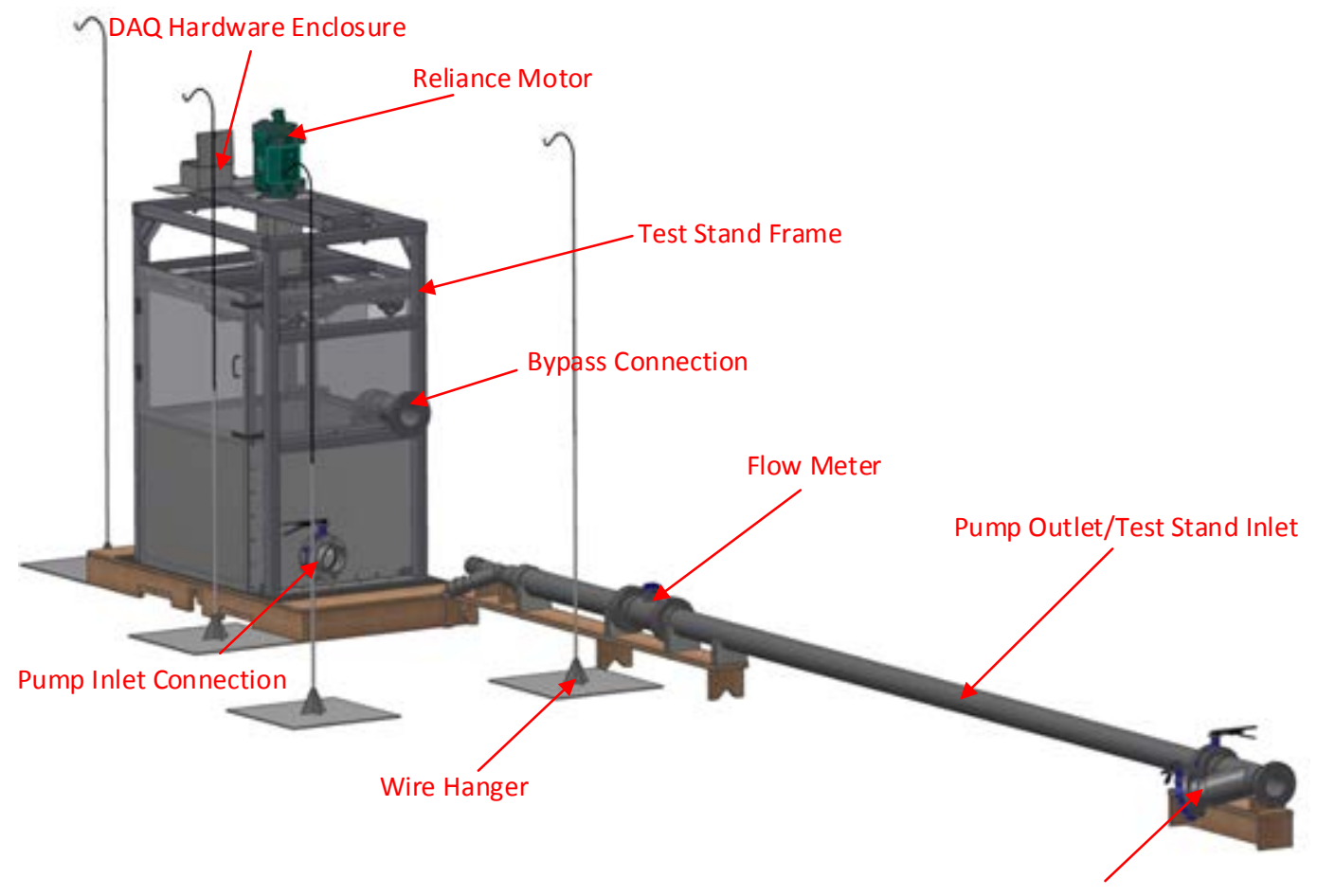

Bypass Connection

Figure 19: Illustrates an overview of the CAD model of the test set-up

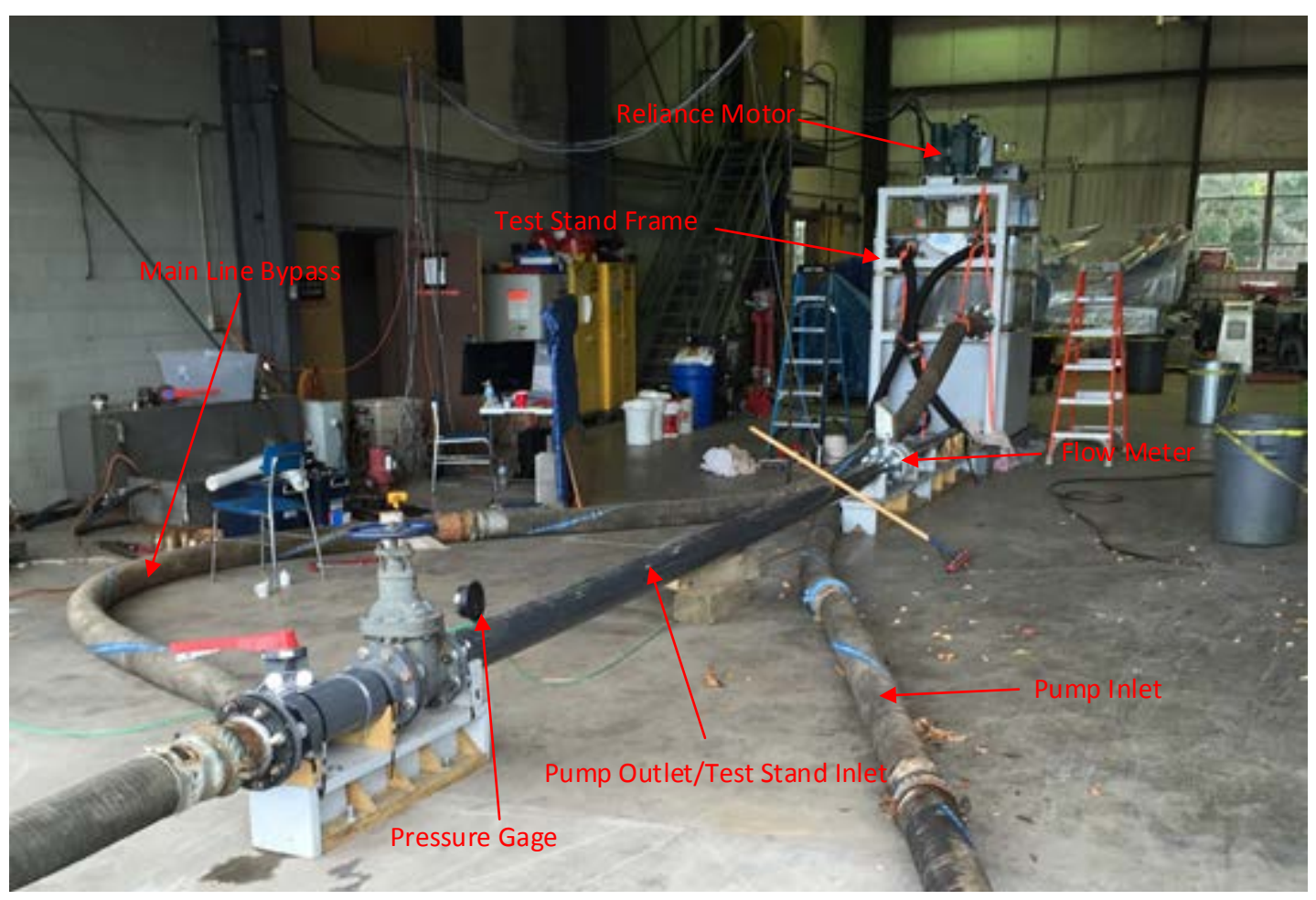

Figure 20: Picture of the final assembly of the test set-up 


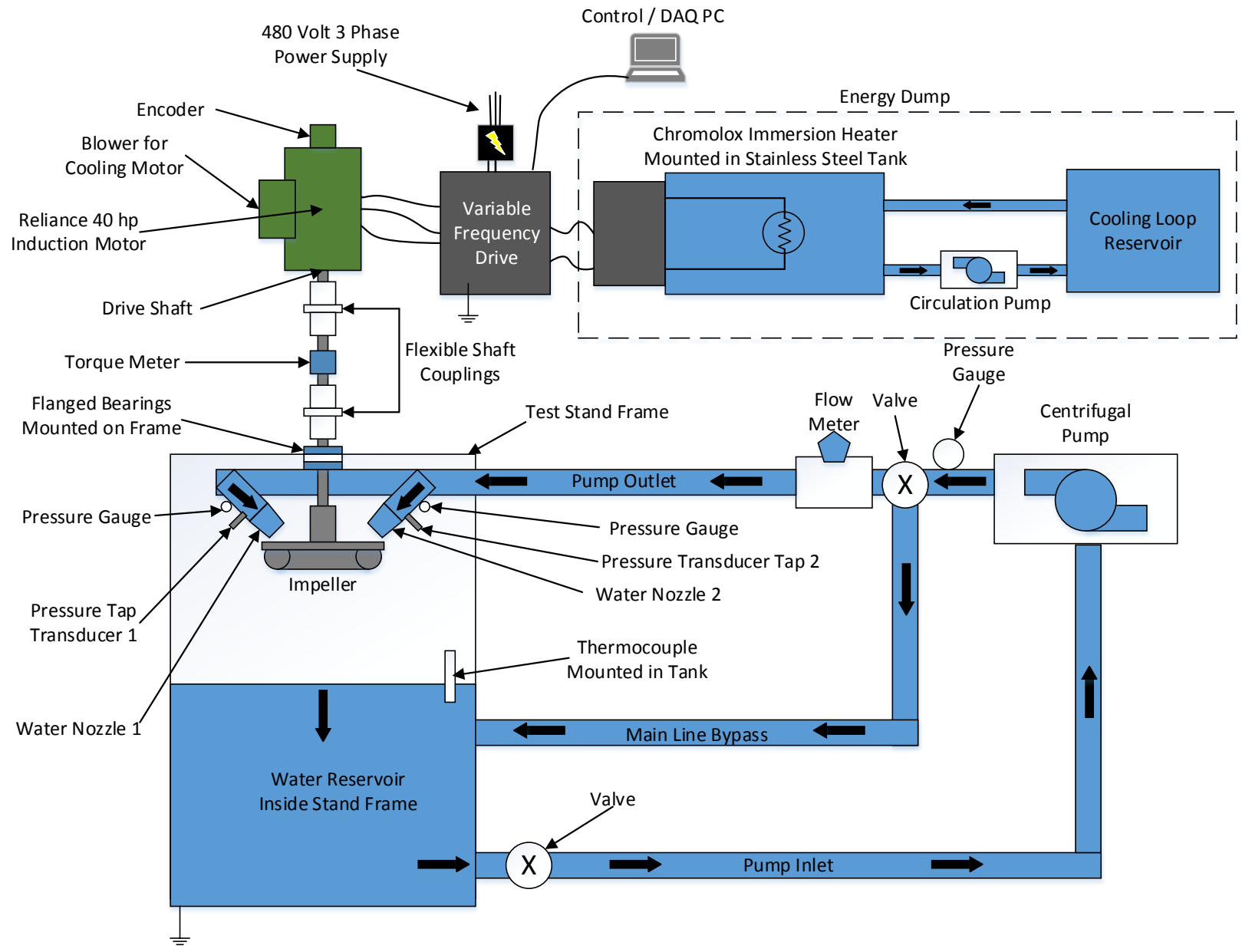

Figure 21: Schematic of the impulse turbine test set-up

\subsubsection{Centrifugal Pump}

The pump used to circulate water through the test stand and create pressure head at the water nozzles was a Rain for Rent HH150SA high head pump. It is represented by the large pump symbol on the right side of the schematic in Figure 21. It utilized a centrifugal pump connected to a diesel engine. The system was self-priming and continually removed air from the water lines during operation. The pump was capable of producing a maximum of $319 \mathrm{ft}$. of head at 2,300 GPM. This pump was chosen to run the experiment because the requirements of $160 \mathrm{ft}$. of head at a maximum flow rate of 1,200 GPM allowed the pump to operate without heavy strain. The 
experimental operating conditions fall near the middle of the recommended operating range for the pump. Two pictures of the pump are shown below in Figure 22.

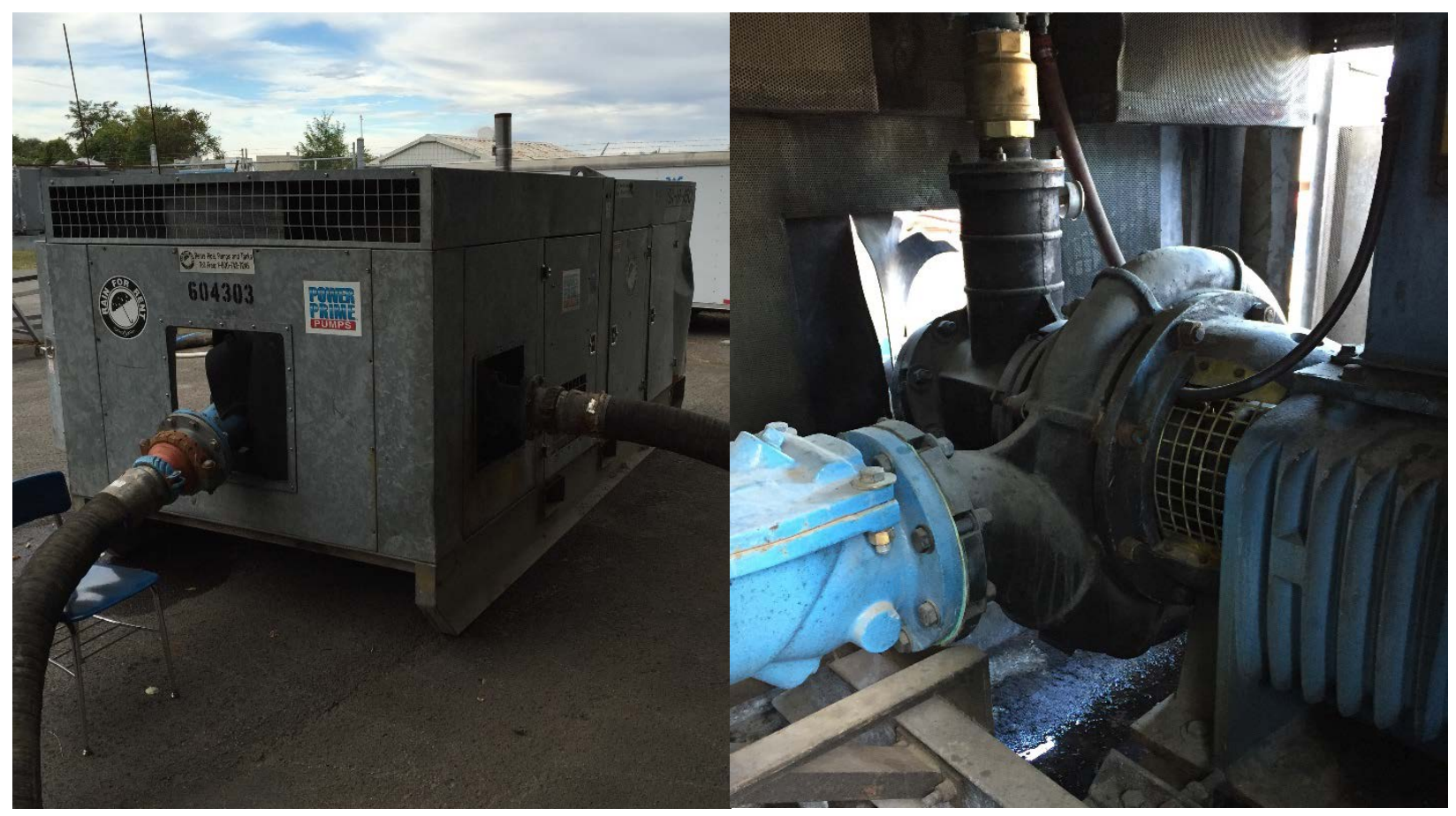

Figure 22: Rain for Rent HH150SA Pump used to circulate water in the test stand

As seen in Figure 22, the pump was connected to the rest of the test stand with six inch flexible rubber Victraulic hoses. The hoses were connected with Victraulic “Quick Vic” couplings and gaskets.

\subsubsection{Flow Meter}

The flow meter used to measure the flow rate of water being discharged from the pump to the water nozzles was a Siemens Mag 5100W model with a Siemens Mag 5000 signal transmitter mounted directly on top of the meter. The flow meter was connected downstream of a piece of schedule 80 PVC pipe that was $19 \mathrm{ft} .6$ in. long. The long length of pipe was installed in effort to ensure that the water flow in the pipe was fully developed so that it did not affect the accuracy of the flow meter measurement. The PVC pipe was significantly longer than the recommended five 
pipe diameters (30”) of straight pipe length upstream of the flow meter. A butterfly valve was installed between the pump and the flow meter piping so that the flow could be diverted into a bypass line when the system was initially started. This was done to protect the flow meter, pressure transducers, and pipe fittings from a pressure spike or water hammer downstream of the pump. The valve, PVC pipe, and flow meter were connected to the discharge connection on the pump via a 10' length of the Victraulic hose. The bypass line consisted of two 20' Victraulic hoses coupled directly to the reservoir built into the bottom of the test stand frame. If the bypass was in use, the diverted water flow would be sent straight back to the reservoir where it would be recirculated. These components can be seen in the middle of Figure 20. Another piece of straight pipe was installed downstream of the meter to further ensure that there were no disruptions in the flow in the meter. The 48 in. length of this section was also longer than the recommended downstream straight pipe length of three pipe diameters (18”). A picture of this portion of the set-up is shown later in Figure 24. The flow meter is shown to the left of the large pump symbol and near the middle of the schematic in Figure 21. The actual flow meter is shown on the next page in Figure 23.

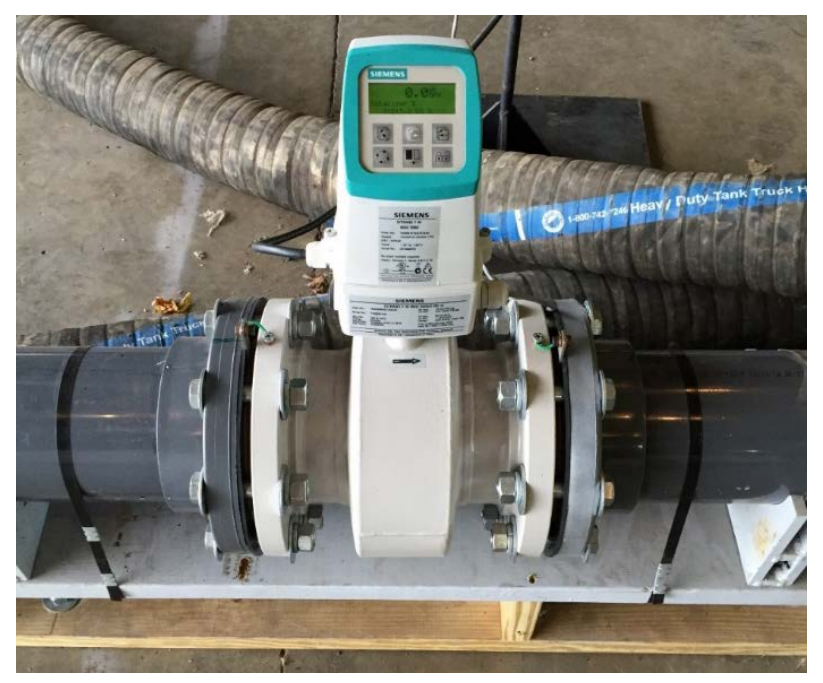

Figure 23: Magnetic flow meter used to measure flow rate in the test stand 55 
The flow meter was connected to the piping by $150 \mathrm{lb}$. eight bolt flanges at each end to the adjacent pipe sections. Grounding rings were installed at each end of the meter to electrically ground the flow meter electrodes to the water flow inside the pipe. The grounding rings were connected to the flow meter body via two copper grounding wires shown in Figure 23. The rings were sandwiched between two gaskets at each connection to ensure a water tight seal on each end.

A signal processor built into the signal transmitter of the flowmeter allowed it to output a signal that was linearly proportional to the flow measurement. This signal was output over a current range from 4 to $20 \mathrm{~mA}$. The $20 \mathrm{~mA}$ reading corresponded to a maximum flow reading which was programmed into the transmitter. The low end four milliamp reading corresponded to a low flow cut off value set in the transmitter. For this experiment, the maximum flow rate measurement was set at 1225 GPM and the low flow cut off was set at 62 GPM. A calibration expression to convert the current reading to a measured flow value in engineering units was formed from a linear fit of the described linear output. The overall accuracy of the sensor was $\pm 0.4 \%$ of the measured flow reading. A factory calibration certificate was provided with the flow meter and is shown in Appendix C. The calibration of the flow meter was not checked with a physical test of the system because of the logistics of trying to measure the amount of water that would pass through the meter at a flow rate of 1200 GPM for the check.

\subsubsection{Flow Splitter and Nozzle Inlet Hoses}

Directly after the flow meter, a 6" x 3" schedule 80 reducer was installed to accommodate a smaller flow splitter on the main line. This also reduced the number of fittings needed to complete the assembly. The 3" flow splitter was connected to two flexible rubber hoses via two threaded adapters. This part of the piping assembly was anchored to the floor with concrete anchors and 
steel banding to prevent movement caused by reaction forces on the flow splitter while the piping was under pressure. A picture of the flow splitter is shown below in Figure 24.

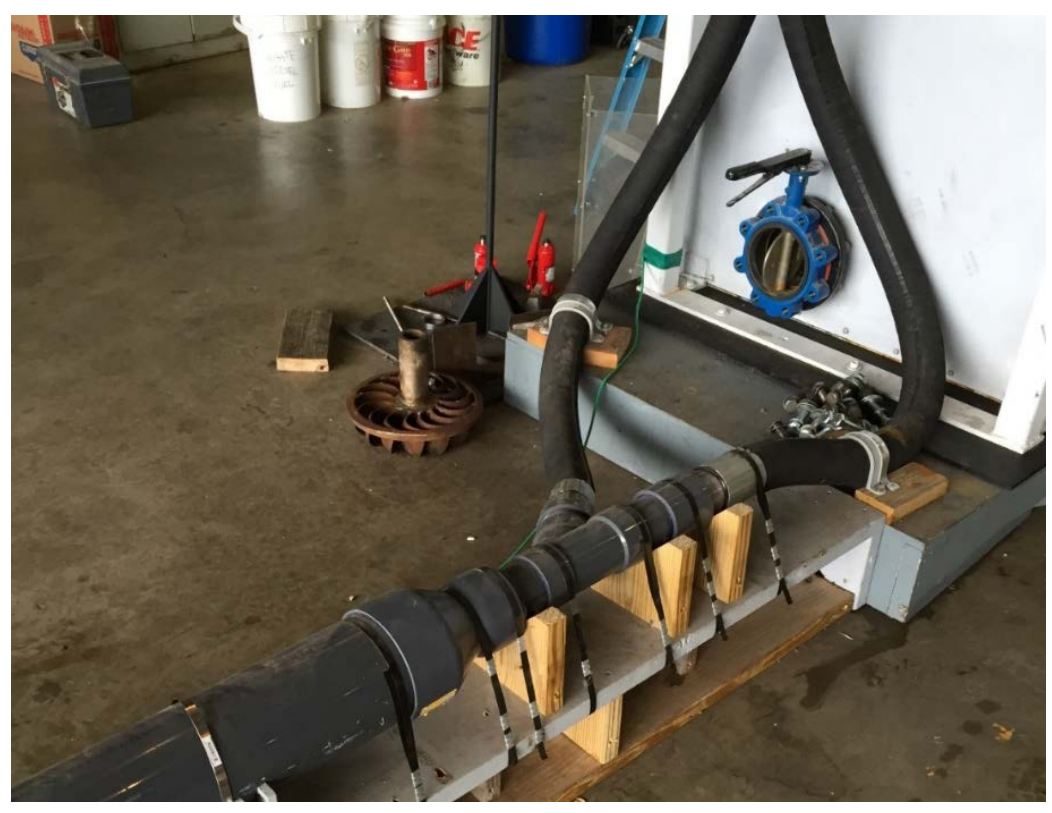

Figure 24: Flow splitter that routes the main line flow to each water nozzle

\subsubsection{Test Stand Frame}

Most of the equipment in this set-up was housed and mounted on the frame of the test stand. The frame was mounted on a 4'x 8' wooden base made of 2"x 8” lumber under a sheet of 3/4" plywood. A piece of soft rubber sheeting was laid underneath the structure to dampen vibrations of the frame during operation. Figure 25 shows the frame from front and back views. The frame is located in the bottom left corner of the schematic in Figure 21.

The inner box served several purposes during operation including: catching water that exited the turbine in the reservoir in the bottom of the box, containing spray from the nozzles and impeller in the upper section, housing the water nozzles and hoses, and providing a surface to mount the bearings that held the drive shaft and impeller in place on the top of the test stand. The box was made from pieces of structural square tubing and steel plate. Clear Lexan sheeting was used to construct the windows so that the turbine could be viewed during experiments. Two of the 
windows were mounted on plastic hinges and served as doors to the inside of the box. The bottom of the box was large enough to hold approximately 330 gallons of water. During testing, the tank was filled with all valves open in the water lines so they would be filled simultaneously with the tank. This ensured that the entire system was full and the water level in the reservoir would not drop when the pump was started. The inlet to the pump was connected to a tank fitting welded to an opening at the bottom of the tank.

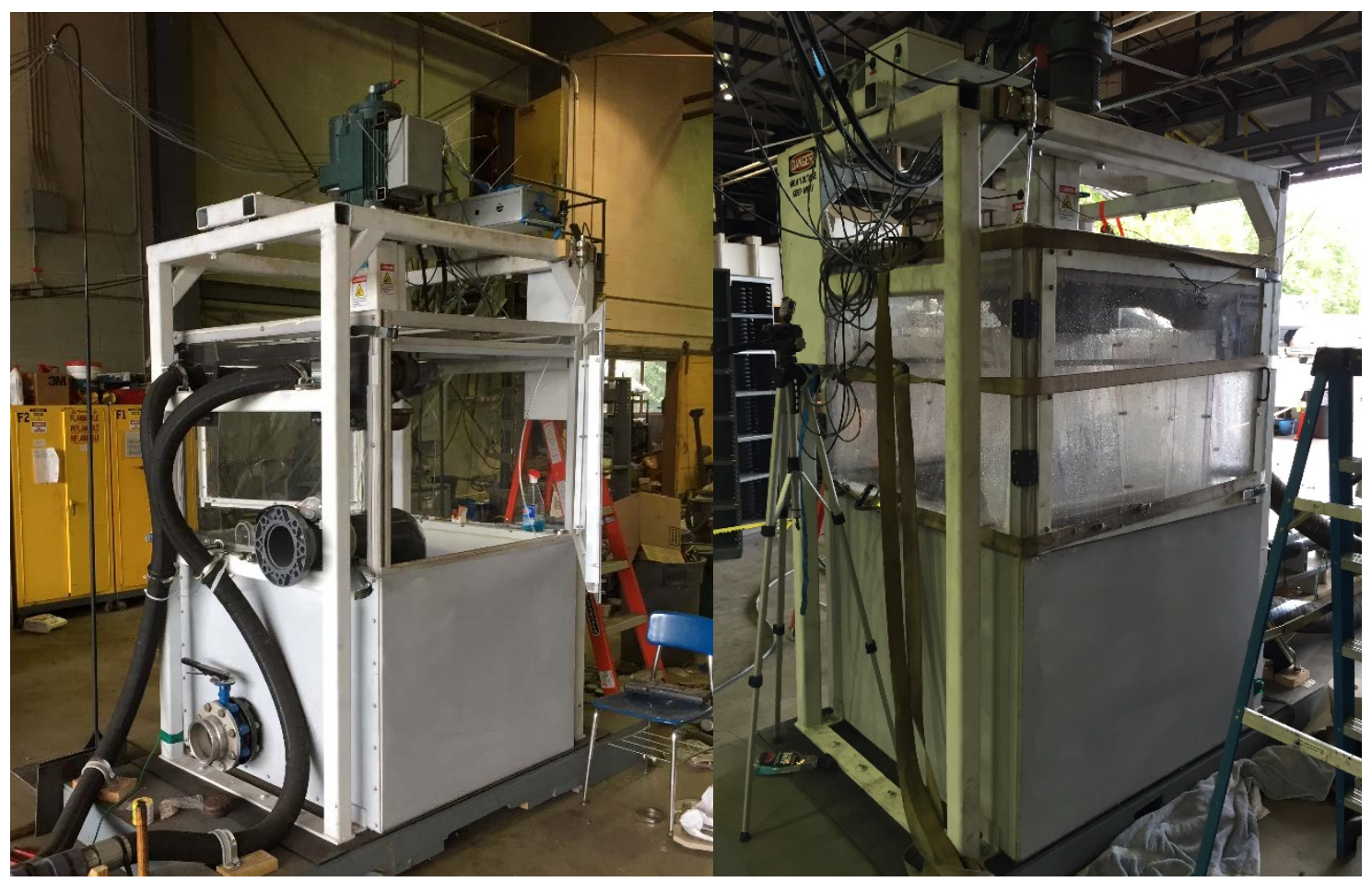

Figure 25: Test stand frame (Left-Front View, Right-Back View)

A heavier outer frame was constructed around the box for mounting the electric motor, electrical enclosures, and DAQ hardware. It was constructed from pieces of 3” structural square tubing with a $1 / 4$ " wall thickness. This outer frame was bolted to the wooden base via footplates shown at the bottom of Figure 25. The heavier material was used so that the outer frame could withstand the reaction from the torque of the motor. 


\subsubsection{Water Nozzles and Mounting Brackets}

The flow splitter and hoses described in Section 3.2.3 routed water flow to the water nozzles inside the test stand. Each hose entered the frame box through holes cut into the front Lexan window. The end of each hose was threaded into an adapter that led into a long sweep schedule 80 PVC $90^{\circ}$ elbow. Each elbow directed the flow toward the impeller through the water nozzles. A piece of 3" straight pipe was assembled in between the water nozzle and the elbow. It served as a point to attach the bracket that held the water nozzles in a fixed position. A pressure gauge and pressure tap were also mounted on each of these pipe sections using drilled and tapped holes in the pipe wall. Each pressure tap was connected to nylon tubing using Swagelok fittings to a pressure transducer mounted on the outside of the outer test stand frame. A picture of this portion of the set-up is shown on the next page in Figure 26. A CAD model of the brackets is shown in Figure 27.

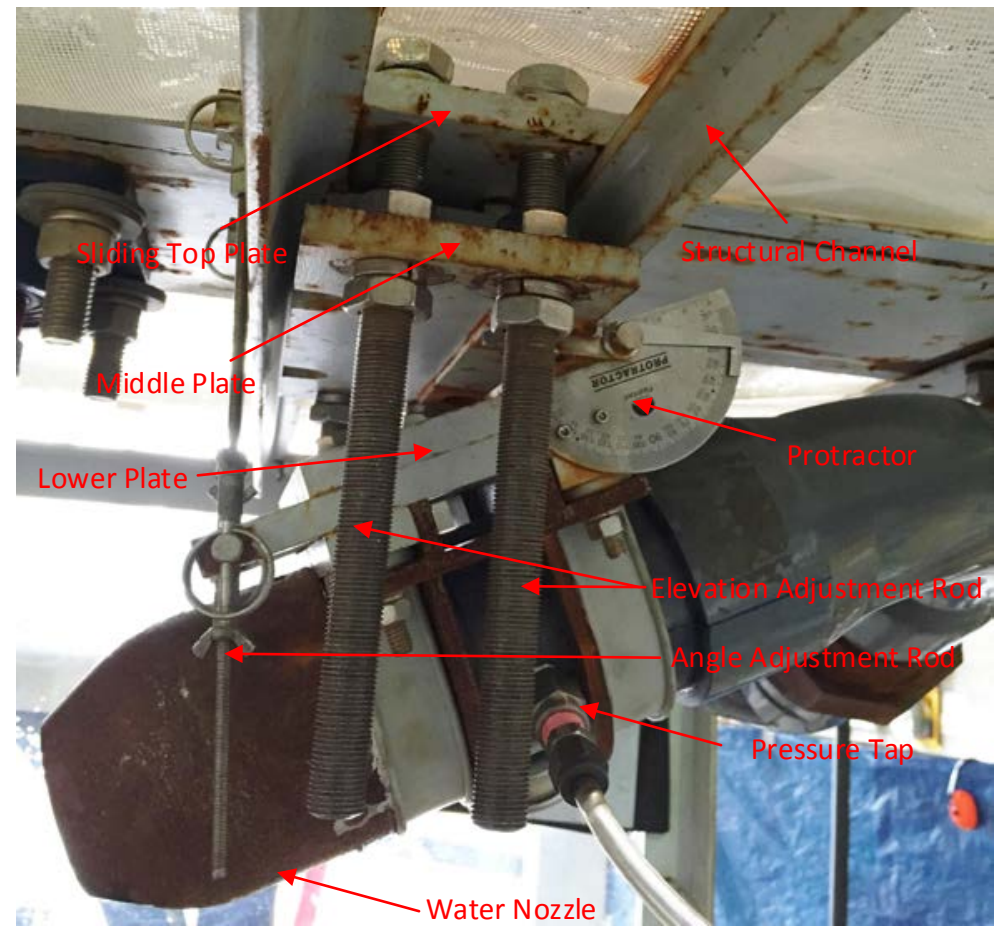

Figure 26: Nozzle 2 in an angled position on the inside of the test stand 


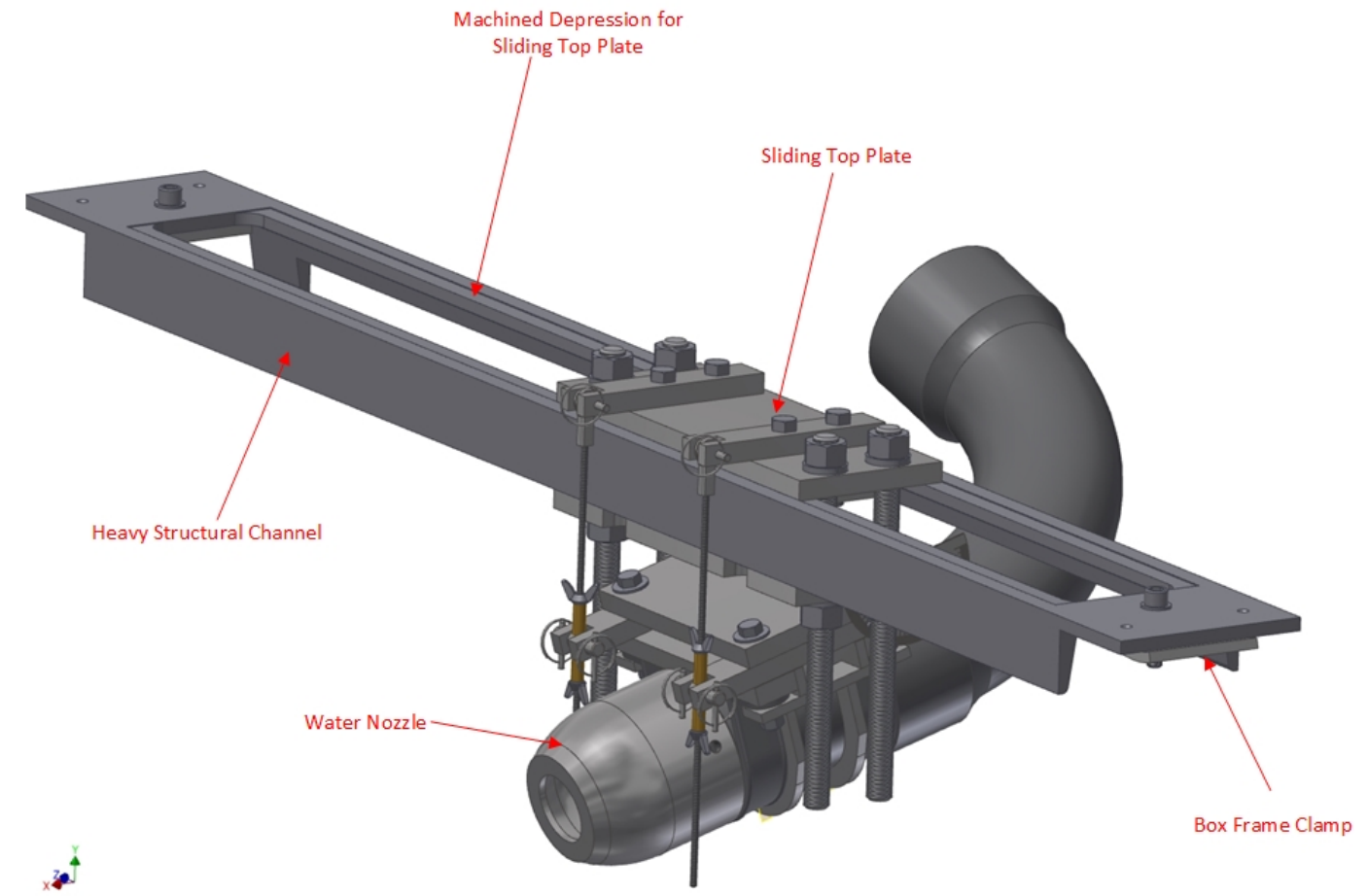

Figure 27: CAD model developed to guide the fabrication of the nozzle brackets that hold each water nozzle

Each nozzle bracket was mounted on a piece of heavy channel with a hole cut in the center. This piece of channel was clamped in place on the inside of the box frame near the top. The position this piece was in set the horizontal distance of the nozzle exit from the aim points shown in Figures 17 and 18. A shallow depression was milled around the two longer sides of the rectangular hole in the channel. This depression served as a smooth pathway on which the plate could slide and also allowed the nozzles to slide as well. This allowed the bracket assembly to slide along the channel so the nozzles could be adjusted to the pitch diameters of each impeller. These components are labeled in Figure 28. When in the correct position, the nozzle bracket could be clamped in place with bolts that tighten steel blocks on the underside of the channel. The clamp blocks are labeled in Figure 28. 


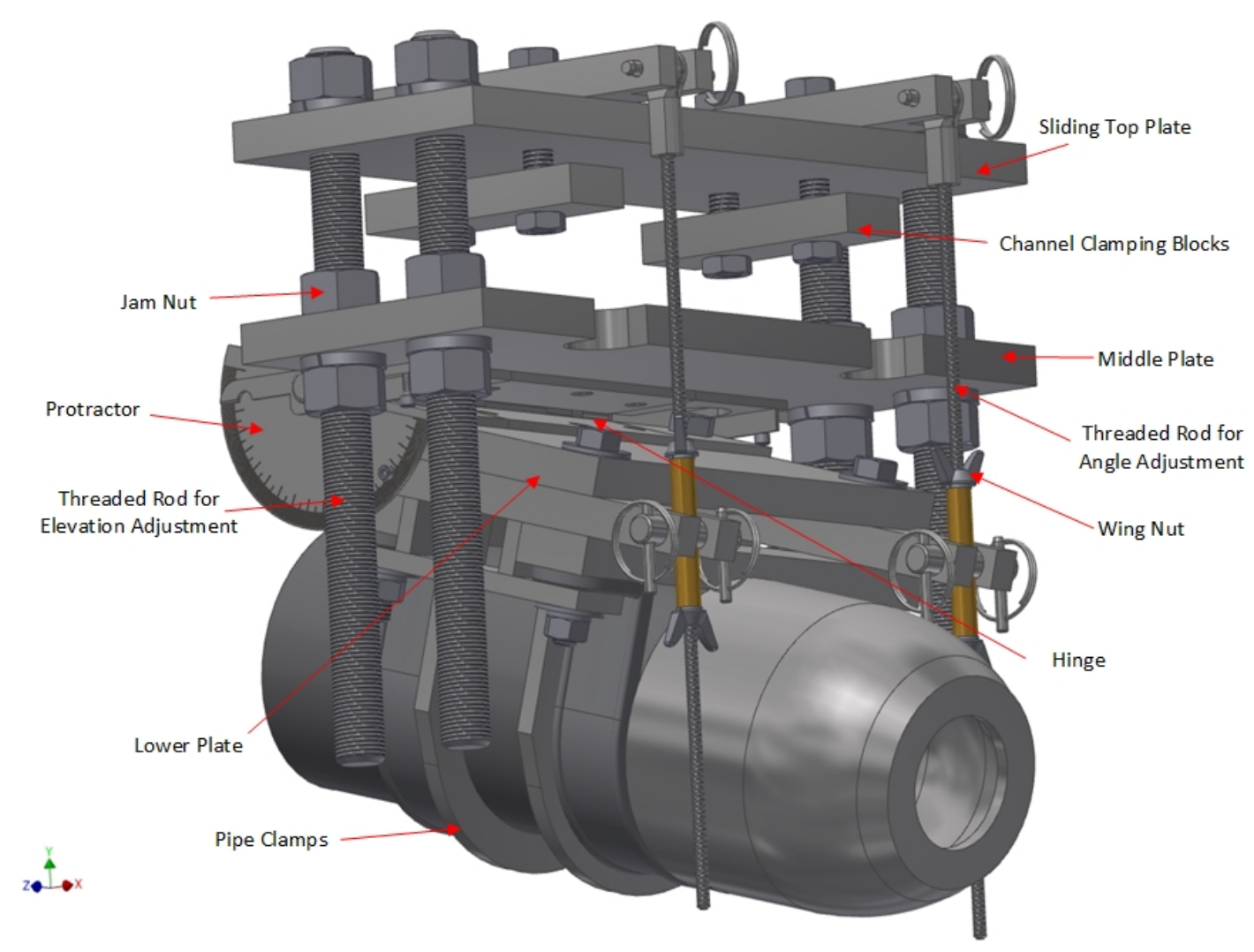

Figure 28: Illustration of an underside view of the nozzle bracket without the piece of channel it is mounted on shown

The elevation where the water nozzles rested at was controlled by four threaded rods that were secured to the lower two plates. Jam nuts on the top and bottom of the middle plate were adjusted vertically on the threaded rod which moved the water nozzle and piping vertically as well. The water nozzle and PVC pipe were attached to the bracket with steel and plastic pipe clamps that bolted to the lower plate. The plates are labeled in Figure 28.

A steel protractor was bolted to each side of the lower plate on each nozzle bracket. The protractor provided the measurement of the horizontal angle where the nozzle was set and coincidently the angle at which the water jet struck the impeller buckets. The protractor had one degree graduations of measurement. Machined blocks held the measuring edges of the protractor 
in place. A hinge was bolted between the middle and lower plates allowing the lower plate to pivot for angle adjustment.

The angle was locked in place by threaded rods that were mounted between the top and bottom plates with pinned connections. It was adjusted by threading the four wingnuts up and down on the two threaded rods. Adjusting the nozzle angle and getting the water nozzles directed at the aim points on the impeller was an iterative process. The elevation and angle needed to be adjusted multiple times, checked for alignment on target with a square, and then readjusted to ensure proper alignment of the water nozzles with the aim points previously described in Figures 17 and 18. This process could take as much as 45 minutes between experimental runs. The different components are labeled in Figure 28. A picture of the combination square being used to align water nozzle 2 is shown in Figure 29.

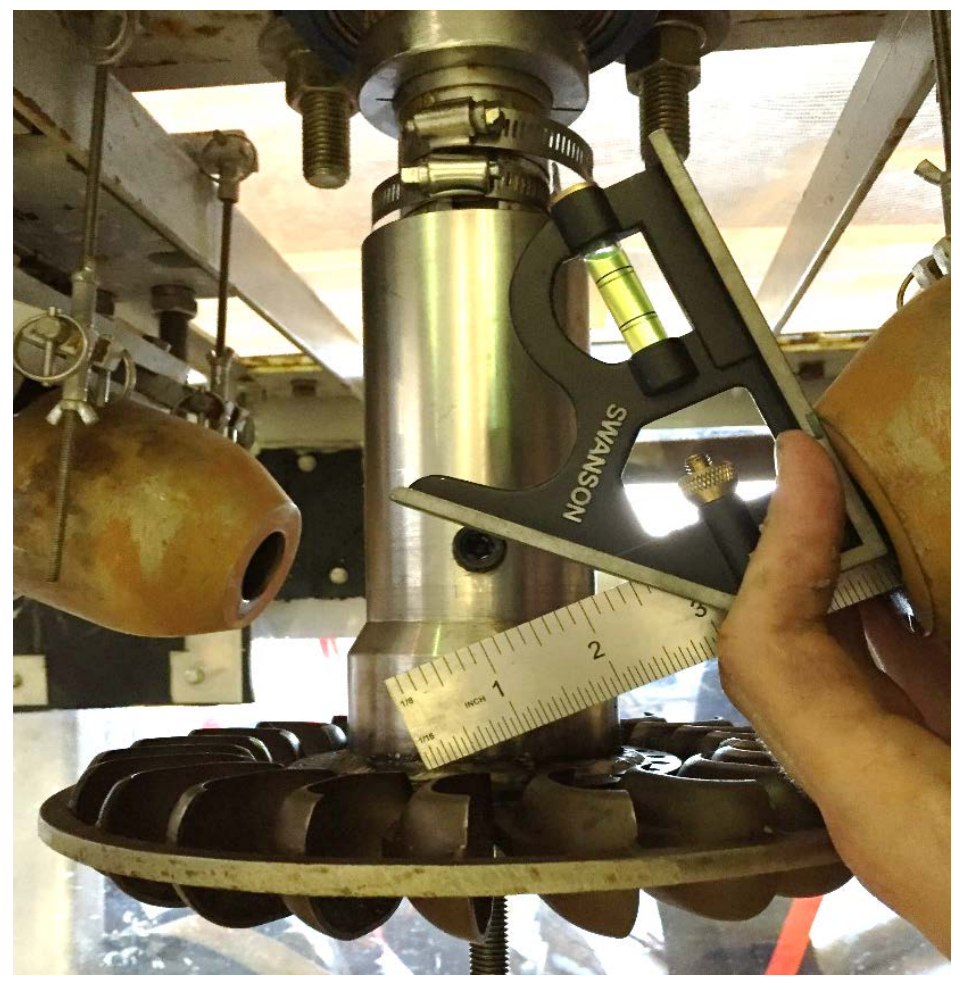

Figure 29: Picture of water nozzle alignment being checked with a combination square 
Most of the parts used in the nozzle bracket were cut on a CNC waterjet. Manufacturing the parts in this way ensured part dimensions would be accurate to the CAD models and helped to ensure proper alignment of each nozzle. Parts that required machining were made at PMI on a Bridgeport manual mill with a digital readout. Machining the brackets in this way and using heavy structural components helped to ensure that the nozzle would not change position due to reaction forces from the water jet during the experiment and keep the water jets aligned on their aim points.

\subsubsection{Water Nozzles}

The methodology for sizing and designing the water nozzles was described in Section 3.1.2. Each of the ten nozzles were turned on a Haas CNC lathe at PMI. The nozzles were threaded with a pipe wrench onto the end of the PVC pipe section held by the nozzle mounting brackets before each test. Once the nozzle was tightly threaded onto the pipe, three set screws were threaded into taped holes on the outside diameter of the nozzle. This ensured that the nozzle would hold its position and would not be affected by water jet reaction forces. A CAD model of one of the water nozzles is shown below in Figure 30. The nozzle position in the bracket is shown in Figures 26, 27, and 28. The nozzles are also shown on the left side of Figure 21 inside the top portion of the test stand frame.
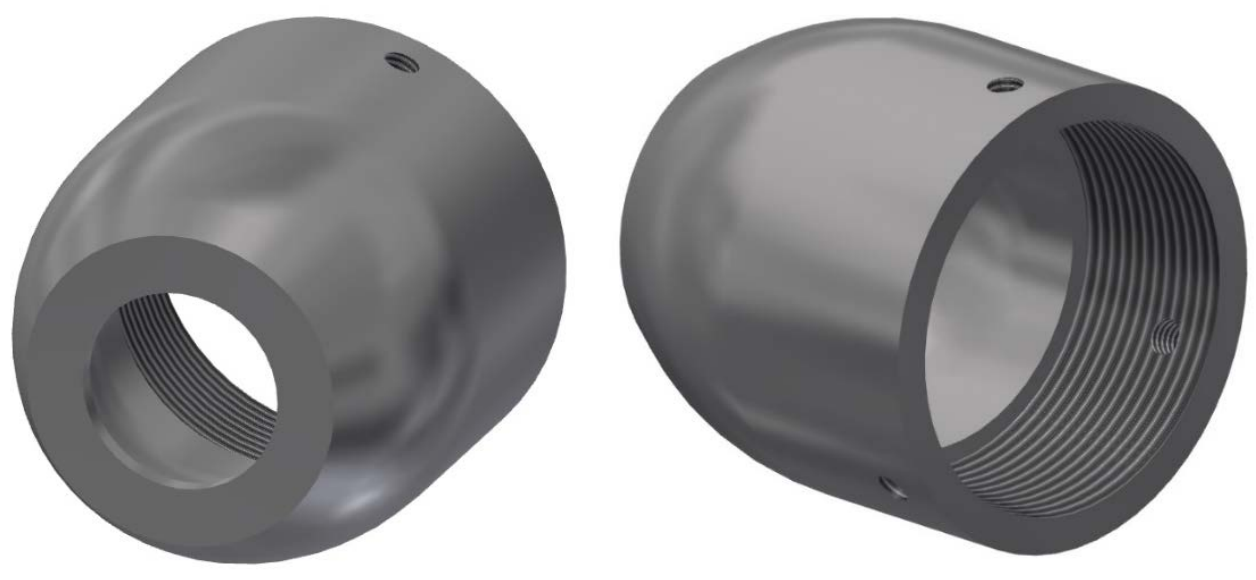

Figure 30: CAD model of one of the water nozzles used in the experiment 63 


\subsubsection{Pressure Transducers}

As mentioned in the previous section, a pressure tap connected the water nozzles to pressure transducers mounted on the outer test stand frame. This protected the transducers from vibration and spray on the inside of the test stand during experiments. A picture of the pressure transducer mounting for nozzle 1 is shown in Figure 31.

It should be noted that an elevation difference was present between the entrance to the pressure tap and the pressure sensor shown in Figure 31. This difference in elevation affected the pressure measurement by decreasing the measured pressure at the tap. The hydrostatic pressure of the air and water that fill the nylon tube during operation acted against the pressure of the water in the water nozzle. These affects varied with the amount of water and air that were trapped in the tube between the pressure tap and the pressure sensors during each test. The maximum elevation difference from the pressure tap to the sensor was approximately 20 ”. If the tube were completely filled with water it could decrease the measured pressure by approximately 0.7 PSI. However, the tubing was never completely full of water because air was sealed in-between the pressure sensor and the pressure tap which means the effect of the elevation difference would have been less than 0.7 PSI. The elevation difference was not taken into account during the experiment because the amount of water trapped in the tube varied between each experiment and would have had to have been accounted for at the beginning of each experiment with the test stand running. This would have meant changing the DAQ software program during the experiment and leaving time where the operational condition of the test stand was not being monitored. This was considered a safety concern and the effect of the elevation difference was neglected. 


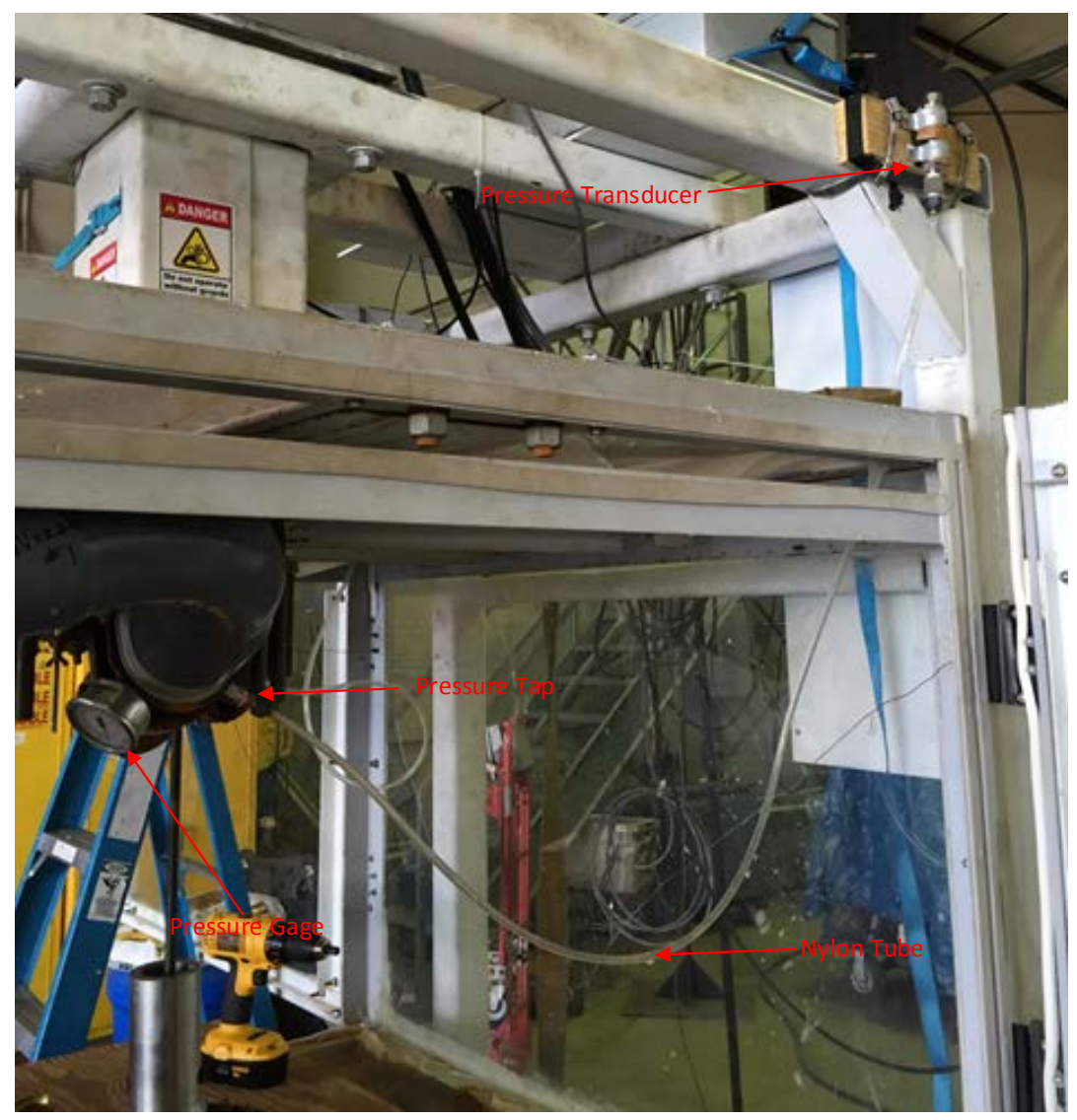

Figure 31: Picture of the pressure transducer mounting for nozzle 1

The pressure transducers used for the experiment were Keller Valueline gage pressure sensors. They were capable of measuring pressure up to $150 \mathrm{psi}$. The accuracy of their total error band was $\pm 0.1 \%$ of their range. Each transducer outputted a DC voltage ranging from 0-5 volts that was recorded by the DAQ hardware based on the measured pressure. A calibration expression was formed from a linear fit of the factory calibration data to convert the voltage output to a measured pressure value. A calibration certificate for each transducer is shown in Appendix C.

Each pressure tap that the transducers were connected to was mounted just before each water nozzle at a $45^{\circ}$ from the vertical. The angled mount was recommended by the IEC standard for hydro turbine model acceptance tests so that the pressure tap could not get blocked by dirt, debris, or air bubbles in the flow [38]. This can be seen in Figure 26 and is not shown in any of the 
CAD models. Ideally, the sensor would be mounted in a position closer to the nozzle exit but this was not possible in this situation due to the fact that it would interfere with the rotation of the impeller if mounted at the end of the nozzle.

The taps were attached by first drilling and tapping a 1/4" NPT holes into the PVC. An Omega stainless steel pressure snubber was threaded into the tapped hole in the pipe. The purpose of the pressure snubber was to reduce pressure fluctuations in the water flow to create a smoother measurement and to protect the transducer from pressure spikes when water first entered the line. The pressure taps that led to the pressure transducers are shown in the same area as the water nozzles on the left side of Figure 21.

In an effort to ensure the accuracy of the pressure measurements, the factory calibration curve was checked for each transducer using a Heise Model PTE-1 digital calibrator with a 30 PSI absolute pressure module installed. The calibration was performed by connecting the calibrator and a hand pump to the pressure transducer with Swagelok fittings and nylon tubing. Once the fittings were tightened and sealed, the pressure in the tubing could be increased using the hand pump. A pressure reading was displayed on the screen of the calibrator and then recorded. This value was plotted against the factory calibration curve to see if they were in agreement. The entire range of the sensor could not be checked because the calibrator could only measure up to 30 PSI absolute pressure. During both checks, eight pressure measurements were recorded between atmospheric pressure ( 14 PSI) and slightly less than 30 PSI by increments of approximately 2 PSI. To be clear, the values used in the check of the calibration are the difference in the absolute pressure measured by the calibrator and the atmospheric pressure. The plots of each calibration check are shown in Appendix C immediately after the calibration certificates. Figure 32 below shows the Heise connected to the pressure transducer for nozzle 2. 


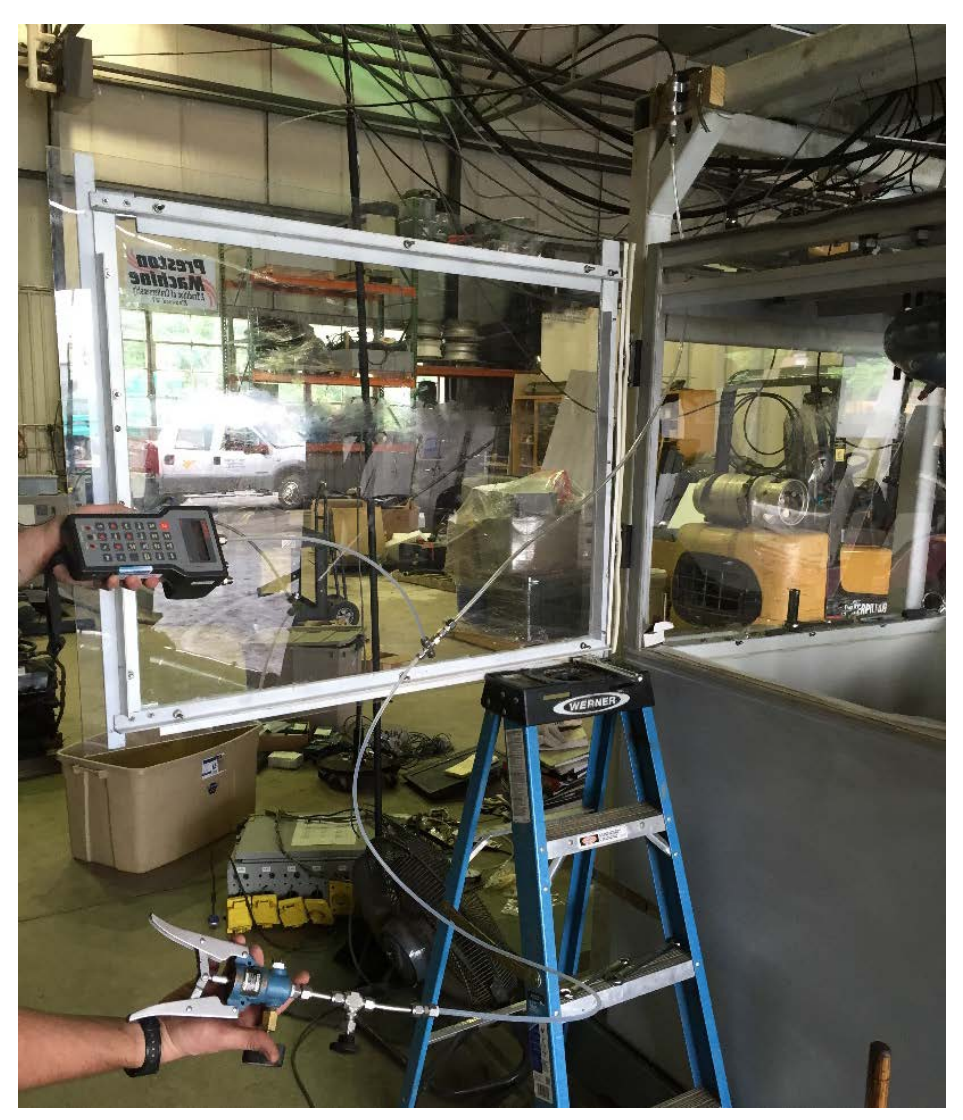

Figure 32: Picture of the Heise calibrator and hand pump connected to the pressure transducer 3.2.8 The Turbine Impellers

As mentioned before, two impellers were compared in this experiment. Impeller A represented a newly designed and fabricated impeller which consisted of 22 individual Turgo buckets welded to a center hub. An outer ring was welded to the outer edge of the buckets. A shaft coupler was welded to the hub so the impeller could be fixed to a driveshaft by putting a bolt through the underside of the hub and threading it into a hole on the generator shaft. The components of the impeller were made from stainless steel and it was not used in the field before this experiment. Impeller A had a pitch diameter of $188 \mathrm{~mm}$ and weighed approximately $16.6 \mathrm{lbs}$. Hartvigsen Hydro of Kaysville, Utah designed the impeller hub and buckets. The approximate angle on the inlet side of the bucket was $47^{\circ}$. The approximate angle on the exit side of the bucket was $9^{\circ}$. A picture of impeller A is shown below in Figure 33. 


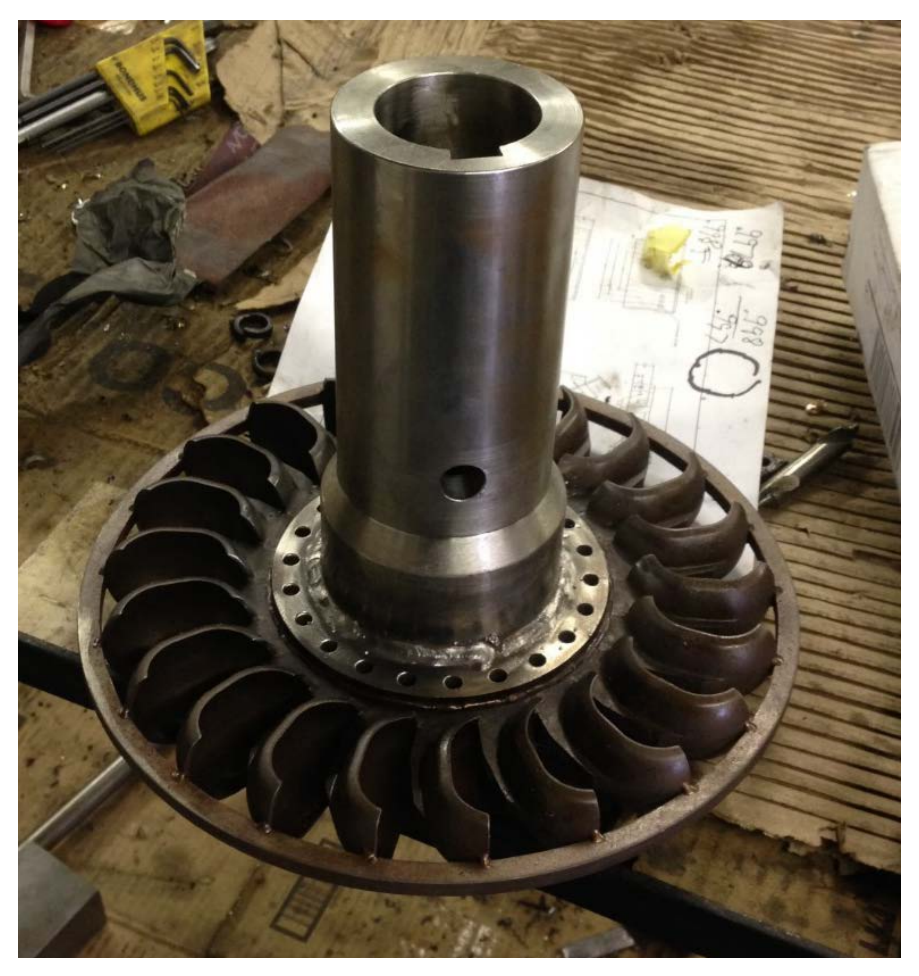

Figure 33: Angled view of impeller A

Impeller B was larger than impeller A. Impeller B had been used extensively in an operational turbine and showed signs of wear and corrosion. It had 14 blades that were shaped very differently when compared to impeller A. Each bucket had a spherical shape on the inner surface. The outer ring welded to the outer edge of impeller B was much larger than the one on impeller A. The inner edges of the bucket were again welded to a hub. Impeller B was made of carbon steel with a nickel plating over most of the surfaces. However, most of the plating had been worn away by use in the field. Most of the bucket surfaces on impeller B were pitted, rusty, and worn from field use as well. It had a pitch diameter of approximately 7.86” or $200 \mathrm{~mm}$ and weighs 33.3 lbs. The approximate angle on the inlet side of the bucket for impeller B was also $47^{\circ}$. The approximate angle at the exit of the blade was $32^{\circ}$. A picture of impeller B is shown below in Figure 34. Both impellers were dynamically balanced in an effort to ensure safe operation and to reduce vibration during testing. 


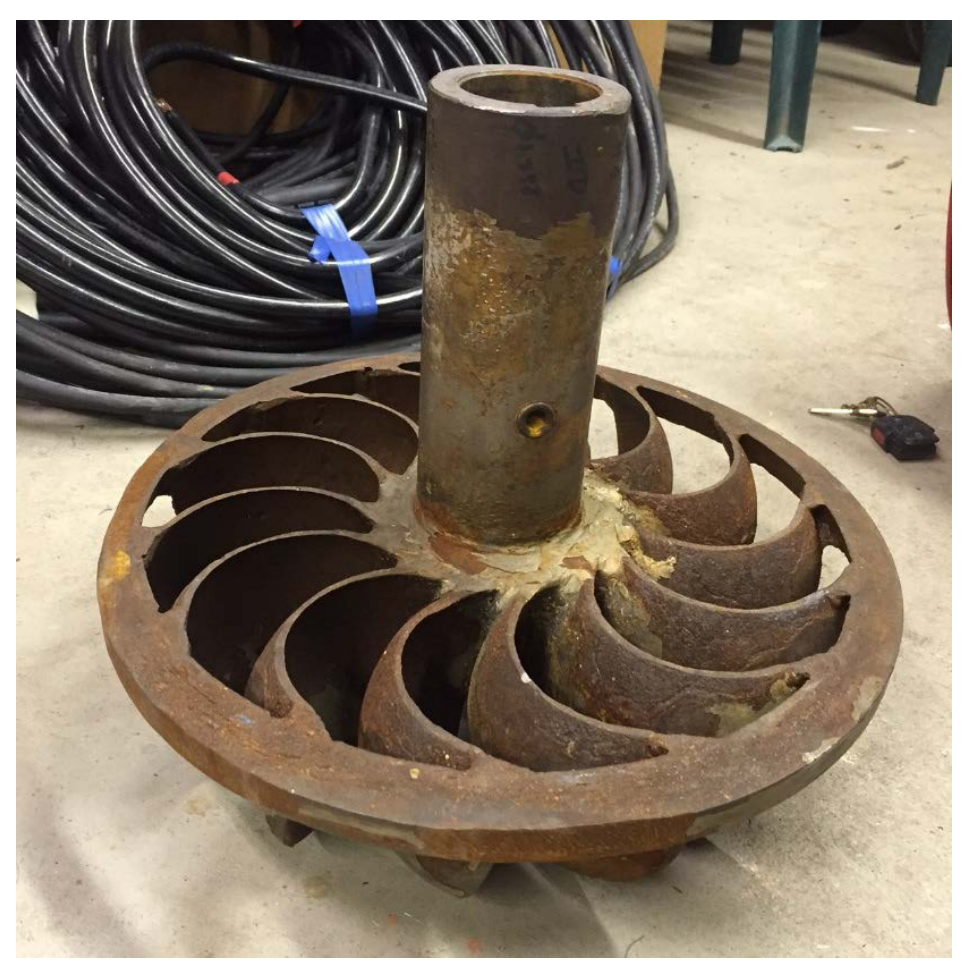

Figure 34: Angled view of impeller B

\subsubsection{Thermocouple}

A thermocouple was mounted in the reservoir to record the temperature of the water as it circulated through the system during operation. The temperature of the water was measured to account for variation in density as the water temperature increased during testing. An Omega JQSS-18U-12 J-Type thermocouple was used in the measurement. The standard accuracy of the thermocouple was the greater value of either $0.75 \%$ of the measured temperature or $2.2^{\circ} \mathrm{C}$. Since the thermocouple had to be mounted on the inside of the test stand, the body of the thermocouple was sealed in a pipe with capped ends with the probe protruding from the bottom end through a hole. The probe end was in direct contact with the water being circulated through the test stand. This protected the thermocouple from high velocity spray inside the test stand. A picture of the thermocouple mount is shown in Figure 35. 


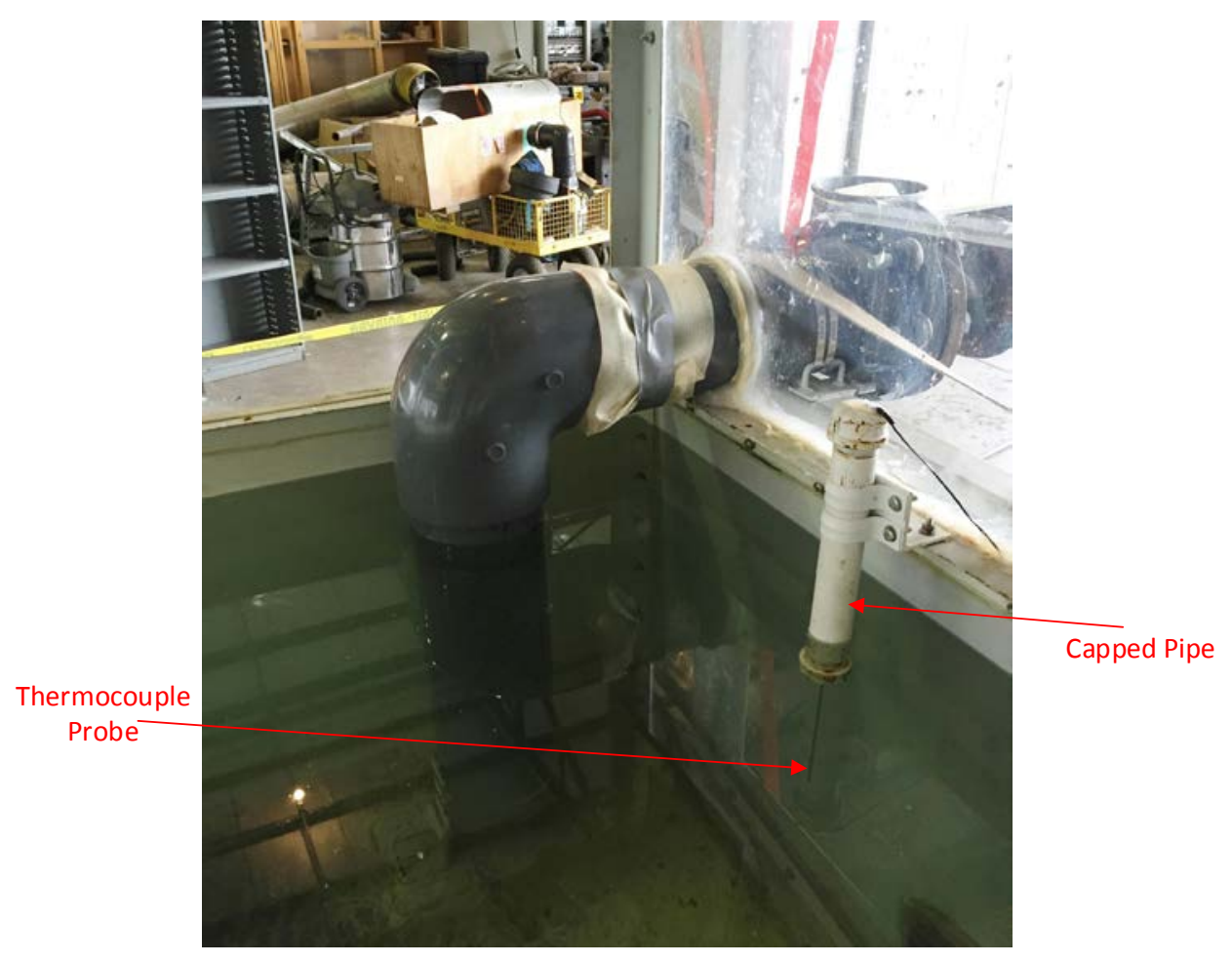

Figure 35: Thermocouple mounted on the inside of test stand frame

In an effort to ensure the accuracy of the measurement, the accuracy of the thermocouple was checked using a hand held thermometer. Both the thermocouple and the thermometer were placed in a bucket of hot water and the temperature measurements from both devices were compared. Multiple measurements were taken as the bucket of water cooled. The measured values agreed with an average percent error of $2.3 \%$ and maximum of $2.9 \%$. The accuracy of the thermometer was $\pm 0.2^{\circ} \mathrm{C}$. The calibration for the thermocouple was programmed into the DAQ software. Changing the calibration would have meant changing the programming of the software which was not possible in a reasonable time frame. The default calibration was also accepted because a small change in temperature produced an insignificant change in the density values calculated. By examining values of specific volume for liquid water in Cengel and Boles [5], it can be seen that a change in temperature of water from $20{ }^{\circ} \mathrm{C}$ to $35{ }^{\circ} \mathrm{C}$ causes an approximate 
decrease in the density of the water of $0.004 \%$. The temperature change in the water in the test stand was similar to this and caused similar change in the water density measurement. Therefore, the default calibration of the thermocouple was deemed accepted.

\subsubsection{Spray Reduction}

One of the factors that can negatively affect the overall efficiency of an impulse turbine is the amount of spray present in the housing during operation. The spray can interfere with the water jet before it strikes the impeller buckets causing a reduction in the velocity of the jet. An effort was made to try to reduce the amount of spray in the test stand during operation in two ways. First, plastic mesh was placed on the inside of the stand in key areas. Spray that contacted the mesh did not rebound as much when compared to unmeshed Lexan or steel surfaces. Second, clear Lexanacrylic spray shields were also placed in the path of the water jets to deflect them downward into the plastic mesh and reservoir. A picture of the shields and mesh on the inside of the test stand is shown in Figure 36. No effort was made to compare how the pattern of spray from the nozzles in the test stand compared to that of the Antrim Turbines because the operational turbines housing provide no access to view the turbines in operation. However, the size of the test stand is larger than that of the housing on the actual turbines. It can be inferred from the size difference that the air/spray mixture in the turbine during operation would have an increased density compared to the air/spray mixture in the test stand because the same amount of spray occupies a smaller space. 


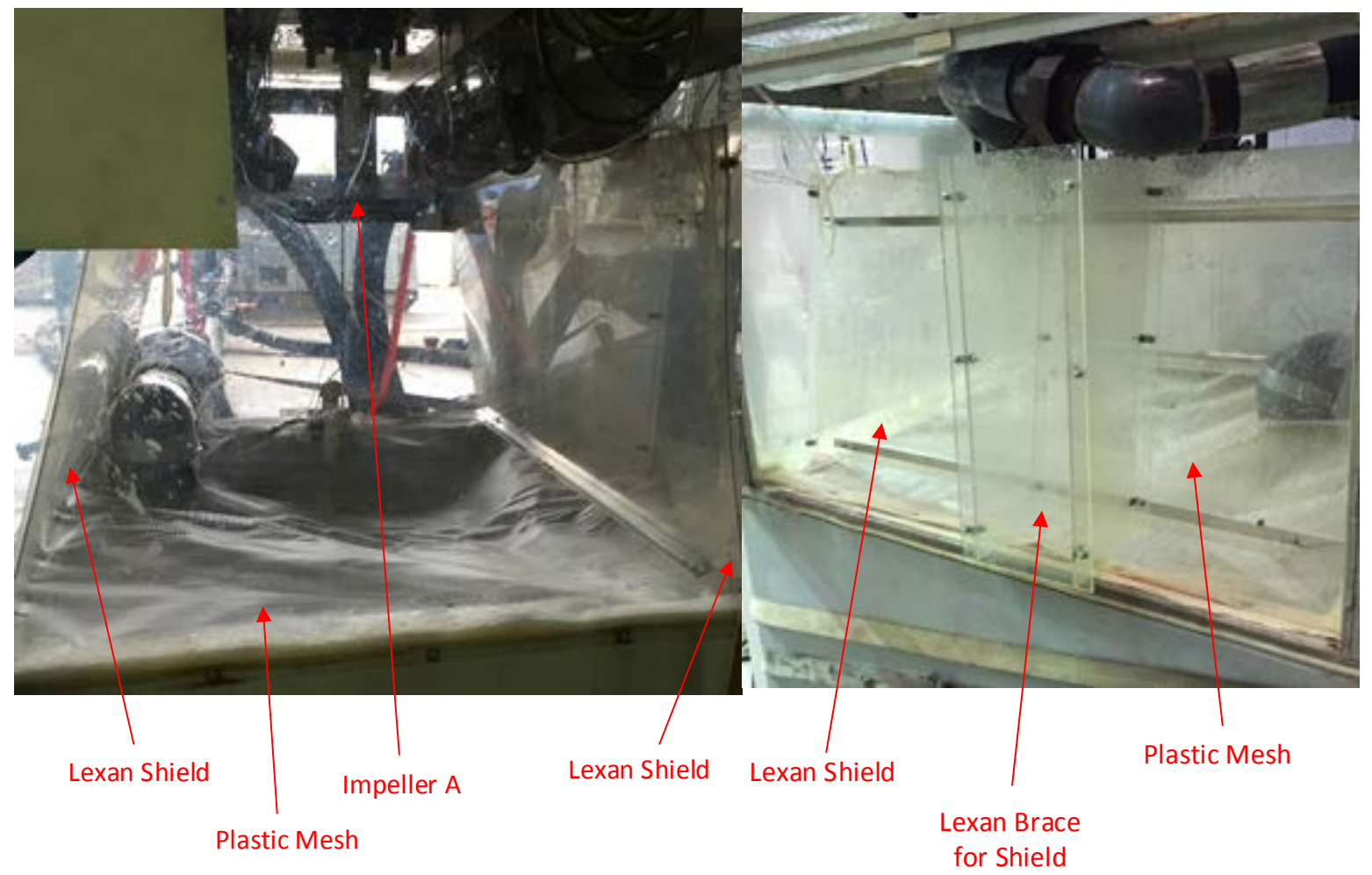

Figure 36: Spray shields and mesh installed on the inside the test stand

\subsubsection{Induction Motor}

In order to create an efficiency map for each impeller, the rotational shaft speed of the impeller needed to be varied during the experiment. A Reliance RPM AC $40 \mathrm{hp}$ induction motor was used to provide a load to the impeller and control the rotational speed of the impeller during testing. Holes were drilled and tapped in the c-face of the motor to allow it to be mounted in a vertical position. The motor was mounted on top of the outer frame of the test stand on a piece of 1/2" thick steel plate bolted to the square tube frame. The motor was controlled using a variable frequency drive that will be described in Section 3.2.14. The variable frequency drive controlled the motor speed by varying the frequency of the $480 \mathrm{~V}$ three-phase electricity that powered the motor. A picture of the motor is shown in Figure 37. The speed-torque curve for the motor is shown in Appendix D. 


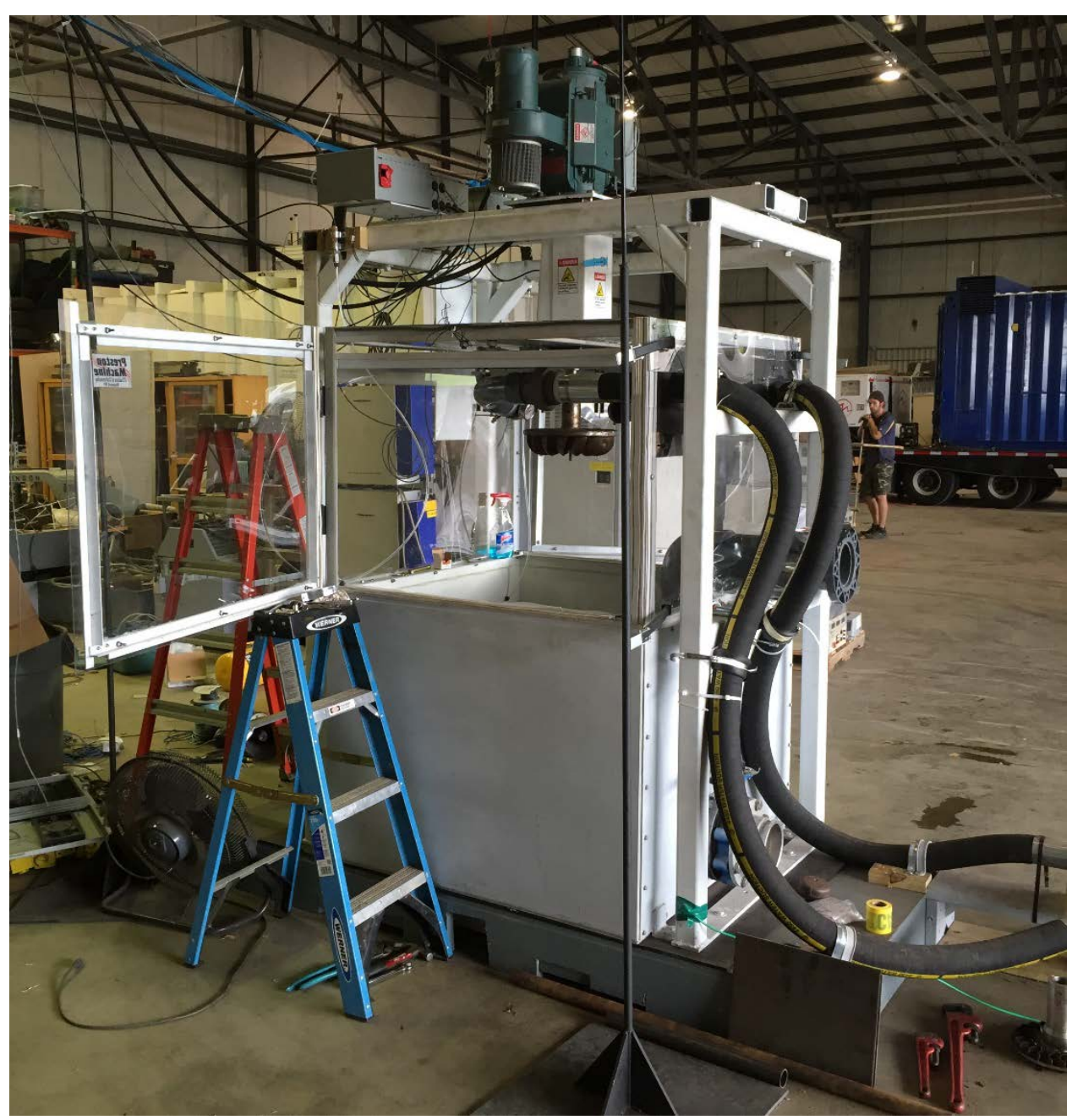

Figure 37: Picture of the Reliance motor mounted on top of the test stand frame

Just before a test was conducted, the motor was used to spin the turbine impeller up to a certain speed. Following this, the centrifugal pump was started to bring pressure to the water nozzles. This caused the water jets to impinge on the impeller and apply torque on the motor shaft. This reduced the torque and power the motor needed to output to keep the impeller spinning at a constant speed. Once the amount of torque that was being applied by the water jets equaled the torque supplied by the motor, the power consumed by the motor was zero because it was no longer needed to drive the impeller. A further increase in torque on the impeller caused the motor to generate power as the induced torque from the turbine surpassed the torque supplied by the motor. 
If the turbine was not loaded by the motor, the rotational speed would begin to increase at that point. To maintain constant speed, the energy generated by the motor was dumped by routing it to a resistance heater. Dumping energy increased the load on the turbine and reduced the shaft speed back to the desired set point. This process was controlled by the operator through the settings in the variable frequency drive (VFD) and the wiring of the resistance heater. This heater will be described in Section 3.2.15 because it is part of the energy dump system. It is shown in Figure 21 at top on the right hand side.

The Reliance Motor was chosen for the experiment because it was readily available and it could be mounted in a vertical position. The motor and VFD had to be closely monitored during testing. Each impeller could produce more torque than the motor and drive were capable of operating with, especially when the rotational speed was decreased or head and flow rate were increased. As a result, if a set-point in the experimental test matrix resulted in a torque that exceeded safe operating limits for the system, then that point was eliminated. The primary factor limiting this was the maximum allowable current that could be passed through the VFD to the resistance heater to dump energy from the system. It could not be determined beforehand which set-points could be tested because the amount of torque produced by the impeller depended on how efficient each impeller was at the test point which was unknown before the test. The motor is shown in green in the top left corner of the schematic in Figure 21.

Ideally, a motor and controller combination would have been chosen that could handle the maximum torque and energy at all operating conditions for the experiment. It was not possible to get this equipment with the allocated budget for the project. 


\subsubsection{Incremental Encoder}

An incremental encoder was used to measure the speed of the motor shaft during each experiment. The encoder used was a Dynapar H20 that produced 1024 pulses per revolution. The accuracy of the encoder was $\pm 0.125^{\circ}$ on the reading of a transition between encoder sections. The encoder produced pulsed signals in the form of a square wave. The frequency of the pulses was recorded by the DAQ hardware and software and converted to a shaft speed measurement. A picture of the encoder is shown below in Figure 38.

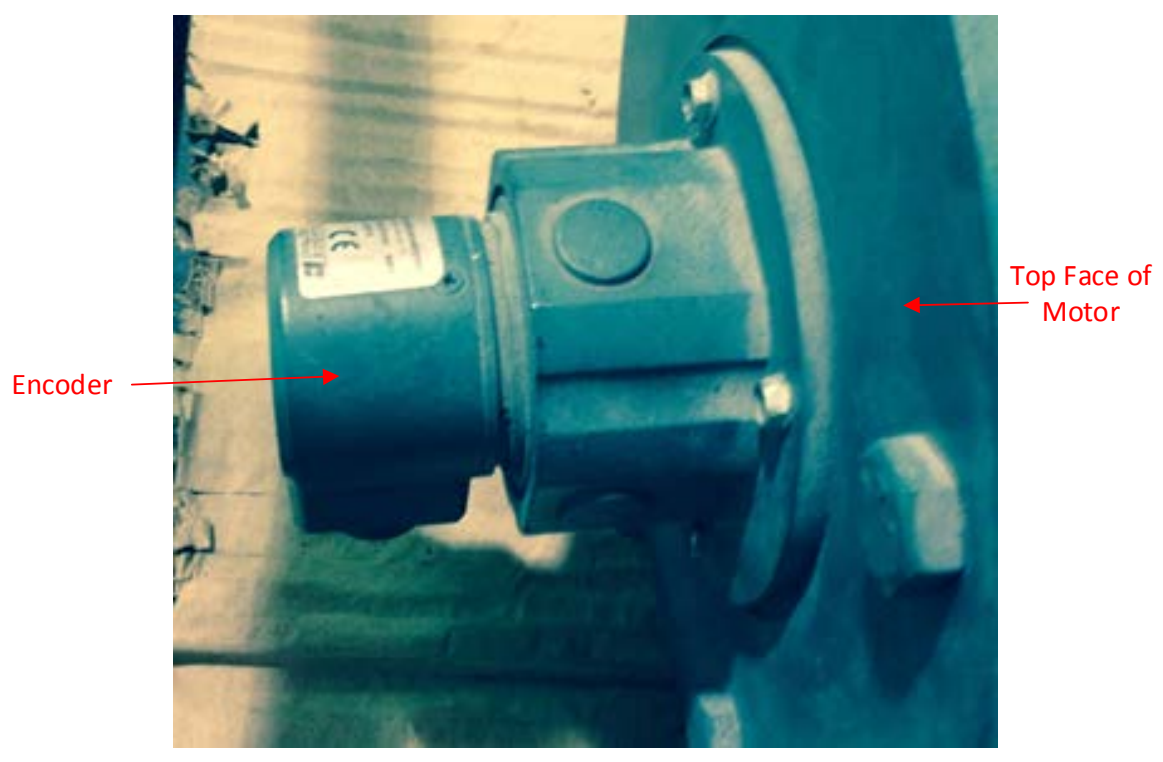

Figure 38: Picture of the Dynapar H20 Encoder mounted on the reliance motor

In an effort to ensure the accuracy of the shaft speed measurement, the shaft speed measured by the encoder was compared to the value set in the software that controlled the VFD with no torque applied to the drive shaft. The encoder shaft speed measurement fluctuated but agreed well with the set value of shaft speed when it was averaged over a period of several seconds or more. This check of accuracy was not recorded.

It should be noted that during an actual test the shaft speed of the motor was affected by motor slip. Slip was caused when the rotor rotational speed fell behind that of the actual rotating 
magnetic field induced in the rotor. Slip is defined as the difference in the actual rotational speed from the synchronous speed. The amount of slip increases when load on the motor is increased. This was evident during testing, especially at higher flow rates where high torque was imposed on the impeller and motor shaft. This was compensated for by increasing the shaft speed set-point during performance testing to bring the actual shaft speed closer to the values described in the test matrix. This did not affect the accuracy of the results beyond what is reported in the uncertainty section. However, it did make the process of setting the rotational speed of the turbine exactly at the desired set-point difficult.

\subsubsection{Torque Meter and Drive Shaft Components}

An in-line rotary torque meter was used to measure the torque on the impeller shaft during the experiment. The torque meter selected was an Interface Force T23 LC with a measurement range of $-500 \mathrm{Nm}$ to $+500 \mathrm{Nm}$. The negative value signified rotation in the counter clockwise direction. The torque meter output a signal ranging from -5 to $+5 \mathrm{~V}$. The output signal was linearly proportional to the measured value. A factory calibration certificate for the torque meter is shown in Appendix C. A calibration expression was fashioned from a linear fit of the factory calibration data to convert the voltage signal into a measured torque value. The selected torque meter measurement range was larger than required for the experimental conditions to protect against possible damage from shock loading that could occur at high rotational speed. This reduced the resolution of the torque measurement. The torque meter measurement was the biggest contributor of bias uncertainty present in the measurement of the turbine efficiency.

In an effort to ensure the accuracy of the torque measurement, a physical check was performed on the torque meter using a torque wrench. This was done by threading a $3 / 4$ " bolt into the end of the drive shaft before the impeller was mounted with a specially-machined shaft coupler. 
A picture of the coupler is shown below in Figure 41. The torque wrench was then used to apply torque in the counter-clockwise direction to the bolt and shaft. The measured torque was then compared to the wrench setting to see if they agreed. The calibration could not be checked over the full measurement range of the sensor because a person turning the wrench could not apply the necessary amount of torque. The torque wrench used was a CDI 2503MFRMH which was accurate to within $\pm 5 \%$ of the set value for counter clock-wise rotation. The accuracy of the wrench was checked by hanging weights from the handle. Weights of 22.4 and $22 \mathrm{lbs}$. were hung $1 \mathrm{ft}$. from the pivoting head of the wrench to induce approximately $44.4 \mathrm{ft}$. lbs. of torque. The wrench was then set to $45 \mathrm{ft}$. lbs. The wrench did not click at $45 \mathrm{ft}$. lbs. but did click at $44 \mathrm{ft}$. lbs. indicating an accurate reading. A picture of this test is shown in Figure 42. A plot of the calibration data for the torque meter is shown in Appendix C.

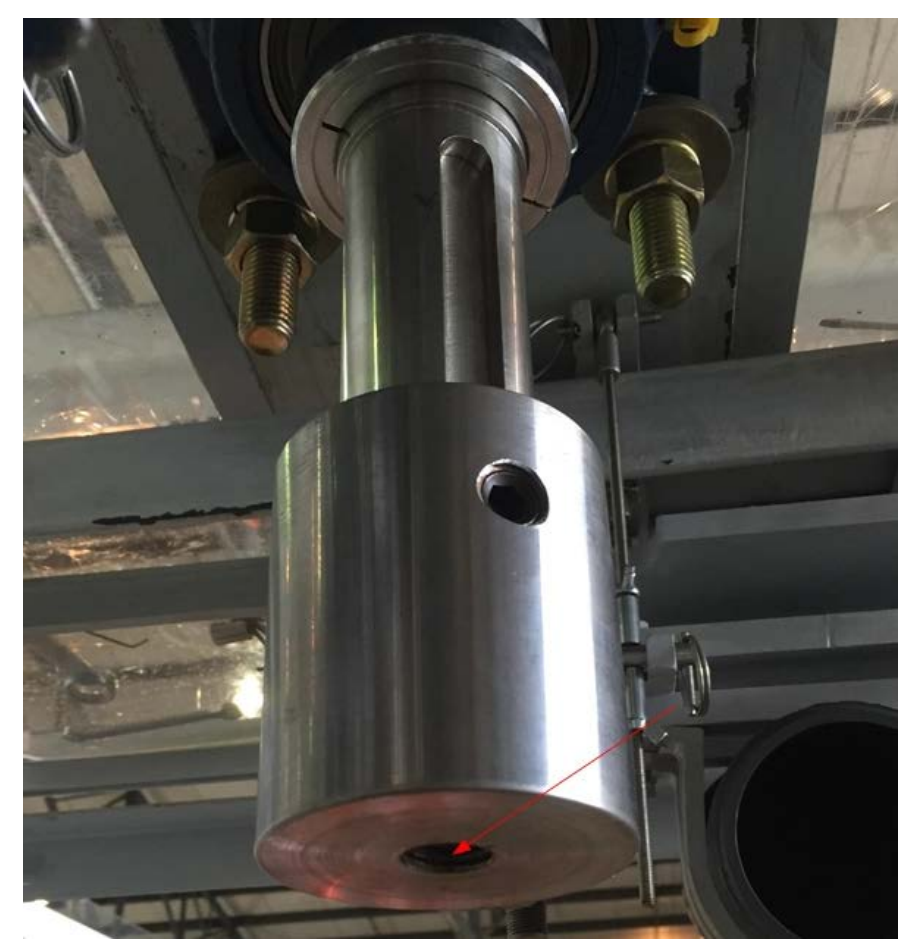

Figure 39: Machined coupler used for torque meter calibration 


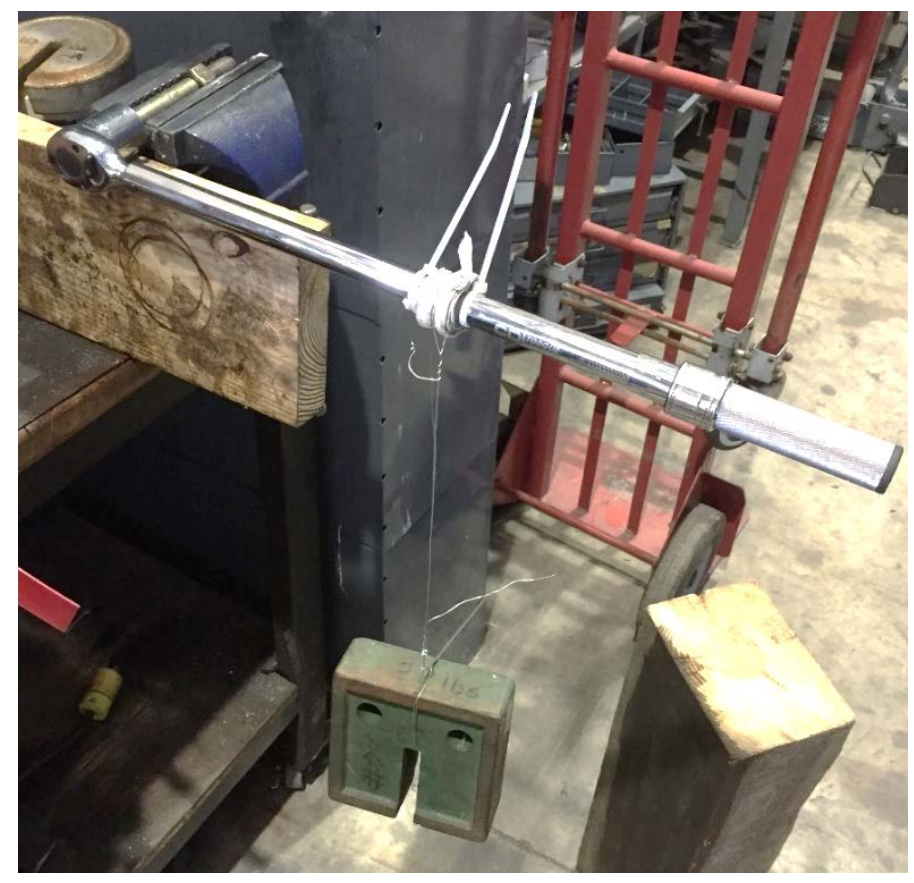

Figure 40: Set-up of the torque wrench accuracy check

To accommodate the vertical set-up of test stand, the torque meter was mounted vertically between the motor shaft and the connecting shaft on which the impeller was mounted. The 1 ” shaft on the torque meter did not have a keyway machined into it. As a result, Mayr single-flex shrink disc shaft couplings were used to connect the meter to each adjacent shaft. A picture of the torque meter and shaft coupling is shown in Figure 15 (on the left). This portion of the test stand is also shown on the left side the schematic in Figure 21 above the test stand frame.

Directly under the torque meter, two flanged SKF YAT 211-200 deep-groove ball bearings were mounted to support the weight of the impeller. They also held the impeller drive shaft in alignment with the motor to reduce vibration. A picture of this portion of the assembly is shown in Figure 39 when it was separated from the frame. During operation, two steel guards were placed around the torque meter and shaft couplings as a safety precaution. Each guard was bolted to the piece of channel on which the shaft bearings were mounted. 


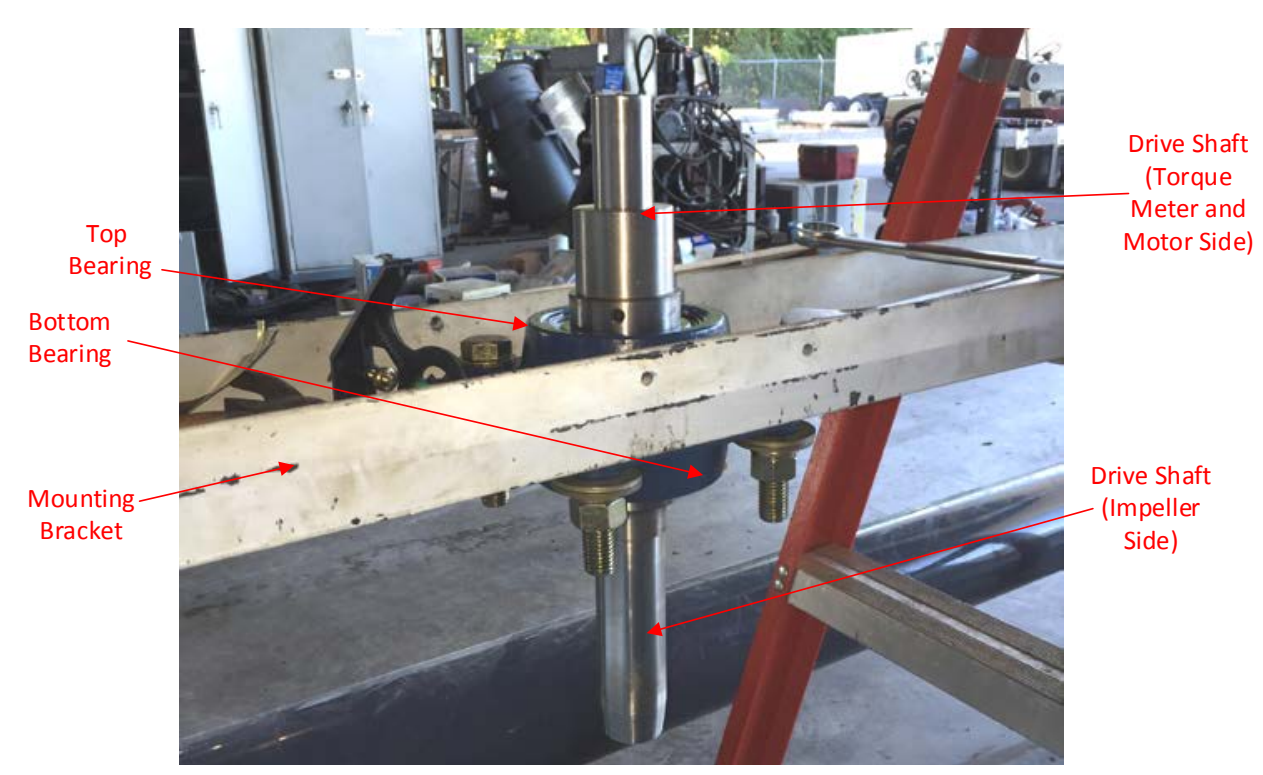

Figure 41: Picture showing drive shaft the impellers were mounted on while it was separated from the test stand frame

In Figure 39, the top machined section of the shaft connected to the torque meter via the aforementioned shaft couplings. The impellers were mounted on the bottom shaft section. Both flanged bearings can also be seen in the Figure bolted together through the channel bracket.

It was critical that the drivetrain components from motor to impeller were aligned to reduce vibration. Several methods were used to align them. First, a flat surface was machined on each side of the piece of channel that held the bearings to ensure that their flanges were parallel to each other and located on the same rotational axis. Second, a straight edge and a dial indicator were used to check the alignment between the motor shaft and the impeller shaft mounted on the bearings. The straight edge was placed on the connecting shaft first. The position of the motor shaft was compared to the straight edge in multiple locations and adjusted accordingly. When the shafts were close to aligned, a similar process was used with a dial indicator in an effort to fine tune the alignment. Figure 40 below shows the alignment tools in position. Steel shims were used to correct the position of the motor and bearings to ensure proper alignment. 


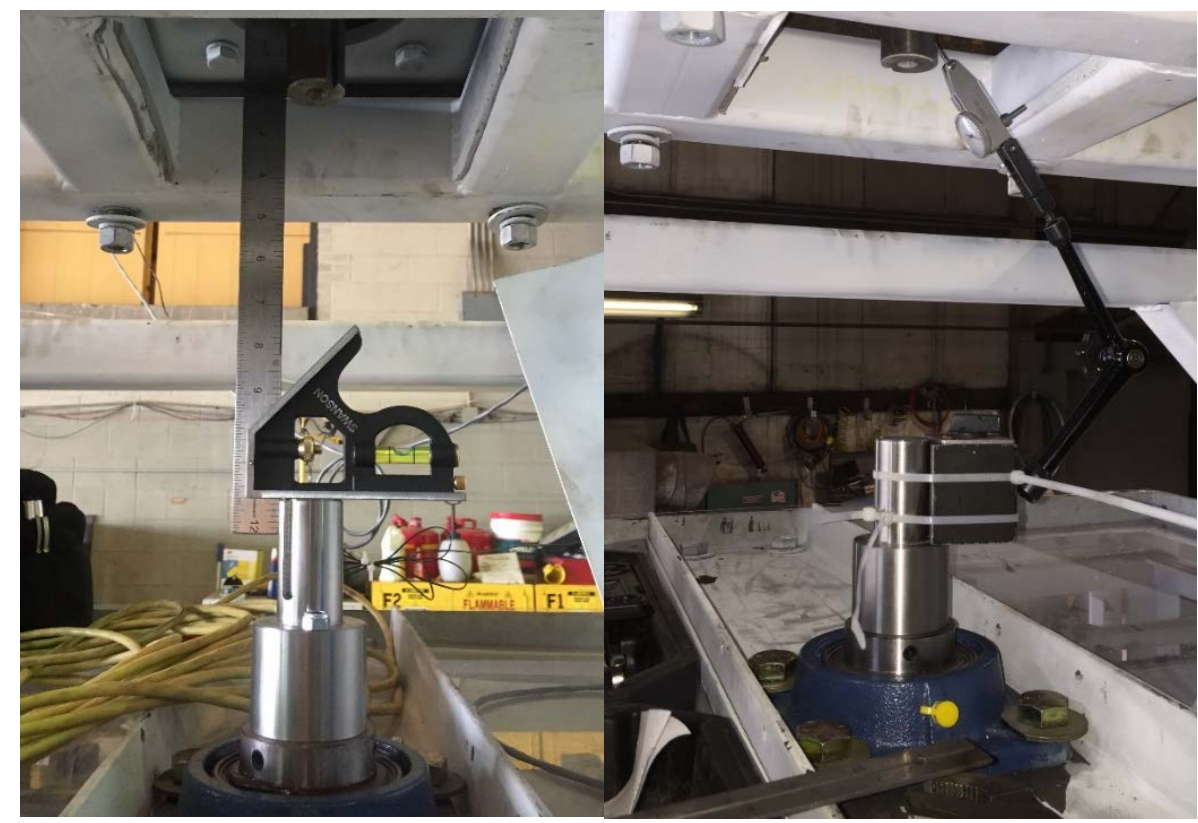

Figure 42: Depiction of the straight edge (Left) and dial indicator (Right) used to align the motor shaft to the impeller shaft

Finally, when the impellers were bolted to the drive shaft, brass spacers were used to ensure a tight fit between the impeller shaft coupler and the drive shaft. A long piece of threaded rod was used to position and tighten the impeller on the shaft. A special tool was fabricated to remove the impellers from the shaft so they were not damaged or the alignment of the drive shaft altered. A shaft collar was placed between the bottom bearing and the impeller to help ensure the position of the shaft would not change vertically during operation.

\subsubsection{Variable Frequency Drive (VFD)}

The VFD used for this experiment was a Delta $40 \mathrm{hp}$ model. In Figure 21, the VFD is located near the top middle of the schematic. It served as the controller of the electric motor and allowed the operator to control the motor rotational speed during experiments. When the motor was driving the impeller at the beginning of a test, the VFD was sending $480 \mathrm{~V}$ three-phase power to the motor at a frequency that resulted in the motor spinning at the desired shaft speed. When the impeller was driven by the water jets, the VFD routed power that was generated by the motor to 
the energy dump system in the form of direct current to a resistance heater. As mentioned in the previous section, the VFD was rated for a maximum current of 73 Amps which was the limiting factor that determined which set-points in the test matrix could not be tested. A picture of the VFD is shown in Figure 43.

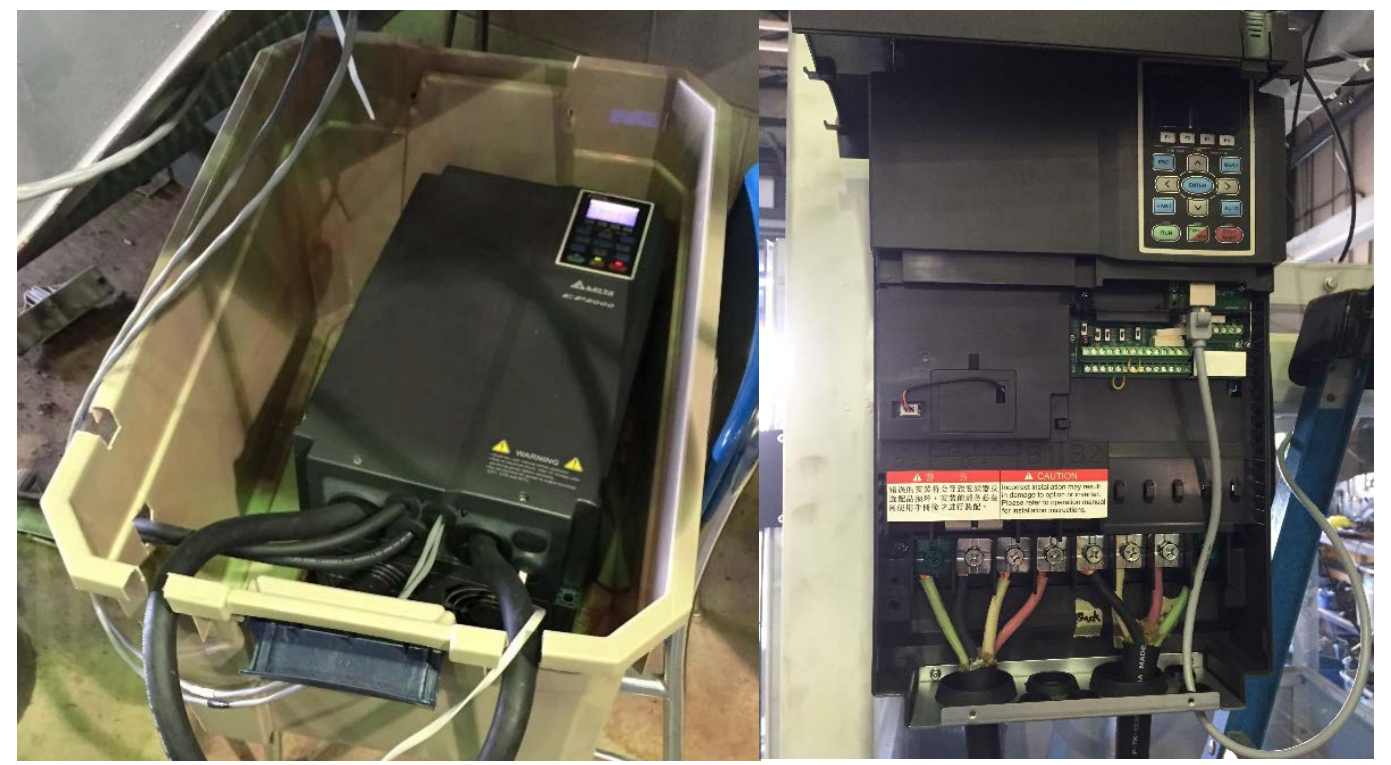

Figure 43: Picture of the Delta VFD in final position (Left) and with cover open (Right)

The drive was positioned in a plastic tub approximately $40 \mathrm{ft}$. away from the test set-up to prevent accidental contact with water. To power the system, the drive received power from a transformer linked to the building main supply. The VFD was connected to the resistance heater in the energy dump system via two flexible copper cables rated for $1 \mathrm{kV}$. A laptop computer was connected to the drive via a phone line with Delta VFDSoft 3.0 software to control the VFD. The drive was connected to the motor and transformer with a heavy duty AWG 6/4 power cable.

\subsubsection{Energy Dump System}

The main component of the energy dump system was a Chromolox Immersion Heater. The heater was capable of dissipating $150 \mathrm{~kW}$ of power from 18 copper coils. The heater was mounted in a closed stainless steel tank that was filled with water during operation. The water in the closed 
tank was circulated by a Grundfos hot water circulation pump to a second open tank nearby. The water was circulated to ensure that it would cool enough to prevent boiling of the water in the loop. The amount of power dissipated by the heater was determined by the configuration in which the heating elements were connected. A CAD model of the Chromolox heater is shown in Figure 44. The wiring configuration of the elements of the Chromolox heater was important because it had an effect on the performance experiment. In Section 3.2.11, it was mentioned that the rotational speed of the motor would increase if the load on the turbine was too low while it is being driven by the water jets. The amount of load placed on the motor was determined by the resistance on the Chromolox heater because that was where the energy produced by the turbine was sent. If the heater failed to dump enough of the generated energy, the rotational speed would begin to rise past the desired set-point. A resistance of 20.1 Ohms was eventually configured on the Chromolox elements which was within a range recommended in the Delta VFD operation manual. A picture of the wiring on the Chromolox elements is shown in Figure 45. The energy dump system is shown on the top right side of the schematic in Figure 21. A picture of the entire set-up is shown below in Figure 46.

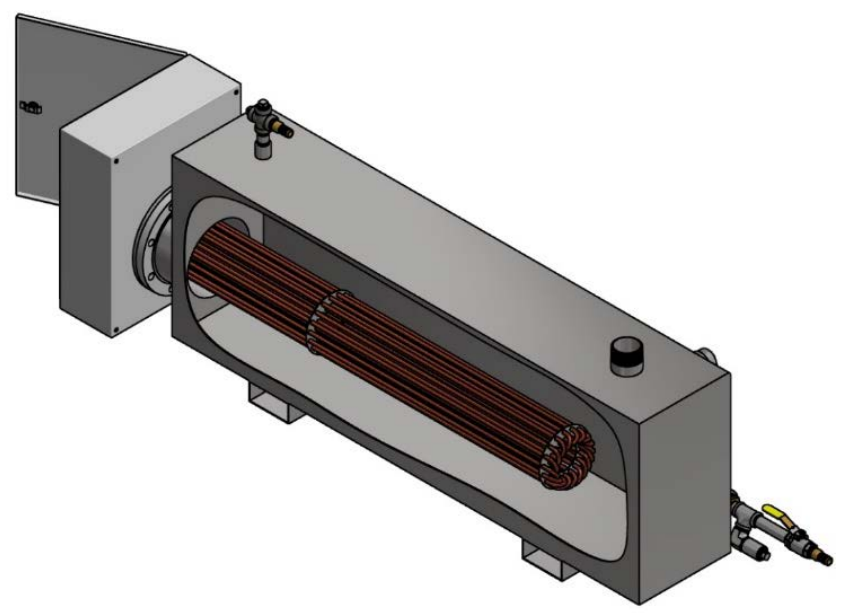

Figure 44: Illustration of a cutaway view of the Chromolox Immersion Heater 


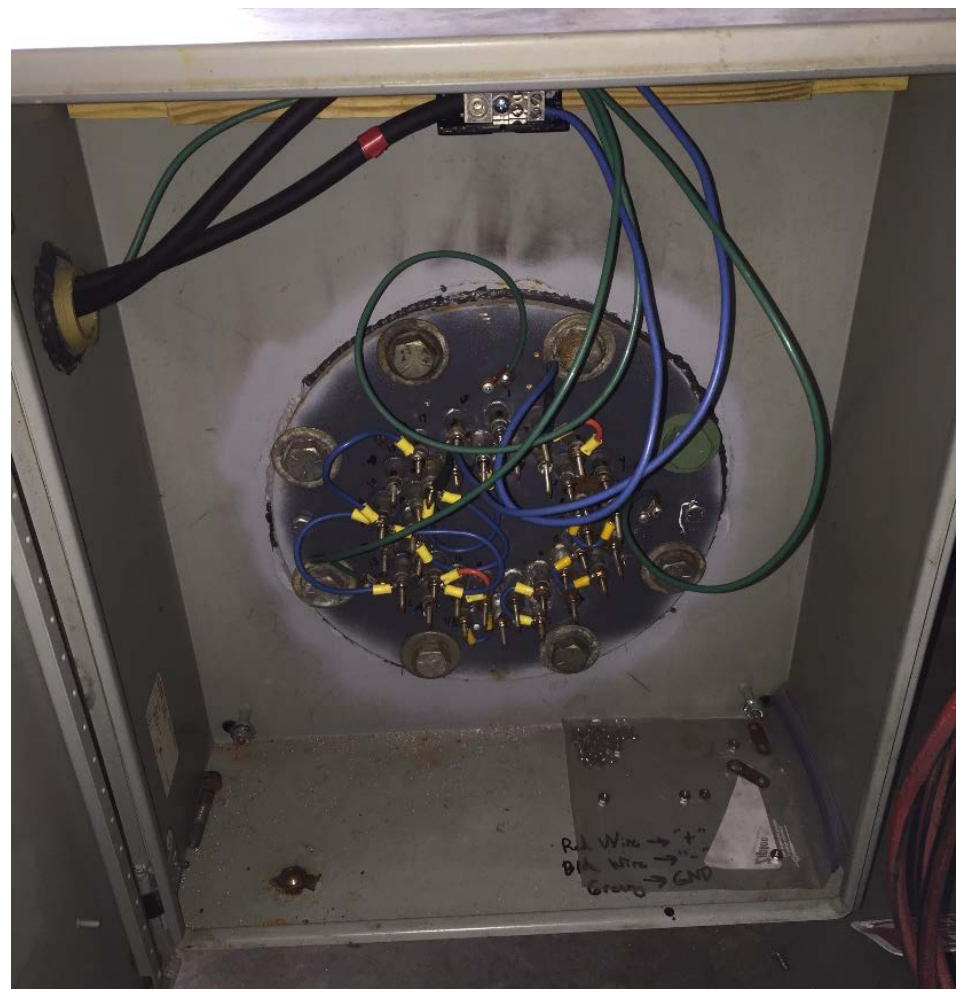

Figure 45: Picture of the wiring of the heating elements

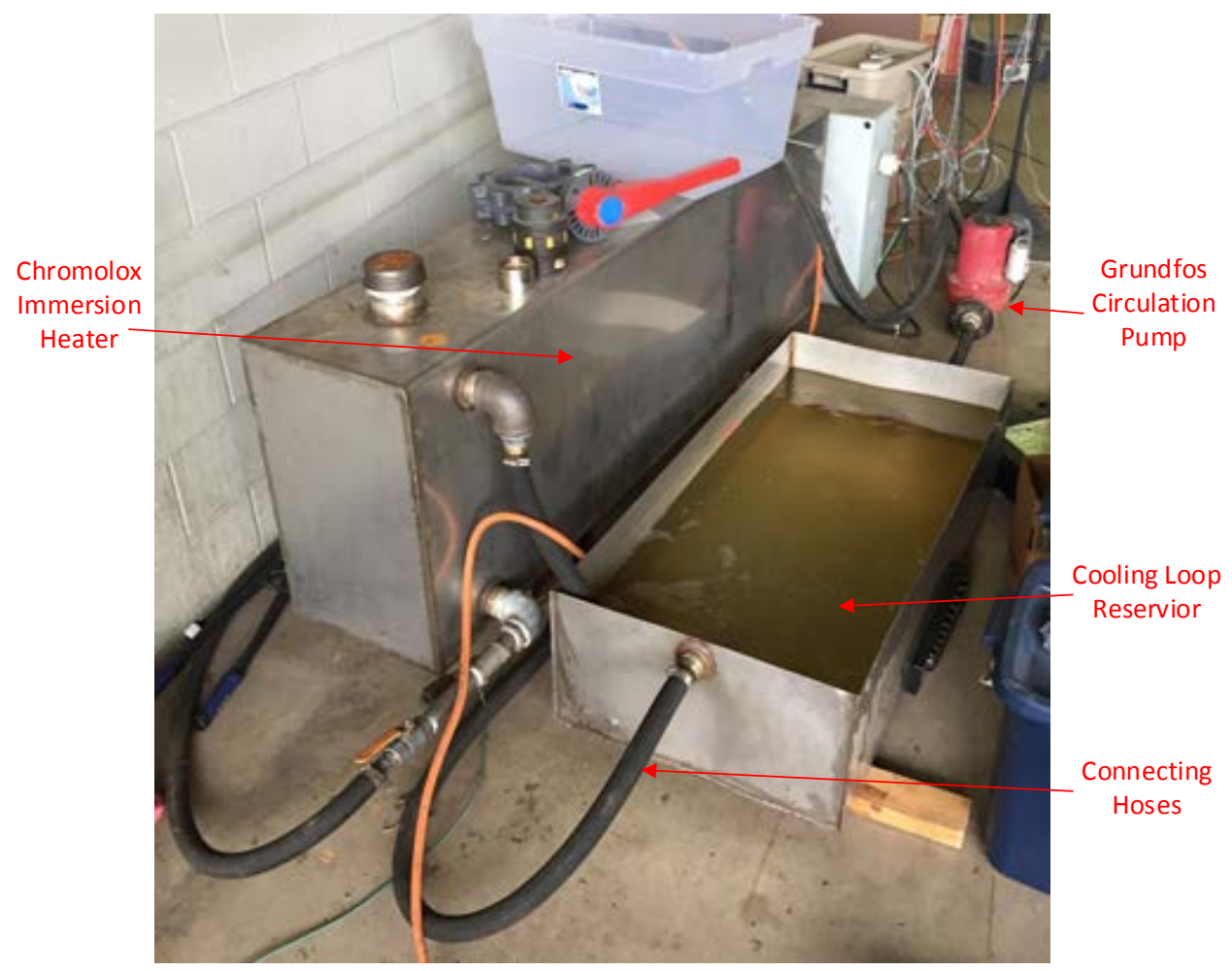

Figure 46: A picture of the energy dump system configuration 


\subsubsection{Data Acquisition (DAQ) Hardware and Software}

All the signals from the different sensors described in this section were routed to an electrical enclosure on the top of the test stand frame. Each signal wire entered the enclosure through rubber knockout plugs installed on the side of the enclosure. This configuration was used to protect the electrical equipment and keep water separated from electricity if an accident occurred. The lid on the enclosure was closed and sealed with a gasket during operation for the same reason. A picture of the enclosure is shown in Figure 47. The enclosure is not shown in the schematic in Figure 21 but it can be assumed that the signal wires from each sensor were routed to the DAQ devices in the enclosure.

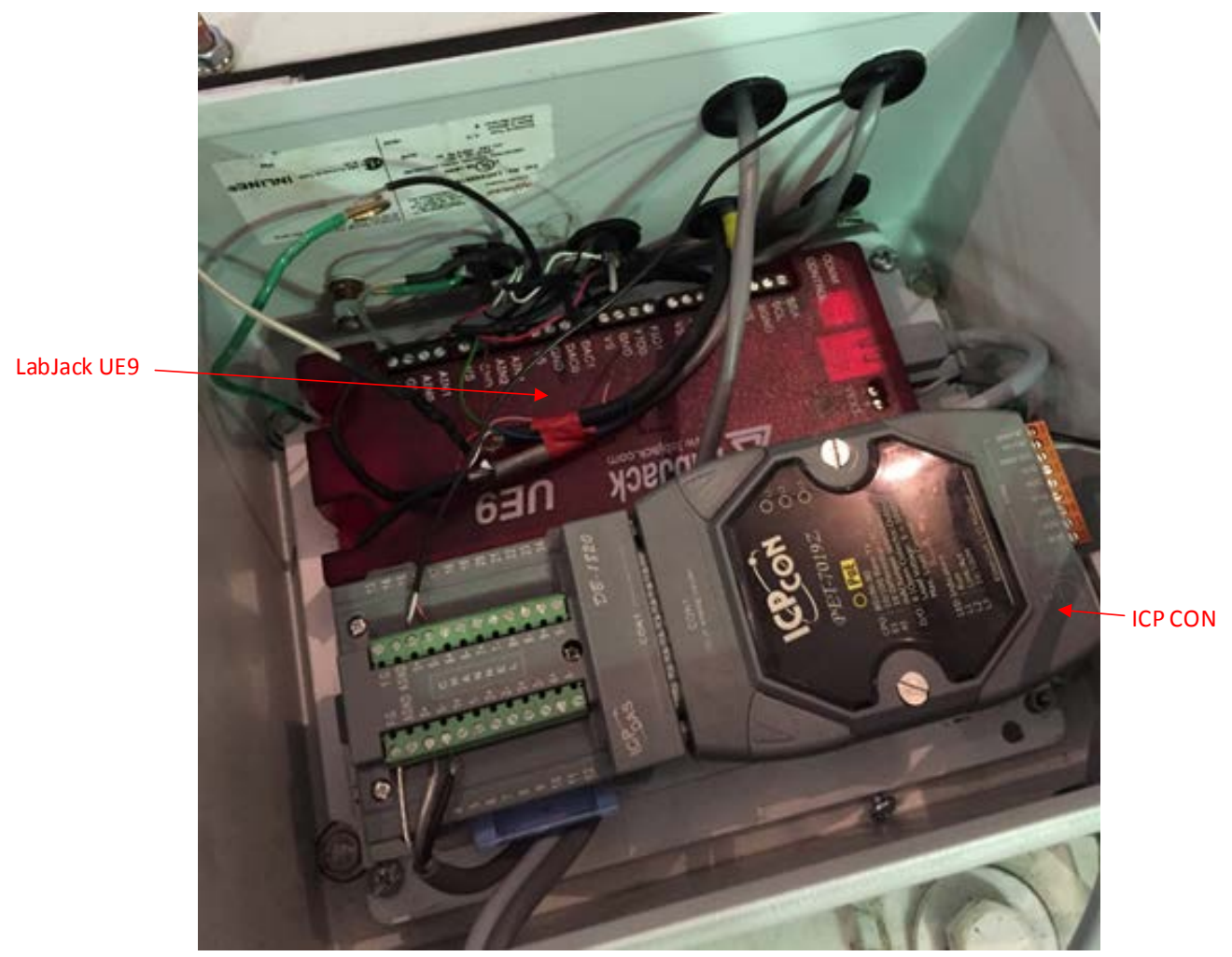

Figure 47: Picture of the Labjack UE9 and ICP CON PET-7019Z DAQ devices in the electrical enclosure on of the test stand

Two DAQ devices were used to collect the measurement signals from each sensor. The first was a Labjack UE9. The Labjack had 14 analog input channels with four of those available 
on external screw terminal connections. These were used to connect the torque meter, and both pressure sensors to the DAQ software. One of the frequency input channels present on the Labjack was used connect the square wave signal of the incremental encoder. Each of the analog channels had an input range of $\pm 5 \mathrm{~V}$. The Labjack has 12-bit resolution across each analog channel. The Labjack is the red device shown in Figure 47.

The second device used for data acquisition was an ICP CON-PET7019Z. It had ten analog input channels. Each channel on the ICP CON could be configured to receive different inputs signals. This is why it was used to read the signal from the flow meter and thermocouple. The flow meter output signal was a current output from 4 to $20 \mathrm{~mA}$. An ICP CON channel was configured by repositioning a small jumper on the inside of the device to engage the correct circuit. The software program that helped to set up the device and configure the channels in operation was then used to activate the channel. This software easily accommodated the J-Type thermocouple used to measure the water temperature in the test stand. The ICP CON had 16-bit resolution across each the analog input channels. It was capable of outputting a total of 10 samples per second. Since there were two sensors connected, it output their measurement signals to the DAQ software at a $10 \mathrm{~Hz}$ sampling rate for each sensor. This sampling rate was accepted because all measurements were viewed as steady-state in the experiment and were averaged over the time interval they were recorded in. The Labjack samples data from the input signals at a much faster rate. A summary of the sensors and their connection to the data acquisition system is shown in Table 4. 
Table 4: Summary of DAQ hardware

\begin{tabular}{|c|c|c|c|c|c|c|}
\hline Sensor & $\begin{array}{c}\text { DAQ } \\
\text { Device }\end{array}$ & Channel & $\begin{array}{c}\text { Output } \\
\text { Range }\end{array}$ & $\begin{array}{c}\text { Measurement } \\
\text { Resolution }\end{array}$ & $\begin{array}{c}\text { Sampling } \\
\text { Rate }\end{array}$ & Uncertainty \\
\hline $\begin{array}{c}\text { Pressure } \\
\text { Transducers }\end{array}$ & $\begin{array}{c}\text { Labjack } \\
\text { UE9 }\end{array}$ & $\begin{array}{c}\text { Analog } \\
0,1\end{array}$ & $0-5 \mathrm{~V}$ & $0.0732 \mathrm{PSI} / \mathrm{Bit}$ & $10 \mathrm{~Hz}$ & $0.1 \%$ \\
\hline Torque Meter & $\begin{array}{c}\text { Labjack } \\
\text { UE9 }\end{array}$ & Analog 2 & $\pm 5 \mathrm{~V}$ & $0.179 \mathrm{ft} . \mathrm{lbs} . / \mathrm{Bit}$ & $10 \mathrm{~Hz}$ & $0.255 \%$ \\
\hline Encoder & $\begin{array}{c}\text { Labjack } \\
\text { UE9 }\end{array}$ & $\begin{array}{c}\text { Frequency } \\
0\end{array}$ & PPR & $1024 \mathrm{PPR}$ & $\begin{array}{c}\text { Pulses } \\
\text { Counted }\end{array}$ & $\begin{array}{c}0.4 \% \text { at } \\
150 \mathrm{RPM}\end{array}$ \\
\hline Flow Meter & $\begin{array}{c}\text { ICP } \\
\text { CON }\end{array}$ & Analog 0 & $\begin{array}{c}4-20 \\
\mathrm{~mA}\end{array}$ & $0.0187 \mathrm{GPM} / \mathrm{Bit}$ & $5 \mathrm{~Hz}$ & $\begin{array}{c}0.4 \% \\
\text { Reading }\end{array}$ \\
\hline Thermocouple & $\begin{array}{c}\text { ICP } \\
\text { CON }\end{array}$ & Analog 5 & $\mathrm{mV}$ & $53 \mu \mathrm{V} /{ }^{\circ} \mathrm{C}$ & $5 \mathrm{~Hz}$ & $\begin{array}{c}0.75 \% \text { or } \\
2.2^{\circ} \mathrm{C}\end{array}$ \\
\hline
\end{tabular}

The DAQ hardware was mounted on the test stand frame so that each signal wire could be as short as possible to reduce noise in each signal. Ethernet cables connected each DAQ device to a network switch. The network switch was connected to a laptop computer that the operator used to control the experiment. The measurements from each device were then displayed and recorded in the DAQ software.

The DAQ software used was Scimitar [53], developed at West Virginia University’s Center for Alternative Fuels, Engines, and Emissions (CAFEE). It was originally designed for emissions testing and contains over 50,000 lines of code. Scimitar samples the incoming signals at $10 \mathrm{~Hz}$. It was also preprogrammed to work with the ICP CON and Labjack devices used for recording data in this project. Before recording data during an experiment, a "parameter tree” had to be created. This was basically a list of each variable in the data reduction routine for the experiment. It contained measured values as well as calculated values. Block diagrams shown in Appendix E illustrate the different parameters used in Scimitar to obtain the experimental data.

All calculations that used physical measurements from the sensors were calculated during the experiment at the same $10 \mathrm{~Hz}$ sampling rate used in Scimitar sampled at. At this rate, a data 
recording that was twenty seconds long would contained 200 values for each parameter. All measured and calculated values were displayed on a computer screen during the test for monitoring. A picture of the signals being displayed is shown in Figure 48.

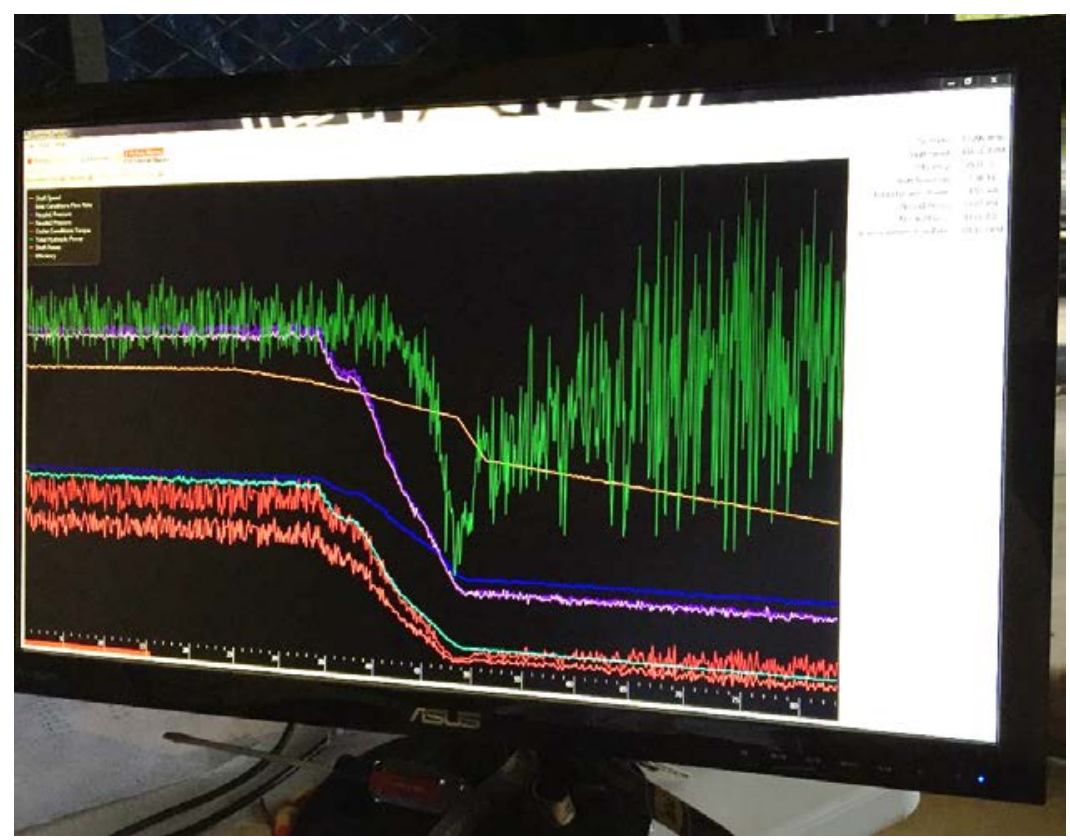

Figure 48: Data being recorded in Scimitar during an experiment

Each recording of data was saved as a “.tz” file. Each file was then loaded into MATLAB ${ }^{\circledR}$ for processing. Several MATLAB ${ }^{\circledR}$ scripts were created that collected and averaged the data, performed uncertainty calculations, and produced plots of the results. 


\section{Results and Discussion}

This section will present the results obtained during the experiment for both impellers. Portions of the performance data are presented below in the form of three dimensional plots to show the relationship between certain variables as the experimental conditions were varied. Each of these plots were oriented to present the best view of the surface created from the data.

\subsection{Vibration}

Vibration measurements were taken during each test to evaluate the balance of the rotating components in the test setup. The vibration data shown in Table 5, Table 6, and Table 7 represent the final tests completed with each impeller attached and without an impeller installed. In each table, peak acceleration $\left(a_{\text {vibration }}\right)$ and velocity $\left(v_{\text {vibration }}\right)$ represent the maximum peak acceleration and velocity of test stand vibration measured using the handheld vibration meter. Displacement $\left(d_{\text {vibration }}\right)$ and vibration frequency $\left(f_{\text {vibration }}\right)$ are calculated values obtained from Equations 12 and 13. The displacement and vibration frequency were used to assess the vibration condition using the general machine vibration severity chart from IRD Mechanalysis, Inc. shown in Appendix A. The vibration condition is shown in the last column of each table.

The vibration measurements varied from day to day due to adjustments made to the test stand. Each vibration test was conducted with the components rotating in the test stand without water circulating through the system. Each test was only conducted until the test stand reached a vibration condition characterized as "rough" or "slightly rough" on the general machinery vibration severity chart. This accounts for why each of the following tables have different numbers of data points. 
Table 5: Data describing the vibration condition for the test stand with impeller $A$ installed

\begin{tabular}{|c|c|c|c|c|c|}
\hline $\begin{array}{c}\text { Shaft } \\
\text { Speed }\end{array}$ & $\begin{array}{c}\text { Peak } \\
\text { Acceleration }\end{array}$ & $\begin{array}{c}\text { Peak } \\
\text { Velocity }\end{array}$ & Displacement & $\begin{array}{c}\text { Vibration } \\
\text { Frequency }\end{array}$ & $\begin{array}{c}\text { Vibration } \\
\text { Condition }\end{array}$ \\
\hline$(\mathrm{RPM})$ & $\left(\mathrm{m} / \mathrm{s}^{2}\right)$ & $(\mathrm{mm} / \mathrm{s})$ & $(\mathrm{mils})$ & $(\mathrm{CPM})$ & - \\
\hline 450 & 0.2 & 0.3 & 0.0354 & 6371 & Very Smooth \\
\hline 750 & 0.5 & 1.1 & 0.1904 & 4344 & Good \\
\hline 1050 & 1.1 & 2.2 & 0.3462 & 4779 & Fair \\
\hline 1350 & 1.3 & 6.4 & 2.479 & 1941 & Slightly Rough \\
\hline 1500 & 2.2 & 6.1 & 1.331 & 3447 & Slightly Rough \\
\hline
\end{tabular}

Table 6: Data describing the vibration condition for the test stand with impeller B installed

\begin{tabular}{|c|c|c|c|c|c|}
\hline $\begin{array}{c}\text { Shaft } \\
\text { Speed }\end{array}$ & $\begin{array}{c}\text { Peak } \\
\text { Acceleration }\end{array}$ & $\begin{array}{c}\text { Peak } \\
\text { Velocity }\end{array}$ & Displacement & $\begin{array}{c}\text { Vibration } \\
\text { Frequency }\end{array}$ & $\begin{array}{c}\text { Vibration } \\
\text { Condition }\end{array}$ \\
\hline$(\mathrm{RPM})$ & $\left(\mathrm{m} / \mathrm{s}^{2}\right)$ & $(\mathrm{mm} / \mathrm{s})$ & $(\mathrm{mils})$ & $(\mathrm{CPM})$ & - \\
\hline 450 & 0.1 & 0.6 & 0.2832 & 1593 & Smooth \\
\hline 750 & 0.6 & 2.5 & 0.8196 & 2294 & Fair \\
\hline 1050 & 1 & 3.2 & 0.8057 & 2987 & Fair \\
\hline 1200 & 3.4 & 25.4 & 14.93 & 1279 & Rough \\
\hline
\end{tabular}

Table 7: Data describing the vibration condition for the test stand with no impeller installed

\begin{tabular}{|c|c|c|c|c|c|}
\hline $\begin{array}{c}\text { Shaft } \\
\text { Speed }\end{array}$ & $\begin{array}{c}\text { Peak } \\
\text { Acceleration }\end{array}$ & $\begin{array}{c}\text { Peak } \\
\text { Velocity }\end{array}$ & Displacement & $\begin{array}{c}\text { Vibration } \\
\text { Frequency }\end{array}$ & $\begin{array}{c}\text { Vibration } \\
\text { Condition }\end{array}$ \\
\hline$(\mathrm{RPM})$ & $\left(\mathrm{m} / \mathrm{s}^{2}\right)$ & $(\mathrm{mm} / \mathrm{s})$ & $(\mathrm{mils})$ & $(\mathrm{CPM})$ & - \\
\hline 450 & 0.4 & 0.6 & 0.0708 & 6371 & Very Good \\
\hline 750 & 1.1 & 1.6 & 0.1381 & 6570 & Good \\
\hline 1050 & 2.4 & 3.8 & 0.4734 & 6036 & Fair \\
\hline 1350 & 2.6 & 3.4 & 0.3498 & 7308 & Fair \\
\hline 1650 & 2.2 & 3.2 & 0.3662 & 6571 & Fair \\
\hline 1800 & 2.8 & 5 & 0.7025 & 5352 & Slightly Rough \\
\hline 1950 & 4.1 & 16 & 4.913 & 2449 & Rough \\
\hline
\end{tabular}

As seen in Table 7, that with no impeller attached, the rotating components of the test stand, excluding an impeller, did not create rough vibration until rotational speeds of 1800 RPM were reached. Rough vibration was induced by Impeller A at 1350 to 1500 RPM and by impeller B at 1200 RPM and above. It was suspected that impeller B created increased vibration at a lower speed when compared to Impeller A because of its larger size and unevenly worn surfaces which caused 
greater imbalance. A good maintenance practice to try to reduce damage from vibration would be to periodically dynamically balance operational impellers as their encounter wear and corrosion. A desired vibration condition in an operating turbine would be "Good" or better. A condition of "fair" or "slightly rough" would indicate that minor issues are present and maintenance is needed at the earliest convenience. A vibration condition of "rough" should be analyzed immediately and the equipment should be shut down for maintenance [54].

\subsection{Coast-Down Experiments}

As previously mentioned, estimating the mechanical losses associated with the rotating components of the test stand and aerodynamic drag on the impeller were the main reasons for conducting the coast-down experiments. The coast down curves also show how the coast down times increased as testing progressed, indicating a slight change in the operational condition in the rotating components of the test stand over time.

\subsubsection{Coast-Down Curves}

Figures 49-52 represent the motor speed decay with respect to time developed from coastdown tests that were performed with impeller $\mathrm{A}$, impeller $\mathrm{B}$, the motor-only and the rotating components of the test stand without an impeller. A coast-down test was performed at the beginning of each day of testing. This process provided a way to check to see if the operational characteristics of the test stand changed from the previous day. 


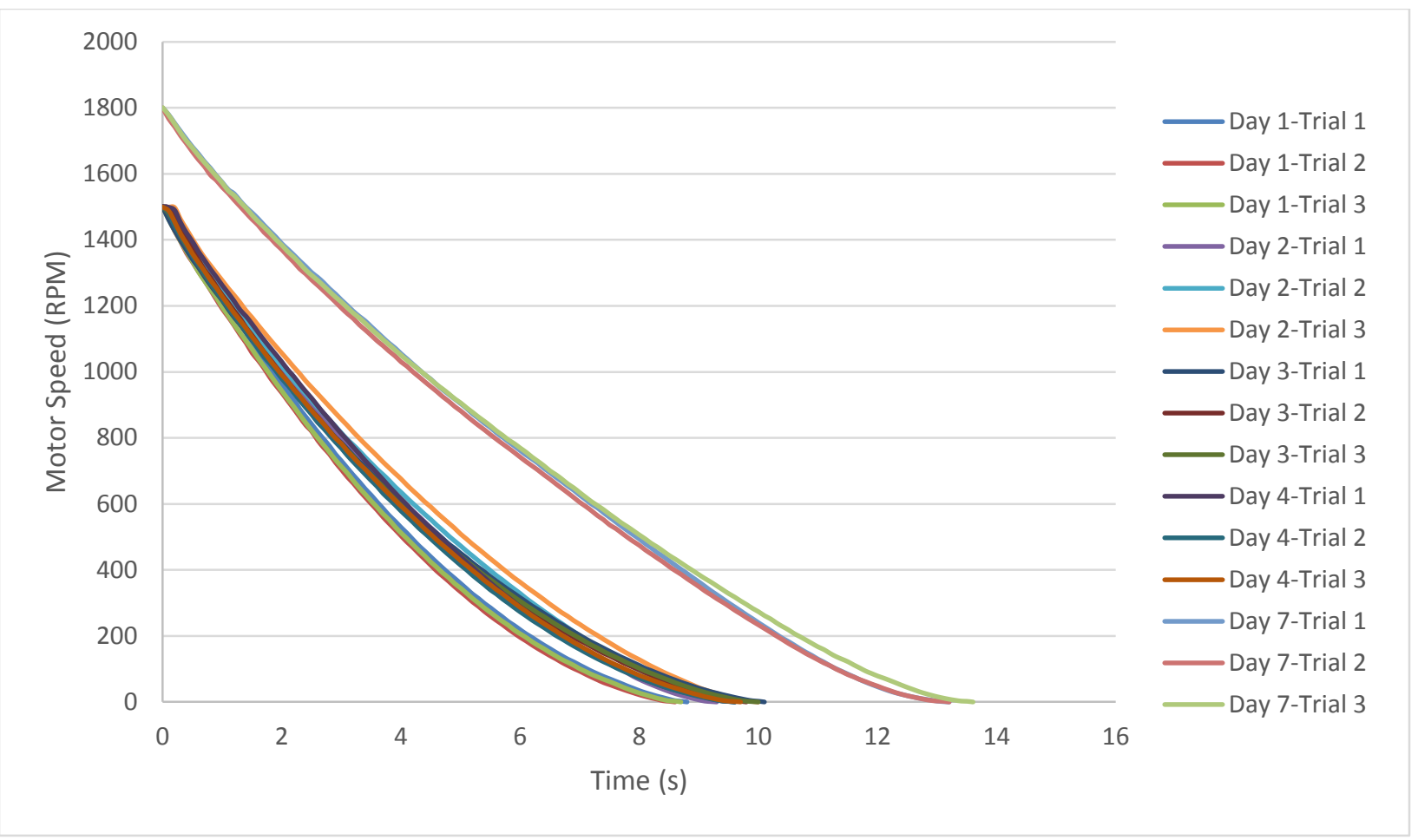

Figure 49: Plot of coast-down curves for tests done with impeller A

As shown in Figure 49, each test was performed with a motor release speed of either 1500 or 1800 RPM for impeller A. The lower speed tests were performed during each day of testing. The higher speed tests were the last to be conducted. The reason for this was to limit operational duration at higher test speeds which produced more severe vibrations as characterized by the IRD chart. Figure 49 indicated the time duration necessary for the rotating components to cease rotating increased from day one through four. This was due to bearings being "worn in” with use and adjustments made to the alignment of the components to reduce friction. The bearings used in the test stand were new and unused when testing began. 


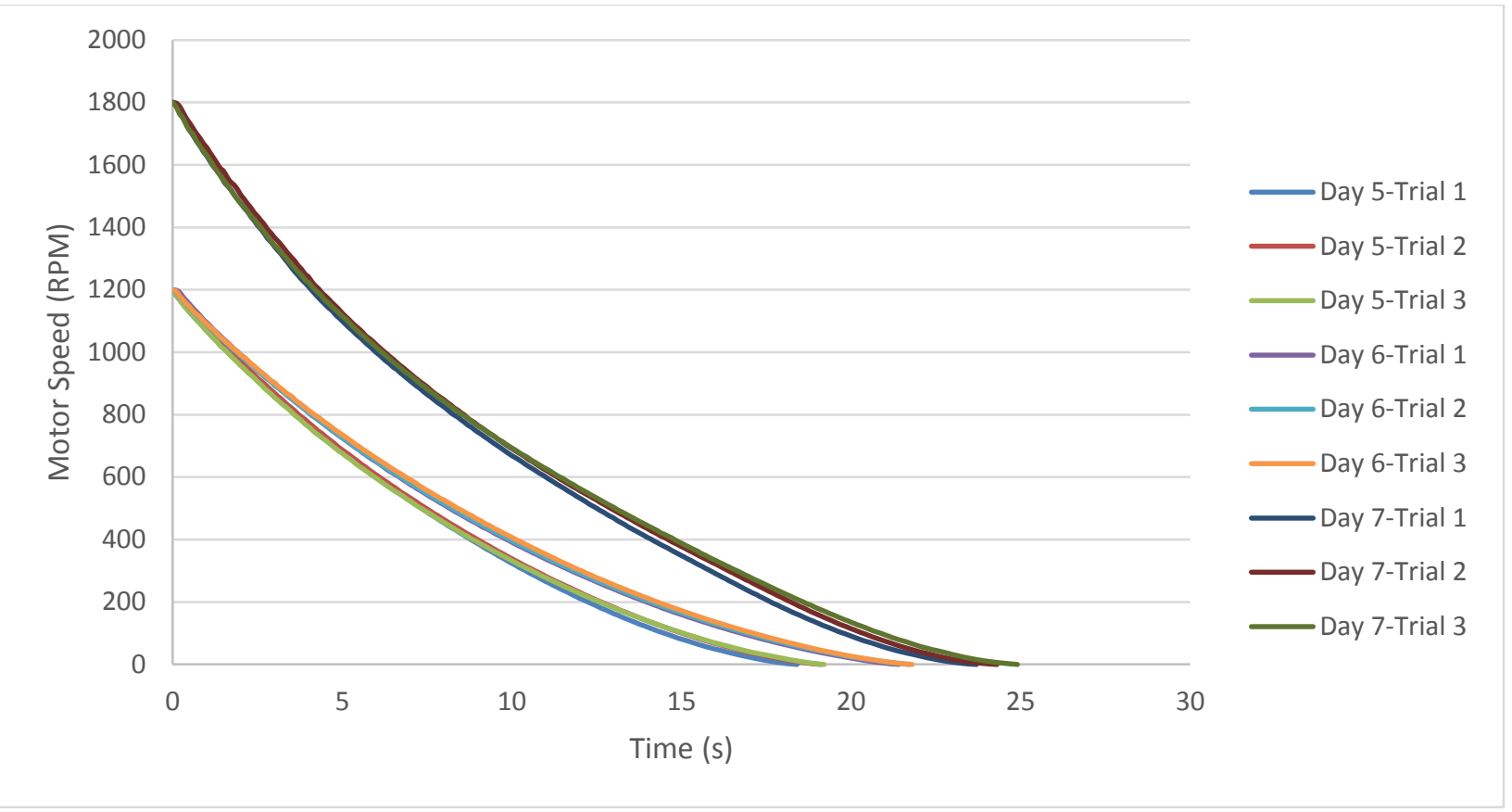

Figure 50: Plot of coast-down curves for tests done with impeller $B$

The coast down curves for impeller B are shown above in Figure 50. The same trend of increasing coast-down time was seen with impeller B installed on days five and six of testing. Impeller B also had significantly longer coast-down times when compared to impeller A due to it having a larger moment of inertia.

Coast-down curves without an impeller installed are shown in Figure 51. This test was performed by releasing the rotating components at 1950 RPM. Results indicate an approximate coast-down time of 9 seconds compared to the approximate times of 13 seconds for impeller A and 25 seconds for impeller B. This can be attributed to the lower moment of inertia of the drive shaft without and impeller connected. 


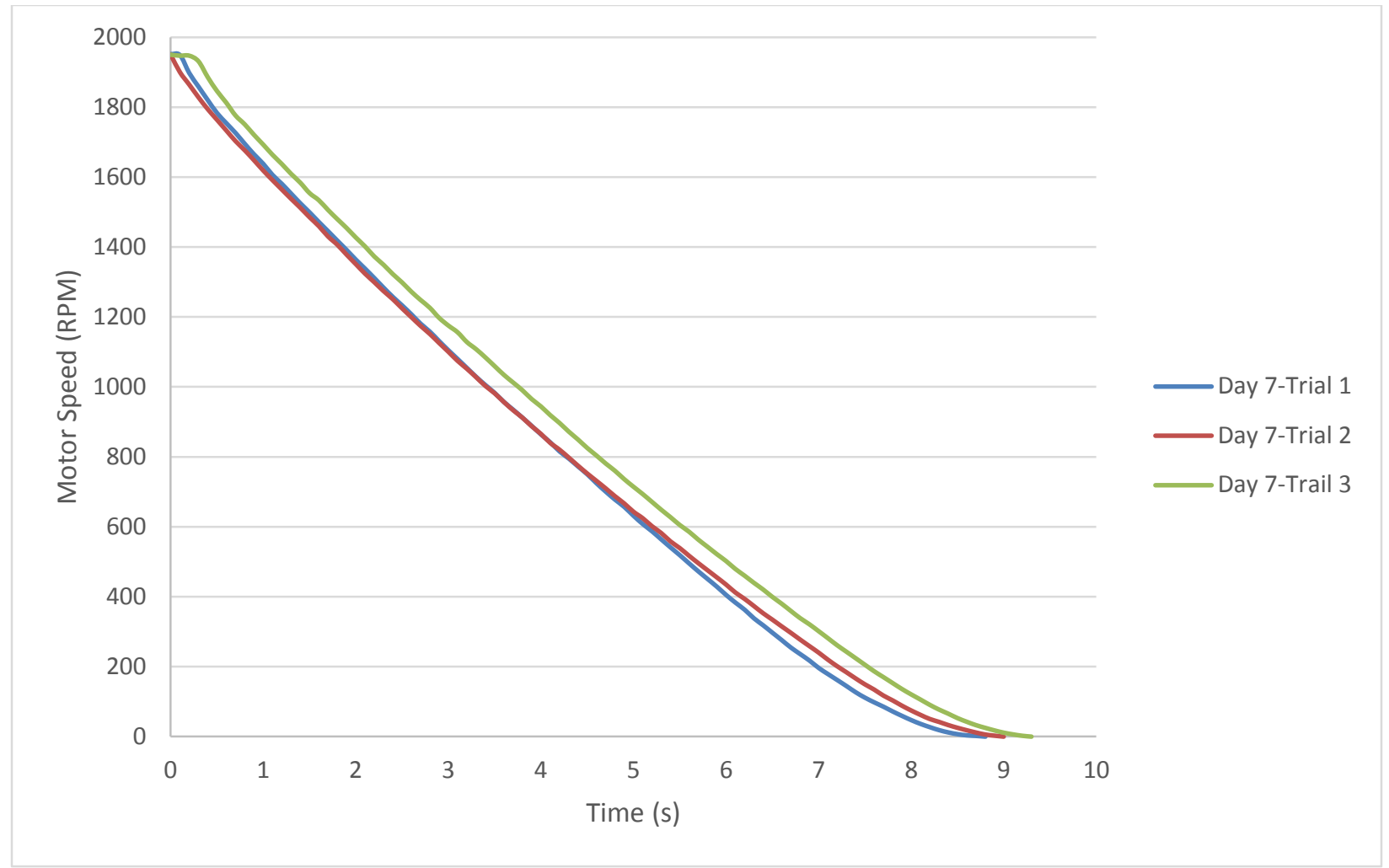

Figure 51: Plot of coast-down curves for tests done without an impeller

The coast-down curves obtained from testing the motor alone are shown in Figure 52. As seen in Figure 52, the motor took between 30 and 35 seconds to cease rotation after being released from a rotational speed of 1800 RPM. From Figures 51 and 52 it can be seen that attaching the driveshaft to the motor caused a decrease in the coast down time of the rotating components of approximately 17 to 26 seconds. This may be due to the introduction of friction from the bearings that support the drive shaft during rotation. 


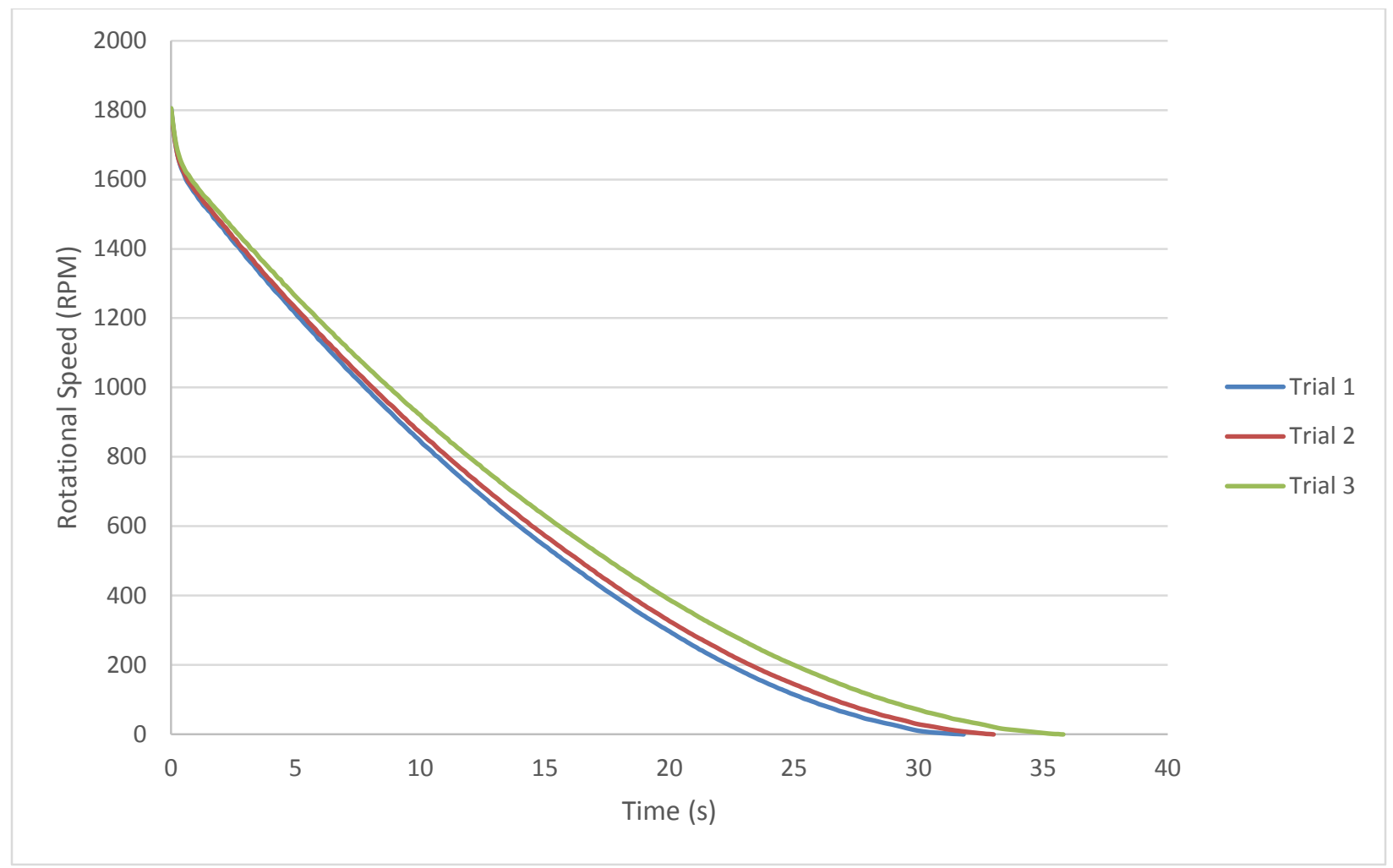

Figure 52: Plot of coast-down curves for tests done with the motor only

\subsubsection{Losses}

An estimation of power losses in the test stand was formed using the method described in Section 3.1.6. A plot of the power losses measured during the coast-down evaluation can be seen in Figure 53. It should be noted that this is not an ideal evaluation of the losses in the test apparatus. The coast-down tests were performed without the water jets active in the test stand. This would affect measurements of aerodynamic drag. In normal operation, water spray around the impeller would cause higher density of the water and air mixture in which the impeller was rotating than that of air alone. With air alone encompassing the impeller during the coast down test, aerodynamic drag across the turbine impeller was reduced. The aerodynamic losses shown from this estimation are smaller than what is across the impellers during normal operation. 
The measurement of the mechanical losses characterizes losses associated with the electric motor and bearings used to support the driveshaft the impellers were mounted to. These losses were found by subtracting the total power losses measured from the motor-only from the losses measured when the motor and drive shaft were connected. This estimation did not take into consideration the vibration conditions and change in loading on the bearings experienced during actual operation with water jets impinging on the impellers. Also, polynomial curve fits were used to calculate a portion of the measured values which influence the accuracy of the estimation.

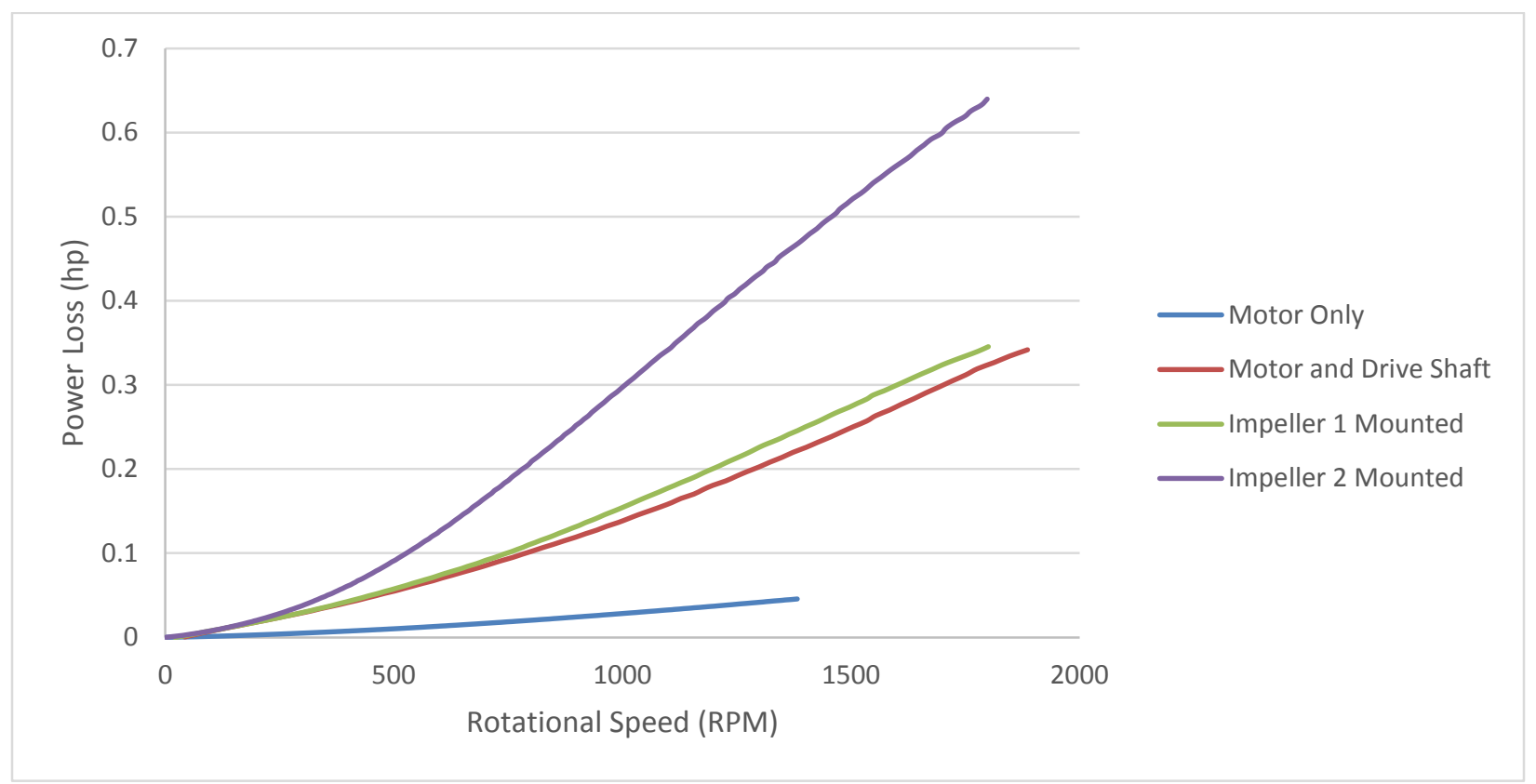

Figure 53: Plot of the losses measured in various configurations of the test stand

The data in Figure 53 indicates that all losses increase with rotational speed with impeller B exhibiting the largest power loss. These results were expected because aerodynamic drag increased with the increased bucket size and increased weight caused increased bearing friction. Impeller A showed slightly higher power losses than the drive shaft attached to the motor. These were significantly less than that of impeller B. The motor alone showed the lowest amount of 
power loss as expected since the motor shaft had very good alignment and very small vibration during operation.

Based on the turbine power output at their peak conditions (occurred near 1650 RPM for both impellers) the losses in the test stand were about $1.1 \%$ of the total output for impeller $\mathrm{A}$ and 2.1\% for impeller B. Thake [6] states the windage and friction losses of a turbine are usually near 1\%. This would suggest that the estimation was reasonable and that impeller A causes less power loss than impeller B.

As mentioned previously, in order to estimate aerodynamic drag and mechanical losses some of the curves were subtracted from each other to try to characterize the windage loss on the impeller and the mechanical losses in the stand components. The results of this process are shown below in Figure 54.

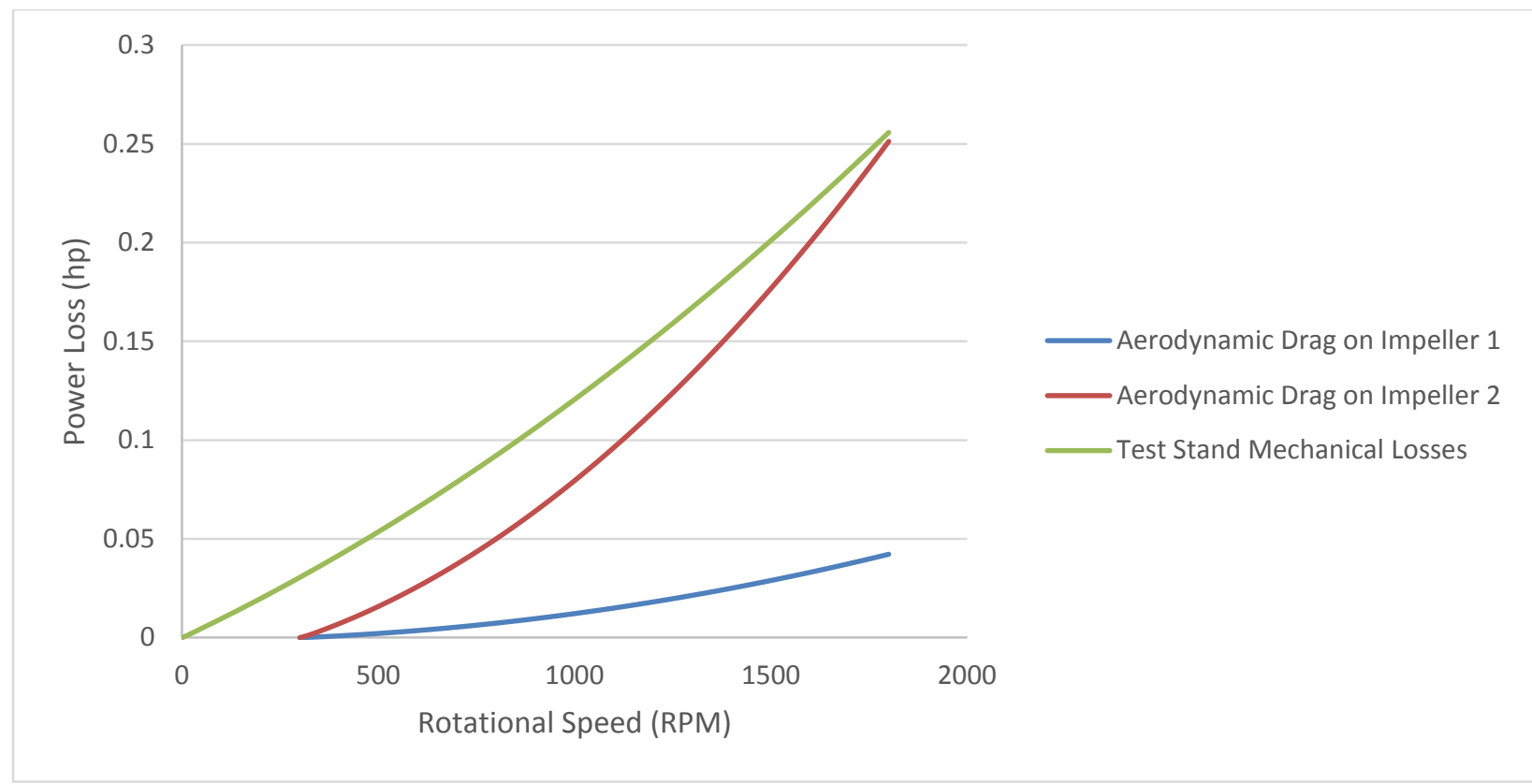

Figure 54: Plot of the estimated losses due to windage and mechanical components

It can be seen from Figure 54 that the test stand mechanical losses were estimated to be larger than the aerodynamic drag at all rotational speeds. The aerodynamic drag on impeller B was 
greater than that of impeller A by an approximate factor of 6 at 1800 RPM. This was due in part to the larger frontal area of the buckets on impeller B and its larger pitch diameter which caused a higher tangential velocity of air on each bucket. The estimated values of drag would represent approximately $0.13 \%$ of the power output from impeller A and $0.77 \%$ for impeller B at the peak output point. Thake [6] suggests values of $0.5 \%$ loss for windage are realistic. The mechanical losses in the test stand were approximately $0.81 \%$ of the peak shaft power produced for both impellers. It should also be noted that the drag on the impellers did reached zero while the impellers were still rotating. However, the curve fitting done to algebraically manipulate the power loss curves interferes with the estimation of the very small numbers by estimating negative drag. Since this was not possible, the point where the drag appeared on the plot was taken as the point at which the shaft speed was fast enough for the drag to cause a significant windage effect.

The percentage of losses varied with the output of the turbine and shaft speed. It can be seen below in Figures 55 and 56 that the losses are more prevalent at low flow and high speed conditions because the power output from the impellers was low with those conditions. As a result, the losses ranged from $0.01-5.2 \%$ for impeller A with the greater percentage coming a low flow and high speed conditions. The losses ranged from $0.05-7.2 \%$ for impeller B with the greater percentages also coming in low flow and high speed conditions. If the system were an actual turbine in operation at the low flow and high speed conditions, it would be important to make every effort to mitigate the losses to ensure that maximum power production is achieved. 


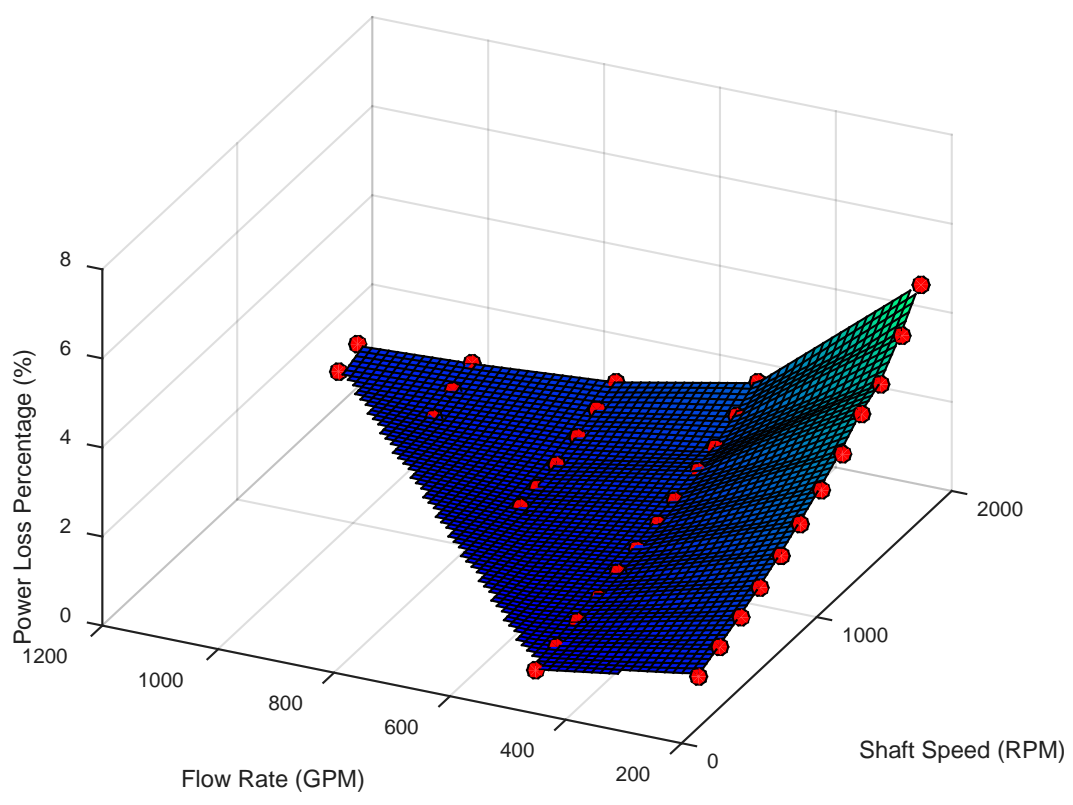

Figure 55: Plot of percentage of the power losses with respect to the shaft power produced by impeller A

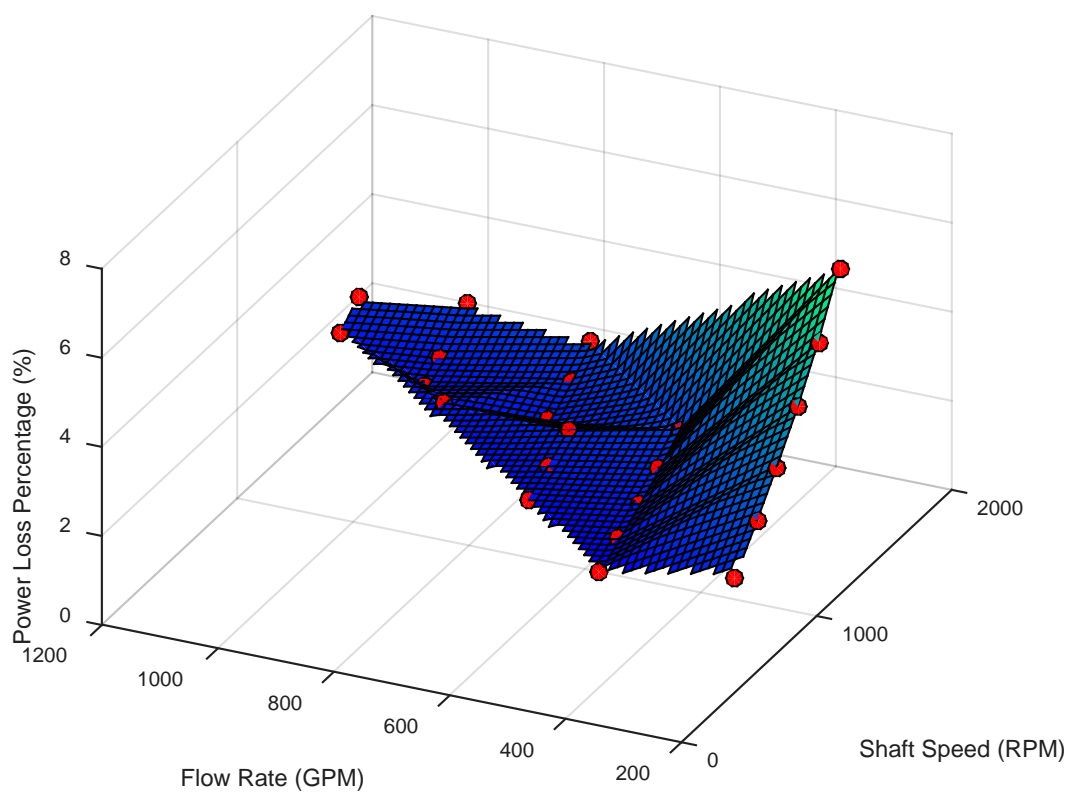

Figure 56: Plot of percentage of the power losses with respect to the shaft power produced by impeller B The estimation of the losses in the test stand and impeller windage allowed for the calculation of an adjusted efficiency value. This represented an estimation of the efficiency of each 
impeller and the water nozzles independent of the test stand components. Graphs of the adjusted efficiency are shown in Section 4.4.1 in Figures 64 and 68.

\subsection{Performance at Different Nozzle Angles}

The first of the performance tests was conducted to show which inlet angle to the turbine would provide the best power output and efficiency. Each test was performed at a flow rate of 750 GPM. For impeller A during this experiment, the maximum efficiency obtained was $79.6 \%$ at an inlet angle of $24^{\circ}$. It can be seen from Figure 57 that all other angles resulted in a lower efficiency. Impeller B displayed the same trend but with a lower maximum efficiency of $72.3 \%$ at an inlet angle of $24^{\circ}$ in this experiment. The results for impeller B are shown in Figure 59. The drop in efficiency at shallow angles could be attributed to larger amounts of water being deflected away from the impellers before traveling downward across the bucket surface. It should be noted that nozzle angle tests for impeller B were performed at a net head of $140 \mathrm{ft}$. of water instead of the

desired $160 \mathrm{ft}$. This was done because the impeller B tests were performed first during the experiment and the net head was lowered on this test to ensure safe operation of the test stand. The tests could not be repeated at the desired head within the allowable time frame of the experiment. Figures 58 and 60 show the shaft power produced by each impeller during these tests. 


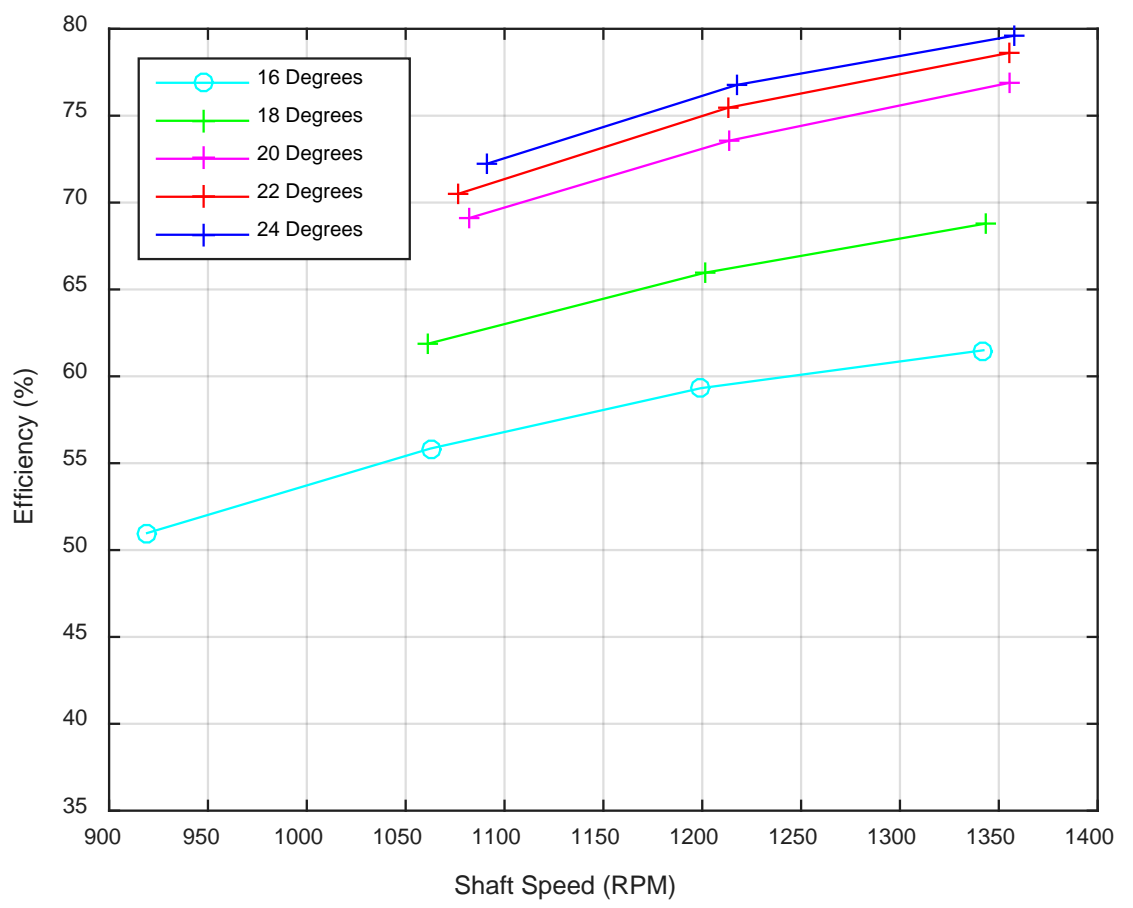

Figure 57: Plot of the efficiency of impeller $A$ at different nozzle angles

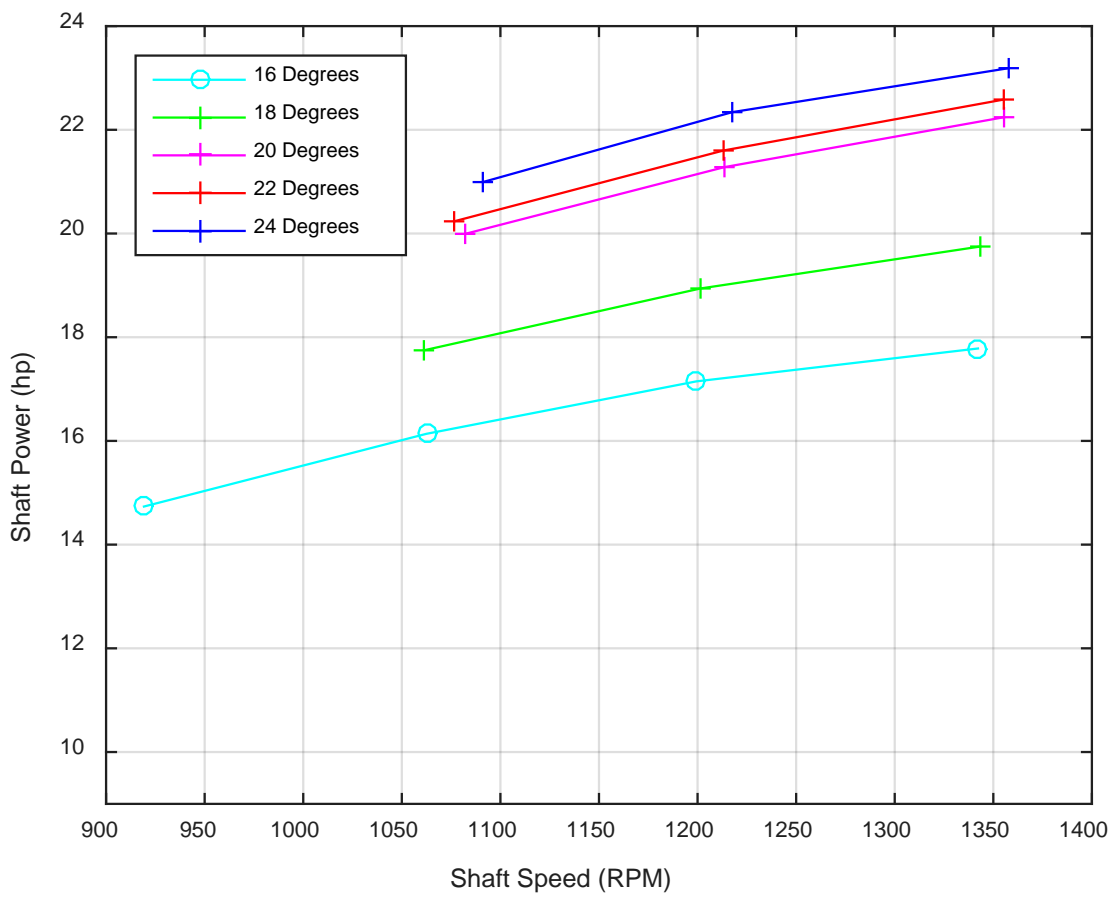

Figure 58: Plot of the shaft power produced by impeller $A$ at different nozzle angles 


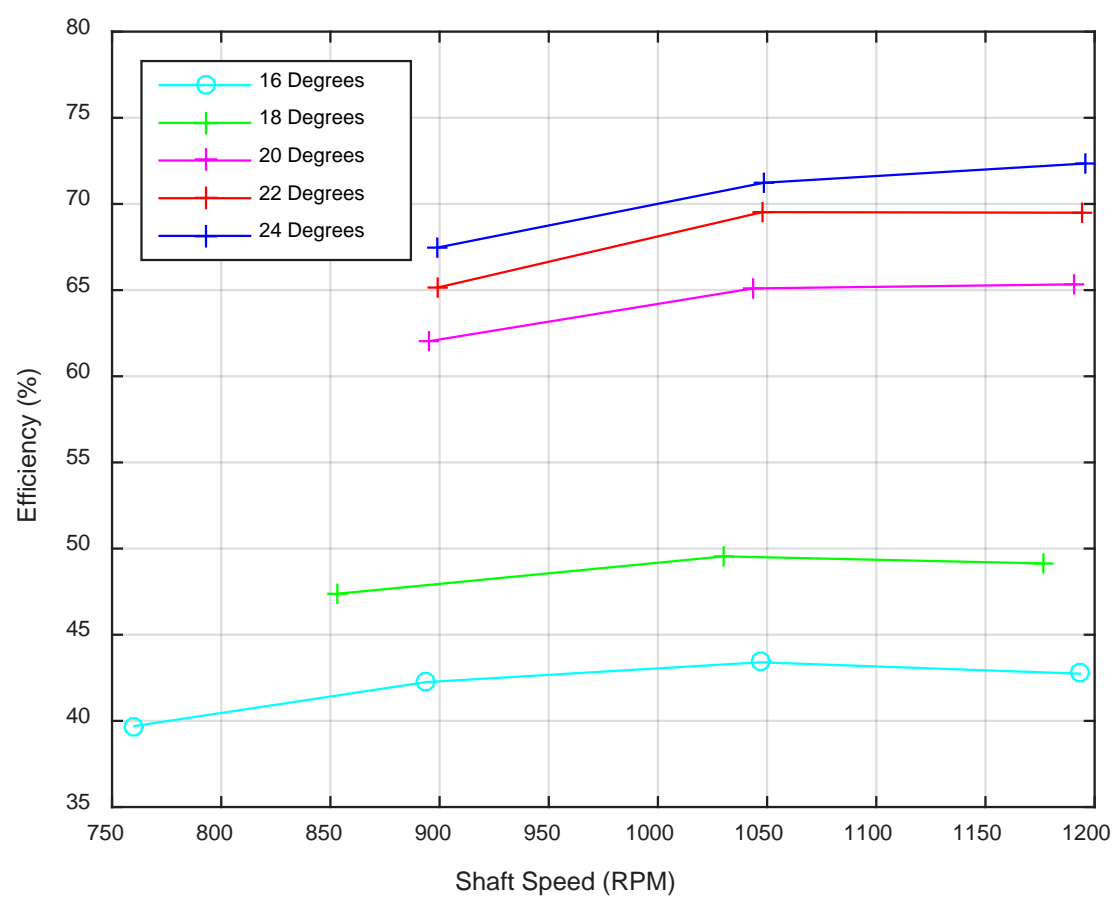

Figure 59: Plot of the efficiency of impeller $B$ at different nozzle angles

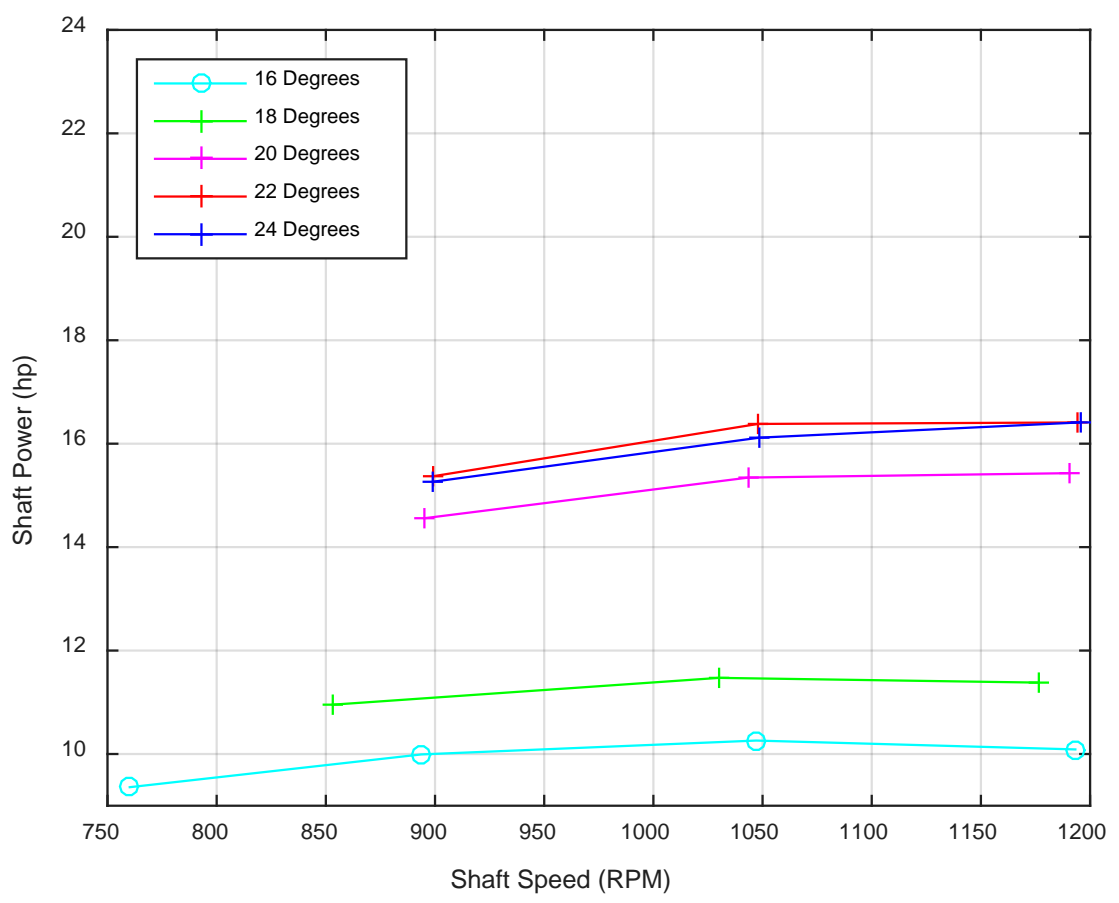

Figure 60: Plot of the shaft power produced by impeller $B$ at different nozzle angles 
It should be noted that the $24^{\circ}$ was the steepest nozzle angle able to be tested in the test stand. However, the trends shown in Figures 57 and 59 suggest that if the nozzle angle were made steeper that the efficiency would increase further. However, literature suggests that a plateau would eventually be reached and the efficiency would no longer increase with a steeper nozzle angle.

A plot of the uncertainty for the calculation of the efficiency is shown in Figures 61 and 62. The uncertainty was calculated using a 95\% confidence interval. The maximum efficiency uncertainty seen for the nozzle angle tests was $4.3 \%$ which occurred in the test at $16^{\circ}$ for impeller B. The uncertainty was higher at smaller angles due to the lower torque produced by each impeller at those angles. This brought the torque measurement much closer to the resolution of the sensor causing bias uncertainty to increase.

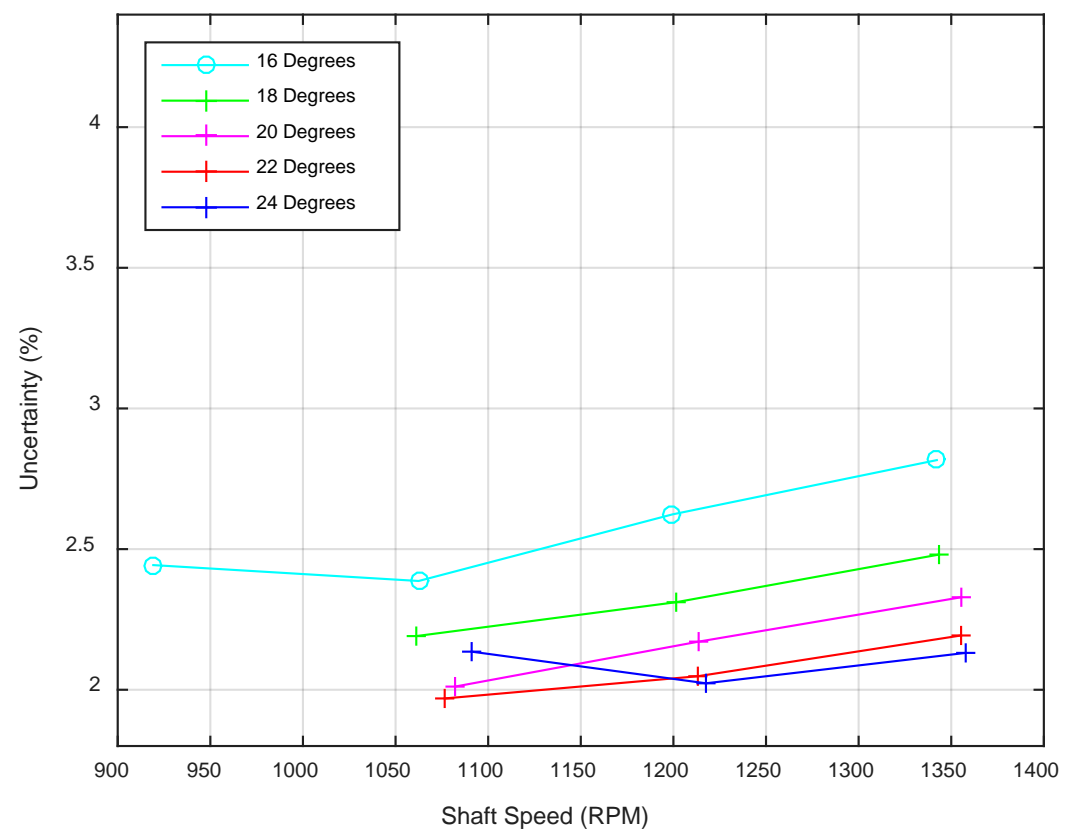

Figure 61: Plot of the uncertainty of the efficiency during nozzle angle tests on impeller A 


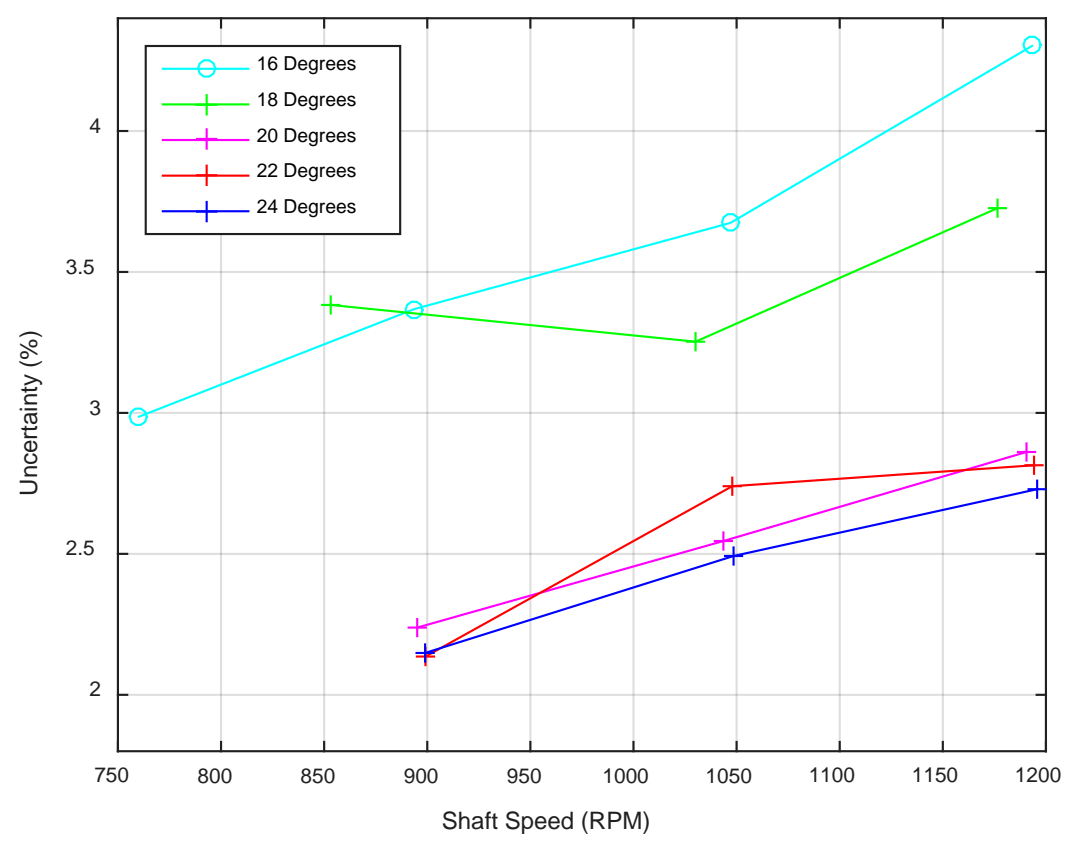

Figure 62: Plot of the uncertainty of the efficiency during nozzle angle tests on impeller B

\subsection{Performance at Varying Flow Rates and Motor Speeds}

Based on the results of the performance tests at different angles, performance tests at varying flow rates and rotational speeds were performed at a nozzle angle of $24^{\circ}$ for both impellers. It should be noted that on each three dimensional contour plot red dots indicate test points on the surface. The red dots arranged in rows parallel to the axis labeled as shaft speed would represent a line of constant flow rate if they were connected. They are near the values of the flow rates outlined in the test matrix outlined in Section 3.1.7 which are 250, 500, 750, 1000, and 1200 GPM. The same concept applies to lines of constant shaft speed for the rows of dots parallel to the flow rate axis. 


\subsubsection{Impeller A Performance Results}

\subsubsection{Measured Efficiency for Impeller A}

It should be kept in mind that the measured efficiency represents the performance of the impellers, water nozzles, and includes power losses from the test stand and aerodynamic drag on the impeller. Figure 63 shows a plot of the measured efficiency for impeller A.

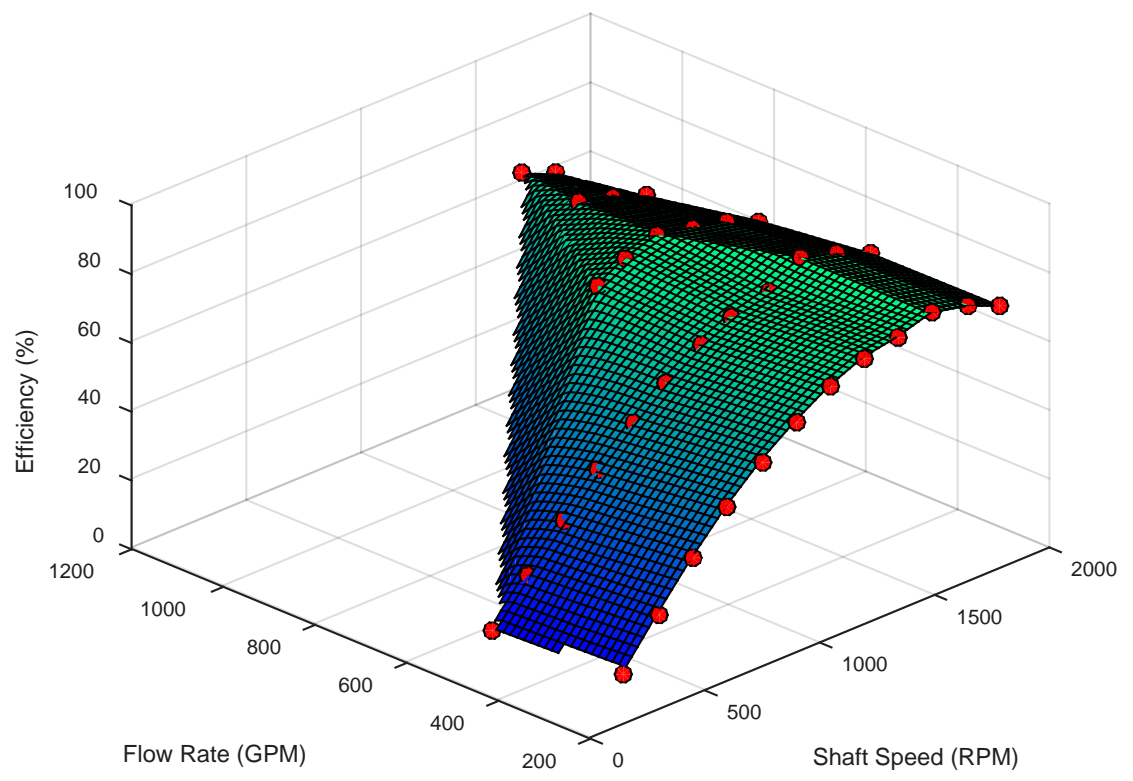

Figure 63: Plot of the efficiency map for impeller $\mathrm{A}$

In Figure 63, the maximum efficiency obtained was $81.8 \%$ from impeller A. This occurred at a motor speed of approximately 1500 RPM and a flow rate of 491 GPM. Looking at the contour of the plot, the efficiency increases rapidly from lower shaft speeds until it reaches 1300 to 1500 RPM. This can be attributed to the speed ratios associated with each water jet reaching the recommended range of $0.45-0.47$ in the range of rotational speeds of the impeller.

\subsubsection{Adjusted Efficiency for Impeller A}

The plots of the adjusted efficiency were created by adding the estimated power loses due to the rotating components in the test apparatus and aerodynamic drag on the impeller to the original power output measured from the impeller to form a new calculation of the efficiency of 
each impeller. The goal of this calculation was separate the impellers from power loss effects caused by the test apparatus components. This would allow for comparison of the adjusted efficiency measurements to others taken on other turbine impellers that have a different design configuration than the test stand used in this project. A plot of the efficiency adjusted to account for the effects of losses for impeller A is shown in Figure 64.

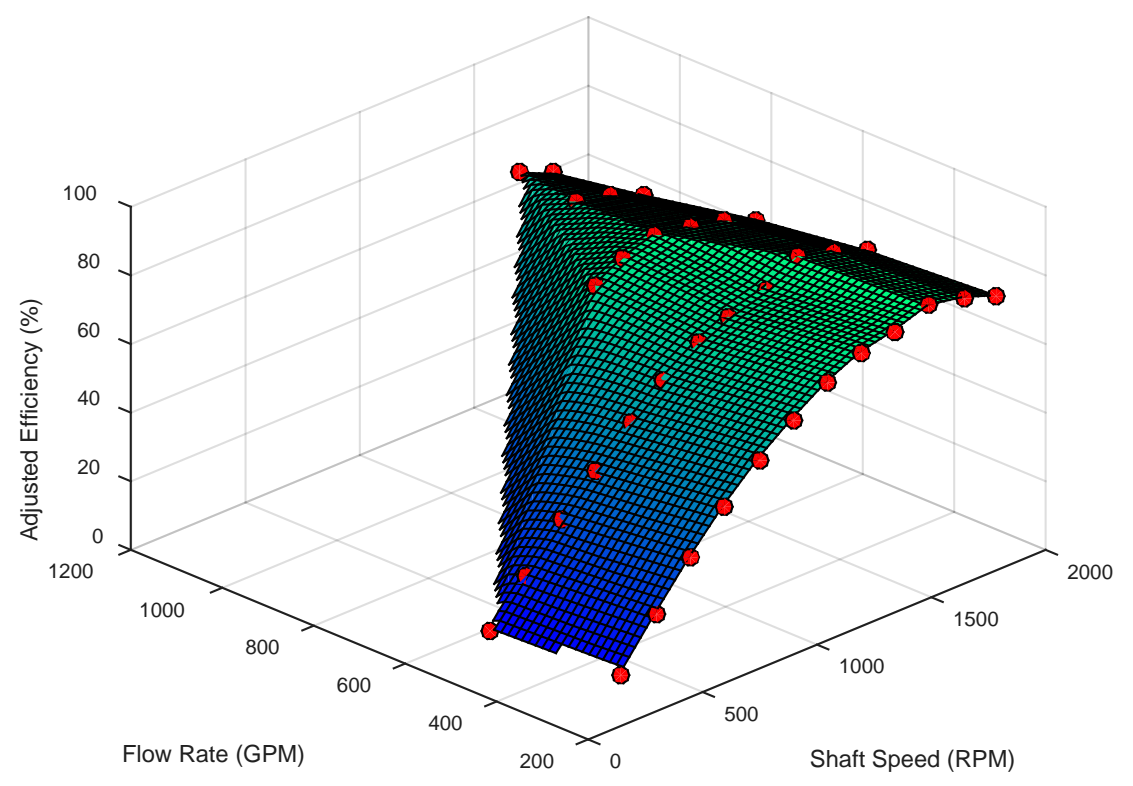

Figure 64: Plot of the efficiency of impeller $A$ adjusted for power losses

The peak efficiency for impeller A was increased from $81.8 \%$ to $84.6 \%$ when the power losses of the test stand components were added to the original measured power output. Both Figures 63 and 64 have similar shape and trends. When looking at the y-axis representing flow rate, the efficiency does not show a decreasing trend until after it passes the 750 GPM flow rate. This can be attributed to the nozzle diameter of the largest two nozzles becoming larger than the width of the buckets on impeller A. When this occurred, the water jet hit the outer edges of the bucket which did not redirect the jet as efficiently as the uniformly curved surface in the middle of the bucket. Also at the higher flow rates, there was a higher occurrence of a portion of the water 
jet being deflected away from the impeller or completely missing it because of increased spray in the casing and increased deflection on non-bucket surfaces.

\subsubsection{Speed Ratios for Impeller A}

As mentioned in Section 4.4.1.1, the optimum speed ratio was reached at rotational speeds between 1300 and 1500 RPM. A plot of the estimated speed ratio for impeller A is shown for each nozzle in Figures 65 and 66.

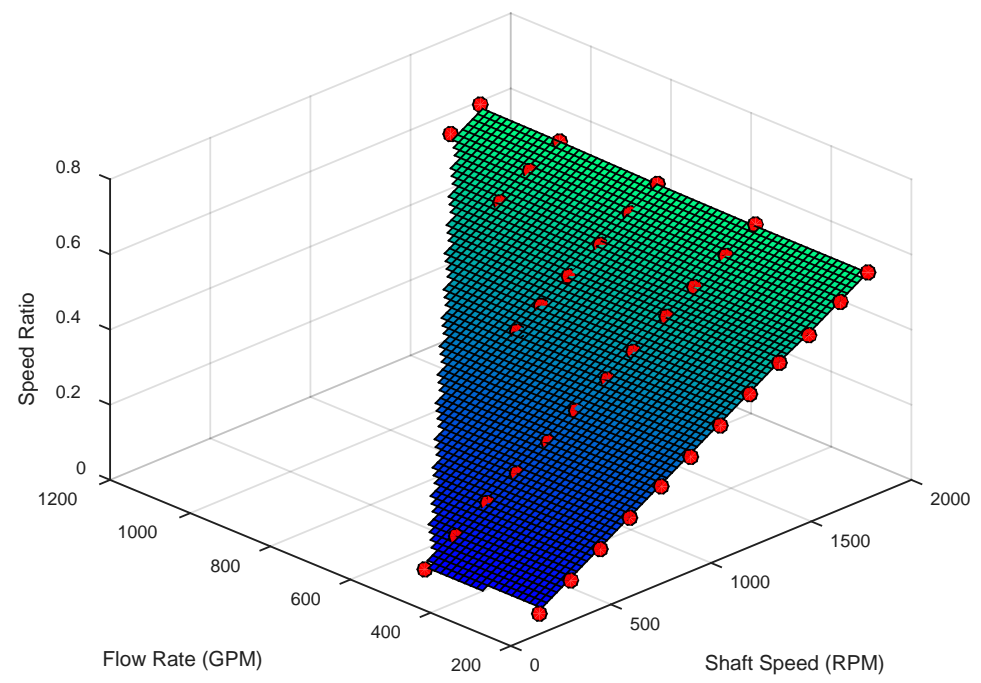

Figure 65: Plot of the speed ratio for the nozzle 1 jet during impeller A tests

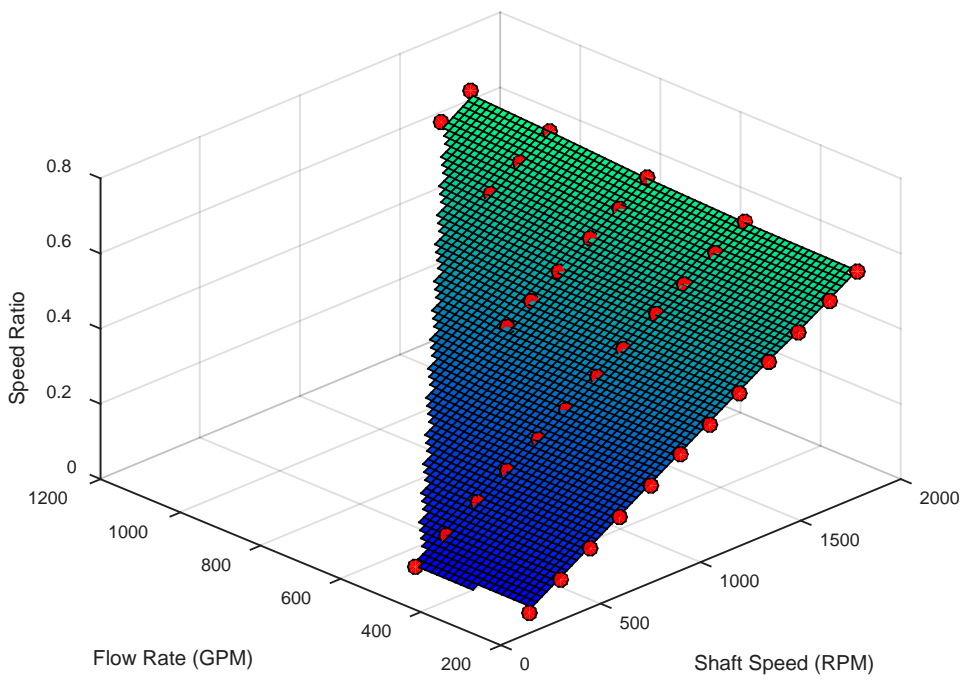

Figure 66: Plot of the speed ratio for the nozzle 2 jet during impeller A tests 


\subsubsection{Shaft Power Produced by Impeller A}

At peak conditions of a rotational speed of 1670 RPM and a flow rate of 1180 GPM impeller A generated $28.6 \mathrm{hp}$. A plot of the shaft power produced by impeller A during the experiments is shown in figure 67.

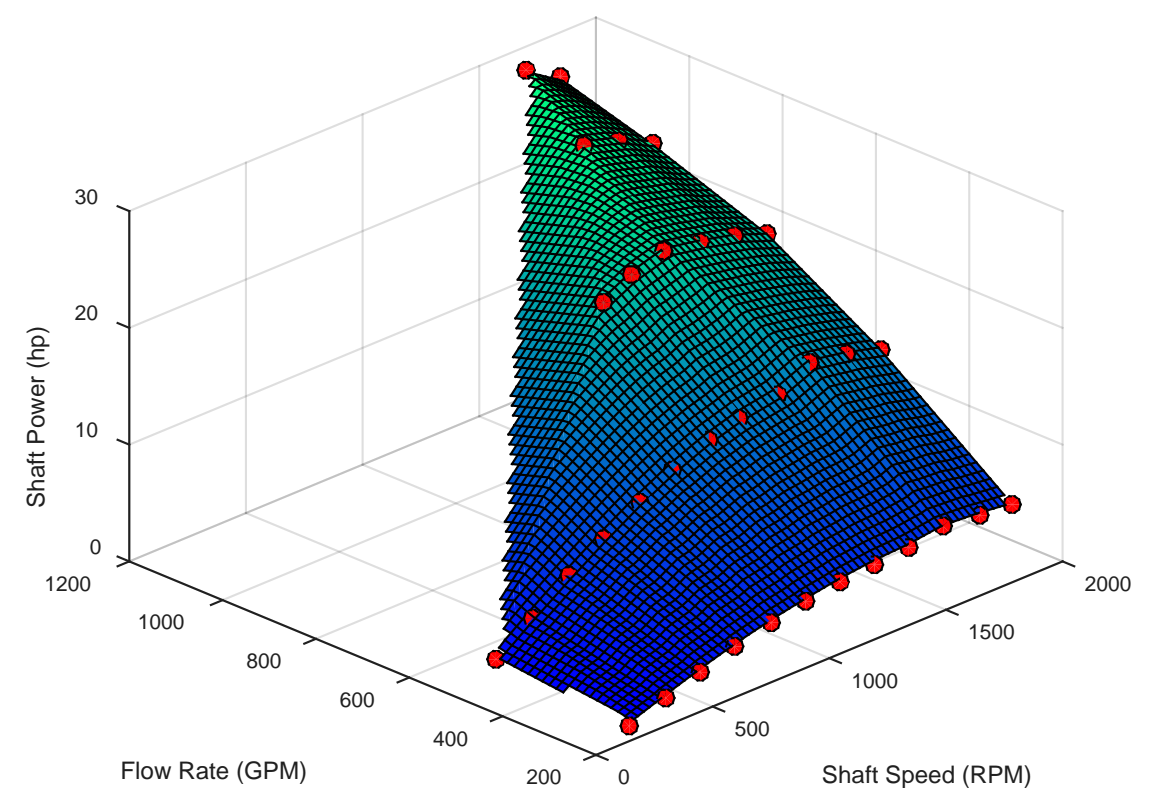

Figure 67: Plot of the shaft power output during performance tests on impeller A

It can be seen from Figure 67 that shaft power increases greatly as the flow of water being passed through the impeller increases. This is the result of a greater change in momentum as an increased amount of water mass is redirected around the surface of the rotating impeller buckets.

\subsubsection{Uncertainty Analysis for Impeller A}

An uncertainty map was formed for each of the impellers to show the uncertainty in the measurements of the overall efficiency. The uncertainty was calculated using the method described previously in Section 3.1.8. An example uncertainty calculation is shown in Appendix F. A plot of the uncertainty for the calculation of the efficiency of impeller A is shown in Figure 68. 


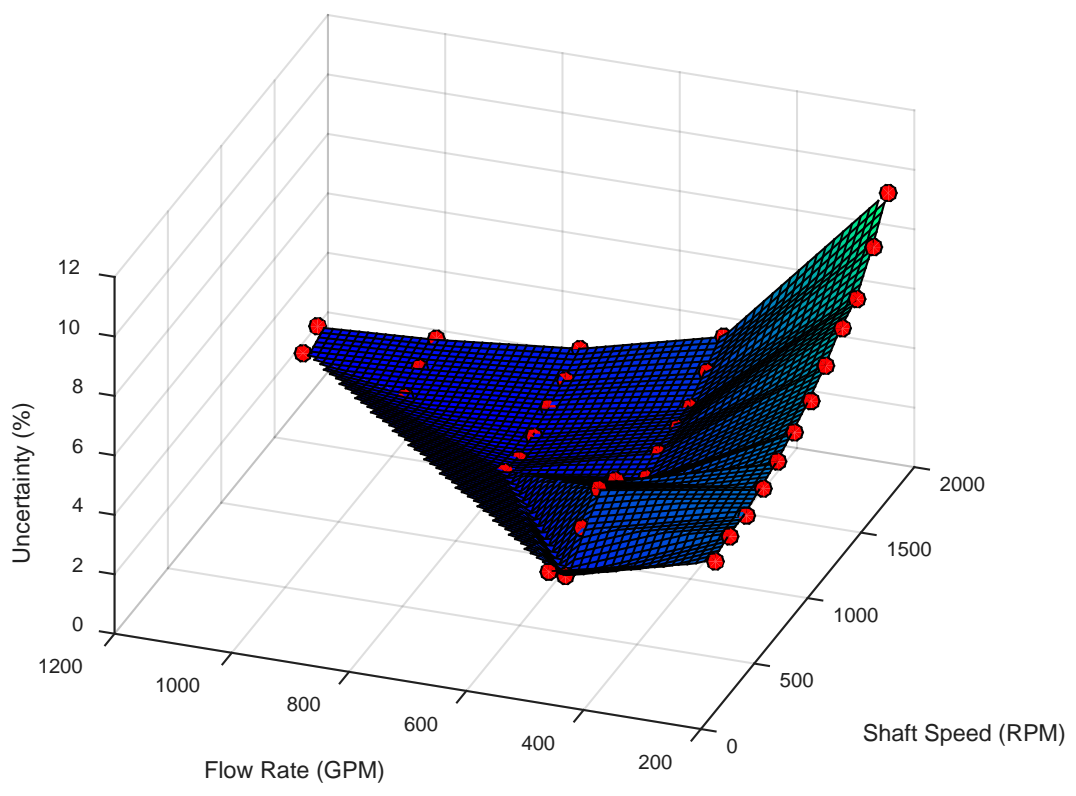

Figure 68: Plot of a map of uncertainty in the turbine efficiency of impeller A

The maximum uncertainty in the measurement of efficiency for impeller A was $10.1 \%$. The bias uncertainty from the torque meter was the largest contributor to the uncertainty. As previously mentioned, the maximum uncertainty occurred at high speed and low flow rate tests points where the torque was lower. 


\subsubsection{Impeller B Performance Results}

\subsubsection{Measured Efficiency for Impeller B}

Impeller B showed a peak efficiency of 73.3\% at approximately 1330 RPM and a flow rate of 740 GPM. The plot of the measured efficiency for impeller B is shown in Figure 69. The efficiency map for impeller B showed a trend of increasing efficiency from low rotational speeds until the peak was reached near 1300 RPM and then decreased. Impeller B does not show decreasing efficiency with increasing flow rate because its larger buckets can accommodate the water jets from the larger diameter water nozzles.

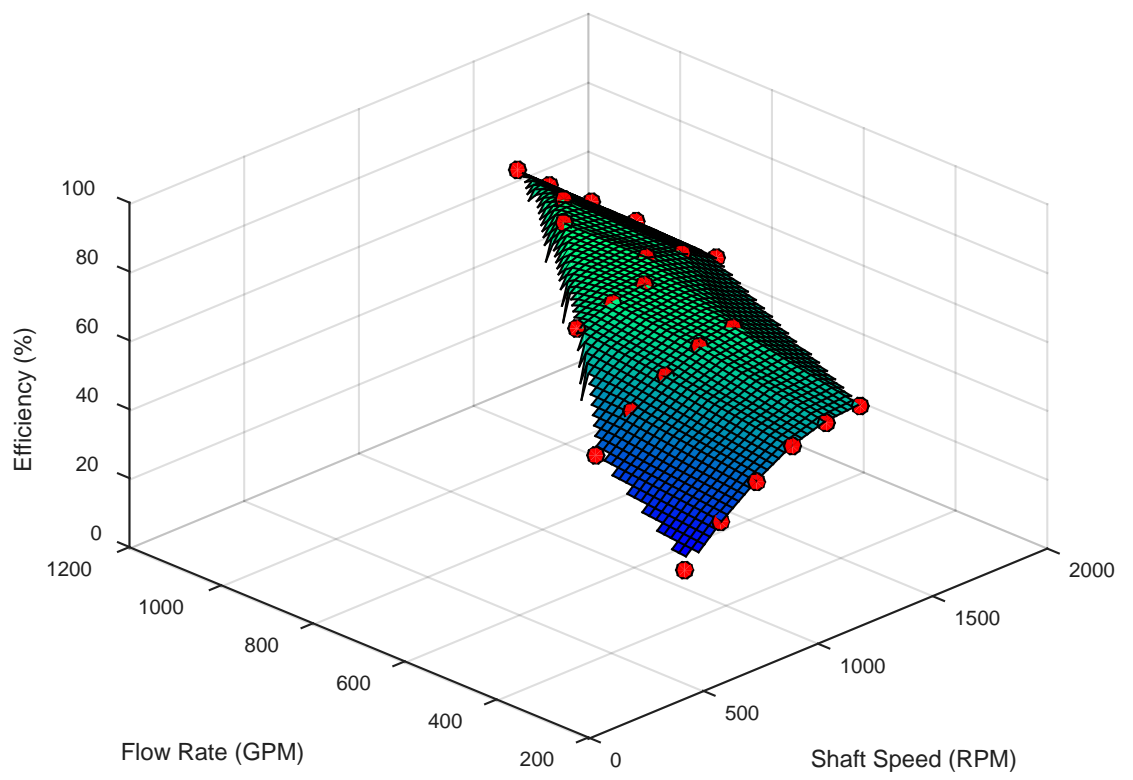

Figure 69: Plot of the efficiency map for impeller B

\subsubsection{Adjusted Efficiency for Impeller B}

The plot of adjusted efficiency carries the same trends as described in the previous section. A plot of the efficiency adjusted for the effects of power losses for impeller B is shown in Figure 70. For both Figures 69 and 70, reaching peak efficiencies between rotational speeds of 1200-1350 RPM can again be attributed obtaining the desired speed ratio. The peak efficiency for impeller B was 
increased from $73.3 \%$ to $74.8 \%$ when the power losses of the test stand components were added to the original measured power output.

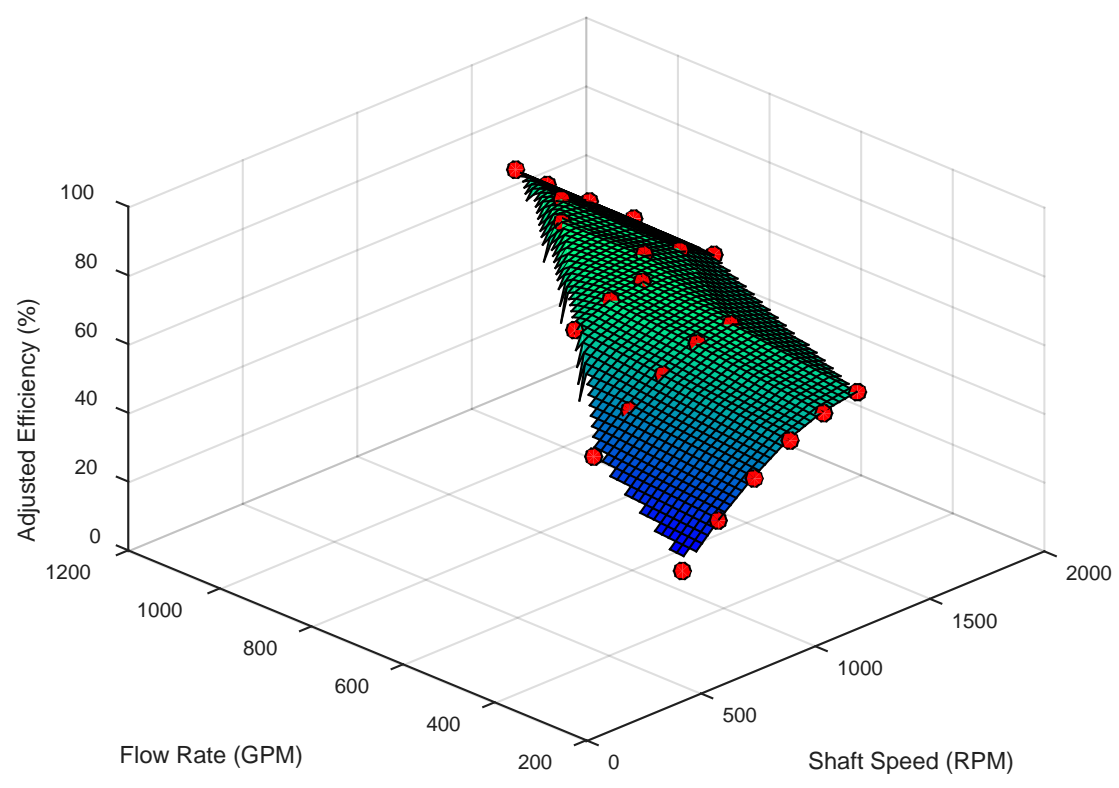

Figure 70: Plot of the efficiency of impeller $B$ adjusted for power losses

\subsubsection{Speed Ratios for Impeller B}

The desired speed ratio for impeller B occurred at a range of approximately 1200 to 1350

RPM. Plots of the speed ratio for impeller B at each water nozzle are shown in Figures 71 and 72. The discontinuities in the surface of the maps in figures 71 and 72 can be attributed to difficulty controlling the experimental conditions during the first several experiments conducted. 


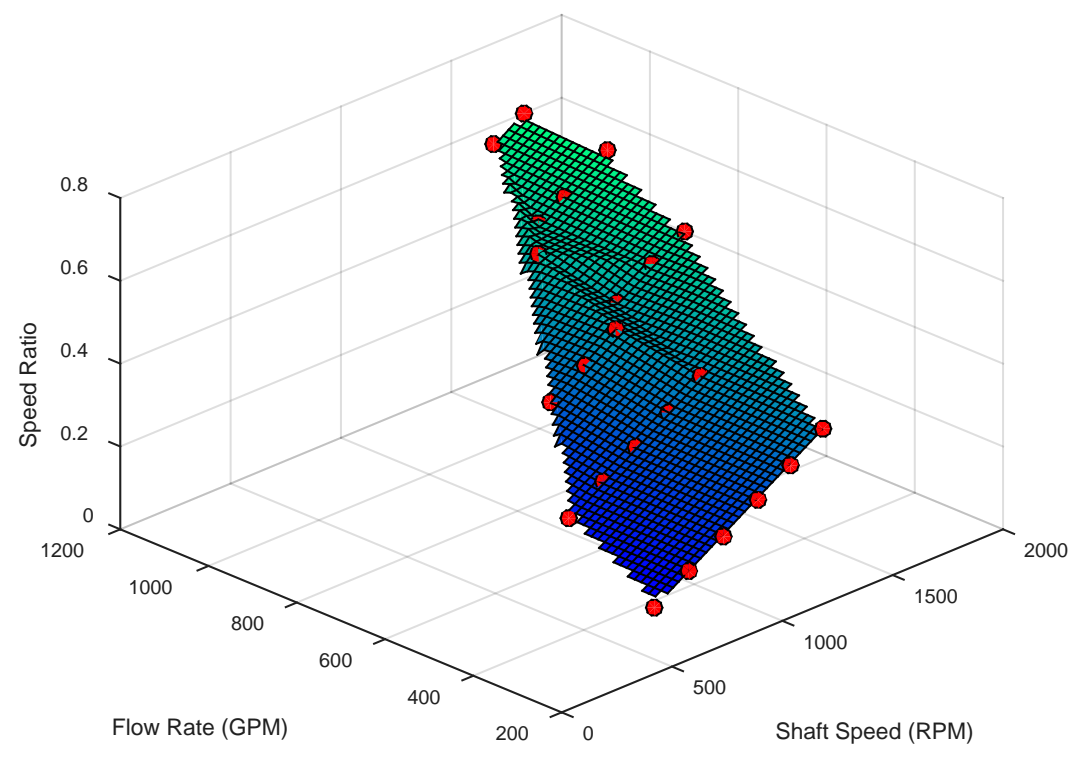

Figure 71: Plot of the speed ratio for the nozzle 1 jet during impeller $B$ tests

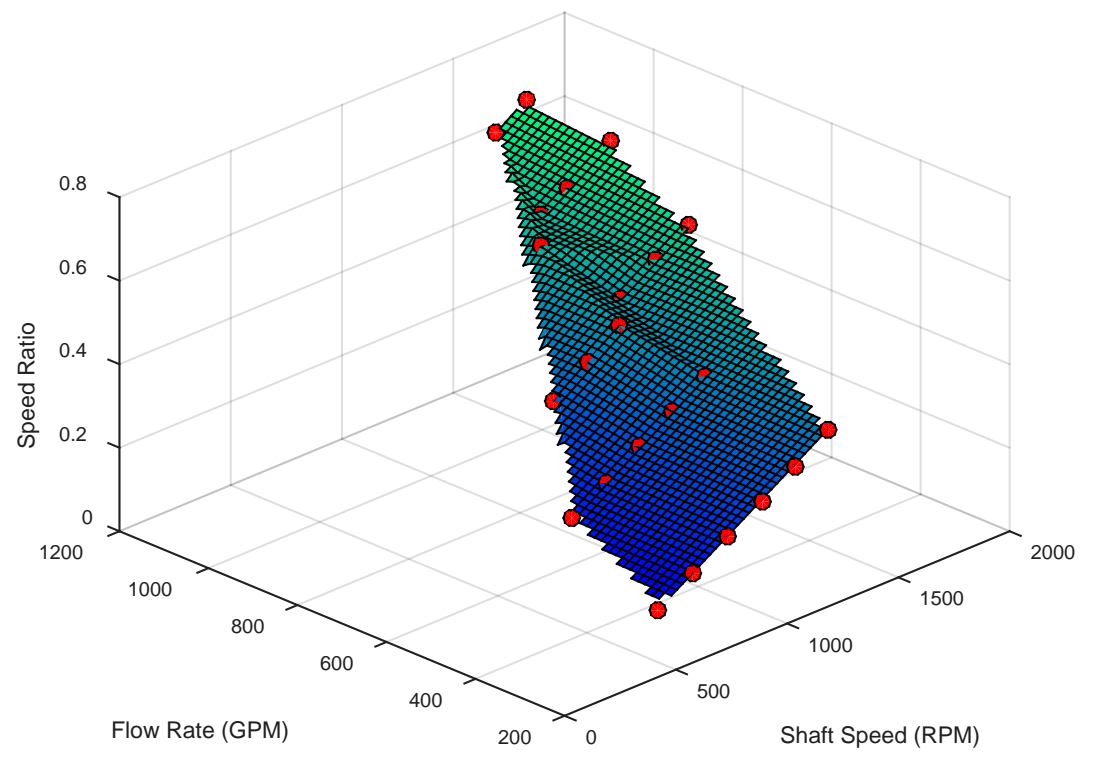

Figure 72: Plot of the speed ratio for the nozzle 2 jet during impeller $B$ tests

\subsubsection{Shaft Power Produced by Impeller B}

Impeller B also generated a peak shaft power of $28.6 \mathrm{hp}$ at peak conditions of 1636 RPM and 1172 GPM. The shaft power produced increased significantly with increased flow rate because of the concept previously described at the end of Section 4.4.1.4 for impeller A. A plot of the shaft power produced by impeller A during the experiments is shown in Figure 73. 


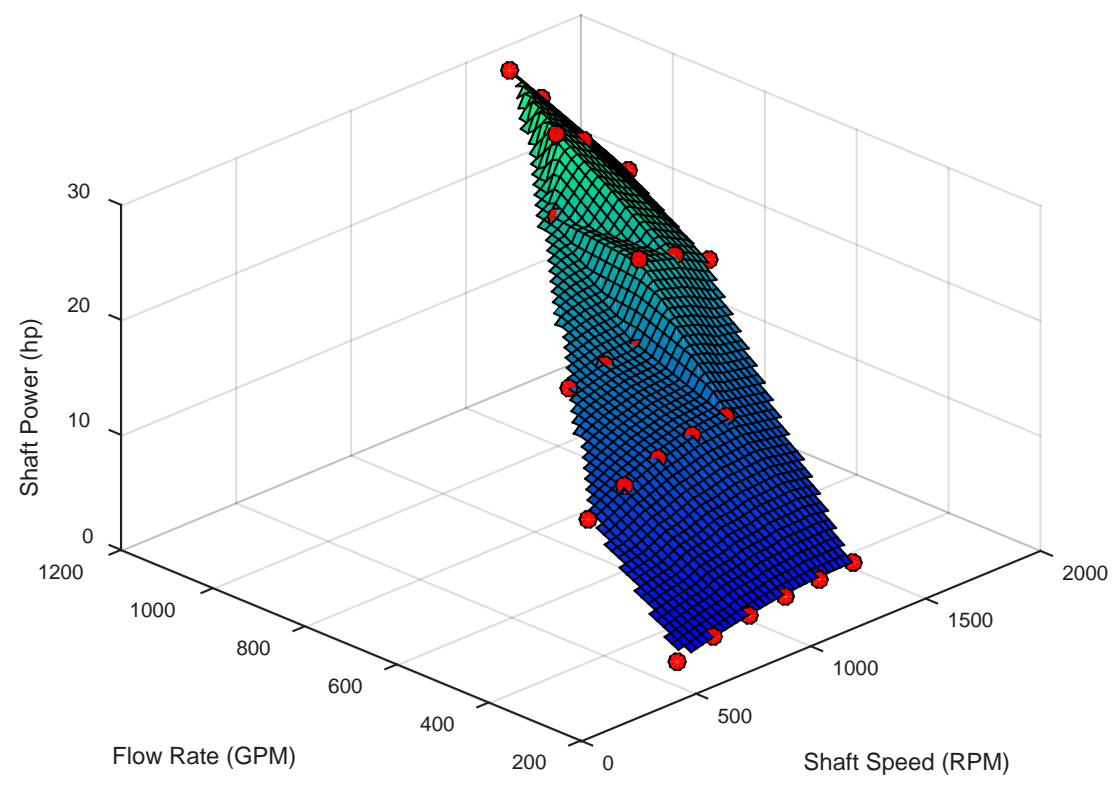

Figure 73: Plot of the shaft power output during performance tests on impeller B

\subsubsection{Uncertainty Analysis for Impeller B}

The maximum uncertainty in the measurement of the efficiency for impeller B was 8.0\%.

The bias uncertainty from the torque meter was the largest contributor to the uncertainty. As previously mentioned, the maximum uncertainty occurred at high speed and low flow rate tests points where the torque was lower. The plot of the measured efficiency for impeller B is shown in Figure 74. 


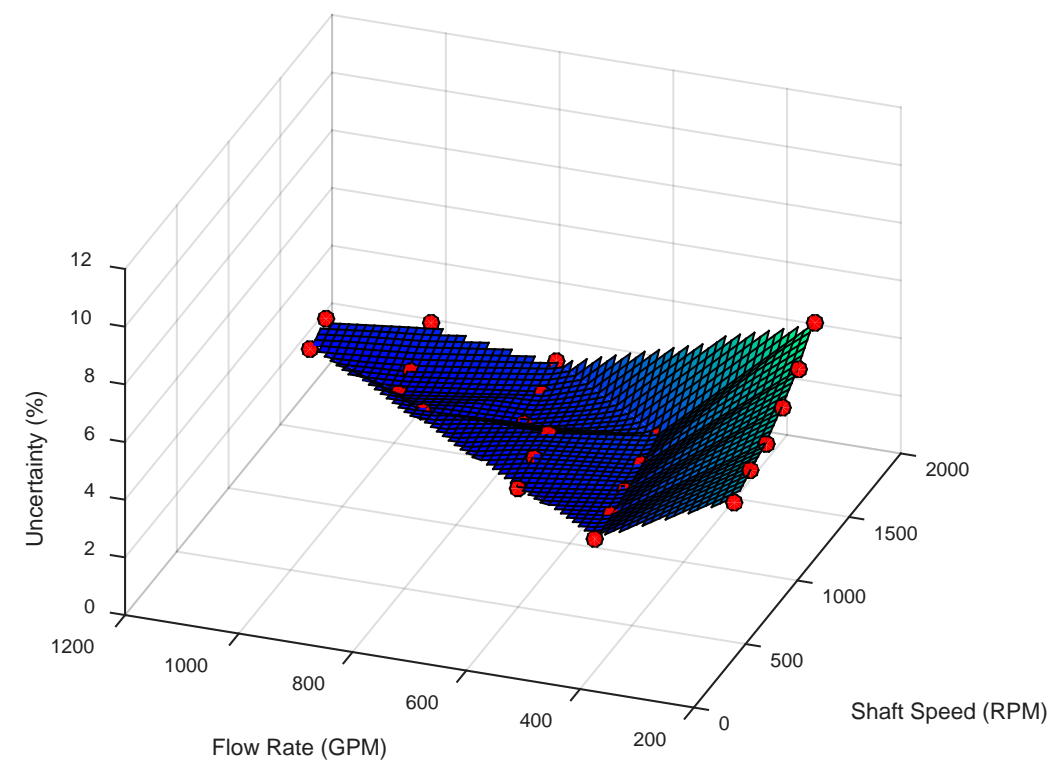

Figure 74: Plot of a map of the overall uncertainty in the turbine efficiency measurement for impeller B 4.4.3 Comparison of the Performance Results

Both impellers produced a maximum of $28.6 \mathrm{hp}$ power at the generator shaft. This occurred at 1667 RPM and 1181 GPM for impeller A and at 1636 RPM and 1172 GPM for impeller B. Both impellers showed similar trends with regards to their efficiency maps except for one difference. The efficiency of impeller A decreased at flow rates above 750 GPM because of the effect of its smaller buckets not fully accommodating the larger water jet from the larger diameter water nozzles. Across the range of set-points in the test matrix, impeller A consistently produced more shaft power by a small margin when compared to impeller B except for set points near the 500 GPM and 600-900 RPM range. The limitations of the equipment prevented set-points in the ranges of 250-500 GPM and 150-450 GPM from being tested for impeller B. The data suggests that impeller B may have been able to outperform impeller A in that range of set-points. 


\subsection{Turbine Operating Speed}

The rotational speed that the turbine settled at during operation was determined by the electrical loading on the generator and how efficient the impeller operates. Figures 75 and 76 show speed torque curves for each impeller at the different flow rates that were tested. The rated motor torque that is displayed on each plot is based on data for the motor driving a load and not being driven as a generator.
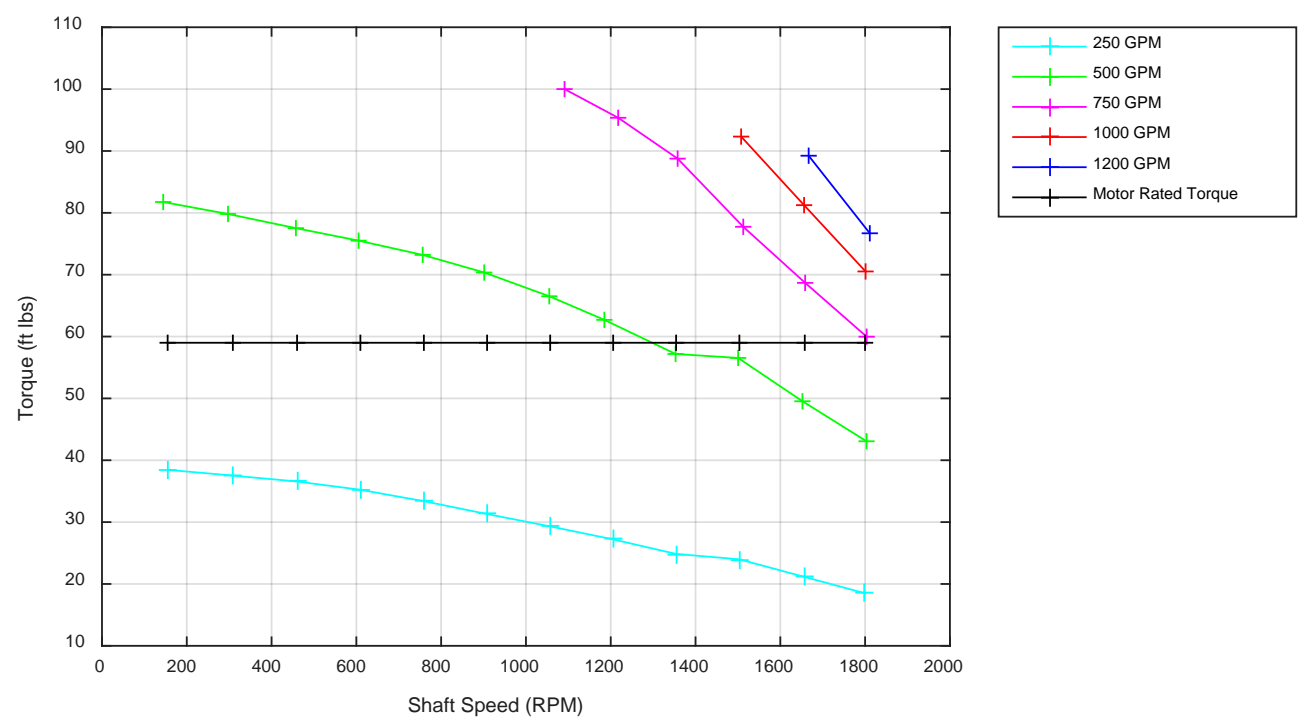

Figure 75: Plot of torque versus rotational speed for the motor and impeller A
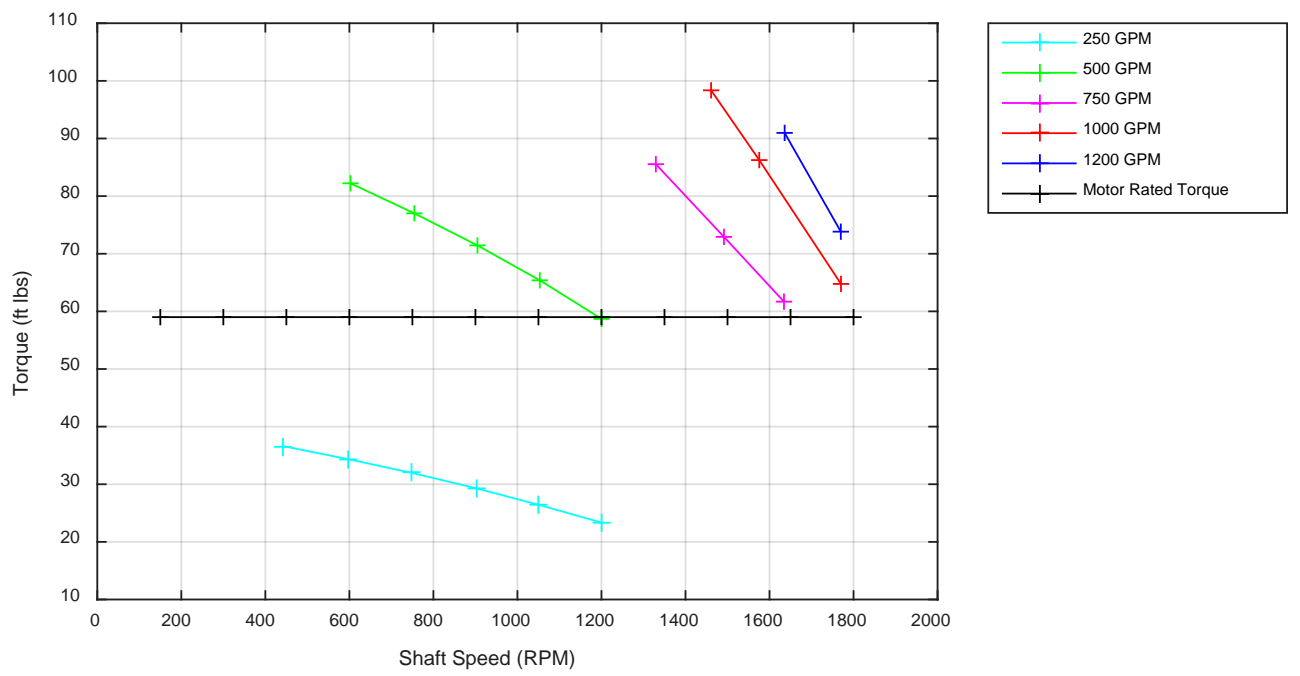

Figure 76: Plot of torque versus rotational speed for the motor and impeller B 
As an example, if the turbine with impeller A mounted and generator were being freely driven by the water jets at 500 GPM flow rate, the turbine would steadily operate at a rotational speed of approximately 1300 RPM. This can be inferred by noting the rotational speed at the point where the line of torque produced by the turbine (green) and the line of torque required by the motor (black) cross in Figure 75. The same example for impeller B would yield an estimated operating speed of 1200 RPM from Figure 76.

This method of determining the turbine operating speed was mentioned for practicality. In an operational turbine, the rotational speed of the generator shaft may not be continually measured and recorded. In order to form an estimation of the turbines performance, this method could be used to determine the rotational speed of the turbine if the characteristics of the generator and electrical load on the generator are known. This information could also be used to prevent the turbine from "running away". This means that if the turbine is producing more torque than is required to meet the demands of the electrical loading, the rotational speed of the generator will begin to increase and could reach dangerous levels. With knowledge of the correct operating speed of the turbine, a runaway scenario can be preventing by controlling the loading of the generator.

\subsection{Water Jet Quality}

As previously discussed, a documented design for the water nozzles was used to create the nozzles used in this experiment. This was done in an effort to ensure that the water jets used for each test would produce a high quality water jet. The quality of the water jet can have a great impact on the operation of the turbine. All water nozzles produced good quality water jets in this experiment. It was originally planned to take pictures of the jet for each nozzle size and then compare them based on jet shape, uniformity, and dispersion. However, this was not possible due 
to the amount of spray in the test stand casing during testing. Figure 77 on the next page shows the water jet emanating from the smallest diameter water nozzle during a performance test.

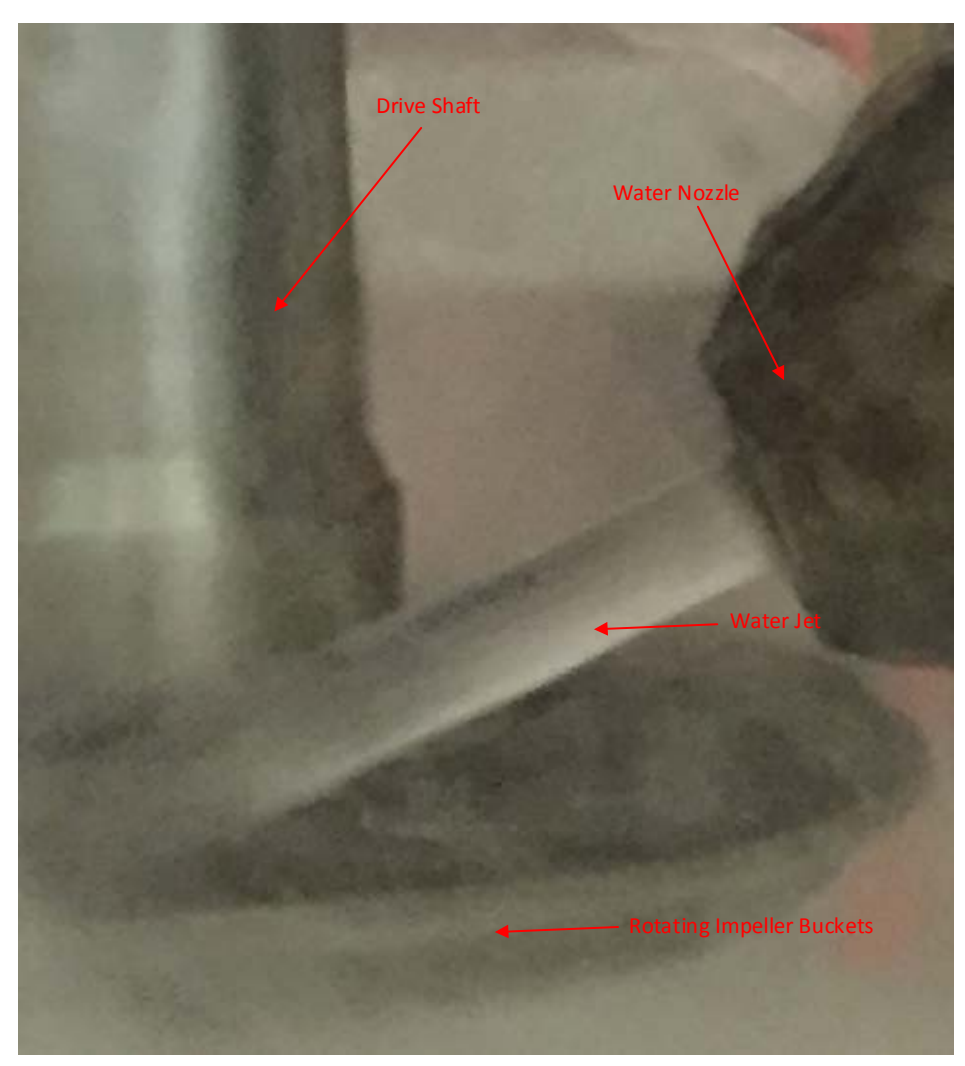

Figure 77: Picture of water jet impinging on impeller $A$ after it exits the water nozzle 


\section{Conclusions}

Several conclusions were drawn from the results of the project. To enable the data to be collected to arrive at these conclusions, a test stand was designed and fabricated to evaluate the performance of two Turgo micro-hydro turbine impellers. The experimental conditions used for the performance evaluation were modeled after the conditions at the BCWA site in Antrim, Pennsylvania that is managed by Biomost, Inc.

Initially, a coast down experiment was performed with the test apparatus to estimate the mechanical losses due to the rotating components in the test apparatus and the aerodynamic drag on each impeller. As expected, this study showed that the power losses in the test stand had a more significant impact on the amount of power produced when the power produced from the impellers was low. Mechanical losses in the test stand represented the largest power loss during the experiment. As expected, the power loss due to aerodynamic drag on impeller B was greater than the drag power loss on impeller A. The power loss due to mechanical losses and aerodynamic drag were estimated so that the performance of the impellers could be evaluated independently from the effects of the being test in the test stand.

Vibration measurements were taken on the test stand with different configurations of the rotating components attached to provide a perspective on how well balanced the system was and to create a reference for monitoring the safe operating conditions of the test stand. The vibration measurements were taken until the test stand reached a vibration condition that was characterized as rough by the general machinery vibration severity chart in Appendix A. It was found that with impeller A mounted there was rough vibration created in the test stand in the range of 1350-1500 RPM. With impeller B installed, rough vibration was created at 1200 RPM. As a reference point, 
rough vibration was caused in the range of 1800-1950 RPM with only the driveshaft and motor rotating without either impeller.

The test stand was first used to determine which inlet nozzle angle would result in the best efficiency from each turbine impeller with all of the other test conditions held constant. Tests were conducted over a range of inlet angles from $16^{\circ}$ to $24^{\circ}$. The actual inlet nozzle angle of the operational turbines in Antrim, PA was approximately $16^{\circ}$. It was found that an angle of $24^{\circ}$ was the inlet angle which produced the most shaft power from the turbine with the highest efficiency for each impeller. When the angle was reduced from $24^{\circ}$ to $16^{\circ}$, impeller A showed an approximate drop in efficiency of $19 \%$ and impeller B showed nearly a $30 \%$ drop. Angles steeper than $24^{\circ}$ were not tested due to the physical range of motion of the nozzle mounting brackets inside the test stand but may have produced even higher values of efficiency and shaft power.

The second set of performance experiments the test stand was used for measured the performance from each impeller at varying flow rates and shaft speeds. This experiment was conducted with inlet nozzle angles of $24^{\circ}$ because it was deemed to be the most efficient inlet angle measured for each impeller for the available test equipment. The results of these experiments were used to create three dimensional performance maps for the turbine efficiency and shaft power produced. It was found that impeller A had the higher peak efficiency (81.8\%) and operated with greater efficiency at speeds ranging from 900 RPM to 1800 RPM and flow rates from 225 to 800 GPM. Impeller A consistently produced slightly more shaft power than Impeller B at test points below the peak output except for 3 points at 484 GPM and rotational speeds of 600, 755, and 905 RPM. Impeller B was found to have a peak efficiency of 73.3\%. It also operated more efficiently at rotational speeds between 600 and 1000 RPM and flow rates between 300 and 675 GPM when 
compared to impeller A. Both impellers produced peak shaft power of $28.6 \mathrm{hp}$ at different operating points.

The differences in performance between the two impellers can be explained by looking at several different attributes on both impellers A and B. First, as described in Section 2.1 of the literature review, the exit angle of each bucket is crucial to efficient operation of each impeller. The recommended range for the exit angle of the bucket was $10^{\circ}$ to $15^{\circ}$. The exit angle for impeller B $\left(32^{\circ}\right)$ was steeper than that of impeller A $\left(9^{\circ}\right)$. This means that solely based on the exit angle of each type of bucket, the buckets on impeller A will operate more efficiently because it will produce a greater change in momentum as the water jet is redirected around the bucket surface. Second, the bucket surfaces were also rougher on impeller B when compared to those on impeller A. Impeller B was in an operational turbine before being tested. The bucket surfaces were rusty, pitted, and worn from particulate in the water flow that it was used in. This surface condition was assumed to have caused an increased amount of friction to occur with the water jet on the surface of the bucket. The friction reduced the velocity of the water jet at the exit of the bucket and in turn the amount of momentum transferred to the impeller which reduces efficiency and power output.

Even with impeller A being more efficient than impeller B over a greater operating range, both impellers produced approximately the same amount of shaft power at their peak operating point. This can be explained by the size of the buckets on the two impellers. Although, impeller A operated more efficiently, it has much smaller buckets than impeller A. At higher flow where the nozzle diameter is larger, more water is deflected away or bypasses impeller A completely. Since it operates with a higher efficiency, it produces the same amount of shaft power with less water mass being passed through the buckets. Impeller B produces the same amount of shaft power by capturing more with larger buckets at a lower efficiency when compared to impeller A. 
Coast-down tests were performed with different configurations of the test apparatus to estimate the mechanical losses and aerodynamic drag on the impeller in the test stand during the experiment. Estimating these losses allowed for the calculation of an adjusted efficiency of each impeller that was independent of the effects of the test stand used in this experiment. These experiments showed that the estimated values are consistent with the literature for turbines that are not directly coupled to the generator shaft. At peak shaft power output, the total losses were estimated to be $1 \%$ of the output for impeller A and $2 \%$ of the output for impeller B. The accuracy of this estimation could have been improved by conducting the coast down tests while the water jets were active and the test stand was filled with an air and water spray mixture. This would cause a slight increase in aerodynamic drag due to increased density of the fluid the rotating components were traveling through.

Several recommendations can be made from the conclusions drawn from the experimental data with regards to how both impellers should be used in an operational turbine system. If the impellers were to be used at a site with the conditions that were used in this experiment, impeller A would be best suited for use in a turbine. It produced higher or approximately the same amounts of shaft power with higher efficiency throughout the range of conditions. However, impeller B would be a better option at flowrates that are greater than the maximum of 1200 GPM that was tested in this experiment. This is because the larger size of the buckets on impeller B would allow it to produce more shaft power at higher flow rates because it captures more of the water jets. In the same situation, impeller A would improperly deflect or miss a large amount of the water jet resulting in decreased power production.

An ideal turbine impeller that could be used over a larger range of conditions with higher flow rates would combine attributes from both impeller A and impeller B. Impeller A produced 
power more efficiently because of the shape of its buckets. Impeller B produced similar amounts of power to impeller A because its larger size made up for its less efficient bucket shape. The buckets on an ideal impeller would have the shape of Impeller A's buckets, but all of the different components of the impeller would be near the same size as impeller B's components. This would allow the impeller to capture the maximum amount of water from larger water jets while still transforming the kinetic energy in the jet into shaft power efficiently.

The results from this project could have been improved in several ways. Firstly, the time allocated for the experiment due to project resources was limited to two weeks. Increasing this time would have allowed for better control of the experimental conditions by providing the opportunity for a practice run of each experiment to see how equipment responded to experimental conditions.

Secondly, the allowable torque on the motor shaft limited the test points that could be tested in the experiment. A larger motor with a base speed of 1800 RPM would have been more suitable for this application but was not able to be obtained within the resources of the project.

A header tank would also have served as a better option to supply water to the test stand under constant pressure head. The water level in the tank would have been kept at a constant level to create a more precise control over the head pressure of the water flow supplied to the test stand. However, a tank with the capability to provide a 1200 GPM water flow at $160 \mathrm{ft}$. of water pressure head could not be fabricated within the resources of the experiment.

In conclusion, it was determined that both impellers have strengths and weaknesses in their design. Both turbines are very capable of producing satisfactory performance in a range of different operating conditions. This experiment shows that each turbine is sensitive to the operating conditions in which they are used. Proper design of components of a turbine system and 
management of the operating conditions are important factors in obtaining long term, efficient, and reliable power production from each turbine impeller. 


\section{Bibliography}

[1] Page, B. J., Danehy, T. P., Neely, C. A., Busler, S. L., Denholm, C. F., Mahony, R. M. and Dunn, M. H., 2012, "Micro-Hydroelectric Power Facility Using Mine Drainage", Biomost, Inc. , Mars, Pennsylvania

[2] J.Lyman, E., 12/14/15, "Paris Climate Deal: Hard Work Comes Next", USA Today

[3] January 2016,"Monthly Energy Review: January 2016", U.S. Energy Information Administration Office of Energy Statistics, p.5

[4] Young, D. F., Munson, B. R., Okiishi, T. H. and Huebsch, W. W., 2007, "A Brief Introduction to Fluid Mechanics", John Wiley \& Sons, Hoboken, NJ.

[5] Cengel, Y. A. and Boles, M. A., 2008, "Thermodynamics: An Engineering Approach", McGraw-Hill, New York, New York.

[6] Thake, J., 2000, "The Micro-Hydro Pelton Turbine Manual: Design, Manufacture and Installation for Small-Scale Hydro-Power", Practical Action Publishing, Warwickshire, United Kingdom.

[7] Williamson, S. J., Stark, B. H. and Booker, J. D., 2013, "Performance of a Low-Head PicoHydro Turgo Turbine," Applied Energy, 102(0), pp. 1114-1126.

[8] Logan Jr, E. and Roy, R., 2003, "Handbook of Turbomachinery: 2nd Edition Revised and Expanded", Marcel Dekker, Inc., New York, New York.

[9] Bracken, L. J., Bulkeley, H. A. and Maynard, C. M., 2014, "Micro-Hydro Power in the UK: The Role of Communities in an Emerging Energy Resource," Energy Policy, 68, pp. 92-101.

[10] Hall, D. G., Reeves, K. S., Brizzee, J., Lee, R. D., Carroll, G. R. and Sommers, G. L., 2006,"Feasibility Assessment of Water Energy Resources of the United States for New Low Power and Small Hydro Classes of Hydroelectric Plants", Document No.11263, U.S. Department of Energy

[11] Williams, A. and Porter, S., 2006, "Comparison of Hydropower Options for Developing Countries with Regard to the Environmental, Social and Economic Aspects," Proc. Conference on Renewable Energy for Developing Countries, Washington, D.C.

[12] Doig, D. A., 2009, "Micro-Hydro Power", Practical Action, Warwickshire, United Kingdom

[13] Guerrero-Lemus, R. and Martínez-Duart, J. M., 2012, "Renewable Energies and $\mathrm{CO}_{2}$ : Cost Analysis, Environmental Impacts and Technological Trends-2012 Edition", Springer Science \& Business Media, London, England. 
[14] 2001,"Small Hydropower Systems: Energy Efficiency and Renewable Energy Clearinghouse", Document No.102001-1173, U.S. Department of Energy National Renewable Energy Laboratory (NREL), p.1-8

[15] Nababan, S., Muljadi, E. and Blaabjerg, F., 2012, "An Overview of Power Topologies for Micro-Hydro Turbines," Proc. Third International Symposium on Power Electronics for Distributed Generation Systems Aalborg, Denmark, Institute of Electrical and Electronics Engineers, pp. 737-744.

[16] Paish, O., 2002, "Small Hydro Power: Technology and Current Status," Renewable and Sustainable Energy Reviews, 6(6), pp. 537-556.

[17] Kosnik, L., 2010, "The Potential for Small Scale Hydropower Development in the US," Energy Policy, 38(10), pp. 5512-5519.

[18] 2007, "Gilkes Hydraulic Turgo Impulse Turbine". Gilbert Gilkes \& Gordon Ltd. , Kendal Cumbria, United Kingdom

[19] Harvey, A., Brown, A., Hettiarachi, P. and Inversin, A., 1993, "Micro-Hydro Design Manual: A Guide to Small-Scale Water Power Schemes", Practical Action Publishing, Warwickshire, United Kingdom.

[20] Williamson, S. J., Stark, B. H. and Booker, J. D., 2012, "Experimental Optimisation of a LowHead Pico Hydro Turgo Turbine," Proc. Third International Conference on Sustainable Energy Technologies (ICSET), Kathmandu, Nepal, Institute of Electrical and Electronics Engineers, pp. 322-327.

[21] Koukouvinis, P. K., Anagnostopoulos, J. S. and Papantonis, D. E., 2011, "SPH Method Used for Flow Predictions at a Turgo Impulse Turbine: Comparison with Fluent," World Academy of Science, Engineering and Technology, 5, pp. 567-574.

[22] Židonis, A., Benzon, D. S. and Aggidis, G. A., 2015, "Development of Hydro Impulse Turbines and New Opportunities," Renewable and Sustainable Energy Reviews, 51, pp. 16241635.

[23] Liu, H., Masera, D. and Esser, L., 2013, "World Small Hydropower Development Report 2013," United Nations Industrial Development Organization International Center on Small Hydro Power, Hangzhou, China.

[24] Skancke, N., Alsberg, C. and Matlock, J., 2010, "Small Hydro Council Initial Report - 2010," National Hydropower Association Small Hydro Council, Washington, D.C.

[25] O’Connor, G. C., 2013, "America's Quest for Clean Energy: Is Hydropower Relevant?," The Electricity Journal, 26(2), pp. 15-24.

[26] 2013, "Hydropower Regulatory Efficiency Act", Law Number 113-23, 113th United States Congress 
[27] 2015, "Hydropower Improvment Act ", Senate Bill 1236, United States Senate

[28] Durkay, J., 7/1/15, "State Renewable Portfolio Standards and Goals", National Conference of State Legislatures

[29] March 2016,"Monthly Energy Review: March 2016", U.S. Energy Information Administration Office of Energy Statistics, p.5

[30] Anagnostopoulos, J. S., 2013, "Design of Impulse Hydro Turbines," Journal of Applied Mechanical Engineering, 2(4), p. 2.

[31] Crewdson, E., 1922, 1922, "Design and Performance of a New Impulse Water-Turbine," Proc. Minutes of the Proceedings of the Institute of Civil Engineers, pp. 396-407.

[32] Anagnostopoulos, J. S., Koukouvinis, P. K., Stamatelos, F. G. and Papantonis, D. E., 2012, "Optimal Design and Experimental Validation of a Turgo Model Hydro Turbine," Proc. Eleventh Biennial Conference on Engineering Systems Design and Analysis, Nantes, France, American Society of Mechanical Engineers, pp. 157-166.

[33] Davis, S., 2010, "Serious Microhydro: Water Power Solutions from the Experts", New Society Publishers, Gabriola Island, British Columbia.

[34] Daugherty, R. L., 1920, "Hydraulic Turbines: With a Chapter on Centrifugal Pumps", McGraw-Hill Book Company, Incorporated, New York, New York.

[35] Correa, J. L. C., De Andrade, J., Noguera, R., Croquer, S., Jeanty, F. and Asuaje, M., 2012, "Design Procedure for a Turgo Type Turbine using a Three-Dimensional Potential Flow," Proc. Turbo Expo 2012: Turbine Technical Conference and Exposition, Copenhagen, Denmark, American Society of Mechanical Engineers, pp. 2039-2052.

[36] Dorji, U. and Ghomashchi, R., 2014, "Hydro Turbine Failure Mechanisms: An Overview," Engineering Failure Analysis, 44, pp. 136-147.

[37] Stamatelos, F., Anagnostopoulos, J. and Papantonis, D., 2011, "Performance Measurements on a Pelton Turbine Model," Proceedings of the Institution of Mechanical Engineers, Part A: Journal of Power and Energy, 225(3), pp. 351-362.

[38] 1999, "Model Acceptance Tests: Hydraulic Turbines, Storage Pumps and Pump-Turbines", International Electrotechnical Commission, Standard Number IEC: 60193

[39] Aggidis, G. A. and Židonis, A., 2014, "Hydro Turbine Prototype Testing and Generation of Performance Curves: Fully Automated Approach," Renewable Energy, 71(0), pp. 433-441.

[40] Cobb, B. R. and Sharp, K. V., 2013, "Impulse (Turgo and Pelton) Turbine Performance Characteristics and Their Impact on Pico-Hydro Installations," Renewable Energy, 50(0), pp. 959-964. 
[41] Cobb, B. R., 2011, "Experimental Study of Impulse Turbines and Permanent Magnet Alternators for Pico-Hydropower Generation," Oregon State University.

[42] Agar, D. and Rasi, M., 2008, "On the Use of a Laboratory-Scale Pelton Wheel Water Turbine in Renewable Energy Education," Renewable Energy, 33(7), pp. 1517-1522.

[43] Thapa, B. and Dahlhaug, O. G., 2009, "Turbine Testing Laboratory and its Role in Hydropower Development," Hydro Nepal: Journal of Water, Energy and Environment, 5(1), pp. 66-70.

[44] Sakurai, T., Funato, H. and Ogasawara, S., 2009, "Fundamental Characteristics of Test Facility for Micro Hydroelectric Power Generation System," Proc. Sixth International Power Electronics and Motion Control Conference, Wuhan, China, Institute of Electrical and Electronics Engineers, pp. 2612-2617.

[45] Climescu, O., Jaliu, C., Saulescu, R., Neagoe, M. and Badea, M., 2010, "Laboratory Small Hydropower Plant Testing Stand," Proc. Twenty First International DAAAM Synposium Vienna, Austria, B. Katalinic, ed., DAAAM International, pp. 1125-1126.

[46] Keck, H. and Sick, M., 2008, "Thirty Years of Numerical Flow Simulation in Hydraulic Turbomachines," Acta Mechanica, 201(1-4), pp. 211-229.

[47] 2015, "United States Geological Survey National Map Viewer", U.S. Department of the Interior http://viewer.nationalmap.gov/viewer/, [Date Accessed: 6/5/15]

[48] Hibbeler, R. C., 2007, "Engineering Mechanics: Dynamics ", Pearson Prentice Hall, Upper Saddle River, NJ.

[49] Montgomery, D. C., 2006, "Strategy of Experimentation", John Wiley \& Sons, Inc., Hoboken, New Jersey.

[50] Moffat, R. J., 1988, "Describing the Uncertainties in Experimental Results," Experimental Thermal and Fluid Science, 1(1), pp. 3-17.

[51] Hayes, S. A., 2014, "An Experimental Investigation on the Effects of Freestream Turbulence Intensity on Film Cooling Effectiveness and Heat Transfer Coefficient for an Anti-Vortex Hole," Master of Science in Mechanical Engineering, West Virginia University, Morgantown, WV.

[52] Nix, A. C., 2003, "Effects of High Intensity, Large-Scale Freestream Combustor Turbulence on Heat Transfer in Transonic Turbine Blades," Doctor of Philosophy in Mechanical Engineering, Virginia Polytechnic Institute and State University, Blacksburg, Virginia.

[53] Luzader, Z., 2015, "Scimitar", West Virginia University Center for Alternative Fuels, Engines, and Emissions, Morgantown, WV

[54] 1988, "Vibration Technology Manual 1: Basics of Vibration". Entek IRD International, Milford, Ohio 


\section{Description of Appendices}

Appendix A IRD General Machinery Vibration Severity Chart which was used to ensure safe operation of the test stand and characterize the balancing of the impellers and test stand rotating components

Appendix B Four configurations of the test stand components during coast-down testing

Appendix C Transducer calibration certificates and plots of calibration checks conducted to ensure the accuracy of measurements in the experiment

Appendix D Reliance motor parameters and speed-torque curve

Appendix E Flow chart of how various quantities were calculated and measured in the Scimitar Parameter Tree

Appendix F Example uncertainty calculation 


\section{Appendix A - IRD General Machinery Vibration Severity Chart}

\section{GENERAL MACHINERY VIBRATION SEVERITY CHART}

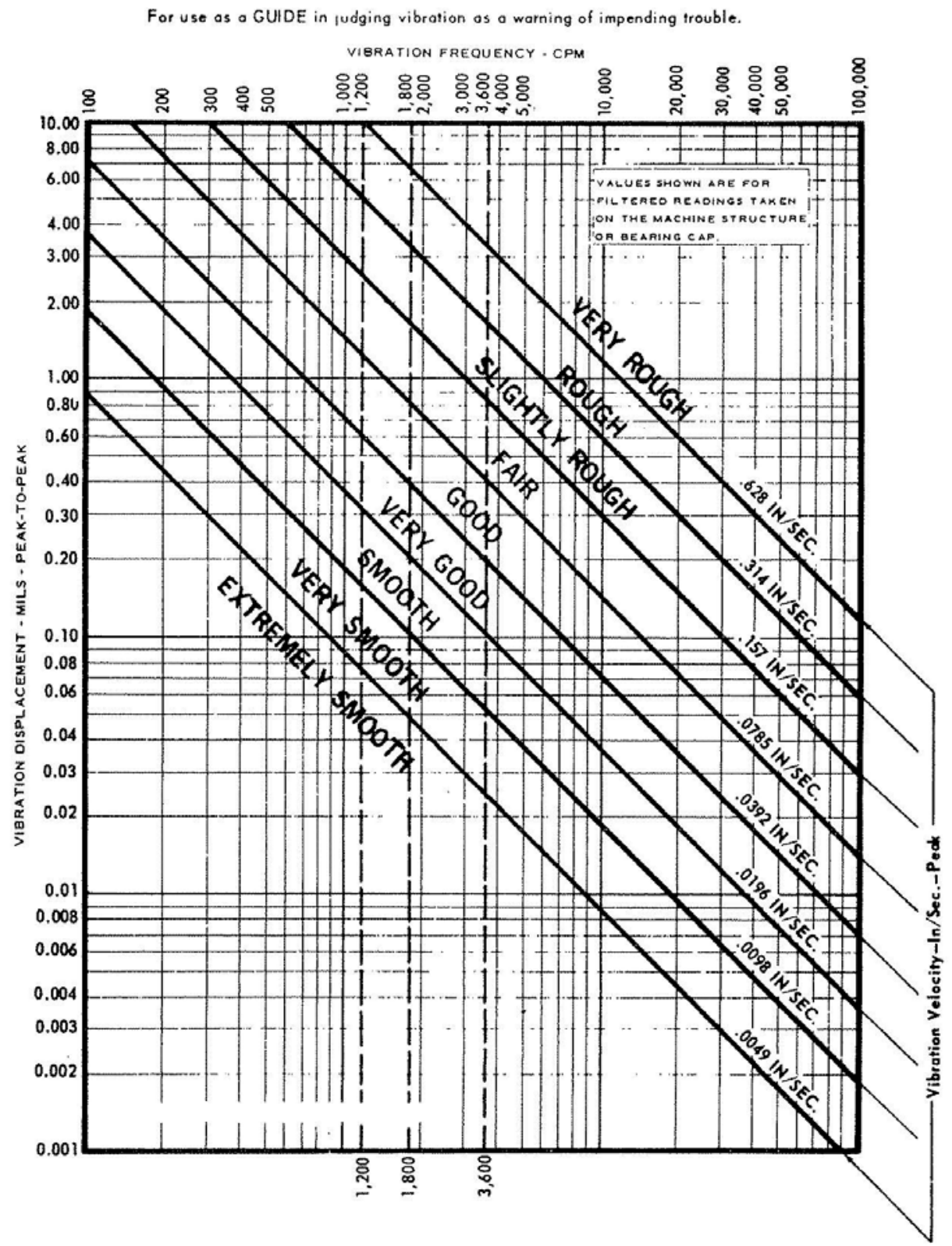

IRD Mechanalysis, Inc.

Subsidiary of H. H. Robertson Company 


\section{Appendix B - Coast-down Test Component Configurations}

Reliance Motor Only

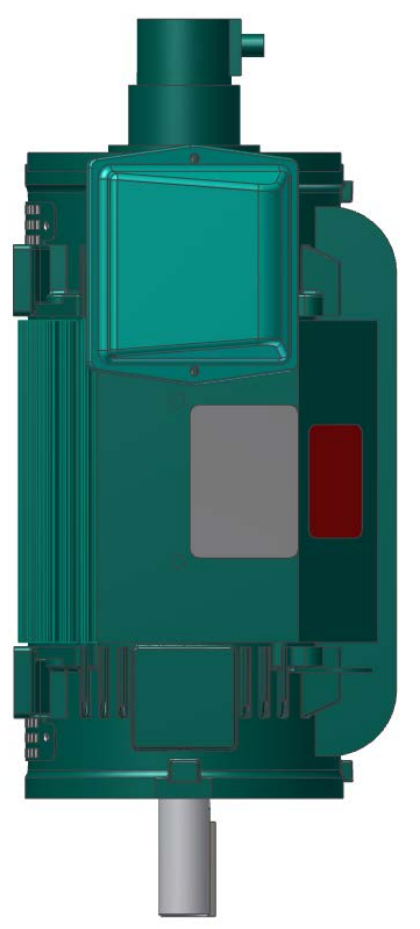

Reliance Motor + Drive Shaft

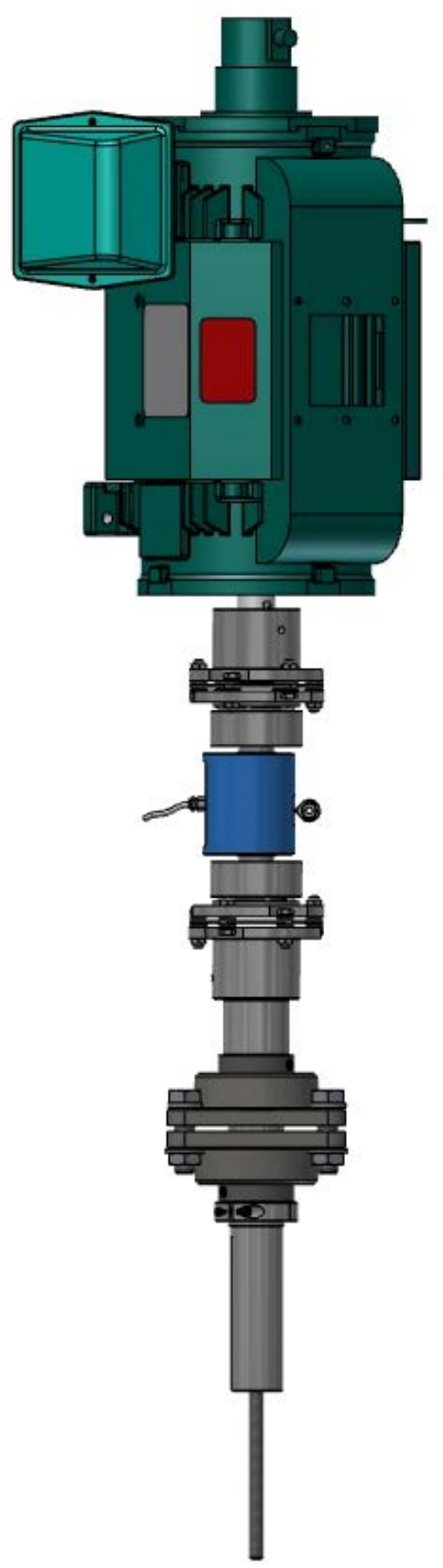

B-1 
Motor + Drive Shaft + Impeller A

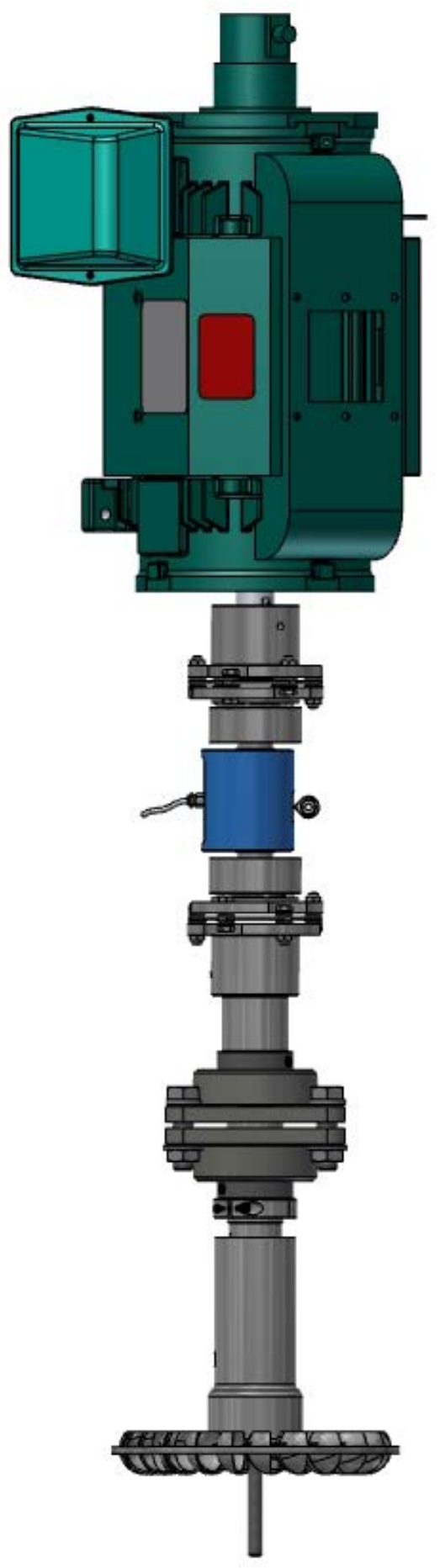

Motor + Drive Shaft + Impeller B

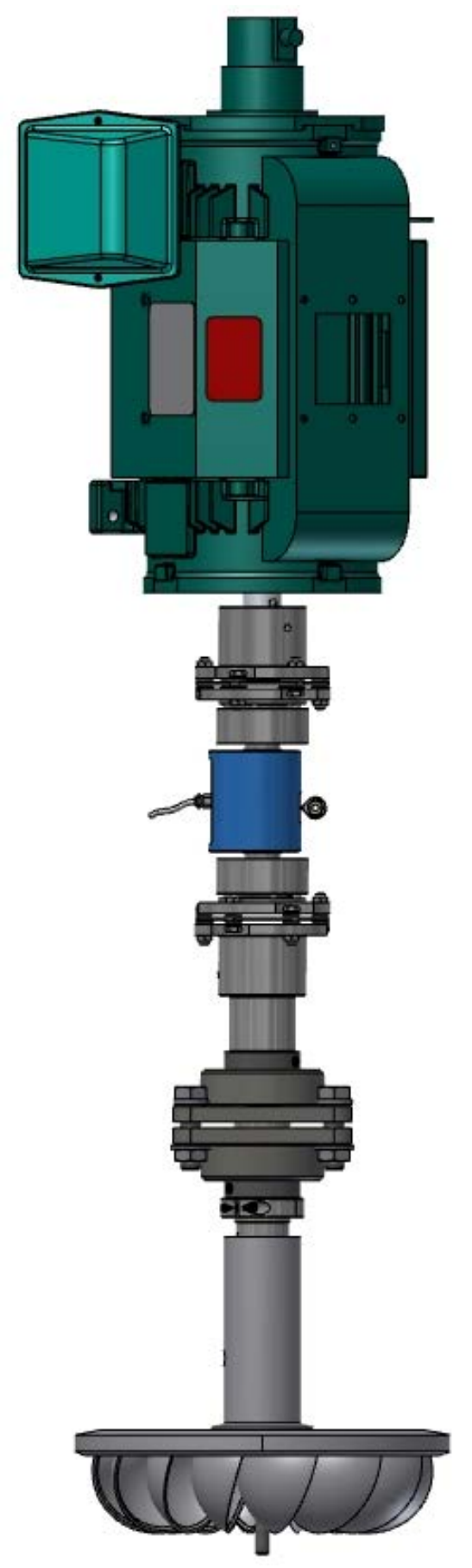

B-2 


\section{Appendix C - Transducer Calibration Certificates}

\section{Siemens Sitrans MAG 5100W Flow Meter and MAG 5000 Transmitter}

\section{SIEMENS Industry Sector}

\section{Factory Calibration Certificate / Certificado de calibración de fábrica / Certificat d'étalonnage usine}

\begin{tabular}{lll}
\hline Topic / Tema / Sujet: SITRANS F Flowmeter / Caudalímetro / Débitmètre & \\
\hline Object / Asunto / Objet: & & \\
\hline Siemens order / Pedido de Siemens / Commande Siemens & $:$ & $3005368127 / 000010$ \\
Flowmeter type / Tipo de caudalimetro / Type de débitmètre & $:$ & Sitrans FM MAG5100 W \\
Nominal sensor diameter / Diámetro nominal del sensor / Diamètre nominal de capteur : & DN 150 (6") \\
Product order No. / Referencia del producto / N ${ }^{\circ}$ de référence d'appareil & $:$ & 7ME65804HJ142LA2 \\
System serial No. / No. de serie del sistema / N ${ }^{\circ}$ de série du systeme & $:$ & 776303U145 \\
Sensor serial No. / No. de serie del sensor / N ${ }^{\circ}$ de série de capteur & $:$ & 645001D454 \\
\hline
\end{tabular}

\section{Technical data / Datos técnicos / Données techniques:}

Calibration factor / Factor de calibración / Facteur d'étalonnage

Calibration medium / Medio de Calibración / Moyen de calibration

Calibrated full scale flow / Flujo calibrado a plena escala / Fin de plage de mesure

étalonnée

Calibration rig / Banco de Calibración / Plate-forme d'étalonnage

\subsection{6 \\ Water / Aqua / Eau \\ $300 \mathrm{~m}^{3} / \mathrm{h} / 1320.855$ US gpm \\ CN-RIG5}

Standards / Estándares / Normes: $\quad$ Reference meter method (reference meter calibrated according to ISO 4185-1980) / Método con medidor de referencia (medidor calibrado según ISO 4185-1980) / Méthode avec compteur de référence (étalonné suivant ISO 4185-1980)

Results / Resultado / Résultats:

\begin{tabular}{|c|c|c|c|c|c|c|c|c|}
\hline \multirow{3}{*}{$\begin{array}{c}\text { Point \# } \\
\text { Punto no. } \\
\text { Point me sure n }\end{array}$} & \multirow{3}{*}{$\begin{array}{c}\begin{array}{c}\text { Flowrate } \\
\text { Caudal } \\
\text { Débit }\end{array} \\
{[\%]}\end{array}$} & \multirow{2}{*}{\multicolumn{2}{|c|}{$\begin{array}{l}\text { Fluid temperature } \\
\text { Temperatura del fluido } \\
\text { Température du fluide }\end{array}$}} & \multirow{2}{*}{\multicolumn{2}{|c|}{$\begin{array}{c}\text { Reference flow value } \\
\text { Caudal de referencia } \\
\text { Débit de référence }\end{array}$}} & \multicolumn{3}{|c|}{ Flowmeter output/ Salida del caudalímetro / Sortie de débittmètre } \\
\hline & & & & & & \multicolumn{2}{|c|}{$\begin{array}{c}\text { Flowrate } \\
\text { Caudal / Débit }\end{array}$} & \multirow{2}{*}{$\begin{array}{c}\text { Error } \\
\text { Error/Emeur } \\
{[\%]}\end{array}$} \\
\hline & & {$\left[{ }^{[} \mathrm{C}\right]$} & {$[\mathrm{F}]$} & {$\left[\mathrm{m}^{3} / \mathrm{h}\right]$} & [US gpm] & {$\left[\mathrm{m}^{3} / \mathrm{h}\right]$} & [US gpm] & \\
\hline 1 & 92 & 19.1 & 66.4 & 276.92 & 1219.24 & 276.79 & 1218.68 & -0.05 \\
\hline 2 & 92 & 19.3 & 66.7 & 275.97 & 1215.06 & 275.70 & 1213.89 & -0.10 \\
\hline 3 & 27 & 18.6 & 65.5 & 80.74 & 355.47 & 80.77 & 355.64 & 0.05 \\
\hline$\overline{4}$ & 27 & 18.6 & 65.5 & 80.70 & 355.33 & 80.64 & 355.05 & -0.08 \\
\hline
\end{tabular}

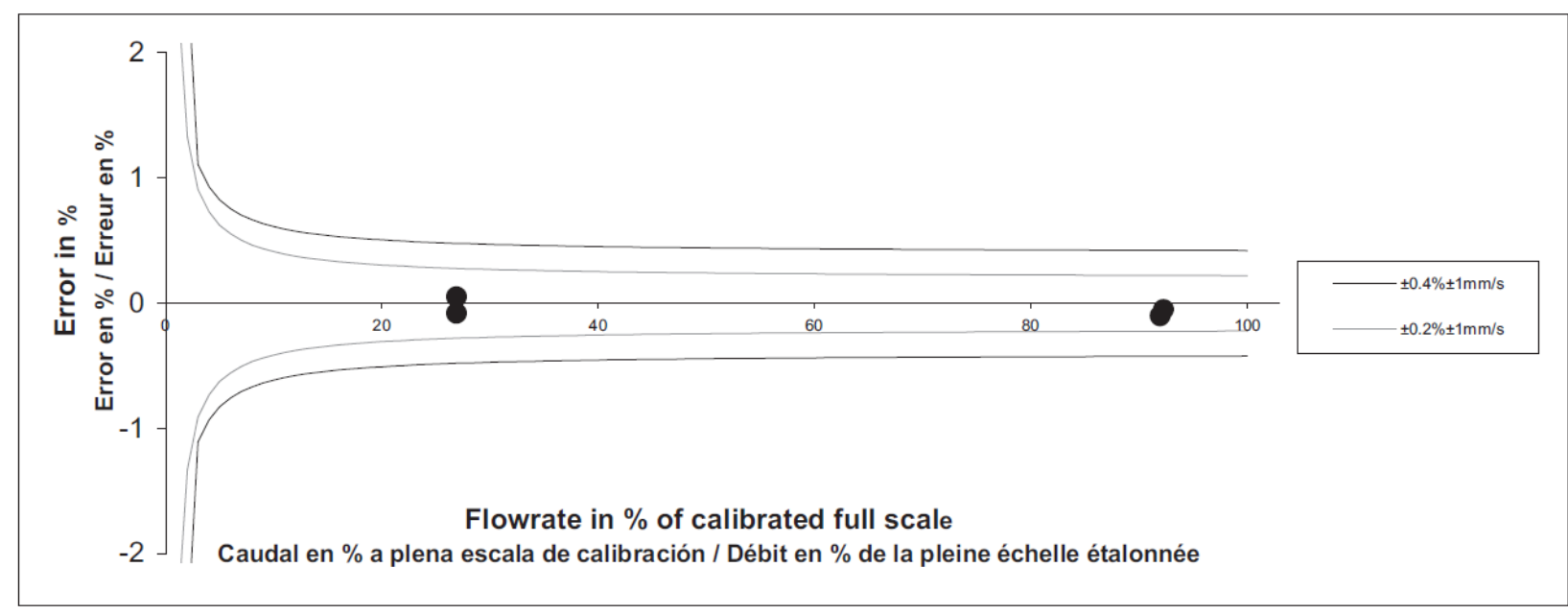

C-1 
Summary of the results / Resumen de los resultados / Sommaire des résultats obtenus : :

- The measured values are within the specified limits / Los valores medidos se encuentran dentro de los límites especificados / Les résultats de mesure se trouvent dans les tolérances définies

SIEMENS

Industry Sector

Factory Calibration Certificate / Certificado de calibración de fábrica / Certificat d'étalonnage usine

\begin{tabular}{|l|l|l|}
\hline \multicolumn{3}{|c|}{ Test rig characteristics } \\
\hline \multicolumn{2}{|c|}{ (2) } \\
(2)
\end{tabular}

C-2 
Traceability / Trazabilidad / Tracabilité

The Siemens flowmeter calibration process is ISO9001-certified, ensuring the entire calibration procedure is controlled to the highest quality standards.

All primary measuring instrumentation used by the Siemens Flow Laboratory during the performance of its calibrations, has been calibrated with international standards traceability referring directly to the physical unit of measurement according to the International System of Units (SI). Therefore the calibration certificate ensures recognition of the test results worldwide, including the US (NIST traceability).

El proceso de calibración de Siemens es certificado bajo ISO 9001, asegurando que todo el proceso de calibración es controlado por las más altos estándares.

Todos los instrumentos primarios de medida utilizados en los Laboratorios de Calibración de Siemens están calibrados en conformidad con las normas internacionales vigentes relativas a la unidad física de medición, establecida por el Sistema Internacional de Unidades (SI). El certificado de calibración garantiza por tanto la trazabilidad y la conformidad de los resultados obtenidos a nivel internacional, incluyendo EE.UU. (NIST).

Le processus d'étalonnage des débitmètres Siemens est certifiée ISO9001 et est contrôlé périodiquement selon les normes qualités en vigueur les plus élevées.

Tous les instruments de mesure primaires utilisés dans les laboratoires Siemens Flow durant les opérations d'étalonnage ont été étalonnés en conformité avec les normes internationales relatives à l'unité de mesure physique, conformément au système international d'unités (SI). Le certificat d'étalonnage garantit ainsi que les résultats obtenus lors des essais sont conformes aux normes internationales, y compris NIST (USA).

Siemens Industry, Inc.

Siemens Industry, Inc.
1201 Sumneytown Pike

Spring House, PA 19477

United States
Tel +1 (215) 6467400

$\mathrm{Fax}+1$ (215) 5910420

Issued by / emitido por / émis par

Date / Fecha / Date

ybs

2015/03/31 
Keller Valueline Pressure Transducer for Nozzle 1

\begin{tabular}{|c|c|c|c|c|c|c|c|}
\hline $\mathrm{P} / \mathrm{N}:$ & \multicolumn{2}{|c|}{0208.02102 .041303 .02} & \multicolumn{5}{|l|}{6} \\
\hline S/N: & & 168688 & & & & 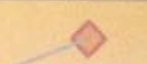 & \\
\hline Px Zero & Px FS & Units & & & & & \\
\hline 0 & 150 & PSIG & & & & & \\
\hline Spec & Actual Max & Pass/Fail & & 50 & & 150 & חמכ \\
\hline $0.10 \%$ & $0.00 \%$ & Pass & & 0 & 100 & 130 & 200 \\
\hline Point & Px In & Output & & in reg & Deviation & $\%$ Error & Status \\
\hline $0.00 \%$ & 2.90 & 0.096 & & 0.095856 & 0.000244 & $0.00 \%$ & In Spec \\
\hline $20.00 \%$ & 30.00 & 1.000 & & 0.999358 & 0.000142 & $0.00 \%$ & In Spec \\
\hline $40.00 \%$ & 60.00 & 1.999 & & 1.999636 & -0.000636 & $-0.01 \%$ & In Spec \\
\hline $60.00 \%$ & 90.00 & 3.000 & & 2.999908 & 0.000092 & $0.00 \%$ & In Spec \\
\hline $80.00 \%$ & 120.00 & 4.000 & & 4.000142 & -0.000042 & $0.00 \%$ & In Spec \\
\hline $100.00 \%$ & 150.00 & 5.001 & & 5.000400 & 0.000200 & $0.00 \%$ & In Spec \\
\hline
\end{tabular}

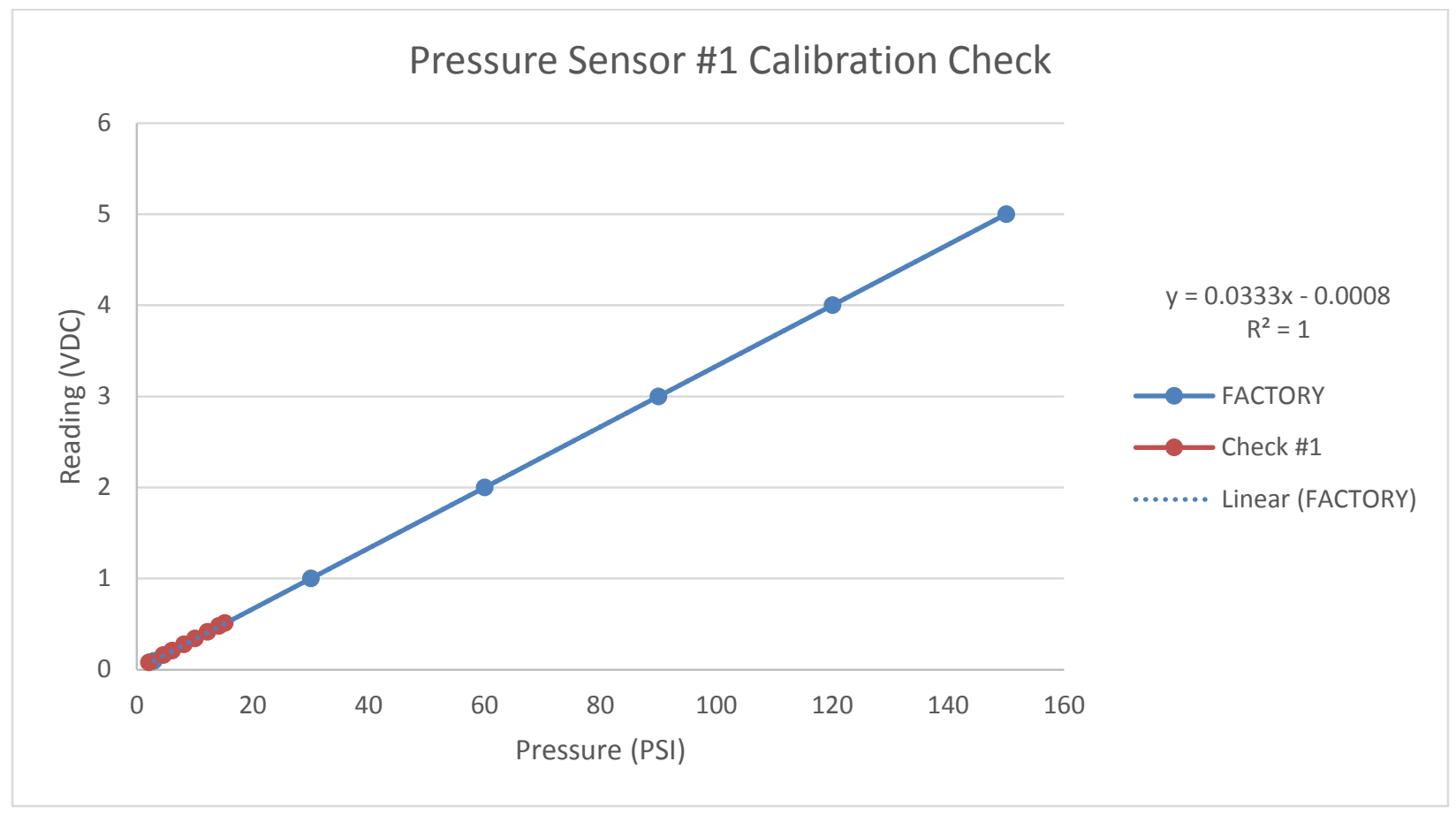

Figure 78: Plot of the calibration check for the pressure transducer for nozzle 1

C-4 
Keller Valueline Pressure Transducer for Nozzle 2

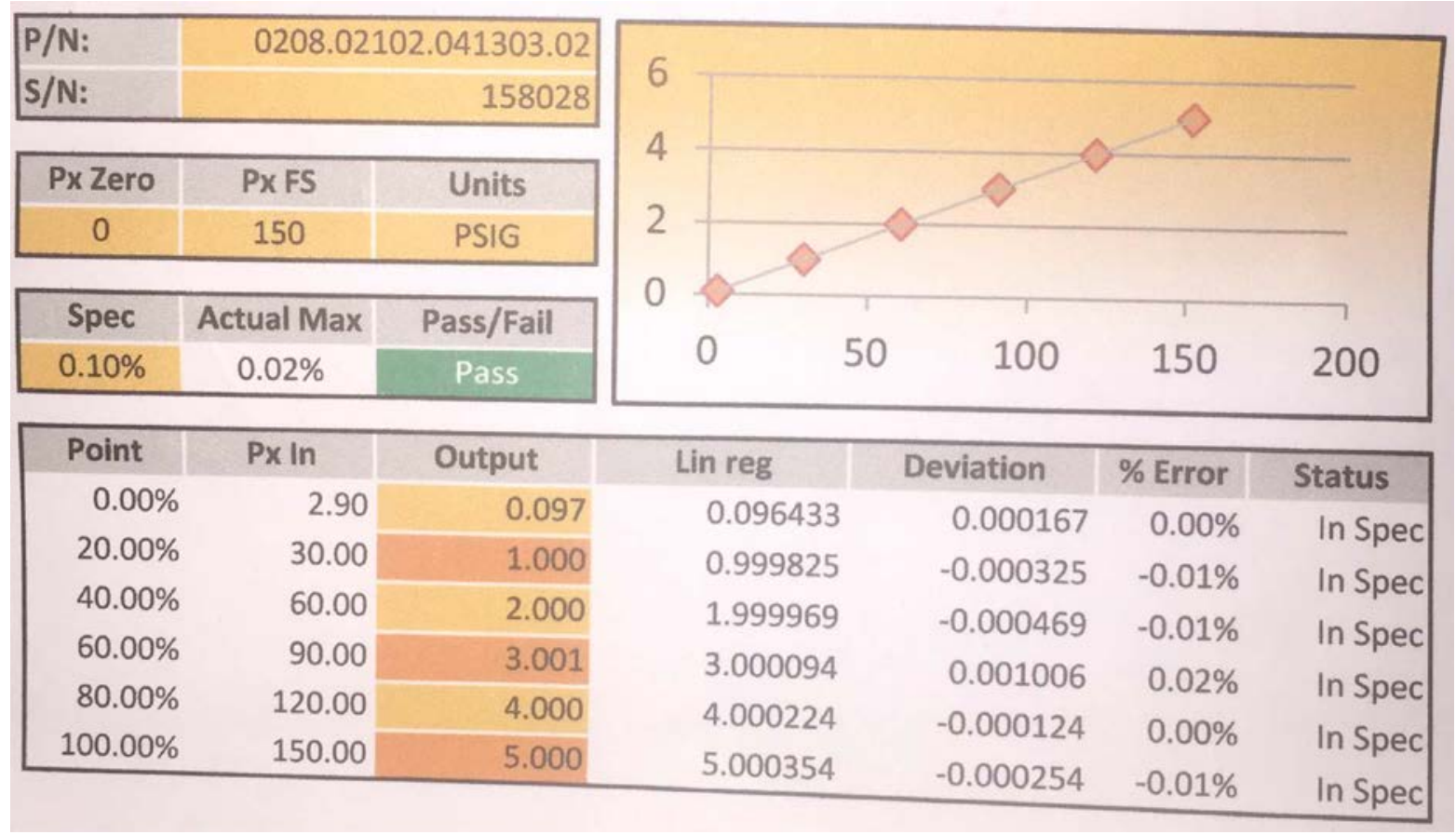

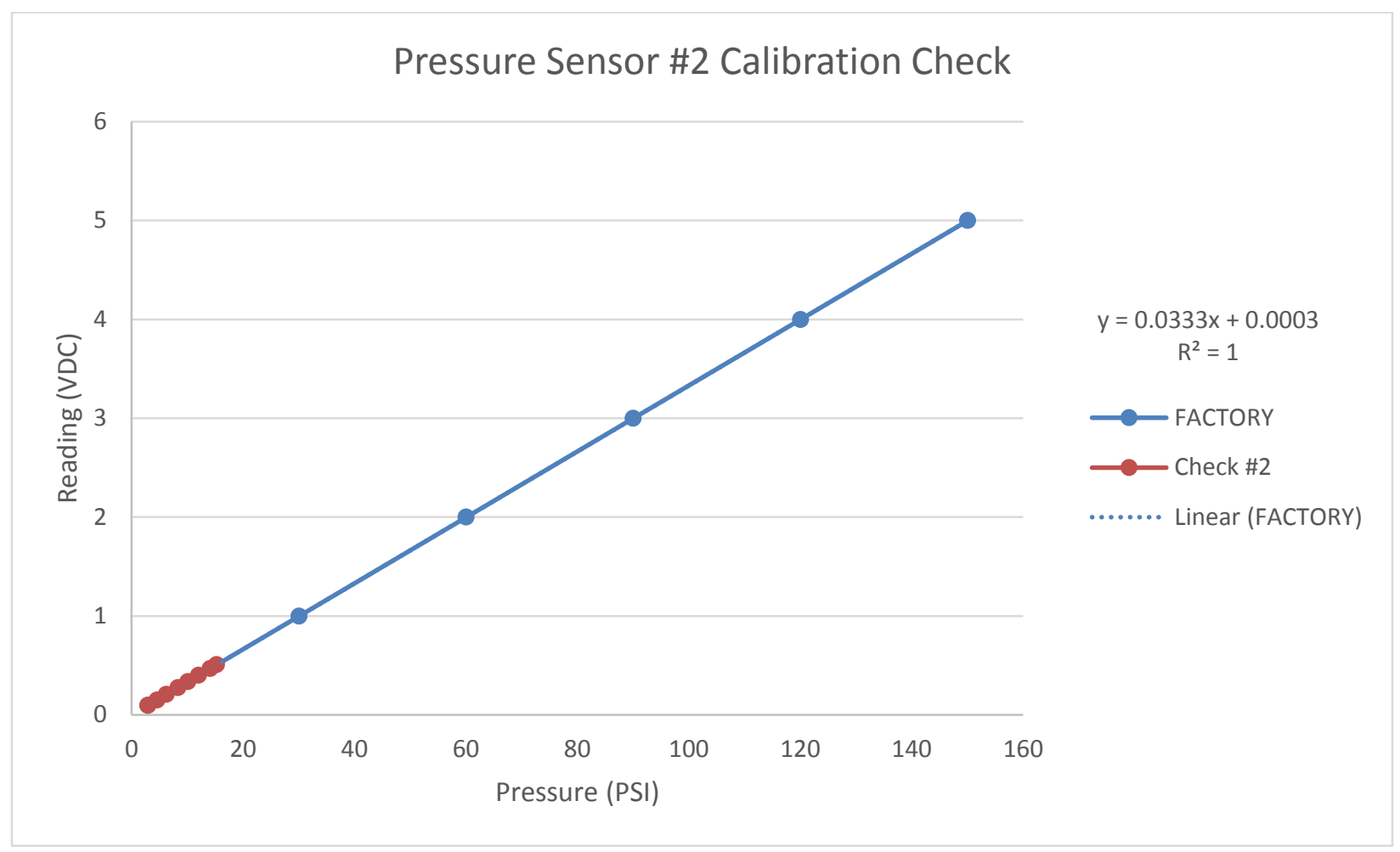

Figure 79: Plot of the calibration check for the pressure transducer for nozzle 2

C-5 


\section{Interface Force Calibration Certificate for T23 Rotary Torque Meter}

incerface

ADVANCED FORCE MEASUREMENT

TORQUE TRANSDUCER CALIBRATION CERTIFICATE

Model: T23-500-A3A

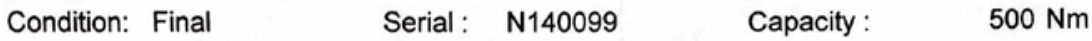

Conditions:

Temperature: $\quad 22^{\circ} \mathrm{C}$

Supply Voltage: $15 \mathrm{VDC}$

Cable length: $\quad 1 \mathrm{~m}$

\begin{tabular}{|lc|}
\hline Zero Load Signal: & $\begin{array}{c}\text { Clockwise } \\
-0.003 \text { VDC }\end{array}$ \\
\hline Zero Load Signal: & $\begin{array}{c}\text { Counter Clockwise } \\
-0.011 \text { VDC }\end{array}$ \\
\hline
\end{tabular}

Calibration Data:

unction

\begin{tabular}{|c|c|}
\multicolumn{1}{c}{ Function } & Pin \\
\hline Excitation (+) & White \\
\hline Excitation (GND) & Red \\
\hline Signal (+) & Brown \\
\hline Signal OV (GND) & Green \\
\hline Angle A & Pink \\
\hline Angle B & Blue \\
\hline Shield & Shield \\
\hline & \\
\hline & \\
\hline & \\
\hline & \\
\hline & \\
\hline & \\
\hline
\end{tabular}

\begin{tabular}{|c|c|}
\hline $\begin{array}{c}\text { Test Load } \\
\text { Applied (Nm) }\end{array}$ & $\begin{array}{c}\text { Clockwise } \\
\text { VDC }\end{array}$ \\
\hline 0 & 0.0000 \\
\hline 250 & 2.5020 \\
\hline 500 & 5.0000 \\
\hline 250 & 2.5010 \\
\hline 0 & 0.0000 \\
\hline
\end{tabular}

\begin{tabular}{|c|c|}
\hline $\begin{array}{c}\text { Test Load } \\
\text { Applied (Nm) }\end{array}$ & $\begin{array}{c}\text { Counterclockwise } \\
\text { VDC }\end{array}$ \\
\hline 0 & 0.0000 \\
\hline 250 & -2.5000 \\
\hline 500 & -5.0020 \\
\hline 250 & -2.5000 \\
\hline 0 & 0.0010 \\
\hline
\end{tabular}

\begin{tabular}{|l|l|}
\hline Nonlinearity (\%FS) & 0.040 \\
\hline
\end{tabular}

\begin{tabular}{|l|l|}
\hline Nonlinearity (\%FS) & -0.020 \\
\hline
\end{tabular}

Angle:

$2 \times 360$ Imp.

Calibration data is traceable to national standards. This transducer meets published specifications.
Calibrated by:
Gentner
Date:
1-Apr-15

Interface Inc

7401 East Butherus Drive - Scottsdale, Arizona 85260 - USA

Telephone (480) 948-5555 - Fax (480) 948-1924

www.interfaceforce.com

C-6 


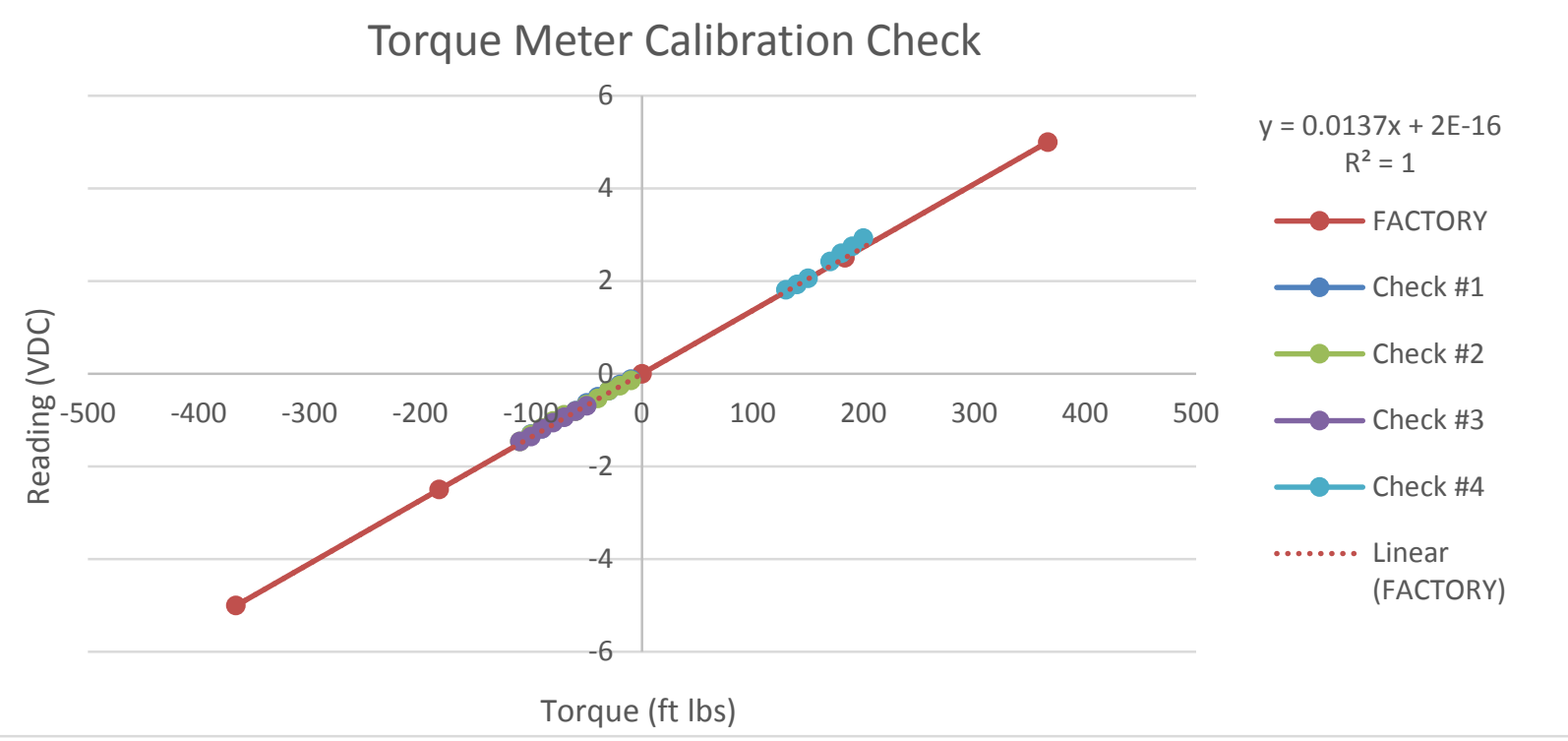

Figure 80: Plot of the calibration check for the T23 torque meter 


\section{Appendix D - Reliance Induction Motor Speed-Torque Curve}

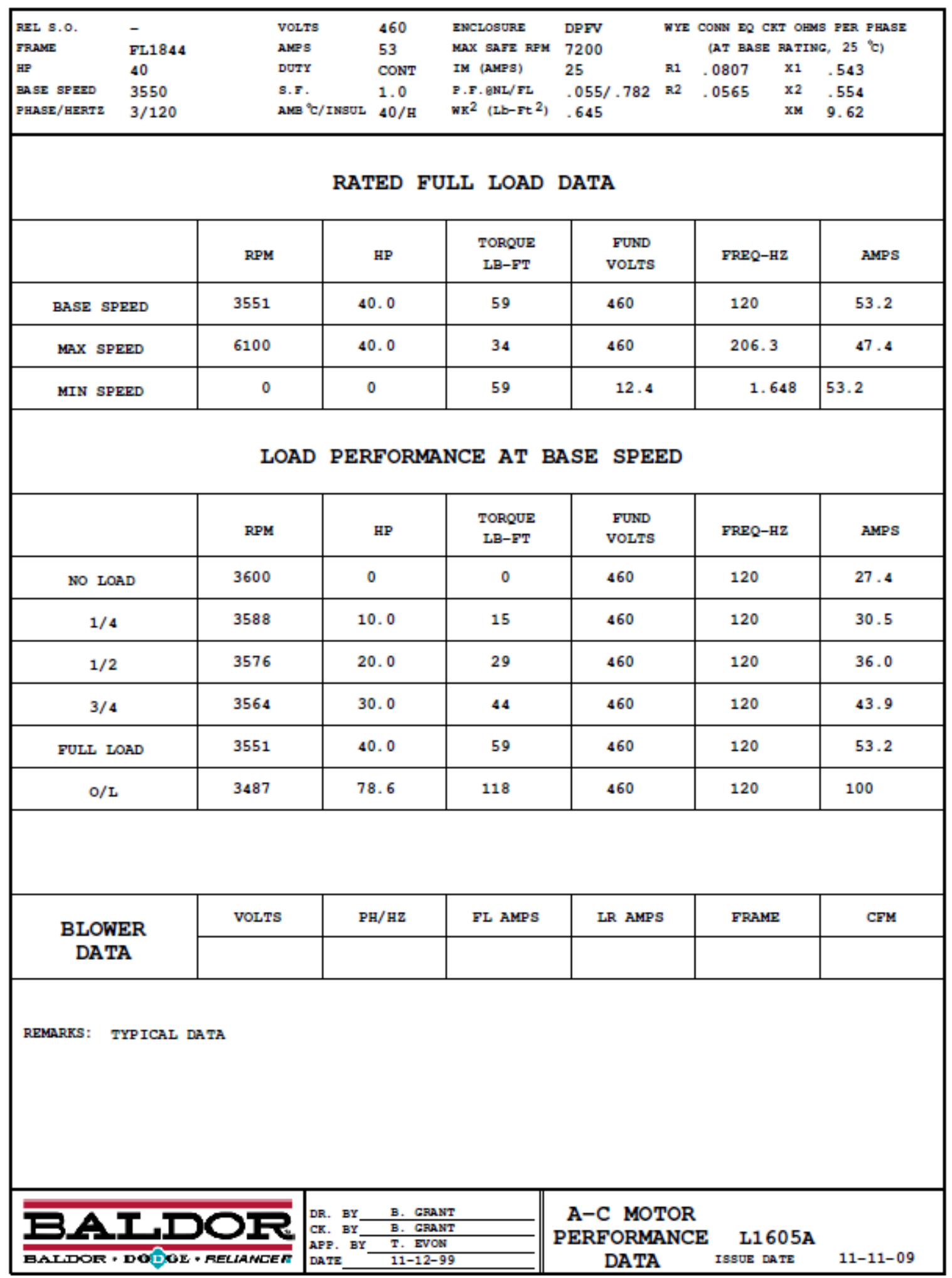

D-1 


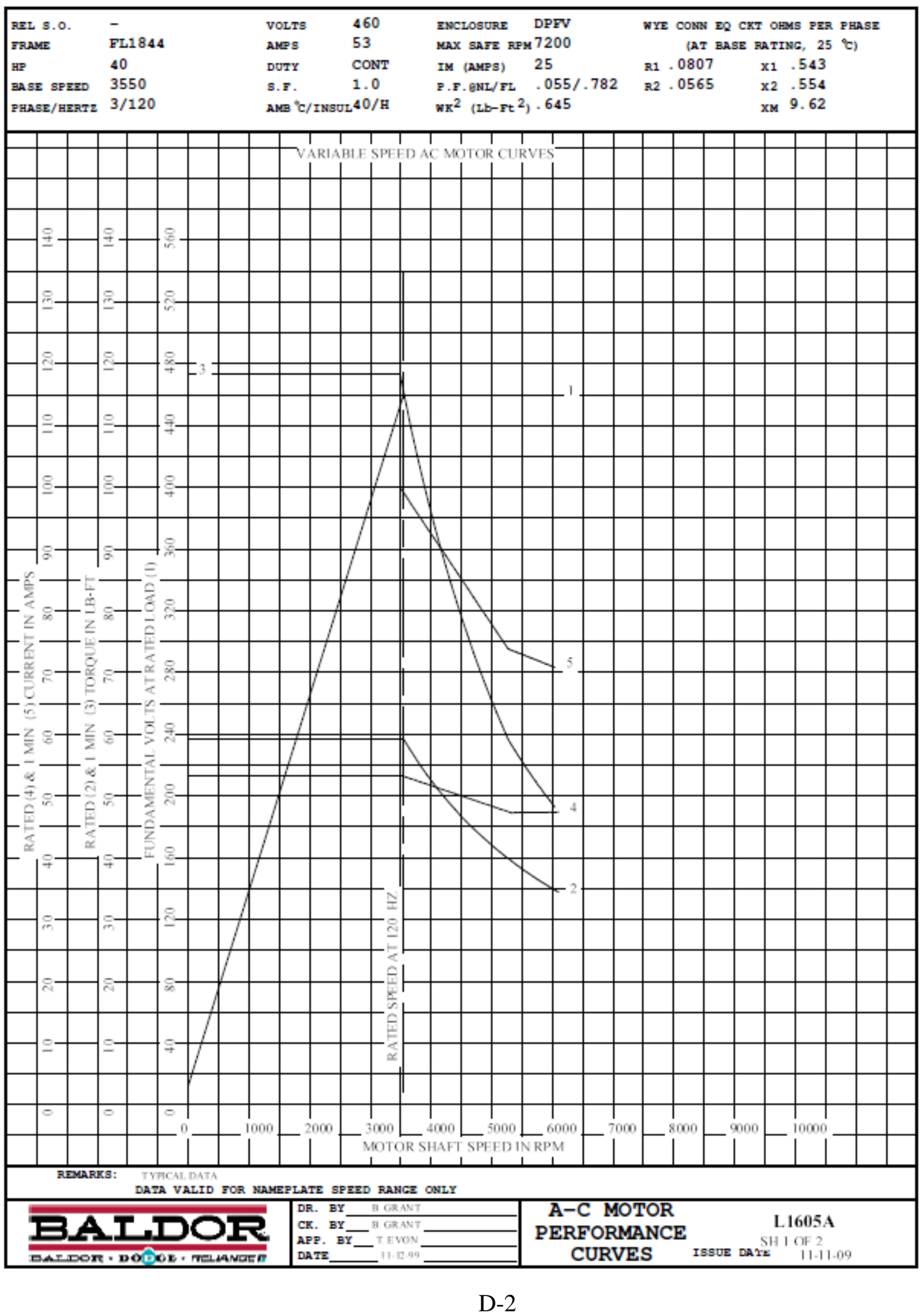




\section{Appendix E - Scimitar Parameter Tree}

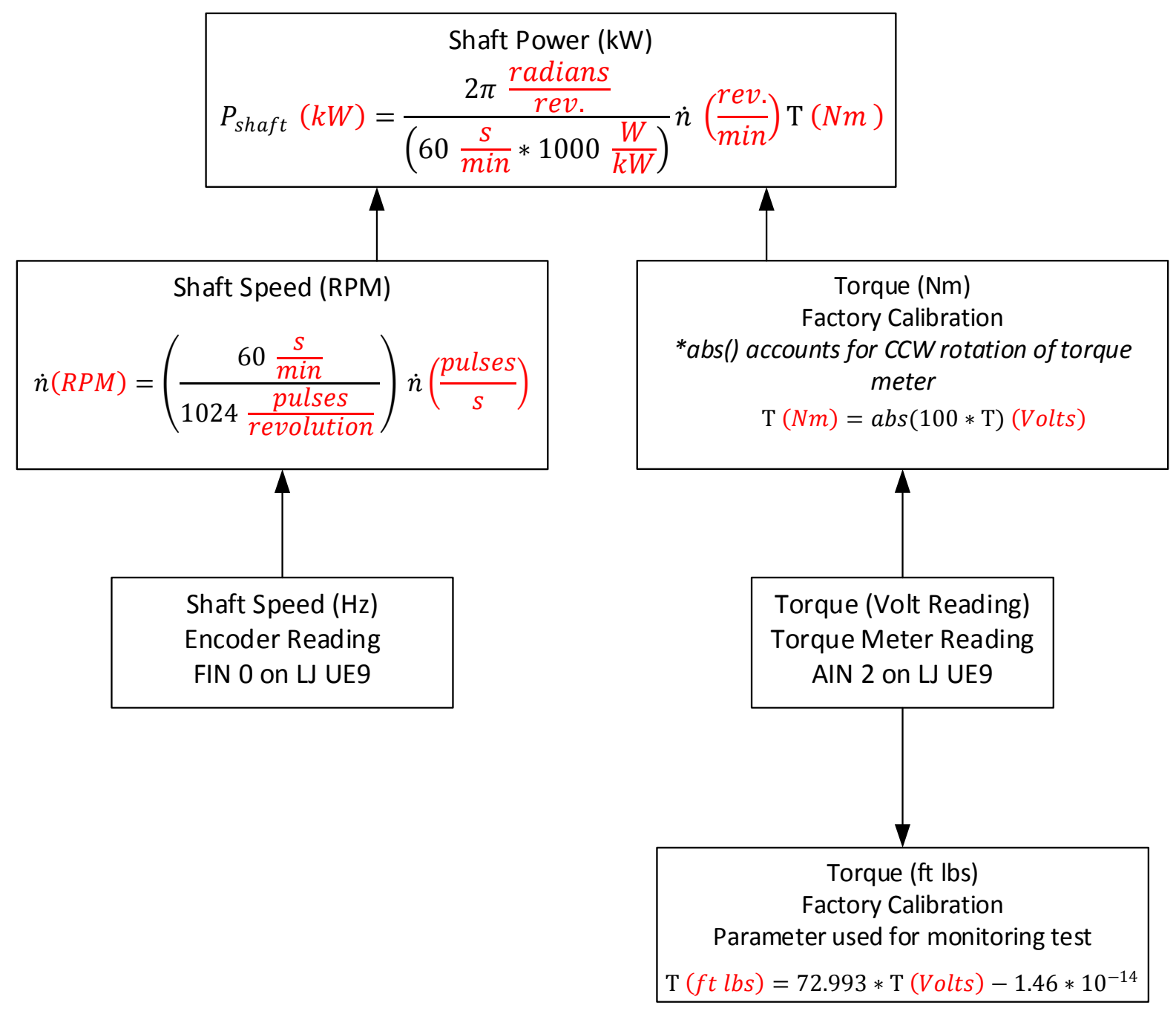

E-1 


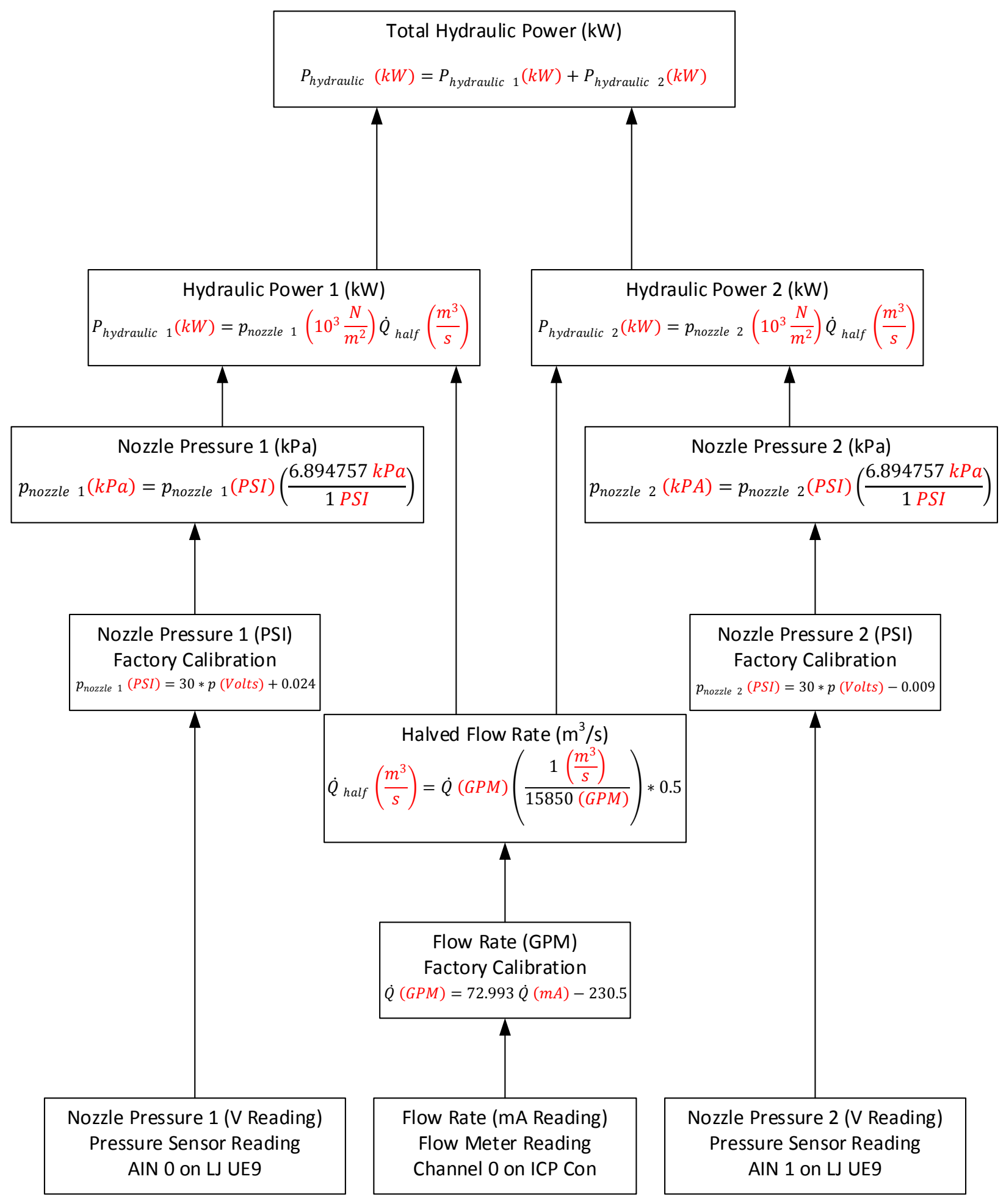

E-2 


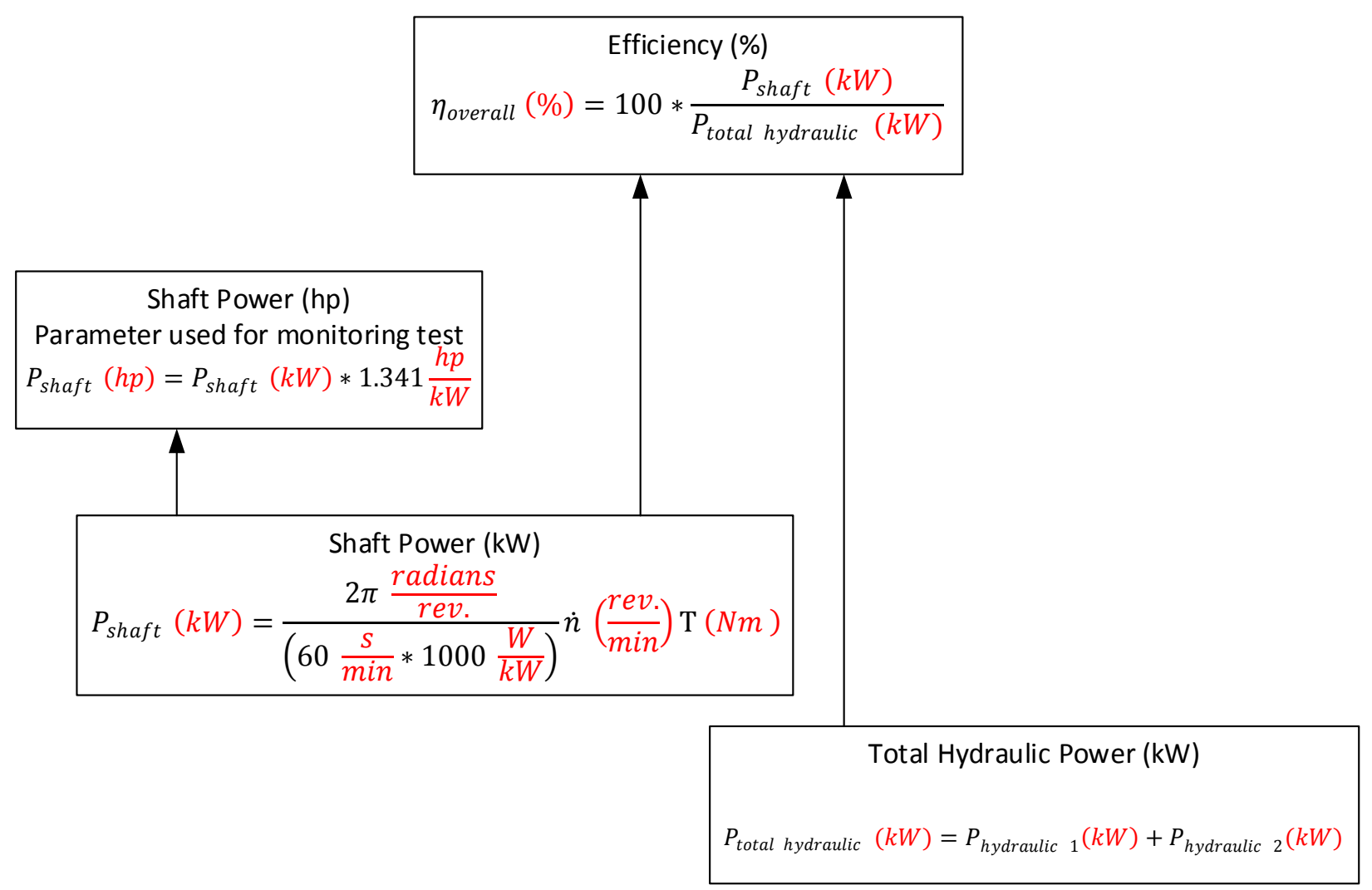

E-3 


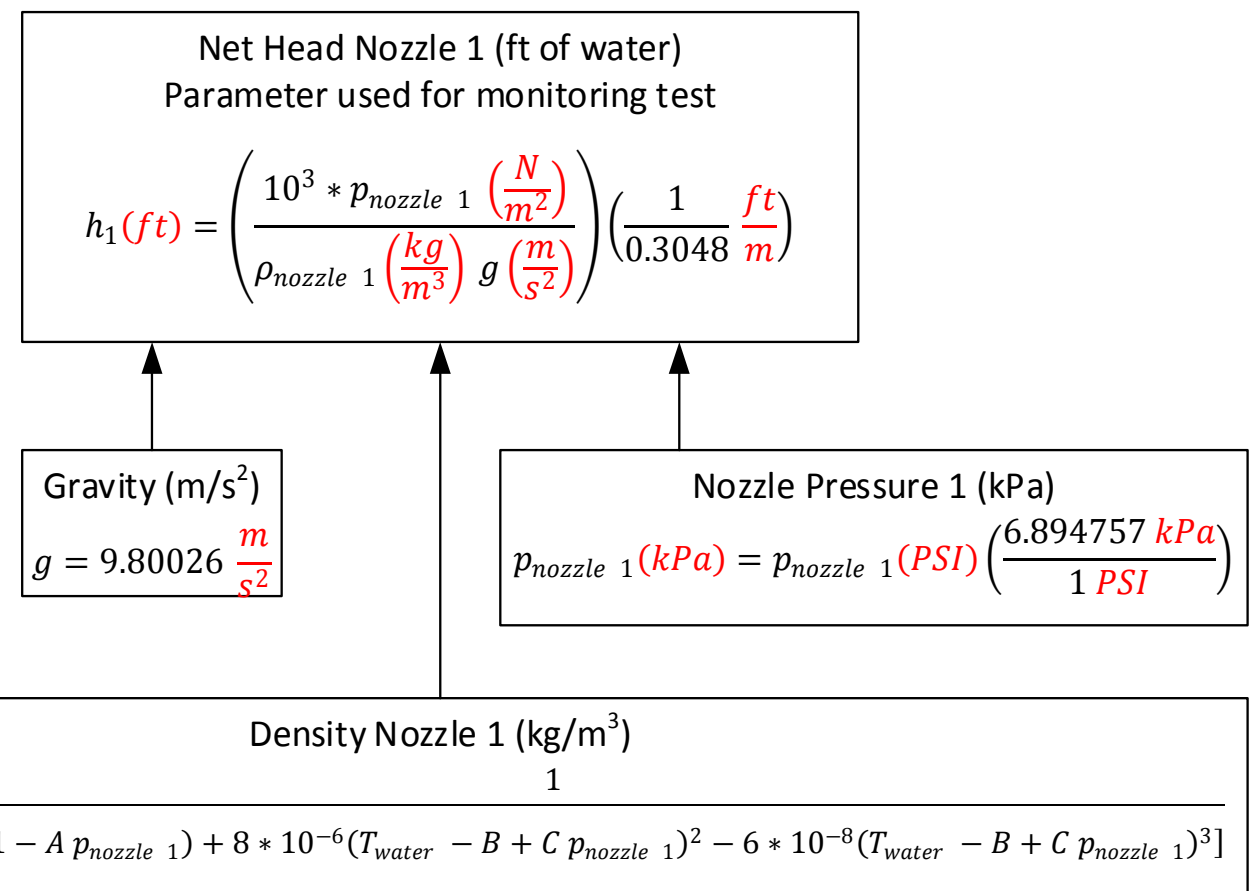

\begin{tabular}{|c|c|}
\hline & 4 \\
\hline $\begin{array}{l}\text { Water Temperature }\left({ }^{\circ} \mathrm{F}\right) \\
\text { Parameter used for monitoring test } \\
T_{\text {water }}\left({ }^{\circ} \mathrm{F}\right)=1.8 * T_{\text {water }}\left({ }^{\circ} \mathrm{C}\right)+32\end{array}$ & $\begin{array}{c}\text { Nozzle Pressure } 1(\mathrm{~Pa}) \\
p_{\text {nozzle } 1}(\mathrm{~Pa})=p_{\text {nozzle } 1}(\mathrm{kPa}) \frac{1000 \mathrm{~Pa}}{1 \mathrm{kPa}}\end{array}$ \\
\hline 4 & 4 \\
\hline $\begin{array}{c}\text { Water Temperature }\left({ }^{\circ} \mathrm{C}\right) \\
\text { Reading from Thermocouple } \\
\text { Channel } 5 \text { on ICP Con } \\
\text { Automatically Scaled in Scimitar }\end{array}$ & $\begin{array}{c}\text { Nozzle Pressure } 1(\mathrm{kPa}) \\
\text { (Calculated value from previous page) }\end{array}$ \\
\hline
\end{tabular}




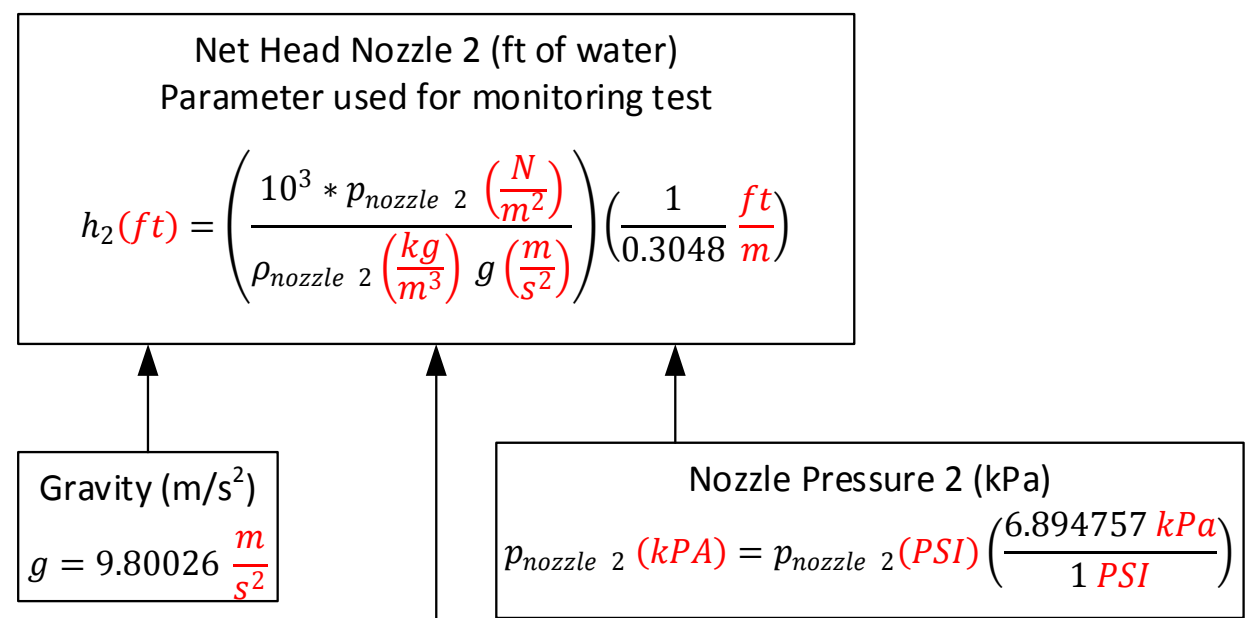

\begin{tabular}{|c|}
$\rho_{\text {nozzle } 2}\left(\frac{\mathrm{kg}}{\mathrm{m}^{3}}\right)=\frac{\text { Density Nozzle } 2\left(\mathrm{~kg} / \mathrm{m}^{3}\right)}{v_{0} \frac{\mathrm{m}^{3}}{\mathrm{~kg}}\left[\left(1-A p_{\text {nozzle } 2}\right)+8 * 10^{-6}\left(T_{\text {water }}-B+C p_{\text {nozzle } 2}\right)^{2}-6 * 10^{-8}\left(T_{\text {water }}-B+C p_{\text {nozzle } 2}\right)^{3}\right]}$ \\
\hline
\end{tabular}

\begin{tabular}{|c|}
\hline Water Temperature $\left({ }^{\circ} \mathrm{F}\right)$ \\
Parameter used for monitoring test \\
$T_{\text {water }}\left({ }^{\circ} \mathrm{F}\right)=1.8 * T_{\text {water }}\left({ }^{\circ} \mathrm{C}\right)+32$ \\
\hline Water Temperature $\left({ }^{\circ} \mathrm{C}\right)$ \\
Reading from Thermocouple \\
Channel 5 on ICP Con \\
Automatically Scaled in Scimitar \\
\hline
\end{tabular}

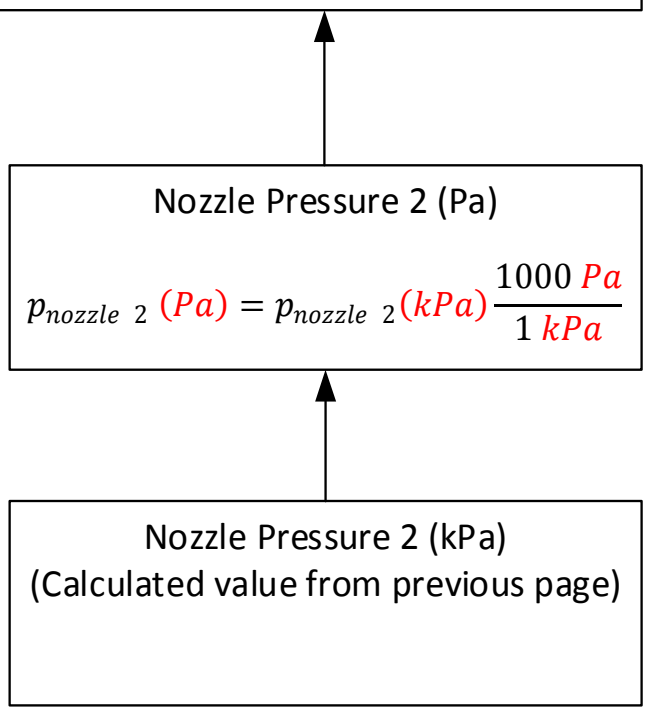




\section{Appendix F - Example Uncertainty Calculation}

This example is provided to show the process that was used to calculate the uncertainty of measured and calculated values. This example will show the bias uncertainty, precision uncertainty, and the overall uncertainty for a measurement of water density in this experiment. Based on the accuracy for the Keller Valueline pressure transducers used to measure the nozzle pressure in the experiment, the value of $p_{\text {nozzle } 1}$ would be perturbed by $\pm 1.03 \mathrm{~Pa}$. Based on the accuracy for the Omega J-type thermocouple used to measure water temperature, the value $T_{\text {water }}$ was perturbed by $\pm 2.2^{\circ} \mathrm{C}$. Each perturbed value was used to calculate high and low value of the resulting density. These high and low values were then compared to the unperturbed results. The absolute of average was taken which can be seen below in Equations 15 and 16.

$$
\begin{gathered}
\delta \rho_{p_{\text {Nozzle 1 }}}=\frac{\mid \delta \rho_{p_{\text {Nozzle } 1+}|+| \delta \rho_{p_{\text {Nozzle 1- }}} \mid}}{2} \\
\delta \rho_{T_{\text {water }}}=\frac{\left|\delta \rho_{T_{\text {water }}}\right|+\left|\delta \rho_{T_{\text {water- }} \mid}\right|}{2}
\end{gathered}
$$

These values are then combined into an RMS value for the bias uncertainty. This is shown below in Equation 17.

$$
\rho_{\text {bias }}=\sqrt{\left(\delta \rho_{p_{\text {Nozzle } 1}}\right)^{2}+\left(\delta \rho_{T_{\text {water }}}\right)^{2}}
$$

The precision uncertainty is described by the expression shown in Equation 18.

$$
\rho_{\text {precision }}=\frac{\Delta \rho}{\rho}=\frac{t S_{\rho}}{\bar{\rho} \sqrt{N}}
$$

In Equation 18, t (2.353) is the student-t variable, $\mathrm{N}$ (3) is the number of samples taken during the experiment, $\bar{\rho}$ is the mean value of the density of the different samples, and $S_{\rho}$ is the variance of 
the density in the samples. The overall uncertainty for the water density can then be determined from both the bias and precision uncertainties. This is shown in Equation 19.

$$
\rho_{\text {uncertainty }}=\sqrt{\left(\rho_{\text {bias }}\right)^{2}+\left(\rho_{\text {precision }}\right)^{2}}
$$

A similar sequence of calculation was completed for all measured and calculated variables in the Scimitar parameter tree for each set-point test during the experiment. Graphs of the uncertainty for shaft power, hydraulic power, and overall efficiency can be seen in the results section accompanying their respective discussions on the performance test results. Maximum and minimum values are also reported in the uncertainty section of the experimental methodology. 